Universidade de São Paulo

Instituto de Química de São Carlos

\title{
DEPENDÊNCIA DA TEMPERATURA E DO PH DA SOLUÇÃO E DE OUTROS PARÂMETROS NA ELETRO- OXIDAÇÃO DE MOLÉCULAS ORGÂNICAS PEQUENAS
}

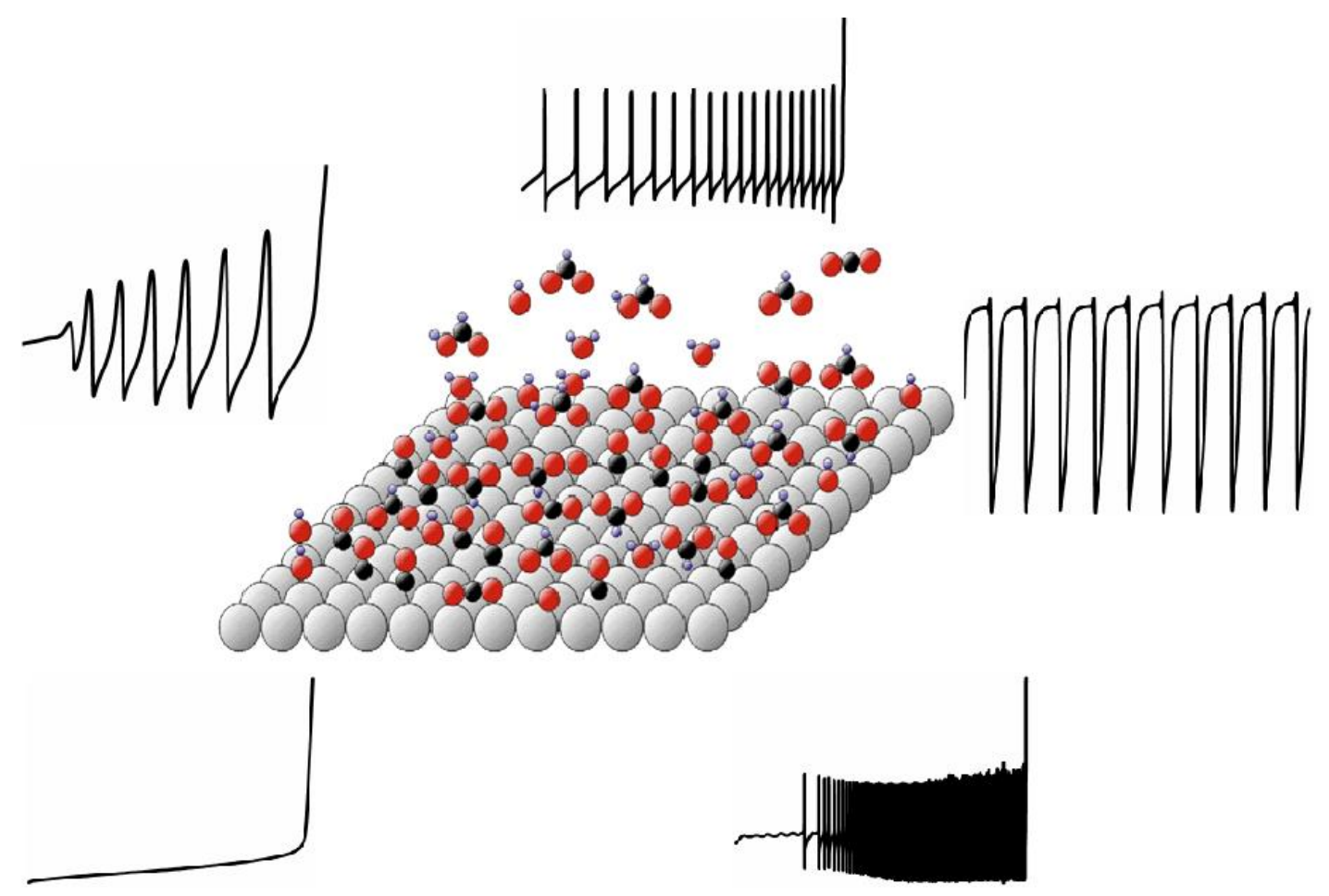

CANDidato: DiPl. Chem. FABIAN WolfGANG HartL ORIENTADOR: PROF. DR. HAMILTON VARELA 
Fabian Wolfgang Hartl

\section{The dependence of temperature, the bulk solution $\mathrm{pH}$ and other parameters in the electro-oxidation of small organic molecules}

Thesis presented in the Institute of Chemistry of São Carlos of the University of São Paulo for obtaining the degree of doctor in chemistry.

Area: Physical Chemistry

Supervisor: Prof. Dr. Hamilton Varela

São Carlos

November 2018 
Die Wissenschaft fängt eigentlich erst da an interessant zu werden, wo sie aufhört."

Justus von Liebig, "Chemische Briefe" 


\section{Acknowledgement}

I have to say, that I would have not been able to achieve this work without the outstanding help of many people, which always were of great help and support. All of them have a contribution in this work, which should be acknowledged here.

At first I want to thank Prof. Hamilton Varela and Prof. Angel Cuesta for giving me the opportunity to work in their groups and to do my studies for achieving the $\mathrm{PhD}$. I cannot say, how much I have learned, advanced and widened my horizon about oscillating systems, self-organization, electrochemistry and even in science in general.

I also want to acknowledge all my (ex)colleagues of both groups, Eduardo, Nickson, Alana, Marcelo, Paulo, Jessica, Graziela, Paula, Marcelo, Alfredo, Osmando, Bruno, Marco, Chris, Faith, and Laura. It has always been an amazing environment for many discussions, scientific or not, which not just allowed me to see things from another point of view, but also to learn about good practices in science. Not to forget the countless beers and nice evenings. Apart of that, there has always been help, if there was a problem with the language like in translation, bureaucracy and conversation. The daily talks were and are the main reason, that I learned Portuguese from zero.

I acknowledge the Instituto de Química de São Carlos of the University of São Paulo for a professional, scientific environment and the São Paulo Research Foundation for the scholarship (grants \#2014/08030-9, and \#2017/07286-8) and for financial support (grant \#2013/16930-7) to the Electrochemistry Group.

Moreover I want to write some extra words to Bruno, whom I co-supervised in his scientific initiation, which has always been a great pleasure. I did not just learn many things about teaching and orientation, but it always was a great time. I can truly say, I won a close friend.

"And at last, but for sure not at least", will ich meiner Familie danken: Meinen Eltern, Wolfgang und Gudrun, meinem Bruder Maximilian, meinem Onkel und meiner Tante, Wolfgang und Angelika, meinen Cousins, Bernd und Tobias, und meinen Omas, Käthe und Inge. Ihr wart immer da zur Unterstützung, moralisch, seelisch, finaziell, einfach in jeder Hinsicht. Obwohl $10000 \mathrm{~km}$ und ein ganzer Ozean daziwschen liegen, wart ihr nie aus der Welt. 


\section{Resumo}

A eletro-oxidação de ácido fórmico vem sendo discutida por muito tempo na literatura, em particular, a natureza do intermediário ativo no caminho direto tem sido debatida. Recentemente alguns grupos relataram novos aspectos deste processo por meio da análise da oxidação de ácido fórmico e sua dependência com o pH da solução. Mas tem que ser considerado que todos os processos superficiais dependem no $\mathrm{pH}$ e na temperatura também. A maioria dos estudos, no entanto, foi realizado sob condições convencionais, ou seja, próximas ao estado de equilíbrio termodinâmico. Alternativamente, o sistema pode ser estudado longe do equilíbrio pelo controle da corrente. Nessas condições a oxidação de moléculas orgânicas pequenas sobre platina pode apresentar a formação de padrões e mostrar comportamentos oscilatórios. Pelas condições drasticamente diferentes é possível alcançar um melhor entendimento da complexa rede da reação, que fica escondido em experimentos convencionais. Dessa maneira, a dependência do $\mathrm{pH}$ de oxidação de ácido fórmico na voltametria cíclica foi revisitada e estendida a uma ampla região de temperatura e condições oscilatórias. Algumas observações adicionais podem ser obtidas, que podem ser confirmadas pela espectroscopia de absorção no infravermelho intensificada pela superfície na configuração de reflexão total (ATR-SEIRAS) e espectroscopia de reflexão differencial: a) a dependência do $\mathrm{pH}$, como relatada anteriormente, pode ser reproduzida, reforçando a proposição do formiato como espécie ativa mais provável, invés do ácido fórmico; b) em meio ácido um terceiro caminho ao lado dos caminhos direto e indireto poderia ser ativo; c) padrões oscilatórios foram encontrados em meio alcalino e evidenciaram o caráter bloqueante de espécies oxigenadas como responsável pela formação de padrões; d) geralmente, todos os processos envolvidos direta ou indiretamente, podem ser muito propensos a variações pequenas no $\mathrm{pH}$ e na temperatura da solução, de modo que a atividade deles pode mudar significativamente e o sistema apresentar resultados diferentes sob condições similares. Adicionalmente, os estudos foram estendidos à oxidação de metanol, que permitiu uma visão diferenciada da adsorção das espécies carbonáceas e oxigenadas, as quais principalmente poderiam ter caráter inibitório. Apesar disso, como os resultados mostraram sob algumas condições, uma interação efetiva de ambas espécies via o mecanismo de LangmuirHinshelwood pode ocorrer, e o caminho direto da oxidação pode mostrar uma atividade mais alta e os padrões oscilatórios desaparecem. Observou-se ainda que o ácido fórmico produzido como subproduto parcialmente oxidado poderia ter um papel importante na reação da eletro- 
oxidação de metanol. Por fim foi encontrado que não apenas ajustamentos como a ligação de platina com ouro pode melhorar o desempenho do catalisador pelos efeitos eletrônicos e ligantes, mas também modificações no conteúdo da solução, como a oxidação simultânea do ácido fórmico e metanol poderiam permitir um aumento no desempenho. Em ambos os casos a formação de CO pode ser suprimida, que o processo mais ativo, notadamente a oxidação direta do ácido fórmico, é mais pronunciada. Resumindo, este trabalho pôde dar mais entendimento na oxidação de ácido fórmico e metanol e mostrou algumas perspectivas para trabalhos futuros, que poderia melhorar o desempenho de células combustíveis de ácido fórmico direto (DFAFC) e células combustíveis de metanol direto (DMFC). 


\begin{abstract}
The electro-oxidation of formic acid remained under discussion for a long time in literature, where especially the active intermediate in the direct oxidation pathway was discussed controversially. Recently some groups reported new insight by the analysis of the formic acid oxidation in dependence on the bulk solution $\mathrm{pH}$. But it should be considered, that all surface processes, like surface oxidation, anion adsorption as reported in literature, may depend on $\mathrm{pH}$ and temperature as well. Yet, the majority of the studies are carried out under conventional conditions, which are close to the thermodynamic equilibrium. On the other hand the system can be driven far from equilibrium by controlling the current, conditions where the oxidation of small organic molecules over platinum may undergo pattern formation and show oscillatory behaviour. Due to the drastically different conditions one may get a better understanding of the complex reaction network, which remains hidden in conventional experiments. Thus, the $\mathrm{pH}$ dependence of formic acid oxidation was revisited under steady state voltammetry and extended to a wide temperature range and oscillating conditions. Here insight could be given in various points, which could be confirmed by the analysis of the adsorption layer on the Pt surface under oscillating conditions by Surface Enhanced InfraRed Adsorption Spectroscopy in Attenuated Total Reflection configuration (ATR-SEIRAS) and differential reflectance spectroscopy: a) the $\mathrm{pH}$ dependence, as reported earlier, could be reproduced and strongly suggests formate rather than formic acid as most active species, which has no contribution to the formation of oscillation patterns; b) in acidic media a third pathway beside direct and indirect ones may be active; c) newly found oscillation patterns in alkaline media revealed the site blocking character of adsorbed water species as possible origin for pattern formation; and d) generally, all surface processes, which are directly or indirectly involved, can be very susceptible to small variations in the bulk solution $\mathrm{pH}$ and temperature, that their activity can change significantly and the system emerge different results under similar conditions. The alloying of Pt with Au showed the reported suppression of $\mathrm{CO}$ formation, what lead to a more effective formic acid oxidation and changes in the oscillation pattern. Further effort was done to extend the study to methanol oxidation, which allowed a differentiated view on the adsorption of carbonaceous and oxygenated species, which may have mostly inhibiting character. Yet, as the results showed under some conditions, an effective interaction of both species via Langmuir-Hinshelwood mechanism can be realized, that the direct oxidation pathway can undergo higher activity and oscillation
\end{abstract}


patterns may cease. It could also be found, that the produced formic acid as partially oxidized by-product may have a crucial role in the reaction network of the electro-oxidation of methanol. At last it could be found, that not just adjustments like alloying of platinum with gold can enhance the catalyst performance by electronic and ligand effects, but also modifications in the solution content, such as simultaneous oxidation of formic acid and methanol allow an increasing performance. In both ways the formation of $\mathrm{CO}$ can be suppressed, that the most active process, namely the direct oxidation of formic acid is more pronounced. In summary, this work could give deeper insight in the oxidation mechanism of formic acid and methanol and showed up some perspectives for future works, which may improve the performance of Direct Formic Acid Fuel Cells (DFAFC) and Direct Methanol Fuel Cells (DMFC). 


\section{Scientific works in relation to this thesis}

Poster presentation in the Brazilian-German Workshop: The effect of solution pH on the oscillatory electro-oxidation of formic acid, 11.-14.04.2016, Maresias, Brazil.

Article: G. Cabello, R. A. Davoglio, F. W. Hartl, J. F. Marco, E. C. Pereira, S. R. Baggio, H. Varela, A. Cuesta, Microwave-assisted synthesis of Pt-Au nanoparticles with enhanced electrocatalytic activity for the oxidation of formic acid, Electrochimica Acta, 224 (2017) $56-63$.

Article: F. W. Hartl, A. A. Zülke, B. J. Fonte, H. Varela, Temperature dependence of the evolving oscillations along the electrocatalytic oxidation of methanol, Journal of Electroanalytical Chemistry, 800 (2017) 99-105.

Article: F. W. Hartl, H. Varela, The Effect of Solution pH and Temperature on the Oscillatory Electro-Oxidation of Formic Acid on Platinum, Chemistry Select, 2 (2017) 8679-8685.

Poster presentation in the conference of the International Society of Electrochemistry: ATRSEIRAS in situ pH dependent potential oscillation in Formic Acid Oxidation, 2.7.09.2018, Bologna, Italy.

Article: G. B. Melle, F. W. Hartl, H. Varela, E. Sitta, The effect of solution pH on the oscillatory electro-oxidation of methanol, Journal of Electroanalytical Chemistry, 826 (2018) 164-169.

Article: F. W. Hartl, H. Varela, A. Cuesta, The oscillatory electro-oxidation of formic acid: insights on the adsorbates involved from time-resolved ATR-SEIRAS and UV reflectance experiments, submitted.

Article: A. Calderón-Cárdenas, F. W. Hartl, H. Varela, Potential oscillations in the electrooxidation of formic acid on platinum, in progress.

Article: F. W. Hartl, B. J. Fonte, H. Varela, Simultaneous oxidation of methanol and formic acid: The influence of temperature and molar fraction on the reaction kinetics, in progress. 


\section{List of Figures}

Figure 1: Snapshots $(96 \times 96 \mathrm{~nm} 3)$ of 3D phase-field simulations highlighting the solid-liquid interface and compositional domains at the early stage of dealloying. Copied from [9]..20

Figure 2: Steady state voltammograms of $\mathrm{Pt}$ in $0.5 \mathrm{M} \mathrm{K}_{2} \mathrm{SO}_{4}+\mathrm{x} \mathrm{M} \mathrm{H}_{2} \mathrm{SO}_{4} / \mathrm{KOH}, \mathrm{pH} 1.02$ (black), 13.12 (red). The grey and red boxes indicate the double layer region.................22

Figure 3: a)-f) Different stages of the surface oxidation of Pt. Copied from reference [27].... 23

Figure 4: a) Fixed points in the flow field of $f(x), b$ ) position of stable (dashed black line) and unstable fixed points (red solid line) in dependence on parameter a. 25

Figure 5: a)-c)differential equations of third order $\left.\left.\left.d x / d t=a x-x^{3} . a\right) a>0, b\right) a=0, c\right) a<0 . .26$

Figure 6: a) position of fixed points from Figure 7a)-c) in dependence on a for a supercritical

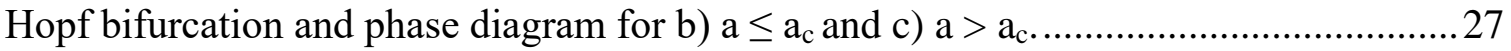

Figure 7: a) position of fixed points for a subcritical Hopf bifurcation in dependence on a and

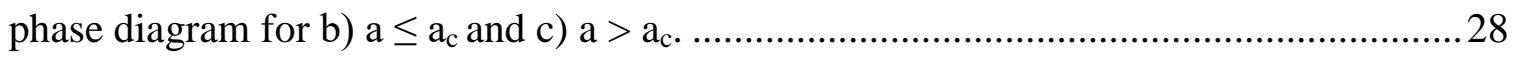

Figure 8: Circuit of an electrochemical cell connected to a potentiostat applying the potential E. $\varphi$ potential drop at the double layer, $R_{S}$ resistance of the system, $Z_{F}$ faradaic impedance, $\mathrm{C}_{\mathrm{DL}}$ double layer capacitance at the working electrode.

Figure 9: Current-potential curves for the case of a) N-NDR, b) HN-NDR and c) bistability.30

Figure 10: Feedback loops of an oscillating electrochemical reaction. 31

Figure 11: a) real (black) and theoretical response (red) potentiodynamic response of an $\mathrm{HN}$ NDR system in the NDR region, b) potential dependent adsorptionisotherm of the inhibitor. 32

Figure 12: Typical impedance spectrum for a HN-NDR system. Copied from [35]. 33

Figure 13: Representative impedance spectra in the potential region of a HN-NDR oscillator along the potentiodynamic profile. Copied from [37] .................................................... 34

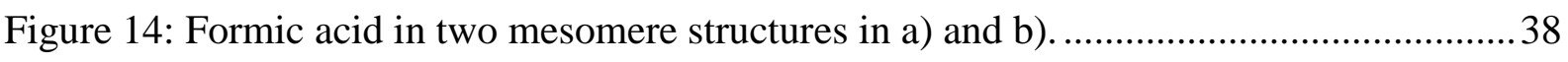

Figure 15: Molar fractions of formic acid (black) and formate (red) vs. bulk solution $\mathrm{pH} . . . .39$

Figure 16: Steady state voltammogram of formic acid oxidation in $0.5 \mathrm{M} \mathrm{K}_{2} \mathrm{SO}_{4}+\mathrm{x} \mathrm{M}$ $\mathrm{H}_{2} \mathrm{SO}_{4} / \mathrm{KOH}$, a) $\mathrm{pH} 1.02$ and b) 13.12. The dashed lines indicate the steady state voltammogram in the used electrolyte, shown in Figure 3. Scan rate $0.05 \mathrm{~V} \mathrm{~s}^{-1}$.

Figure 17: a) Potential oscillations of $0.2 \mathrm{M} \mathrm{HCOOH}$ in $0.5 \mathrm{M} \mathrm{K}_{2} \mathrm{SO}_{4}$ (pH 1.02), b) $\mathrm{dE} \mathrm{dt}^{-1} \mathrm{vs}_{\text {. }}$ $E$ of the oscillation pattern. 
Figure 18: Molecular structure of methanol.

Figure 19: Steady state voltammogram of the electro-oxidation of $1 \mathrm{M} \mathrm{H}_{3} \mathrm{COH}$ over Pt in 0.5 $\mathrm{M} \mathrm{K}_{2} \mathrm{SO}_{4}$. a) $\mathrm{pH} 1.02$, b) $\mathrm{pH}$ 12.97. Scan rate $0.05 \mathrm{~V} \mathrm{~s}^{-1}$

Figure 20: Reaction mechanism of the electro-oxidation of methanol. 44

Figure 21: a) potential oscillations of $1 \mathrm{M} \mathrm{H}_{3} \mathrm{COH}$ in $0.5 \mathrm{M} \mathrm{K}_{2} \mathrm{SO}_{4}(\mathrm{pH} 1.02)$, b) $\mathrm{dE} \mathrm{dt}^{-1} \mathrm{vs}$. E of the oscillation pattern.

Figure 22: Schematic electrochemical cell used for all measurements. 49

Figure 23: Schematic set-up for the ATR-SEIRAS. .51

Figure 24: Schematic set-up for the differential UV reflectance spectroscopy..... 52

Figure 25: Enegry level diagrams of a) an atom, b) molecule and the energy bands of multiatom compositions like in the case of c) a semiconductor and d) a metal. 55

Figure 26: Steady state voltammograms of the graphite-supported NPs in $0.5 \mathrm{M} \mathrm{H}_{2} \mathrm{SO}_{4}$. Scan rate $0.05 \mathrm{~V} \mathrm{~s}^{-1}$

Figure 27: Steady state voltammograms of the graphite-supported NPs in $0.5 \mathrm{M} \mathrm{H}_{2} \mathrm{SO}_{4}+0.05$ $\mathrm{M} \mathrm{HCOOH}$. Scan rate $0.05 \mathrm{~V} \mathrm{~s}^{-1}$

Figure 28: Potential time series of the NPs (a) Pt, b) $\mathrm{Pt}_{3} \mathrm{Au}, \mathrm{c}$ ) $\mathrm{PtAu}$, d) $\mathrm{PtAu}_{3}$, e) $\mathrm{PtAu}_{9}$ ) in 0.2 $\mathrm{M} \mathrm{HCOOH}+0.5 \mathrm{M} \mathrm{H}_{2} \mathrm{SO}_{4}$ with the highlighted first (red) and last, complete oscillation cycle (green) and f)- h) their corresponding derivatives against the measured potential on the right. Applied, normalized current density 0.2 .

Figure 29: Positive (notation 1) and negative (notation 2) sweeps of the steady state voltammogram in (a) $0.4 \mathrm{~K}_{2} \mathrm{SO}_{4}+\mathrm{x} \mathrm{M} \mathrm{H}_{2} \mathrm{SO}_{4}(\mathrm{pH} 0.25$ ), and (b) y M KOH (pH 13.86); with formic acid concentration of $0.2 \mathrm{M}$ in the temperature range between 10 and $50{ }^{\circ} \mathrm{C}$. Scan rate $0.05 \mathrm{~V} \mathrm{~s}^{-1}$

Figure 30: Influence of the solution $\mathrm{pH}$ on the current peaks described in Figure 31: I (triangles, forward sweep), II (circles, forward sweep), and III (squares, backward sweep). Molar fractions of solution $\mathrm{HCOOH}$ and $\mathrm{HCOO}$ are also given in right y-axis. Grey areas depict the $\mathrm{pH}$ windows where potential oscillations were found (see below). Remaining conditions as in Figure 31.

Figure 31: Galvanodynamic measurements of $5 \mu \mathrm{A} \mathrm{cm}^{-2}$ of $0.2 \mathrm{M} \mathrm{HCOOH}$ in $0.4 \mathrm{M} \mathrm{K}_{2} \mathrm{SO}_{4}$ of different $\mathrm{pH}$. 68

Figure 32: Galvanodynamic measurements of $5 \mu \mathrm{A} \mathrm{cm}^{-2}$ of $0.2 \mathrm{M} \mathrm{HCOOH}$ in $0.4 \mathrm{M} \mathrm{K}_{2} \mathrm{SO}_{4}$ of a) $\mathrm{pH} 1.02$ and b) $\mathrm{pH} 13$ of different scan rates. 
Figure 33: Galvanostatic (at three normalized applied currents, see text for details) time-series for the electro-oxidation of formic acid in $0.4 \mathrm{~K} 2 \mathrm{SO} 4+0.2 \mathrm{M} \mathrm{HCOOH}+x \mathrm{M} \mathrm{H} 2 \mathrm{SO} 4 /$ $\mathrm{M} \mathrm{KOH}$ solution at (a) $\mathrm{pH} 1$, (b) $\mathrm{pH} 3$, and (c) $\mathrm{pH} 12$. Temperature $25^{\circ} \mathrm{C}$. .70

Figure 34: Potential time-traces for the electro-oxidation of formic acid in $0.4 \mathrm{M} \mathrm{K}_{2} \mathrm{SO}_{4}+0.2$ $\mathrm{M} \mathrm{HCOOH}+\mathrm{x} \mathrm{M} \mathrm{H} \mathrm{SO}_{4}$ of normalized current density 0.5 and $25^{\circ} \mathrm{C}$ with $\mathrm{pH}$ (a) 0.25 , (b) 1.02, (c) 1.99, and (d) 2.98; and $\mathrm{x} \mathrm{M} \mathrm{KOH}$, and (e) $\mathrm{pH} 11.96$, normalized current density $0.1,25^{\circ} \mathrm{C}$, and (f) $\mathrm{pH} 13.12$, normalized current density $0.5, \mathrm{~T}=50{ }^{\circ} \mathrm{C}$. 72

Figure 35: Oscillation frequency (a) versus temperature for different $\mathrm{pH}$ values, and (b) versus $\mathrm{pH}$ for different temperatures. Normalized current density was 0.5 in all cases, except for pH 11.96, which it was 0.1 .

Figure 36: dE/dt vs. E for the first oscillatory cycle of the potential oscillations from Figure 36(a)-(d). Insert in (a) is a zoom view of results in a) for $\mathrm{pH}=13.11$. 74

Figure 37: Apparent activation energy for the electro-oxidation of formic acid oxidation vs. bulk solution $\mathrm{pH}$. Data obtained from the maximum currents at peak II (red circles), III (black squares) and from the oscillatory frequency (green triangles). Remaining conditions as in Figure 31 and 37.

Figure 38: (a) The effect of temperature on the cyclic voltammograms of the electro-oxidation of methanol on platinum, (b) Arrhenius plots derived from the current densities at 0.70 (black circles) and $0.80 \mathrm{~V}$ (red triangles) of Figure 40a).

Figure 39: Temperature-dependent coverage of platinum oxides estimated by cyclic voltammetry in $0.5 \mathrm{M} \mathrm{H}_{2} \mathrm{SO}_{4} . \theta_{\mathrm{OH}}$ calculated by the ratio between the charge associated to the oxide formation and hydrogen UPD charge $\left(\mathrm{q}_{\mathrm{OH}} / 2 \mathrm{q}_{\mathrm{H}}\right)$ as suggested in [138]...... 78

Figure 40: a) - c): Deconvolution analysis of the main oxidation voltammetricpeak in the forward scan for three typical temperatures. Fitted peaks I (in red), II (in black) and III (in blue) are presented along with the cumulative fitted peak (dashed line). Original voltammetric peak is presented by the continuous black line. d) Current densities for the sub-peaks at different temperatures and the corresponding, e) Arrhenius plots. Temperature dependence on $\mathrm{f}$ ) the distribution of charge, in percentage of the total charge of the original peak, and on g) the potential in which individual peaks are centred, Epeak.

Figure 41: Steady state voltammograms of $\mathrm{Pt}$ in $0.4 \mathrm{M} \mathrm{K}_{2} \mathrm{SO}_{4}+1 \mathrm{M} \mathrm{H}_{3} \mathrm{COH}$ of different $\mathrm{pH}$. a) 0.37 , b) 1.02 , c) 2.04 , d) 3.03 , e) 12.97 , f) 13.76 . 80

Figure 42: maximum current density in cathodic (black squares) and anodic scan (red circles) vs. bulk solution $\mathrm{pH}$. 80

Figure 43: Galvanodynamic measurements of $5 \mu \mathrm{A} \mathrm{cm} \mathrm{cm}^{-2}$ in a) $0.4 \mathrm{M} \mathrm{K}_{2} \mathrm{SO}_{4}+1 \mathrm{M} \mathrm{H}_{3} \mathrm{COH}$ of different $\mathrm{pH}$ at $25^{\circ} \mathrm{C}$, b) $0.5 \mathrm{M} \mathrm{H}_{2} \mathrm{SO}_{4}+2 \mathrm{M} \mathrm{H}_{3} \mathrm{COH}$ in a wide temperature range. 
Figure 44: Effect of temperature in the galvanostatic electro-oxidation of methanol (normalized current density 0.5). Electrolyte: $0.5 \mathrm{M} \mathrm{H}_{2} \mathrm{SO}_{4}+2 \mathrm{M} \mathrm{H}_{3} \mathrm{COH}$ solution .......82

Figure 45: a) and b) rates of $\mathrm{dE} \mathrm{dt}^{-1}$ as a function of $\mathrm{E}$ at different temperatures as indicated; c) upper (upward triangles, Emax) and lower limits (downward triangles, Emin) of electrode potential and $\mathrm{d}$ ) the maximum (upward triangles) and minimum (downward triangles)

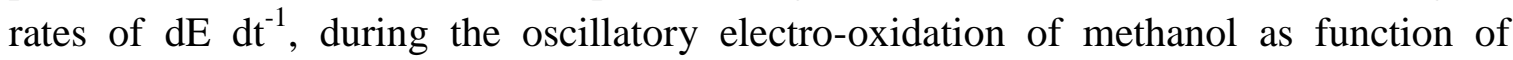
temperature. Data derived from Figure 46.

Figure 46: The effect of temperature on Sosc (full circles), f (full squares) and current densities obtained in voltammetric conditions (forward scan at $0.80 \mathrm{~V}$ vs. RHE) for the (a) the methanol galvanostatic oxidation and (b) formic acid galvanostatic oxidation[8] at $\mathrm{IN}=0.5$.

Figure 47: Potential time series of methanol oxidation in acidic $0.4 \mathrm{M} \mathrm{K}_{2} \mathrm{SO}_{4}+1 \mathrm{M} \mathrm{H}_{3} \mathrm{COH}$ at $25^{\circ} \mathrm{C}$. a) $\mathrm{pH} 0.37$, b) 1.02 , c) 2.04 , d) 3.03

Figure 48: dE/dt versus E profiles depicted in Figure 49 for $\mathrm{pH}$ a) 0.37 , b) 1.02 and c) 2.04. 87

Figure 49: Frequencies of the oscillations of $1 \mathrm{M} \mathrm{H}_{3} \mathrm{COH}$ in solutions of $0.4 \mathrm{M} \mathrm{K}_{2} \mathrm{SO}_{4}$ of different $\mathrm{pH}$ against the temperature. Normalized current density 0.5 .

Figure 50: Apparent activation energy for the formic acid oxidation vs. bulk solution $\mathrm{pH}$. Data obtained from the maximum currents at in anodic (red circles), and cathodic sweep (black squares) and from the oscillatory frequency (green triangles). Remaining conditions as in Figure 43.

Figure 51: Steady state voltammogram of $\mathrm{Pt}$ in $0.4 . \mathrm{M} \mathrm{K}_{2} \mathrm{SO}_{4}+0.2 \mathrm{M} \mathrm{HCOOH}$ with impedance spectra carried out under potentiostatic conditions at the indicated potentials. $\mathrm{pH}$ a) 1.01 , b) 13.05.

Figure 52: Steady state voltammogram of $\mathrm{Pt}$ in $0.4 . \mathrm{M} \mathrm{K}_{2} \mathrm{SO}_{4}+0.2 \mathrm{M} \mathrm{HCOOH}$ with impedance spectra carried out under potentiostatic conditions at the indicated potentials. $\mathrm{pH}$ a) 1.01 , b) 13.05. 95

Figure 53: steady state voltammograms of Pt(111) single-crystal disk in a) $0.5 \mathrm{M} \mathrm{H}_{2} \mathrm{SO}_{4}+1$ $\mathrm{M} \mathrm{HCOOH}$ and b) $0.5 \mathrm{M} \mathrm{HClO}_{4}+1 \mathrm{M} \mathrm{HCOOH}$.

Figure 54: Potential oscillation pattern of formic acid oxidation on a Pt single-crystal disk immersed in $0.3 \mathrm{M} \mathrm{K}_{2} \mathrm{SO}_{4}+0.1 \mathrm{M} \mathrm{H}_{2} \mathrm{SO}_{4}+0.4 \mathrm{M} \mathrm{HCOOH}$ for an applied current of a) 1 $\mathrm{mA} \mathrm{cm}$, b) $2 \mathrm{~mA}$ and c) $2.5 \mathrm{~mA}$ and the simultaneously recorded relative change in the reflectance of the $\operatorname{Pt}(111)$ face at $\lambda=250 \mathrm{~nm}$. 100

Figure 55: Expanded scale of Figure 58b) between 600 and $700 \mathrm{~s}$. The inset shows a potential oscillation (black) and the derivative of the synchronous reflectance oscillation (red). . 100 
Figure 56: Typical SEIRA spectra of $0.3 \mathrm{M} \mathrm{K}_{2} \mathrm{SO}_{4}+0.1 \mathrm{M} \mathrm{H}_{2} \mathrm{SO}_{4}+0.4 \mathrm{M} \mathrm{HCOOH}$ on Pt carried out at $364 \mathrm{~s}$ (red) $367 \mathrm{~s}$ (red) of the chronopotentiogram as indicated in the inset.

Figure 57: Potential oscillation pattern for a current density of $0.15 \mathrm{~mA} \mathrm{~cm}{ }^{-2}$ applied to a $\mathrm{Pt}$ film deposited on a Si prism (a) and integrated band intensities of $\mathrm{CO}_{\mathrm{L}}$ (b) and $\mathrm{HCOO}_{\mathrm{B}}$ (c) obtained from a simultaneously recorded series of ATR-SEIRA spectra. The electrolyte was a $0.3 \mathrm{M} \mathrm{K}_{2} \mathrm{SO}_{4}+0.1 \mathrm{M} \mathrm{H}_{2} \mathrm{SO}_{4}+0.4 \mathrm{M} \mathrm{HCOOH}$ solution. The panel on the right is an expanded view of the oscillation between 820 and $850 \mathrm{~s}$. The background spectrum was recorded at $0.10 \mathrm{~V}$ in the absence of formic acid. 103

Figure 58: Potential oscillation pattern for a current density of $0.4 \mathrm{~mA} \mathrm{~cm}{ }^{-2}$ (left panels) and $0.8 \mathrm{~mA} \mathrm{~cm}^{-2}$ (right panels) applied to a Pt film deposited on a Si prism (a) and integrated band intensities of $\mathrm{CO}_{\mathrm{L}}$ (b) and $\mathrm{HCOO}_{\mathrm{B}}$ (c) obtained from a simultaneously recorded series of ATR-SEIRA spectra. The electrolyte was a $0.3 \mathrm{M} \mathrm{K}_{2} \mathrm{SO}_{4}+0.4 \mathrm{M} \mathrm{HCOOH}$ solution $(\mathrm{pH} 3)$. 105

Figure 59: Typical SEIRA spectra of $0.3 \mathrm{M} \mathrm{K}_{2} \mathrm{SO}_{4}+0.4 \mathrm{M} \mathrm{HCOOH}(\mathrm{pH}$ 13) on Pt carried out at $364 \mathrm{~s}$ (red) $367 \mathrm{~s}$ (red) of the chronopotentiogram as indicated in the inset. 106

Figure 60: Potential oscillation pattern for a current density of $0.12 \mathrm{~mA} \mathrm{~cm}^{-2}$ (left panels) and $0.33 \mathrm{~mA} \mathrm{~cm}^{-2}$ (right panels) applied to a Pt film deposited on a Si prism (a) and integrated band intensities of $\mathrm{CO}_{\mathrm{L}}$ (b) and $\mathrm{HCOO}_{\mathrm{B}}$ (c) obtained from a simultaneously recorded series of ATR-SEIRA spectra. The electrolyte was a $0.3 \mathrm{M} \mathrm{K}_{2} \mathrm{SO}_{4}+0.4 \mathrm{M} \mathrm{HCOOH}$ solution ( $\mathrm{pH} 13)$......

Figure 61: CVs of Pt in $0.5 \mathrm{M} \mathrm{H}_{2} \mathrm{SO}_{4}+$ a) $2 \mathrm{M} \mathrm{H}_{3} \mathrm{COH}$, b) $1 \mathrm{M} \mathrm{H}_{3} \mathrm{COH} / 1 \mathrm{M} \mathrm{HCOOH}$ and c) $2 \mathrm{M} \mathrm{HCOOH}$ at various temperatures. Scan rate $0.05 \mathrm{~V} \mathrm{~s}^{-1}$.

Figure 62: steady state voltammograms of $\mathrm{HCOOH} / \mathrm{H}_{3} \mathrm{COH}(\mathrm{x} / \mathrm{y} \mathrm{M})$ a) 2/0, 1.8/0.2 and 1.6/0.4, b) $1.4 / 0.6-0 / 2$ in $0.5 \mathrm{M} \mathrm{H}_{2} \mathrm{SO}_{4}$, c) peak maximum current densities. Temperature $25{ }^{\circ} \mathrm{C}$. d) apparent activation energy vs $\left.\mathrm{x}\left(\mathrm{H}_{3} \mathrm{COH}\right) . \mathrm{c}\right), \mathrm{d}$ ) anodic (black) and cathodic sweep (red). 111

Figure 63: Deconvoluted sweeps of positive scan direction from the steady state voltammograms of $x / y \mathrm{M} \mathrm{HCOOH} / \mathrm{H}_{3} \mathrm{COH}$ in $0.5 \mathrm{M} \mathrm{H}_{2} \mathrm{SO}_{4}$ (a) 2/0, b) $1 / 1$, c) $0 / 2$ ) and the derived d) charge distribution, e) peak maximum current density and f) peak maximum potential vs. molar fraction of $\mathrm{H}_{3} \mathrm{COH}$. 113

Figure 64: Time series of characteristic potential oscillations in dependence on the molar fraction of methanol and formic acid in $0.5 \mathrm{M} \mathrm{H}_{2} \mathrm{SO}_{4}+\mathrm{x} / \mathrm{y} \mathrm{M} \mathrm{HCOOH} / \mathrm{H}_{3} \mathrm{COH}$ at $25{ }^{\circ} \mathrm{C}$. Normalized current density $=0.5$. 114

Figure 65: a) dE/dt profiles of characteristic oscillation cycles vs. electrode potential in solutions containing differen molar fractions of methanol and b) high and low limits of 
the cycles vs. $x\left(\mathrm{H}_{3} \mathrm{COH}\right) \cdot x\left(\mathrm{H}_{3} \mathrm{COH}\right) \cdot x\left(\mathrm{H}_{3} \mathrm{COH}\right): 0$ (black), 0.2 (red), 0.5 (green), 0.8 (blue), 1 (light blue)

Figure 66: a) potential of the maximum $\mathrm{dEdt}^{-1}$ rate and b) $\mathrm{dEdt}^{-1}$ of the positive part of the derivatives from Figure 66.

Figure 67: Oscillation frequencies, against the molar fraction of methanol for a) 10, b) 25 and c) $50{ }^{\circ} \mathrm{C}$. Other parameters are the same as in Figure 65.

Figure 68: Potential time series of $\mathrm{HCOH}$ oxidation on nanoparticles of a) $\mathrm{Pt}$, b) $\mathrm{Pt}_{3} \mathrm{Au}, \mathrm{c}$ ) $\mathrm{PtAu}$, d) $\mathrm{PtAu}_{3}$ and e) $\mathrm{PtAu}_{9}$. The panels on right in Figure a), b) and c) show an expanded view of the oscillation patterns. Applied normalized current density 0.2...... 126

Figure 69: Derivatives of distinct oscillation cycles from Figure 69 against the measured potential. Pt (black), $\mathrm{Pt}_{3} \mathrm{Au}$ (red), PtAu (green).

Figure 70: Steady state voltammograms of Pd in 0.5 (black) and 2 (red) $\mathrm{M} \mathrm{HCOOH}+0.5 \mathrm{M}$ $\mathrm{H}_{2} \mathrm{SO}_{4}$

Figure 71: Potential time series of a) $0.5 \mathrm{M} \mathrm{HCOOH}+0.5 \mathrm{M} \mathrm{H}_{2} \mathrm{SO}_{4}$ with applied current densities of 0.2 (black) and $0.33 \mathrm{~mA} \mathrm{~cm}^{-2}$ (red) and b) $0.5 \mathrm{M} \mathrm{HCOOH}+0.5 \mathrm{M} \mathrm{H}_{2} \mathrm{SO}_{4}$ with applied current densities of 0.13 (black) and $0.2 \mathrm{~mA} \mathrm{~cm}^{-2}$ (red). 130 


\section{List of Tables}

Table 1: Estimated Pt/Au ratios from XPS.

56

Table 2: Estimated onset potentials under the conditions applied $\left([\mathrm{HCOOH}]=0.05 \mathrm{~mol} \mathrm{l}^{-1}\right.$,

$\left.\left[\mathrm{H}_{2} \mathrm{SO}_{4}\right]=0.5 \mathrm{~mol} \mathrm{l}^{-1}, 25^{\circ} \mathrm{C}\right)$.

Table 3: Oscillation parameters obtained from Figure 30. 61

Table 4: Publications on the oxidation of small organic molecules related to fuel cells. 64

Table 5: Oscillation parameters obtained from Figure 69 


\section{Table of contents}

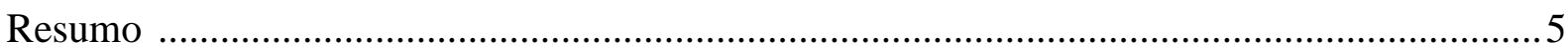

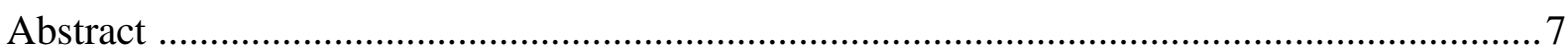

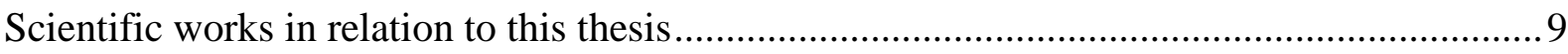

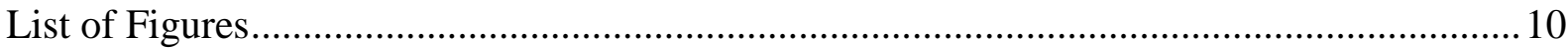

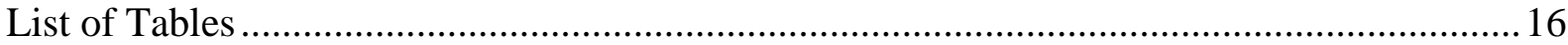

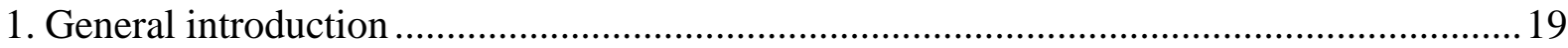

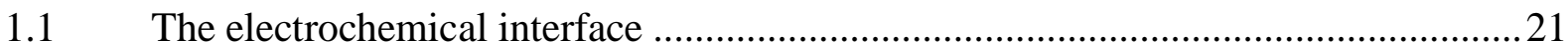

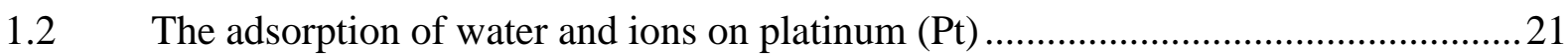

1.3 Dynamic instabilities and oscillations in electrochemical systems .........................25

1.4 HN-NDR oscillators and impedance spectroscopy for their stability analysis..........32

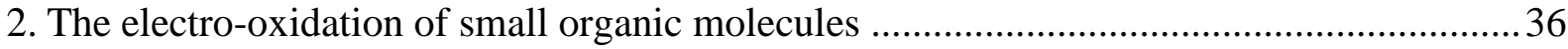

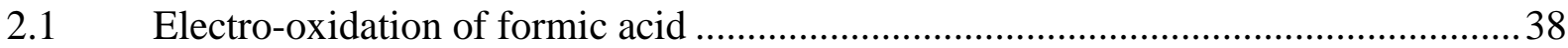

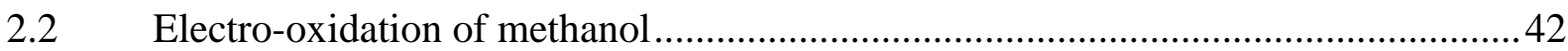

2.3 The electro-oxidation of formic acid and methanol on Pt-based electrodes ..............45

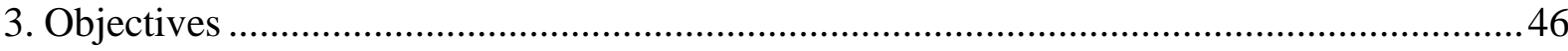

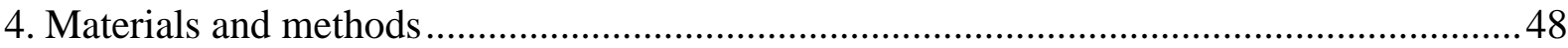

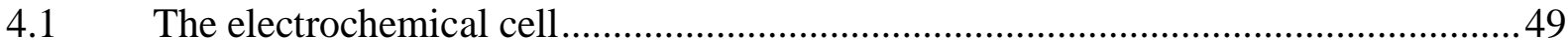

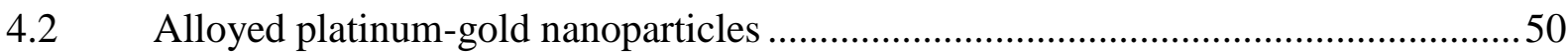

4.3 Surface enhanced infrared adsorption spectroscopy in attenuated total reflection

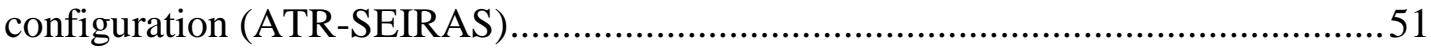

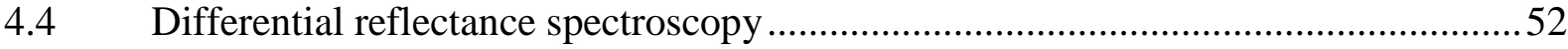

5. Electro-oxidation of formic acid on PtAu nanoparticles (NPs) ..........................................53

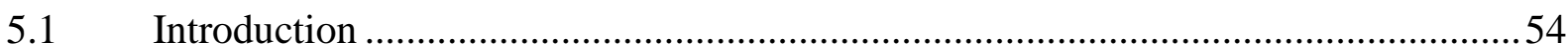

5.2 Initial characterization and performance in $\mathrm{HCOOH}$ oxidation .............................56

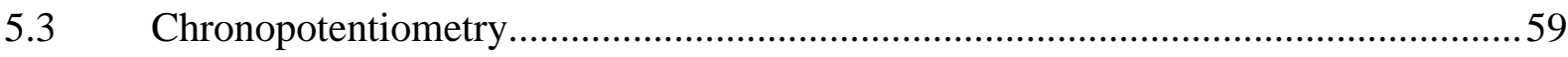

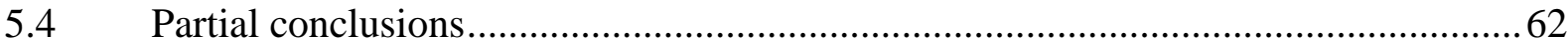

6. Temperature and $\mathrm{pH}$ dependencies of voltammetric response and oscillations ...................63

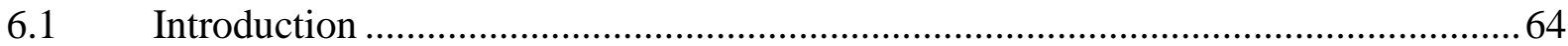

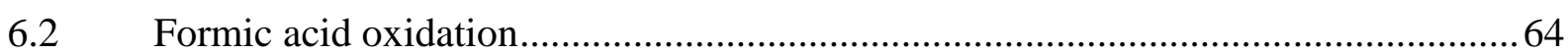

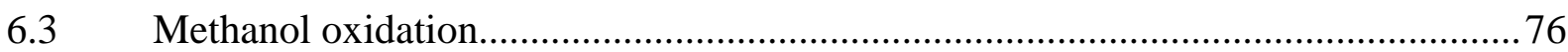

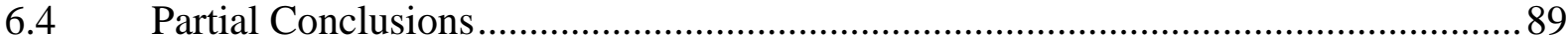

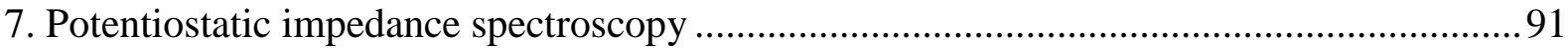

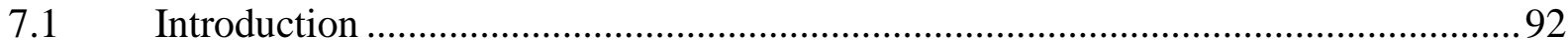




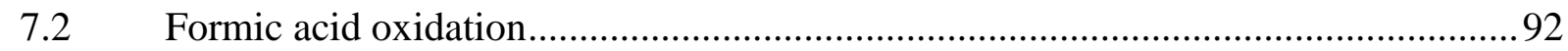

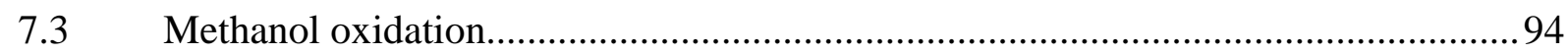

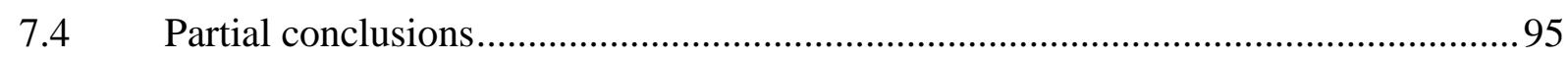

8. ATR-SEIRAS and differential reflectance spectroscopy .............................................. 97

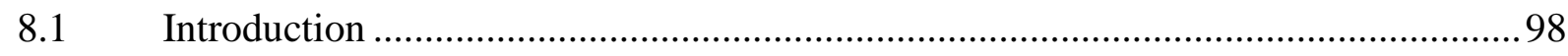

8.2 Formic acid oxidation under potentiodynamic conditions accompanied by differential

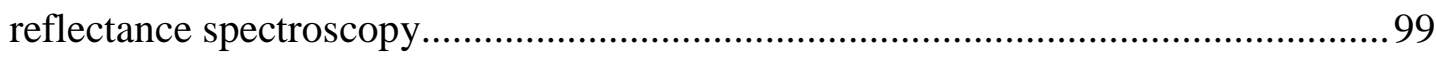

8.3 Oscillating surface coverages of $\mathrm{CO}, \mathrm{HCOO}_{\mathrm{B}}$, surface oxides and adsorbed sulphate at acidic $\mathrm{pH}$ along the galvanostatic formic acid oxidation .................................. 100

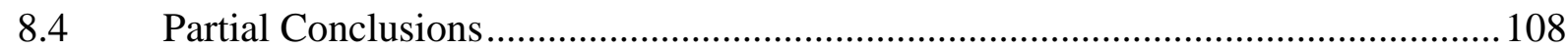

9. Synergy of formic acid and methanol electro-oxidation ............................................... 109

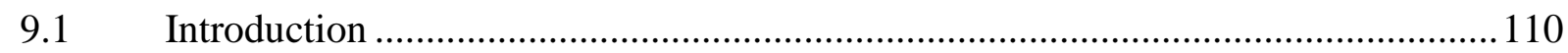

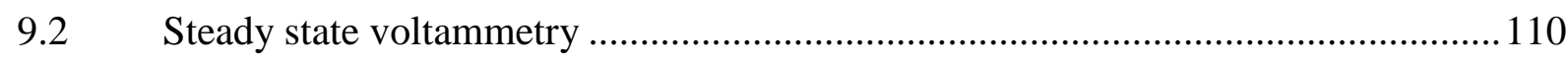

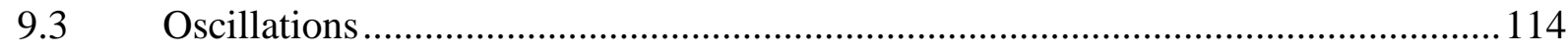

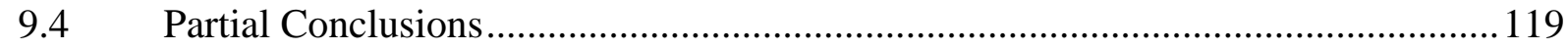

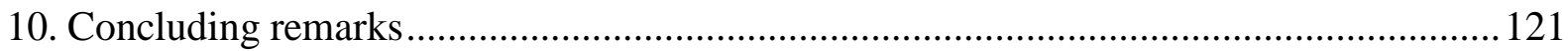

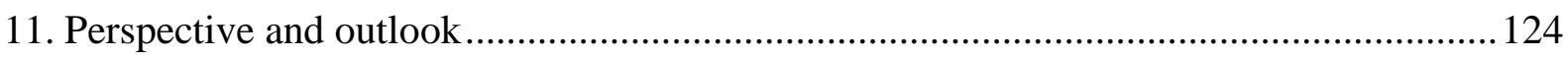

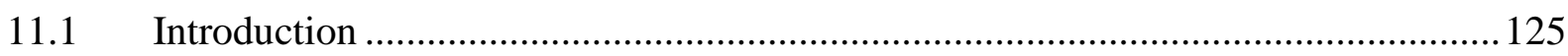

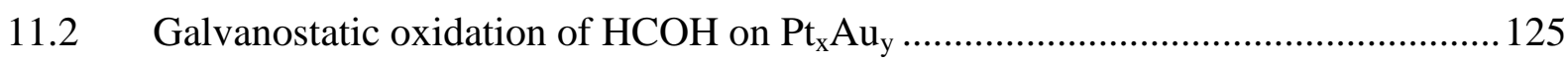

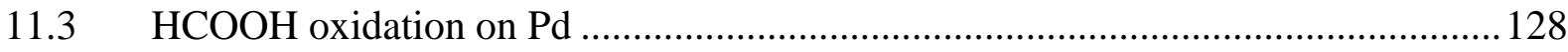

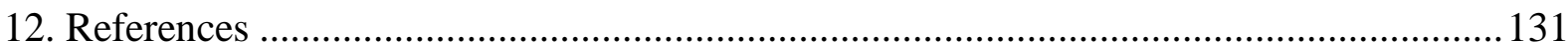




\section{General introduction}

The most basic principles of pattern formation and self-organization are presented in this chapter, that are obligatory to find patterns in any electrochemical system, aside the fundamental electrochemistry of platinum in aqueous solution. 
Self-organization and pattern formation are processes aspects in man-made or natural phenomena, such as crime [1], economy [2] and traffic [3] or brain activity [4], structure formation [5] and swarms [6], respectively. Probably the most famous example in chemistry might be the Belousov-Zhabotisnky (BZ) reaction [7], but most of the self-organizing systems can be found in electrochemical systems like metal dissolution (see Figure 1) [8,9], oxidation and reduction of sulphur species [10,11], hydrogen peroxide reduction [12-14] or the oxidation of small organic molecules [15-19]. These systems can also undergo current and potential oscillations under some conditions.

Figure 1: Snapshots $\left(96 \times 96 \mathrm{~nm}^{3}\right)$ of 3D phase-field simulations highlighting the solid-liquid interface and compositional domains at the early stage of dealloying. Copied from [9].
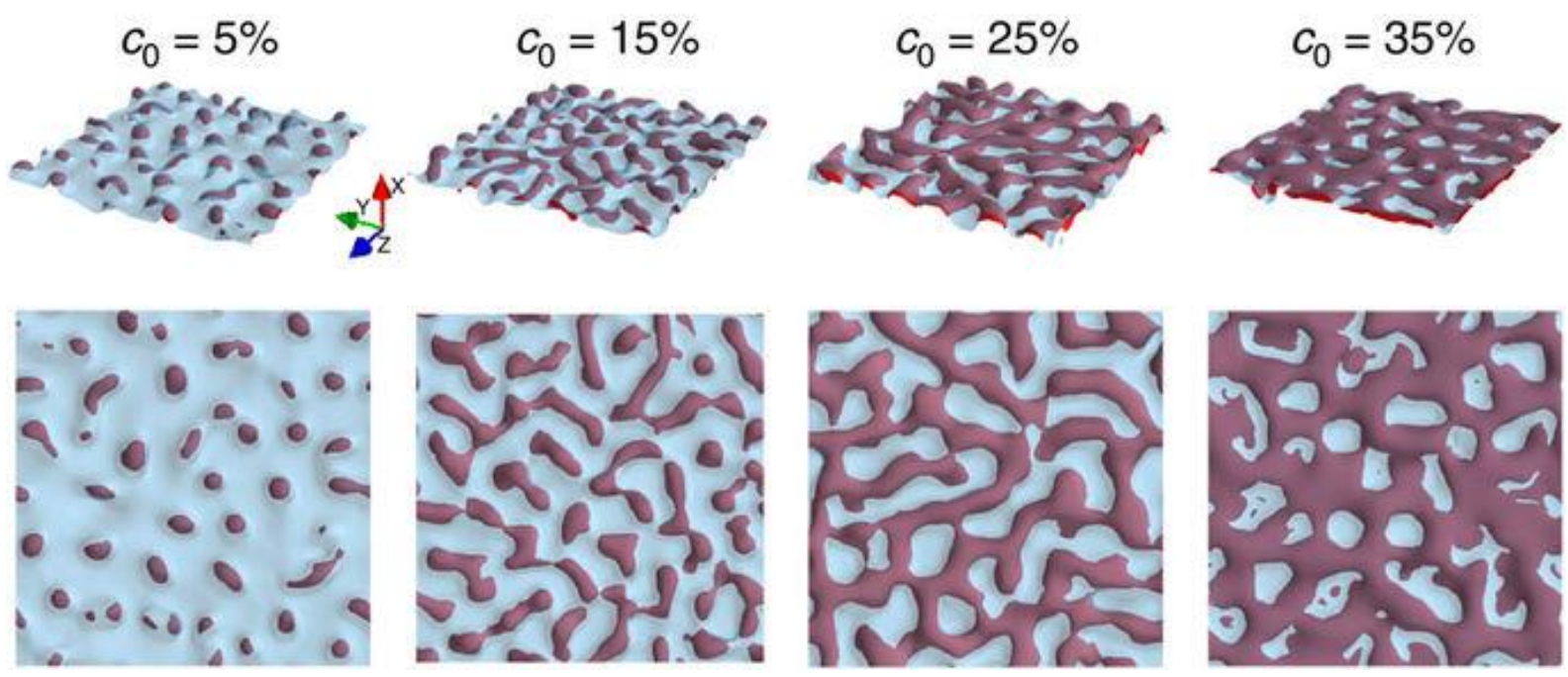

The first report of dynamic instabilities dates back 200 years ago [20]. Since then the studies of self-organization and pattern formation have helped to provide a better understanding of electrochemical systems and have contributed much insight in related surface processes. Due to the underlying competition of all contained species on active surface sites, the solid/liquid interface is sensitive to instabilities in the non-linear dynamics, that self-organization is a common process in electrochemistry. The evolution of all related subunits in time and space obeys the non-linear dynamics of the Butler-Volmer theory and determines the involved processes in pattern formation [21]. Under conditions in thermodynamic equilibrium all parameters will approach a time-independent value of a minimum of energy and a maximum in total entropy, which leaves the system in the most unorganized, possible state. Yet, as the word "self-organization" predicts, the system undergoes organization, which automatically means a decrease in entropy. The second law of thermodynamics just allows an increasing entropy for open partial systems far from 
thermodynamic equilibrium with the ambient. The exact controlling of the intrinsic parameters such as current or potential can drive the system away from equilibrium, which allows the possibility to learn more about the evolution of the dependent variables in this environment, that remain hidden in conventional experiments close to the thermodynamic equilibrium and makes electrochemical oscillators a perfect model system to elucidate more of the non-linear kinetics of complex reaction mechanisms.

\subsection{The electrochemical interface}

An electrochemical system generally consists of two conductively connected electrodes, called working and a counter electrode, which are both in contact with a solution. All electrochemical reactions of interest take place in the phase boundary of the solid electrode and the liquid phase as electrolyte on the working electrode. Thus, the characterization and study of this interface is a crucial objective to understand more about the nature of the applied system. Generally, the electrochemical processes involve the adsorption of the reactants on the surface to implement a charge transfer and close the electrical circuit between electrode and reference electrode. The region, where related processes take place is called the electrochemical double layer and can be described in the easiest way by the Helmholtz model [21].

The easiest model to describe adsorption is named after Langmuir, where adsorbates are treated as rigid spheres like in an ideal gas, adsorbing with a maximum coverage of one monolayer. Consequently, no other interactions than between the surface and the particle are taken into account in this model. It is well known, that such a treatment is just valid for low coverages and simple structured adsorbates, meanwhile attractive or repulsive interactions between the adsorbates or particles in the interface become more important as concentration and complexity in the studied system increase. Other simulations like the Frumkin or Temkin model may be more applicable in such a case. On the basis of this general introduction some important examples should be described in the following.

\subsection{The adsorption of water and ions on platinum $(\mathrm{Pt})$}


Since conventional studies of electrochemical processes are carried out in aqueous solutions, water is very present near the electrode due to an exceedingly high concentration and likely to influence the investigated reaction dynamics. Since water is known to show very strong intermolecular interactions via hydrogen bonds, the surrounding environment of the adsorbing molecules plays an important role as well and has to be included in any studies of the metal-water interface. As it is reported in literature, the strength of water adsorption strongly depends on the nature of metal surface and the surface orientation, but generally chains and ice-like structures can be found on the surface [22-24]. During cyclic voltammetry these structures are mainly found in the so-called double layer region, where the orientation of the water molecules and adsorption strength strongly depends on the potential $[25,26]$. The voltammetric response of platinum in a $0.5 \mathrm{M} \mathrm{K}_{2} \mathrm{SO}_{4}$ solution with additional $\mathrm{H}_{2} \mathrm{SO}_{4}$ or $\mathrm{KOH}$ to adjust the $\mathrm{pH}$, as desired, are plotted in Figure 2:

Figure 2: Steady state voltammograms of Pt in $0.5 \mathrm{M} \mathrm{K}_{2} \mathrm{SO}_{4}+\mathrm{x} \mathrm{M} \mathrm{H}_{2} \mathrm{SO}_{4} / \mathrm{KOH}$, pH 1.02

(black), 13.12 (red). The grey and red boxes indicate the double layer region.

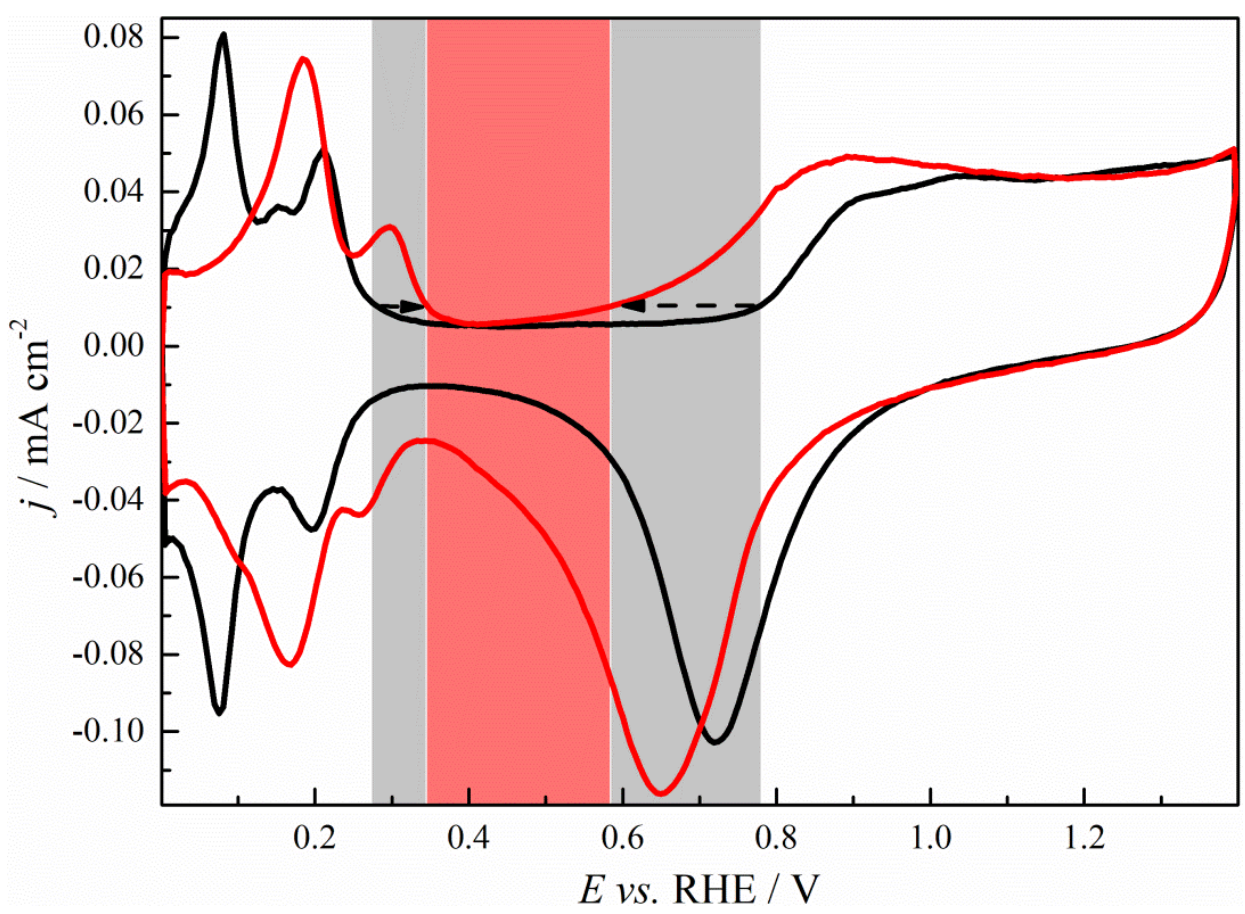

As it illustrates, the double layer region, where water and anions are adsorbed, are influenced significantly by the bulk solution $\mathrm{pH}$ and is reduced in alkaline media. As Osawa and coworkers found by surface enhanced infrared adsorption spectroscopy in attenuated total reflection configuration (ATR-SEIRAS), the water orientation changes from a tilted configuration with hydrogen atoms slightly in direction to the surface in the region of 
overpotential deposited hydrogen to a more flat configuration at low overpotentials and a icelike structure in the double layer region [26]. This interpretation also suggests a potential dependent hydrogen bonding, which is rather weak at low overpotentials, where one lone pair of the oxygen interacts with the Pt surface and is less available for hydrogen bonds. On the other hand hydrogen bonds become very important in the double layer region, where the found configuration allows a strong interaction with the overlying molecules in a bilayer model. At more negative and positive potentials beyond the double layer region water reduction, hydrogen adsorption, water and surface oxidation take place, respectively, as shown in equation 1-4, whose onset potentials also strongly depends on the $\mathrm{pH}$.

$$
\begin{gathered}
\mathrm{H}^{+}+\mathrm{e}^{-}+* \rightleftharpoons \mathrm{H}_{\mathrm{ad}} \\
\mathrm{H}_{2} \mathrm{O}+\mathrm{e}^{-}+* \rightleftharpoons \mathrm{H}_{\mathrm{ad}}+\mathrm{OH}^{-} \\
\mathrm{H}_{2} \mathrm{O}+2^{*} \rightarrow \mathrm{HO}_{\mathrm{ad}}+\mathrm{e}^{-}+\mathrm{H}^{+}+* \rightarrow \mathrm{O}_{\mathrm{ad}}+2 \mathrm{e}^{-}+2 \mathrm{H}^{+} \\
\mathrm{OH}^{-}+2 * \rightarrow \mathrm{OH}_{\mathrm{ad}}+\mathrm{e}^{-}+* \rightarrow \mathrm{O}_{\mathrm{ad}}+2 \mathrm{e}^{-}+2 \mathrm{H}^{+}
\end{gathered}
$$

The asterisk in each equation represents the necessity of one adsorption site on the Pt surface, where the reaction takes place. In the potential range between $\sim 0.7$ to $\sim 1.2 \mathrm{~V}$ the surface oxidation passes through several states, which involve so-called place-exchanges of the adsorbed oxides with surface atoms to the subsurface and the deactivation of the Pt surface [27]:

Figure 3: a)-f) Different stages of the surface oxidation of Pt. Copied from reference [27]. 


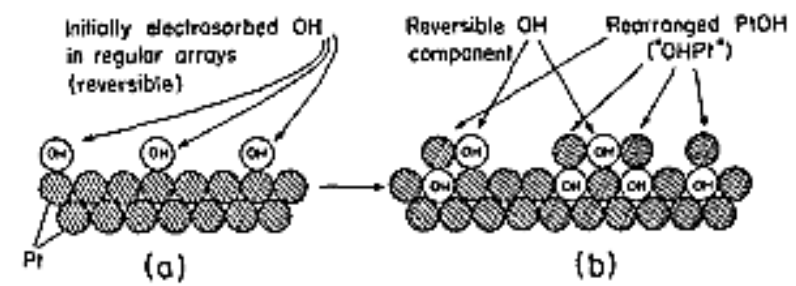

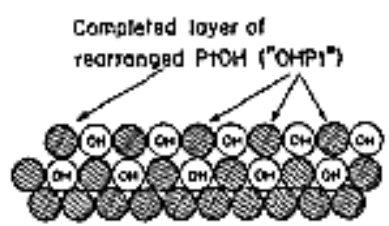

(c)

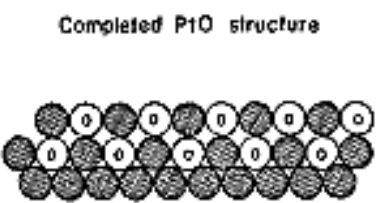

(e)

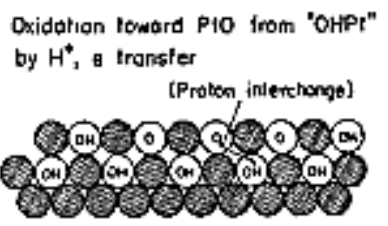

(d)

Qxiddtion tomards Pto,s

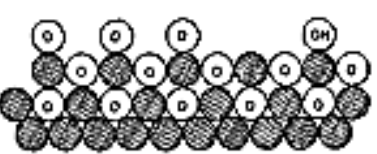

(f)

Meanwhile hydrogen adsorption and desorption appear in the reversible, characteristic shape (see Figure 2), oxide formation and reduction show a potential hysteresis due to the irreversibility of the place-exchange processes [27-29]. Especially the surface oxidation shows a significant shift to more negative potentials in alkaline media due to the facilitated formation of surface oxides in that media [30], decreasing double layer region. Due to the poor conductivity of pure water with a resistance of $18.2 \mathrm{M} \Omega \mathrm{cm}$ electrolytes are used to enhance the charge transfer between working and counter electrode. As Strmcnik et al. reported, the adsorption of cations also has a crucial role in the solid/liquid interface of platinum, which is susceptible to the size of the present alkali ion in solution. Thus, all cations adsorb physically, but meanwhile the smaller $\mathrm{Li}^{+}$and $\mathrm{Na}^{+}$get physically adsorbed directly on the formed surface oxides, the $\mathrm{Cs}^{+}$and $\mathrm{K}^{+}$interact rather via the surrounding hydration shell [31].

In acidic solutions anions undergo either weakly physio- or strong chemisorption, depending on their interaction with Pt surface and go in the order from weak to strong for $\mathrm{ClO}_{4}{ }^{-}<\mathrm{SO}_{4}{ }^{2-}<\mathrm{HPO}_{4}{ }^{2-}<\mathrm{Cl}^{-}$, just to mention some prominent examples, and also interact with the surrounding water environment [32]. As it is shown in literature, adsorbed anions may also influence the structure of the water layer and compete with oxide formation or any other oxidation or adsorption process for active surface sites [26]. Despite the possibly lower presence of anion and cation due to the lower concentration compared to water in the electrochemically double layer, it can be concluded, that their adsorption may have a crucial 
influence on any (non)faradayic process, that takes place in the electrolyte-platinum interface and have to be considered in the analysis of reaction mechanism. Besides the described effects, the accumulation of anions may lead to a phase transition in the adsorption layer, which leads to a higher order of the adsorbates and manifests itself in an immediate increase of the measured current in the potentiodynamic profile of highly ordered, monocrystalline surfaces. In the case of Pt this is especially the case for sulphate adsorption on the $\mathrm{Pt}(111)$ and $\operatorname{Pt}(100)$ terraces [33-35]. A phase transition has also been reported by Fujitani et al. and Kibler et al. for the adsorption layer formate in bridge-bonded configuration on $\mathrm{Cu}(111)$ and Au(111), respectively [36,37]. This fact may be of crucial importance, since the role of bridge-bonded formate has been under debate in literature recently, which will be explicated and discussed below.

\subsection{Dynamic instabilities and oscillations in electrochemical}

\section{systems}

Any system, where an initial parameter $\mathrm{x}$ changes by time $\mathrm{t}$, can be called dynamic and is described by a differential equation:

$$
\frac{\mathrm{dx}}{\mathrm{dt}}=\mathrm{f}(\mathrm{x})
$$

Differential equations can contain useful information, that help to understand the studied phenomena, if the fundamental equation is unknown, which can be understood by the analysis of fixed points $\mathrm{x}_{\mathrm{f}}$, defined as $\mathrm{f}(\mathrm{x})=0$. Since differential equations can be difficult or impossible to solve, even for one-dimensional systems, the function $\mathrm{f}(\mathrm{x})$ can be simplified by the application of a Taylor series at $\mathrm{x}=\mathrm{c}$, which transforms equation 5 to

$$
\frac{\mathrm{dc}}{\mathrm{dt}}=\mathrm{f}(\mathrm{c})\left(+\frac{f^{\prime}(c)}{1 !}(x-c)+\frac{f^{\prime \prime}(c)}{2 !}(x-c)^{2}+\frac{f^{\prime \prime \prime}(c)}{3 !}(x-c)^{3}+\cdots\right)
$$

and further simplified by Lyapunov theorem claiming the close vicinity of every point as linear [38]. In that way all derivatives in the Taylor series are eliminated or neglected in that way, what is expressed with the brackets in equation 6.

Figure 4: a) Fixed points in the flow field of $f(x)$, b) position of stable (dashed black line) and unstable fixed points (red solid line) in dependence on parameter a. 

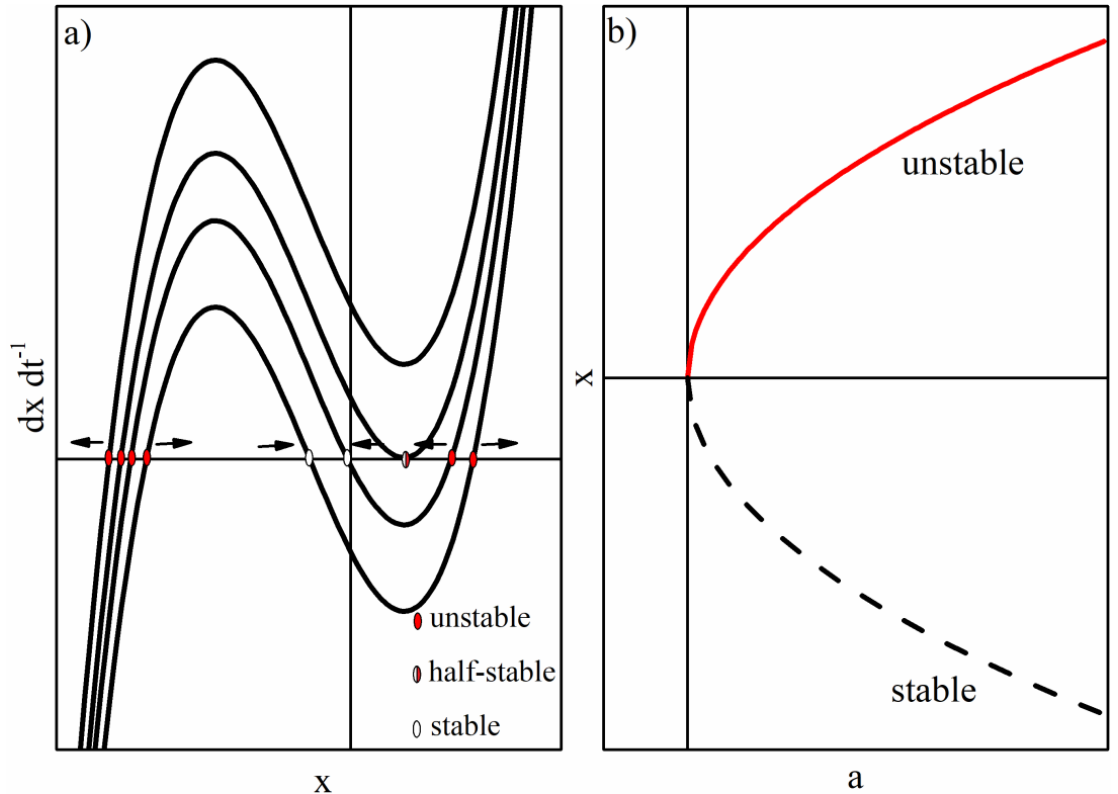

This linear stability analysis is used to characterize the type of the fixed points. There one has to differentiate between stable, half-stable and unstable fixed points, which are marked in Figure 4 in an exemplary case and will be further explained in the following. As the arrows in Figure 4a) indicate, a negative value results in a flow to the left and a positive to the right by definition. Thus, the fixed points are either unstable (saddle), where any small divergence from the fixed point will lead away to the next stable one (node), meanwhile the flow field always goes in the direction to the stable fixed points [38,39]. In the case of halfstable fixed points the flow flied leads to the fixed point on one side, meanwhile it leads away from it on the opposite side, respectively. If a parameter "a" varies, the flow changes accordingly and leads to the convergence/divergence of the fixed points. This can result in the change of a saddle and node to a half-stable fixed point or in their creation/annihilation at the so-called saddle-node bifurcation [38,39]. Figure $4 \mathrm{~b}$ ) highlights the increasing separation of saddles and nodes as the parameter "a" gets more positive, if the flow field in Figure 4a) changes accordingly.

Another kind of bifurcation is the Hopf bifurcation, where one has to distinguish between the supercritical and subcritical type. A few examples for a differential equations of third order are plotted in Figure 5:

Figure 5: a)-c) differential equations of third order $\left.\left.\left.d x / d t=a x-x^{3} . a\right) a>0, b\right) a=0, c\right) a<0$. 


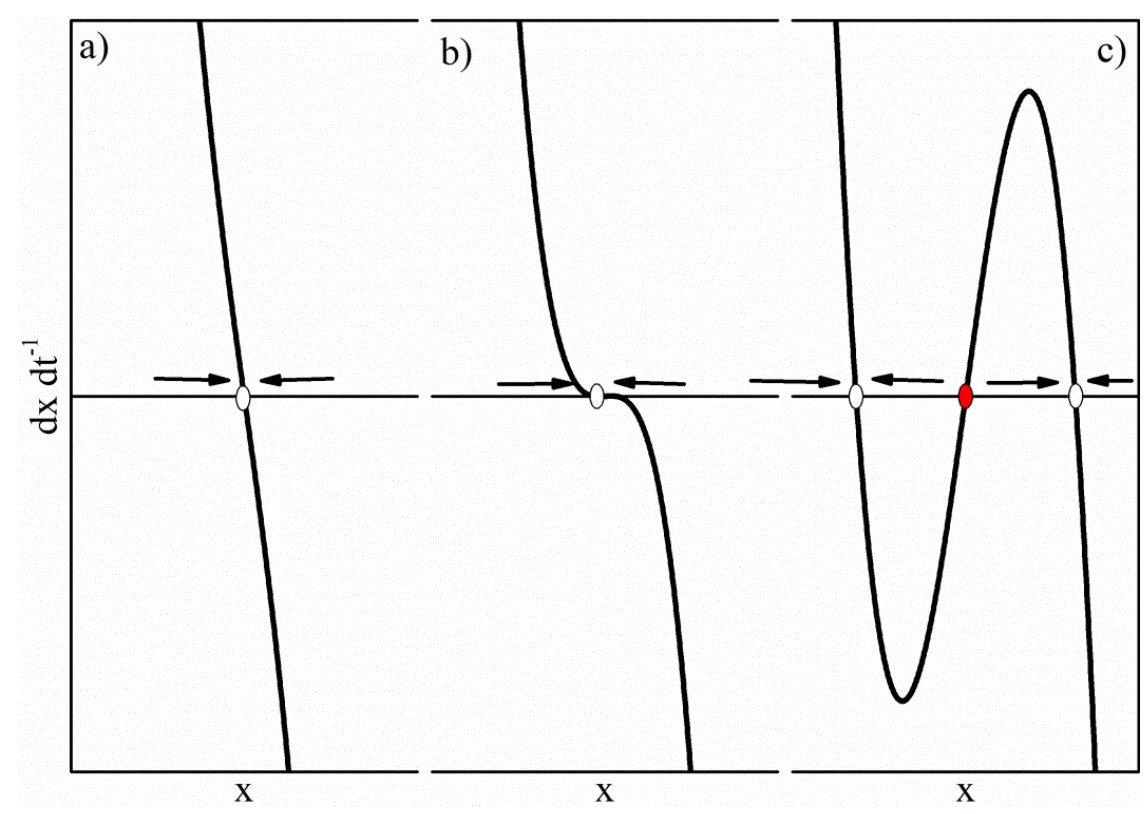

As the transformation in dependence on parameter a demonstrates, until a critical value of $a_{c}$, the type of the fixed point does not change and just the quantitative approach is smoother in comparison of Figure 6a) and b). The situation changes qualitatively, as the bifurcation point is passed at $\mathrm{a}_{\mathrm{c}}$, where the centred fixed point becomes unstable, two stable ones are created (Figure 6c)) and mark the position of a stable cycle [38].

Figure 6: a) position of fixed points from Figure 5a)-c) in dependence on a supercritical Hopf bifurcation and phase diagram for $b$ ) $a \leq a_{c}$ and $c$ ) $a>a_{c}$.

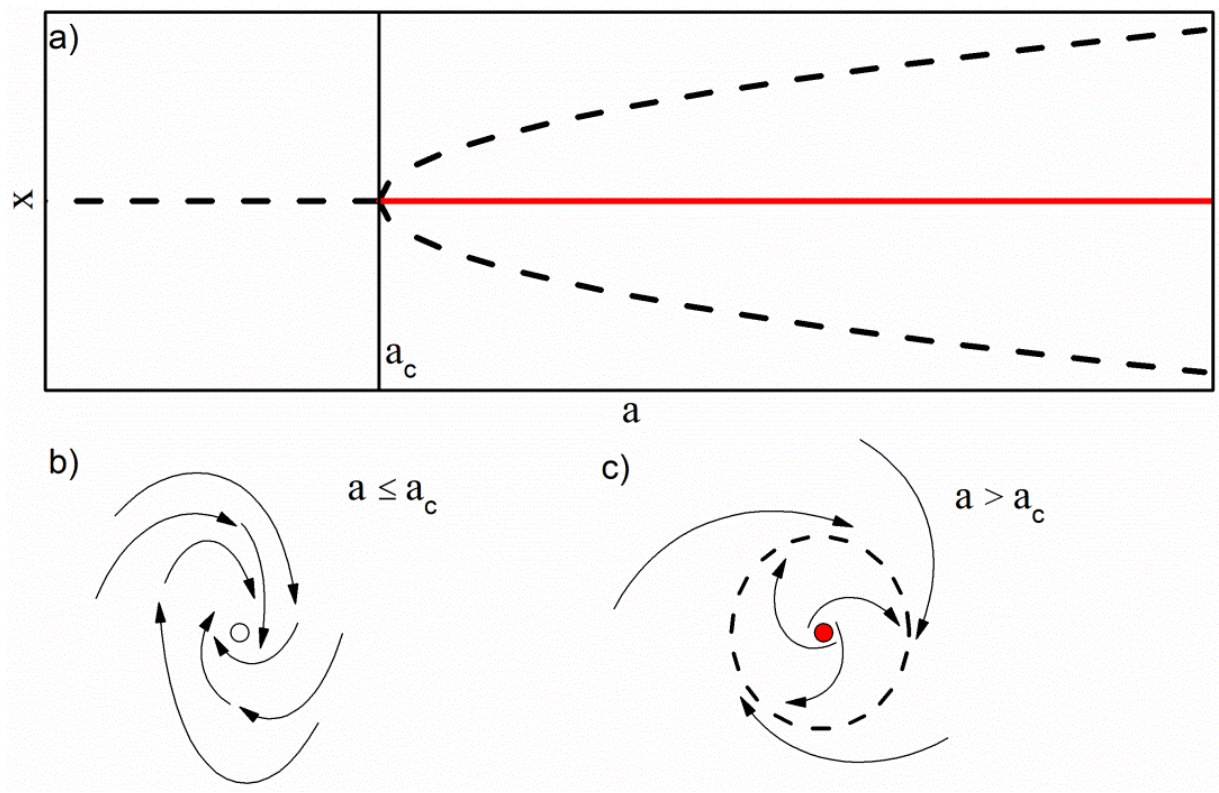


This phenomena is known as supercritical Hopf bifurcation, where the bifurcation and phase diagram are displayed in Figure 7. It highlights the transition from the node to the limiting stable cycle and the unstable saddle point.

Figure 7: a) position of fixed points for a subcritical Hopf bifurcation in dependence on $a$ and phase diagram for $b) a \leq a_{c}$ and c) $a>a_{c}$.

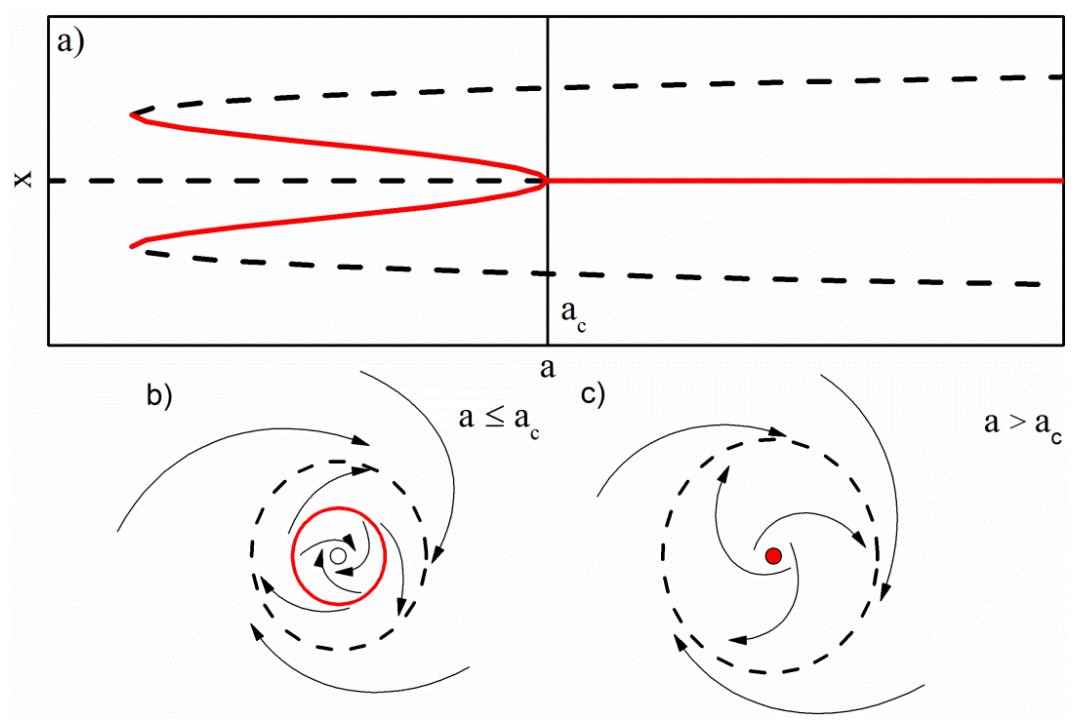

This type of bifurcation is typical for oscillating systems, which evolve with gradually increasing amplitude, as the bifurcation point is passed [38,40]. In a subcritical Hopf bifurcation, plotted in Figure 7, the situation is quite different, where the node jumps to a stable circle of nonzero radius, at the bifurcation. On the other hand, the circle remains as the crititcal value is passed from positive to negative until another bifurcation point is passed, where the stable circle changes back to the fixed point. Both "hard transitions" occur due to the unstable circle between the stable fixed points, where any oscillation will occur or die with the amplitude changing immediately from zero to non-zero and vice versa $[38,40]$. The above introduced bifurcation theory shall be used and elaborated in a more practical point of view in the following to outline its importance in electrochemical systems.

As it is fixed by Kirchhoff's law in equation 7,

$$
\mathrm{i}=\mathrm{i}_{\mathrm{C}}(\varphi)+\mathrm{i}_{\mathrm{F}}(\varphi)
$$

the complete current $\mathrm{i}$, which is set by the voltage $\mathrm{E}$ from the potentiostat and passes through

Figure 8: a) Circuit of an electrochemical cell connected to a potentiostat applying the potential $\mathrm{E}$ and $\varphi$ as potential drop at the double layer. b) possible branches for the current I 
passing the resistance of the system $R_{S}$ and the faradaic impedance $Z_{F}$ or the double layer capacitance $\mathrm{C}_{\mathrm{DL}}$ at the working electrode.

a)
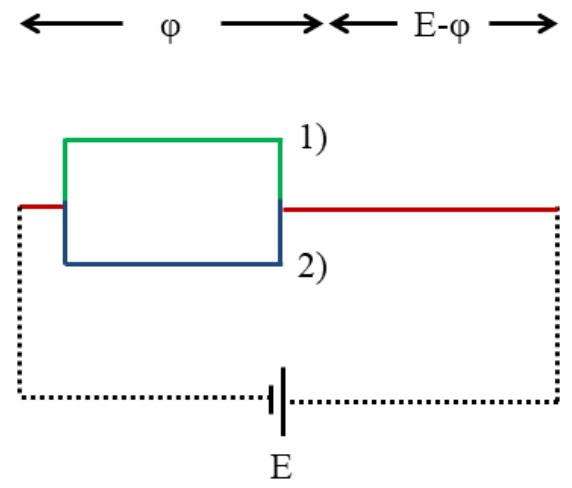

b)
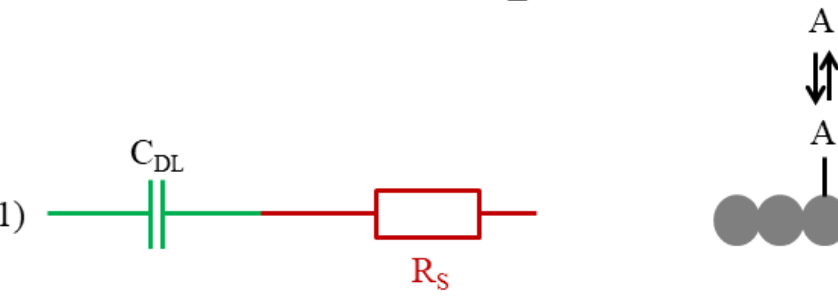

2)
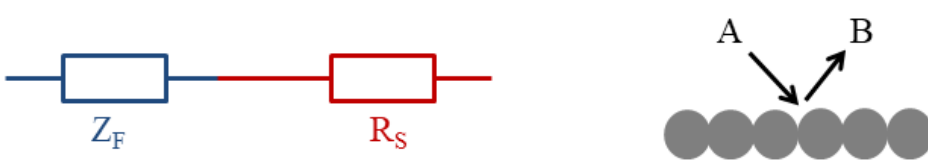

the common branch with the resistance of the system $R_{S}$ (in Figure 8 red), is equal to the sum of the currents, which pass through each branch of the part representing the working electrode (green (1) and blue (2) branches in Figure 8a) and b). As it has already been discussed in the previous chapter, the electrical circuit in an electrochemical system can be closed by adsorption/desorption processes resulting in capacitive currents $i_{C}$ via branch 1), which establish the double layer between adsorbates and surface and its capacitance $\mathrm{C}_{\mathrm{DL}}$ reactive processes in the double layer $i_{F}$. On the other hand currents can flow via branch 2), which occur due to faradaic oxidation and reduction reactions and are represented by the impedance $\mathrm{Z}_{\mathrm{F}}$.Meanwhile $\mathrm{i}_{\mathrm{C}}$ can be represented by the double layer charging, which depends on its capacitance $\mathrm{C}_{\mathrm{DL}}$ and the time dependent change of the potential $\mathrm{E}, \mathrm{i}_{\mathrm{F}}$ can be described simply as the potential dependent current flowing through the faradaic impedance $Z_{F}$, that equation 7 can be transformed to equation 8 ,

$$
\mathrm{i}=\mathrm{C}_{\mathrm{DL}} \frac{\mathrm{d} \varphi}{\mathrm{dt}}+\mathrm{i}_{\mathrm{F}}(\varphi)
$$

where in potentiodynamic and -static experiments the total current is replaced by the fraction of the difference of the applied potential $\mathrm{E}$ and the potential drop at the working electrode $\varphi$, 
divided by the systems resistance $\mathrm{R}_{\mathrm{S}}$, which shall not be discussed deeply and is are not scope of this work. The linear stability analysis of the system is realized by the introduction of a small perturbation $\delta \mathrm{E}$ and the evaluation of $\mathrm{i}_{\mathrm{F}}$ with the linear term of a Taylor series, what changes equation 8 to equation 9 , which can be transformed to equation 10 :

$$
\begin{gathered}
C_{D L} \frac{\mathrm{d} \delta \varphi}{d t}=-\frac{\partial \mathrm{i}_{\mathrm{F}}}{\partial \varphi} \delta \varphi \\
\mathrm{C}_{\mathrm{DL}} \frac{\mathrm{d} \delta \varphi}{\mathrm{dt}}=-\mathrm{Z}_{\mathrm{F}}^{-1} \delta \varphi
\end{gathered}
$$

Since the total current is kept constant in galvanostatic measurements, it becomes zero in equation 9. In equation 10 it becomes clear, that a positive growing perturbation is realized, if the faradaic impedance is negative and manifests the occurrence of possible potential oscillations in a potential range, where a negative differential resistance determines the current flow in the electrical circuit, which forms the shape of a $\mathrm{N}$ (N-NDR) as shown in Figure 9a). It should also be noted, that the equation 10 does not include the resistance $\mathrm{R}_{\mathrm{S}}$, but a theoretically infinite resistance can be assumed as characteristic feature [39,40]. For the purposes of this thesis especially the first is to be considered as the main responsible parameter for the NDR, what can be caused for example by the accumulation of an inhibiting adsorbate on the surface, as the overpotential increases [39]. A schematic example of a $\mathrm{N}$ NDR is displayed in Figure 9a), which shows the shift of the potentiodynamic curve with increasing resistance, for example, by adding an external, serial resistance, to a distorted shape, what results in two saddle-node bifurcations and the change from mono- to bistability and two possible states in the same potential region, shown in Figure 9c) [41]. In which state the system will be, is dependent on the initial conditions. As the arrows indicate the instable part between the limiting potentials $E_{1}$ and $E_{2}$ is not accessible in the experiment and the current changes rapidly between the stable states and manifests itself in a hysteresis. If the NNDR is partly hidden by simultaneous process (HN-NDR), just a part of the potentiodynamic curve follows the N-NDR, as displayed in Figure 9b) [39,41].

Figure 9: Current-potential curves for the case of a) N-NDR, b) HN-NDR and c) bistability. 


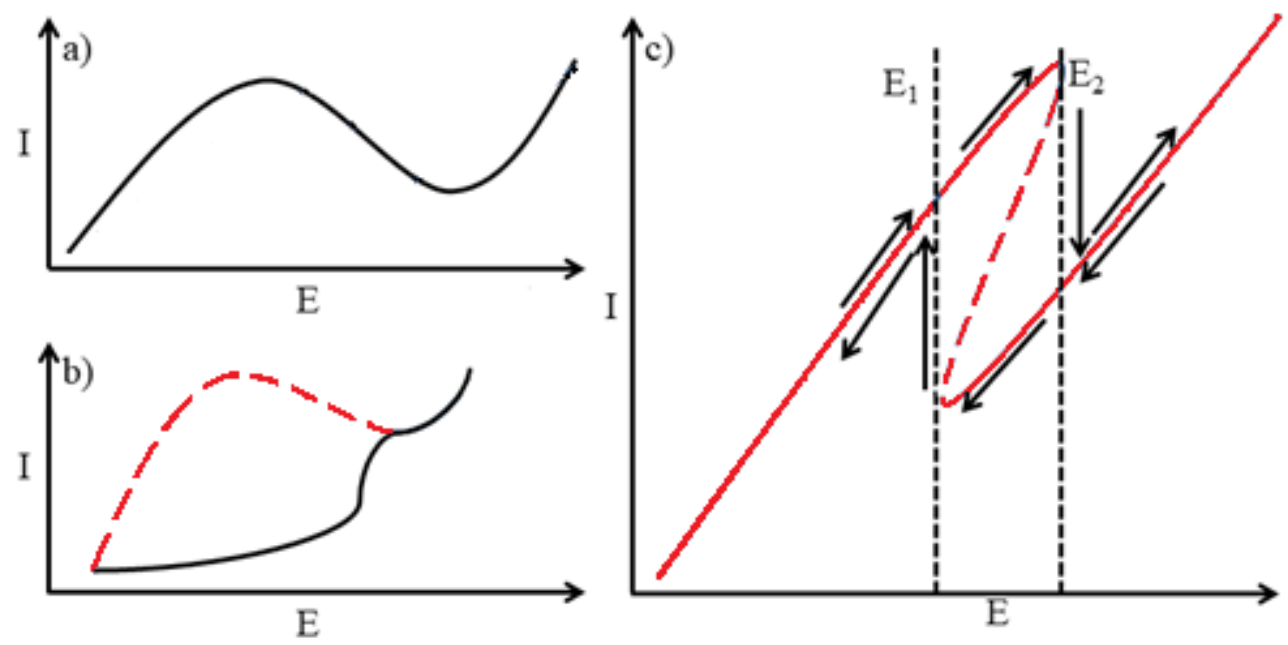

So far the non-linear dynamics have been described for the one-dimensional dependence of current and potential, which is limited to the phenomena of bistability. If current-potential response in the NDR region does not just depend on potential or current, but on at least one other parameter $\theta$, dynamic instabilities can evolve oscillating behaviour and thus, current or potential oscillations. An example for such an additional degree of freedom is the potential dependent adsorption of an activating species, which lowers the coverage of the inhibitor partly or completely and liberates the active surface sites. Figure 10 illustrates the coupling of all involved parameters, where the central autocatalysis of the potential is to be stressed particularly and manifests itself under galvanostatic conditions in the following way. The interaction in the positive cycle is the same, as it has been described in the previous section of bistability, where any slightly positive change in the potential leads to decreasing current [39]. Since the system is forced by the galvanostat to maintain the applied current by a sufficient charge transfer via the double layer, the potential and thus, the activity of all electrochemical processes have to increase. The negative feedback loop responds accordingly, where the parameter $\theta$ suffers a positive response due to the increasing potential, which itself causes and increasing current. The enhanced activity reduces the potential and closes the negative loop [39]. The described interaction is known in literature as activator-inhibitor system with the inhibition processes being slower than the activation $[39,40]$.

Figure 10: Feedback loops of an oscillating electrochemical reaction. 


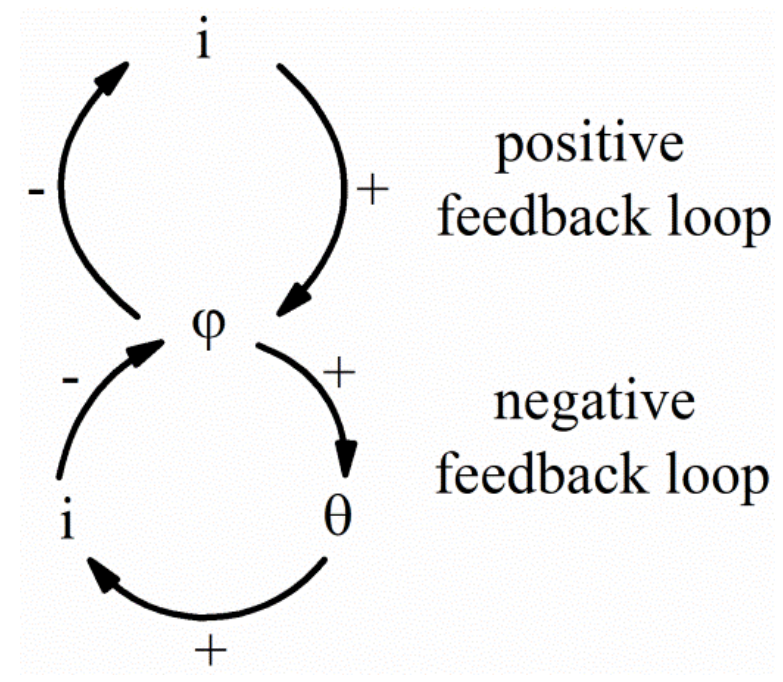

\subsection{HN-NDR oscillators and impedance spectroscopy for their stability analysis}

As mentioned above, the existence of a NDR region and a sufficient, external resistance are crucial for the emergence of oscillatory behaviour besides the dependence on more than one degree of freedom. In the case galvanodynamic and -static conditions with in theory infinite resistance, any HN-NDR oscillator will undergo potential oscillations in the NDR region. But since it can be (partly) hidden as in this case by the potential dependent coverage of the inhibiting species $\theta$, they will appear on a branch of positive slope in the current-potential curve, where the coverage of the responsible species for the HN-NDR decreases. As shown in Figure 11, potential oscillations start, as the curve passes a Hopf bifurcation point and grow in amplitude. If the limiting cycle hits the unstable part of current-potential curve, the only attractor is the stable branch. Hence, the oscillations cease and the potential jumps rapidly to higher overpotentials.

Figure 11: Real (black) and theoretical response (red) potentiodynamic response of an $\mathrm{HN}$ NDR system in the NDR region. 


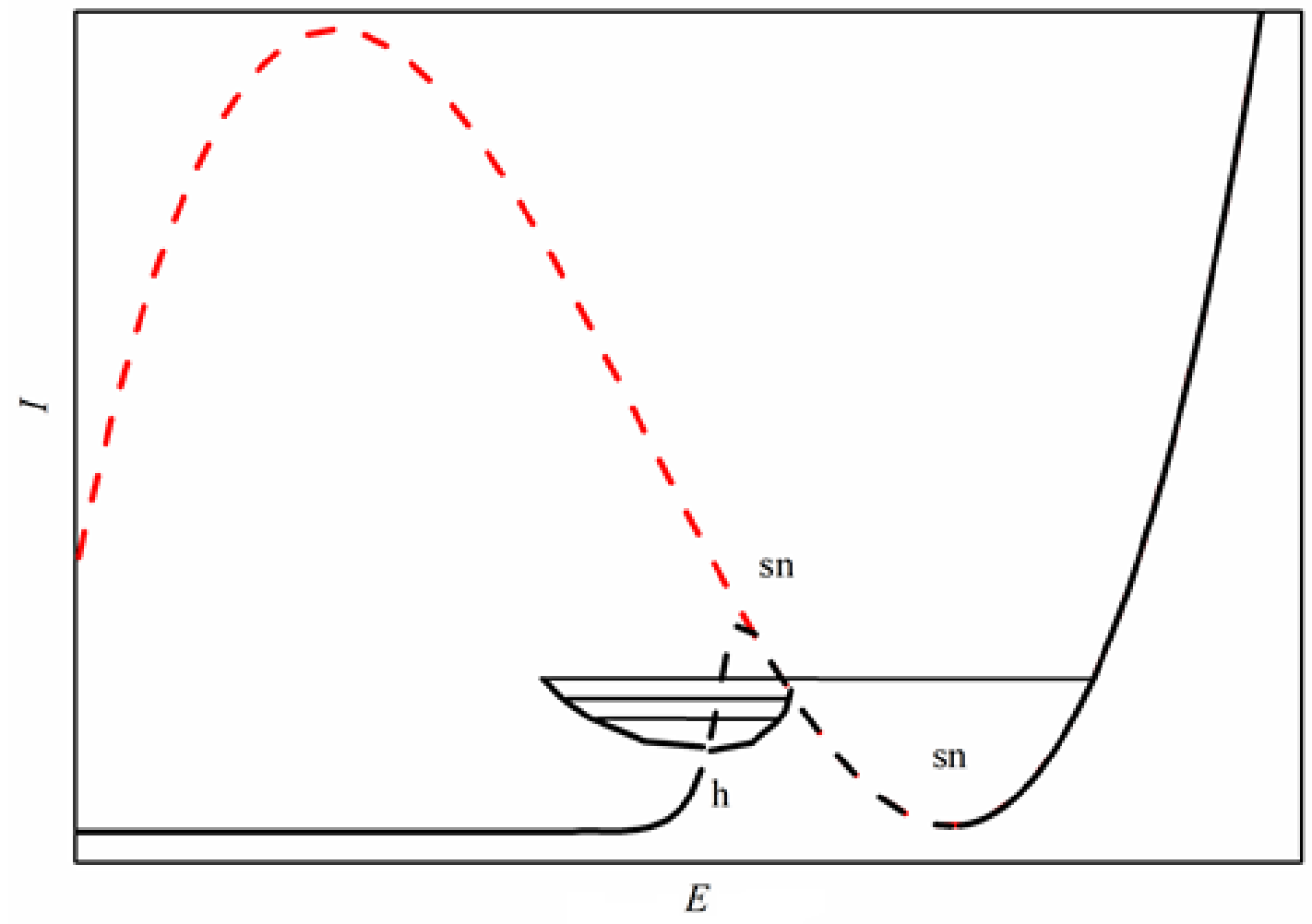

The impedance spectrum usually is plotted in the Nyquist diagram in Figure 12, which show the imaginary against the real impedance of the system measured at different frequencies.

Figure 12: Typical potentiostatic impedance spectrum for a HN-NDR system. Pt in $0.2 \mathrm{M}$ $\mathrm{HCOOH}+0.5 \mathrm{M} \mathrm{H}_{2} \mathrm{SO}_{4}$ at $0.85 \mathrm{~V} v s$. RHE.

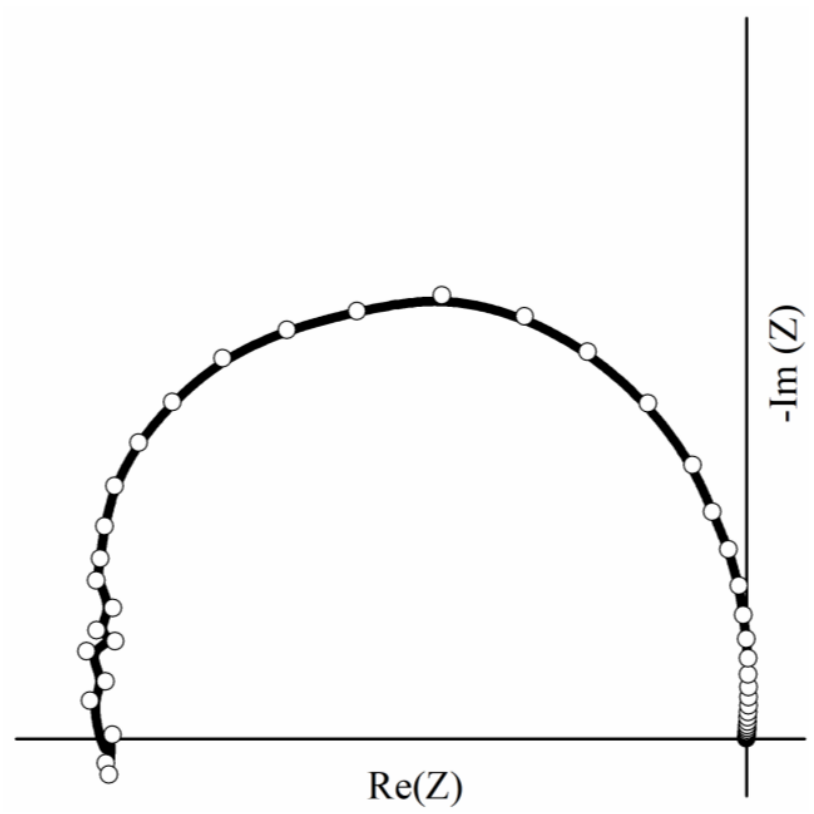


HN-NDR oscillators show a characteristic spectrum, as plotted in Figure 12. How the impedance spectra evolve in a cyclic voltammogram with a HN-NDR is shown in detail in Figure 13.

Figure 13: Representative impedance spectra in the potential region of a HN-NDR oscillator along the potentiodynamic profile. Copied from [42]

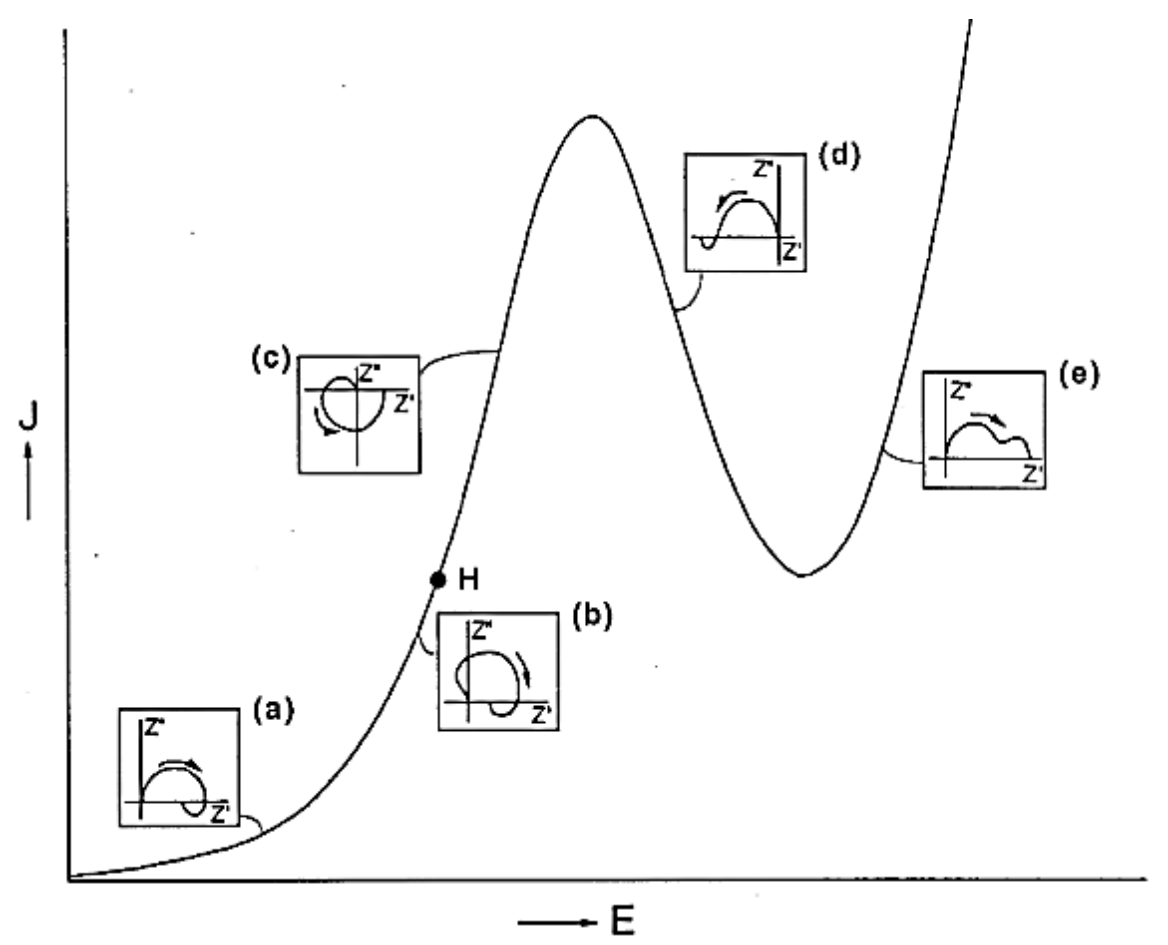

The Nyquist plots exhibit positive, real impedance at small frequencies and first quadrant behaviour due to the positive slope in the potentiodynamic curve, where the slow, inhibiting process dominates the response of the system. The negative resistance is just visible, as the frequency increases in the intermediate range and the spectrum enters the second quadrant. In that frequency range the faster response of the process with the NDR characteristic overcomes the inhibition and reveals the Hopf bifurcation point and the necessary external resistance to find oscillating response in the system, as the curve intersects the $x$-axis $\left(\omega=\omega_{H}\right)$. Thus, in the low potential region the response in the impedance spectrum is mainly positive, but can show negative impedance at low frequencies at potentials closer to the Hopf bifurcation point. Beyond the bifurcation point, the cycle in the spectrum flips back, showing first quadrant behaviour and remains like this until high overpotentials, where the Pt surface oxidation is the dominant process and oxygen evolution starts.

Conditions far from equilibrium are intrinsic for the oscillating regime of the electrooxidation of small organic molecules and a striking difference to conventional 
electrochemical methods like steady-state voltammetry and chronoamperometry. The timedependent evolution of the coverage and the reaction rates of all surface processes can reveal more information and insight in the reaction mechanism and the complex network of all interfacial reactions [43-48] and show higher conversion efficiency [49]. Particularly, the adsorption of carbonaceous and oxygenated species along the oxidation of $\mathrm{HCOOH}$ and $\mathrm{H}_{3} \mathrm{COH}$ on $\mathrm{Pt}$ are essential variables that contribute to the instability. Their analysis and understanding are difficult, but are crucial to improve the performance for an economic application in fuel cells. Moreover electrochemical oscillations along the oxidation of small organic molecules are found to evolve slowly in time compared to the oscillation cycle, although all experimental parameters are fixed. This phenomena was called drift and can be seen as aging process of the surface, which occurs to the irreversible place-exchanges of adsorbed oxides with $\mathrm{Pt}$ surface atoms [50-52]. Since $\mathrm{HCOOH}$ and $\mathrm{H}_{3} \mathrm{COH}$ are oxidation can be seen as models for oxidation of $\mathrm{C} 1-\mathrm{C} 3$ molecules, it is possible to get more information about other reactions as well. 


\section{The electro-oxidation}

of small organic molecules

This chapter contains the general chemistry of formic acid and methanol and the general state of the art in the electro-oxidation of both molecules over platinum under potentiodynamic and chronopotentiometric conditions. 
Since the beginning of last century the energy consumption has increased tremendously and lead to the dependence of the industry nations on the limited fossil resources. Especially, the oil crisis in the 70s had pointed out that dependence, what initiated the research for renewable energy resources and alternative methods for energy conversion. The awareness of drastic human impact in the changing climate augmented the desire for more sustainability. Besides solar, wind and water energy, the technology of fuel cells got in the focus of science. A fuel cell converts the complete chemical energy in electrical energy, what can be realized by the application of hydrogen and its oxidation to pure water. Yet, the energy to break the molecule bond in a hydrogen molecule requires much energy, 4-5 eV [53,54] and a catalyst to enhance the reaction rates, where precious, noble metals like platinum and palladium showed the best performance [55] and make the application of fuel cells under that conditions economically inefficient. Besides the lack of a cost-efficient catalyst, hydrogen is rare in its elementary form, its production, storage and usage is expensive, complicated and/or dangerous. Moreover the majority of hydrogen is produced by steam reforming [56]:

$$
\mathrm{C}_{\mathrm{n}} \mathrm{H}_{\mathrm{m}}+\mathrm{nH}_{2} \mathrm{O} \rightarrow \mathrm{nCO}+\left(\mathrm{n}+\frac{\mathrm{m}}{2}\right) \mathrm{H}_{2}
$$

As it can be seen in equation 11, the reaction produces $\mathrm{CO}$, what acts as strong catalytic poison and declines the activity of fuel cells. Consequently, much effort has been done to find improvements for the catalytic performance of the electrode, to circumvent the adsorption of $\mathrm{CO}$ and to put small organic molecules, such as formic acid and methanol, as natural candidates for an application in focus as well. As Capon et al. has already foreseen in his review on formic acid oxidation 45 years ago, still more efforts are needed for the fuel cells to become a promising alternative to conventional combustion engines [57]:

\footnotetext{
This short review has highlighted the many difficulties encountered in investigations of catalytic behaviour of possible fuel cell electrode materials. It is clear, that there can be no short answer to the problem of how organic molecules interact with the electrode surface and that agreed solutions will only be arrived at through many separate studies, each of which contributes some small piece of information or clarifies some point of disagreement.
}

The following sections shall give a short overview on the current state of the art in formic acid and methanol oxidation over platinum from a general point of view and in steady state voltammetry and oscillating conditions. 


\subsection{Electro-oxidation of formic acid}

Methanoic acid, common name formic acid ( $\mathrm{HCOOH})$, is a colourless, pungent smelling liquid, which naturally occurs mainly in ants and thus, has its name from the latin word for ant "formica". Chemically it is the easiest representatives of the carboxylic acids with the molecular structure asin Figure 14 [58]:

Figure 14: Formic acid in two mesomere structures in a) and b).
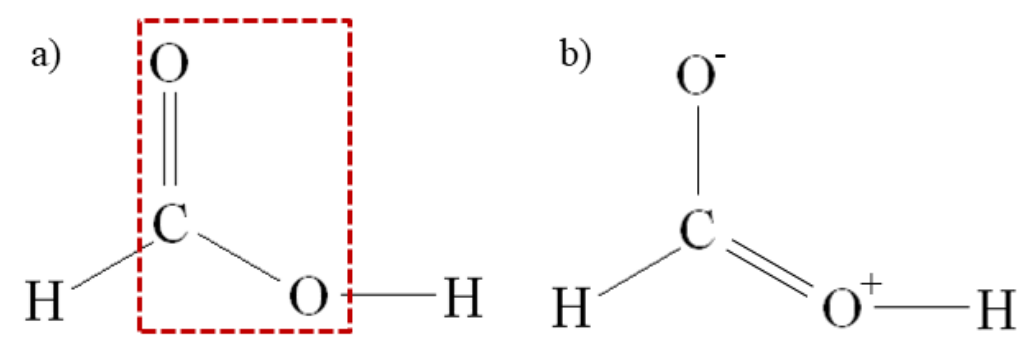

Since $\mathrm{HCOOH}$ is a derivative of water, where one hydrogen atom is replaced by a formyl group, it can also form hydrogen bondings with for example water molecules from its hydration shell or itself. Such dimerization is well known from all carboxylic acids and is to be considered especially at high concentrations [58]. $\mathrm{HCOOH}$ is the most acidic one in the class of carboxylic acid, whose corresponding, weak base is called formate and with a $\mathrm{pK}_{\mathrm{A}}$ of 3.75 generally classified as weak acid. Consequently, shifting the $\mathrm{pH}$ by stronger acids or bases will keep formic acid/formate in its protonated/ deprotonated state. The concentration profile of the acid-base equilibrium is plotted in $\mathrm{pH}$ dependence in Figure 15, where it can be seen, that in strong acidic media formic acid is the dominant species and the molar fraction of formate is close to zero. This changes in the $\mathrm{pH}$ region around the $\mathrm{pK}_{\mathrm{A}}$, where the molar fraction of both species converge and at $\mathrm{pH}>4$ the molar fraction of formate exceeds the one of formic acid to almost 1. As it is indicated by the red box in Figure 14, formic acid can also be seen as hydrogen carrier, which can be oxidized by transfer of two electrons via the breaking the $\mathrm{O}-\mathrm{H}$ and $\mathrm{C}-\mathrm{H}-$ bond. As theory [59] and experiment [60] show, the acidic hydrogen can be abstracted easily, meanwhile the cleavage of the $\mathrm{C}$ - $\mathrm{H}$-bond requires more energy and is the rate-limiting step in the oxidation of $\mathrm{HCOOH}$ to $\mathrm{CO}_{2}$. Generally, it is well accepted in literature, that electro-oxidation of $\mathrm{HCOOH}$ takes place via a dual pathway mechanism with the common product carbon dioxide $\left(\mathrm{CO}_{2}\right)$, which was introduced by Capon and Parsons [57,61,62]. The so-called indirect pathway shows sluggish reaction kinetics, 
where adsorbed carbon monoxide $\left(\mathrm{CO}_{\mathrm{ad}}\right)$ was confirmed as poisoning intermediate [63-65], formed via the dehydration of $\mathrm{HCOOH}$ :

$$
\mathrm{HCOOH} \rightarrow \mathrm{H}_{2} \mathrm{O}+\mathrm{CO}_{\mathrm{ad}}
$$

Figure 15: Molar fractions of formic acid (black) and formate (red) vs. bulk solution $\mathrm{pH}$.

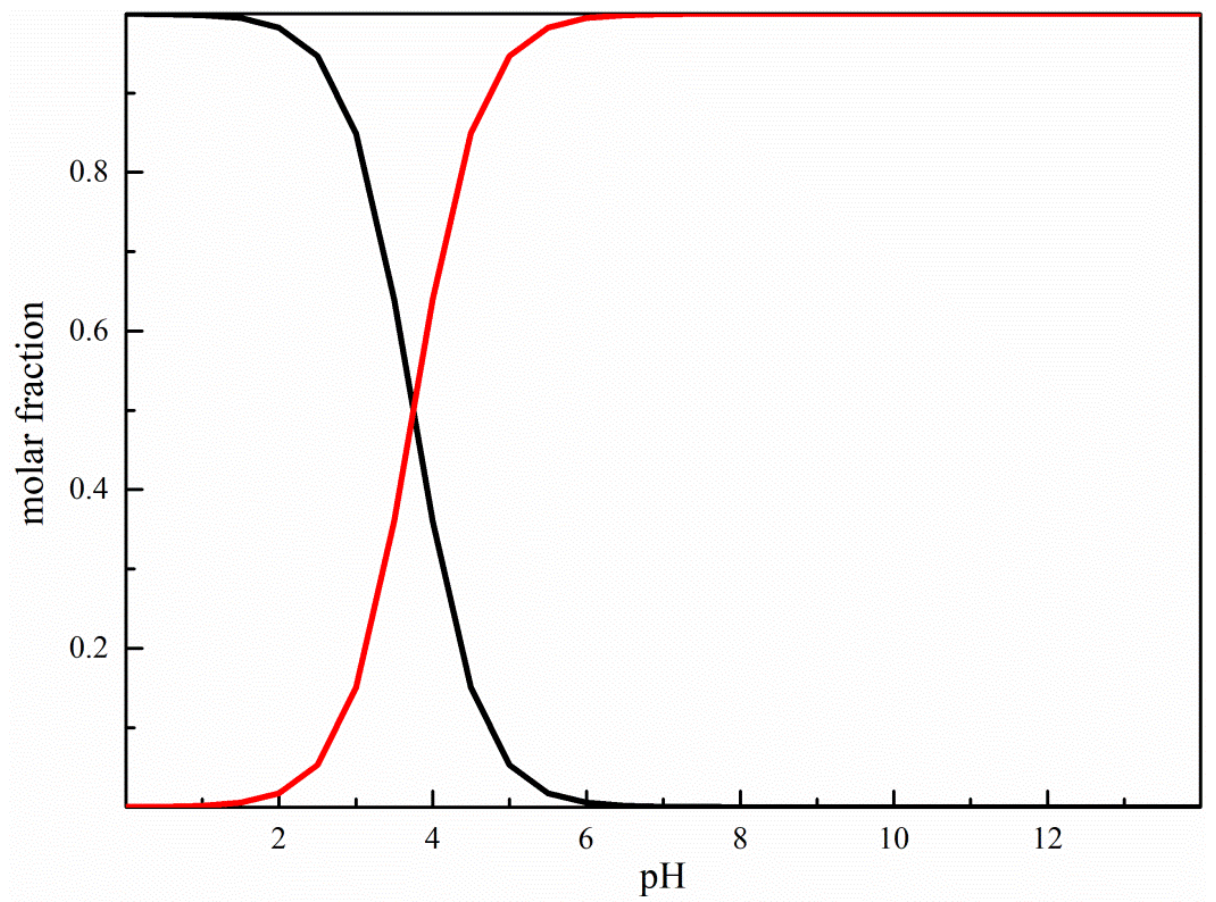

It is well reported, that $\mathrm{CO}_{\mathrm{ad}}$ occurs in linear, bridge and multi-bonded configurations, which changes in dependence on its coverage [66]. On the other hand the active intermediate in the direct pathway remained under debate for a very long time, where many possible candidates like $\mathrm{COOH}_{\mathrm{ad}}$ [67], $\mathrm{HCOOH}_{\mathrm{ad}}$ [68], $\mathrm{HCOO}_{\mathrm{ad}}$ in bi- [66] and monodentate configuration [59] and some dimer species [69] were discussed controversially in literature. Yet, the recent literature agreed, that the most active species rather is formate than formic acid, even under acidic conditions, where its presence is significantly lower [70-75]. Surprisingly, few studies can be found on the mechanism in the indirect pathway despite its great impact on the reaction kinetics. Besides the consideration of $\mathrm{HCOO}_{\mathrm{ad}}$ as precursor for $\mathrm{CO}_{\mathrm{ad}}[73,76,77]$, Zhong et al. recently suggested a simultaneous formation of $\mathrm{CO}_{\mathrm{ad}}$ and $\mathrm{CO}_{2}$ from a complex network of formic acid and water in the solid/liquid interface [78,79]. The steady state voltammograms of formic acid $(\mathrm{HCOOH})$ oxidation in acidic and alkaline media are plotted in Figure 16a) and b). As it can be seen the reaction shows 3 characteristic peaks in both solutions, which can be attributed to the same electrochemical processes. Thus, formic acid oxidation becomes active at $\sim 0.3 \mathrm{~V}$, where it takes place under the influence of other surface 
processes like anion, water and particularly $\mathrm{CO}$ adsorption, which overcome the activity of the direct oxidation pathway at the peak maximum I and are responsible for the following current decrease until peak II appears. It can be seen very clearly, that the inhibition is much more pronounced in alkaline media, where just the very beginning of peak I and II is visible due to the stronger and earlier adsorption of hydroxide (see section 1.2). This effect also explains the appearance of peak II, which coincides with the beginning of the surface oxidation and the consequent removal of $\mathrm{CO}_{\mathrm{ad}}$ via Langmuir-Hinshelwood mechanism:

$$
\mathrm{CO}_{\mathrm{ad}}+\mathrm{O}(\mathrm{H})_{\mathrm{ad}} \rightarrow \mathrm{CO}_{2}+2 \mathrm{e}^{-}\left(+\mathrm{H}^{+}\right)
$$

Due to the slow kinetics even at high overpotentials, the contribution to the total current is below $0.1 \%$. at $0.6 \mathrm{~V}$ [80], emphasizing the great domination of the direct oxidation pathway in the oxidation mechanism. As Osawa and co-workers revealed by ATR-SEIRAS, a diminishing $\mathrm{CO}$ coverage results in a higher presence of $\mathrm{HCOO}_{\mathrm{ad}}$ in $0.5 \mathrm{M} \mathrm{H}_{2} \mathrm{SO}_{4}$ [66,81], whose role in the oxidation mechanism as active or rather spectator species is not completely clear yet. The following region of low current densities coincides with the potential range of surface oxidation in the basic voltammogram (Figure 2), where direct pathway is blocked by adsorbed oxygenated species.

Figure 16: Steady state voltammogram of formic acid oxidation in $0.5 \mathrm{M} \mathrm{K}_{2} \mathrm{SO}_{4}+\mathrm{x} \mathrm{M}$ $\mathrm{H}_{2} \mathrm{SO}_{4} / \mathrm{KOH}$, a) $\mathrm{pH} 1.02$ and b) 13.12. The dashed lines indicate the steady state voltammogram in the used electrolyte, shown in Figure 3. Scan rate $0.05 \mathrm{~V} \mathrm{~s}^{-1}$

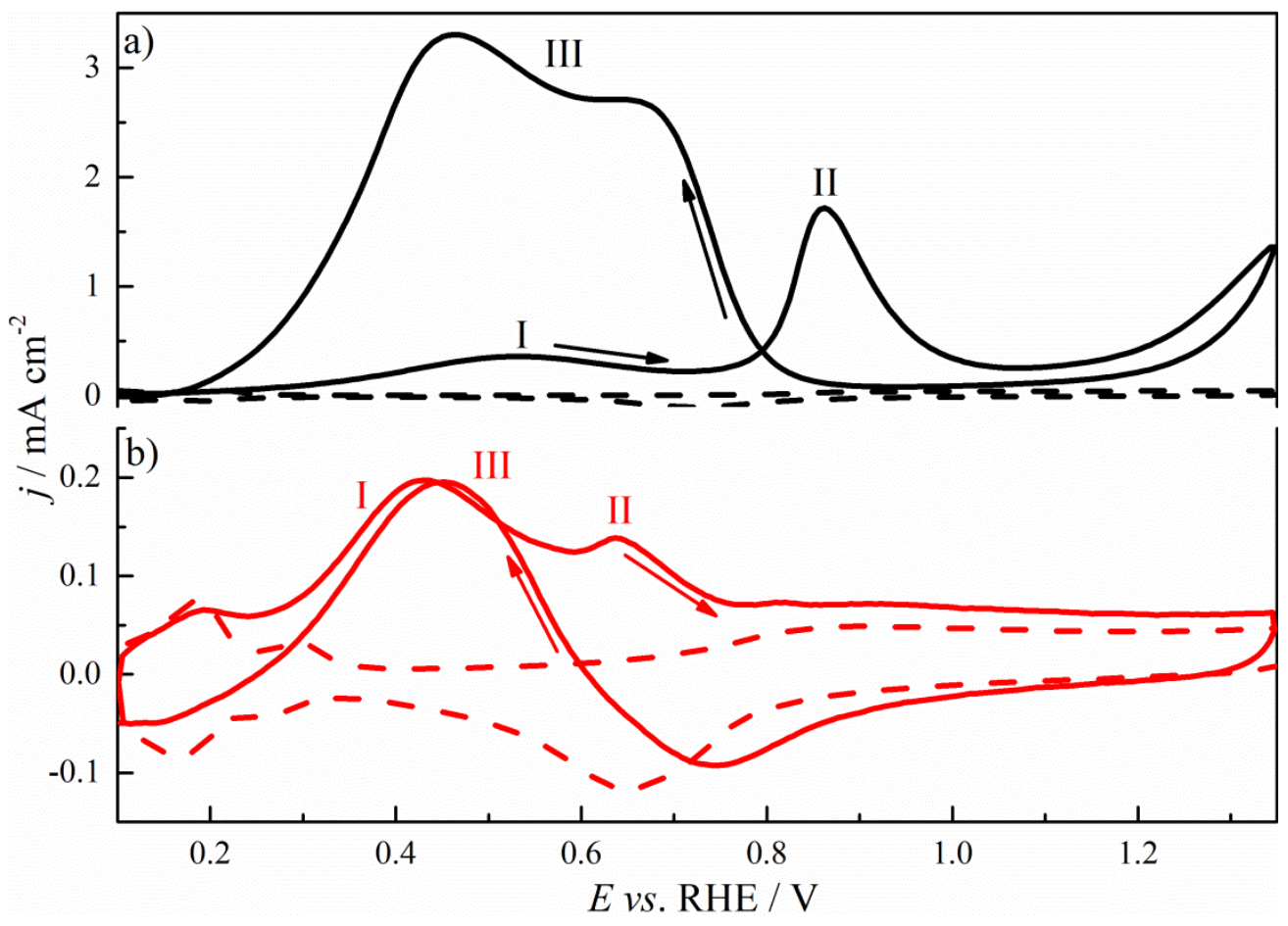


As the oxide layer is lifted in the back scan at $\sim 0.8 \mathrm{~V}$, the voltammogram evolves through to high current density region III due to the unhindered $\mathrm{HCOOH}$ oxidation on Pt showing its possible activity. The comparison of Figure 16a) and b) the current densities in alkaline solution are close to the level of the bare electrolyte. Furthermore peak III and peak I do not show a hysteresis as in the acidic conditions, but rather reversible behaviour, what suggests similar conditions and a significantly lower influence of $\mathrm{CO}_{\mathrm{ad}}$. Yet, the emergence of the latter is evident in the small peak II. This behaviour can be explained by the easier surface oxidation in high $\mathrm{pH}$ solutions and points out the susceptibility of the direct oxidation pathway to suppression by competing adsorption processes. As Joo et al. reported recently, the coverage of $\mathrm{CO}_{\mathrm{ad}}$ as also of $\mathrm{HCOO}_{\mathrm{B}}$ decrease with increasing $\mathrm{pH}$ [72] and illustrates the manifold impact of the bulk solution $\mathrm{pH}$, what shall be discussed in detail in section 6 . Due to the region of negative differential resistance in the potentiodynamic profile which is hidden by the high presence of $\mathrm{CO}_{\mathrm{ad}}, \mathrm{HCOOH}$ oxidation generally fulfils the conditions to undergo potential oscillations. Their emergence is already well known from many publications and was studied under the influence of various parameters like temperature [50,82], surface orientation [83], composition of the electrode surface $[44,45,84]$ or bulk solution $[46,85,86]$ and current density [81].

Figure 17: a) Potential oscillations of $0.2 \mathrm{M} \mathrm{HCOOH}$ in $0.5 \mathrm{M} \mathrm{K}_{2} \mathrm{SO}_{4}(\mathrm{pH} 1.02)$, b) $\mathrm{dE} \mathrm{dt}^{-1} v s$. E of the oscillation pattern.
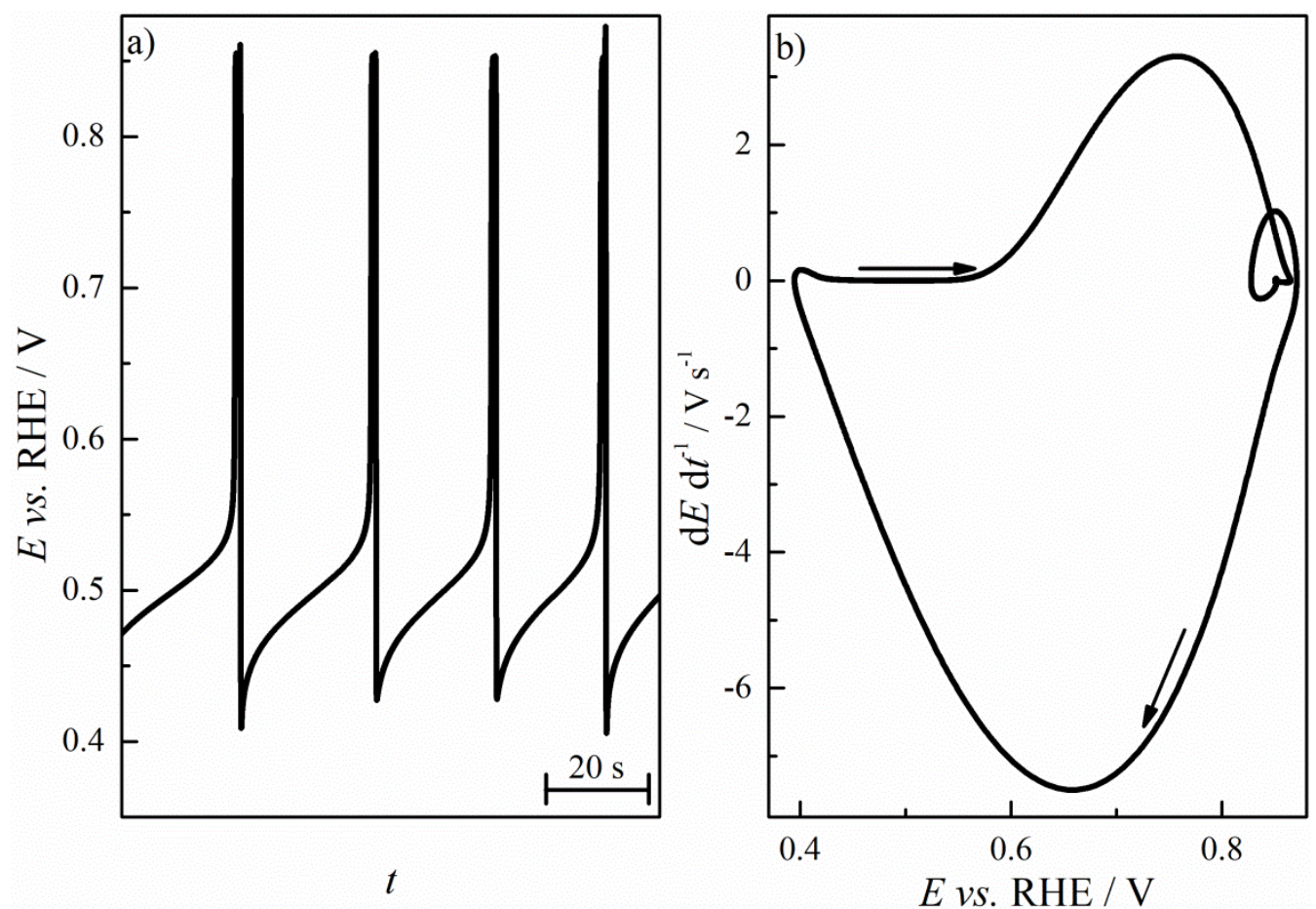
Figure 17a) and b) display the characteristic profile of the potential oscillations of $\mathrm{HCOOH}$ oxidation on $\mathrm{Pt}$ in acidic $0.5 \mathrm{M} \mathrm{K}_{2} \mathrm{SO}_{4}(\mathrm{pH} 1.02)$ and the related derivative against the potential, respectively. Potential oscillations are born via a subcritical Hopf bifurcation and die at the end of the time series by passing a saddle-loop bifurcation point, where the limit cycle collides with the fixed point in the oxygen evolution region and the potential evolves to high overpotentials (not shown) [82]. As it can be seen, the oscillation profile remains most of the time in the lower potential range, where $\mathrm{CO}_{\mathrm{ad}}$ is accumulated on the surface, until the potential increases and surface oxidation becomes active to remove the inhibitors from the surface as in equation 13 , what results in a fast potential drop and a new oscillation cycle. In the derivative in Figure 17b), positive values represent the poisoning rate along the oscillation cycle, which find a maximum at $\sim 0.7 \mathrm{~V}$, meanwhile negative values stand for the rates in liberation rates. The two times smaller poisoning rates indicate the basic activator-inhibitorsystem with a slow inhibiting and fast reactivation process.

\subsection{Electro-oxidation of methanol}

The name methanol $\left(\mathrm{H}_{3} \mathrm{COH}\right)$ is the abbreviation for methyl alcohol, which comes from the Greek words methy = "alcoholic liquid" and hulē ="wood" indicating its former acquisition from the distillation of wood [87]. It is the simplest alcoholic compound, shown in Figure 18, where the characteristic hydroxyl group is linked to methyl group, that it can be seen as water derivative like formic acid:

Figure 18: Molecular structure of methanol.

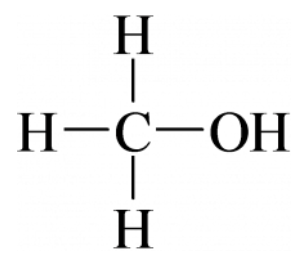

However, the methyl group polarizes the O-H bond less than a carbonyl group, that hydrogen bonds with water or itself play a minor role in aquatic solutions of methanol. Also due to that fact, its acidity $\left(\mathrm{pK}_{\mathrm{A}}=15.5\right.$ [88]) is negligible and its addition does not influence the bulk solution $\mathrm{pH}$, contrary to $\mathrm{HCOOH}$. Since $\mathrm{H}_{3} \mathrm{COH}$ just contains one oxygen atom, the integration of an oxygen atom is required along the oxidation to $\mathrm{CO}_{2}$. 
Figure 19: Steady state voltammogram of the electro-oxidation of $1 \mathrm{M} \mathrm{H}_{3} \mathrm{COH}$ over $\mathrm{Pt}$ in 0.5 $\mathrm{M} \mathrm{K}_{2} \mathrm{SO}_{4}$. a) $\mathrm{pH} 1.02$, b) $\mathrm{pH}$ 12.97. Scan rate $0.05 \mathrm{~V} \mathrm{~s}^{-1}$.

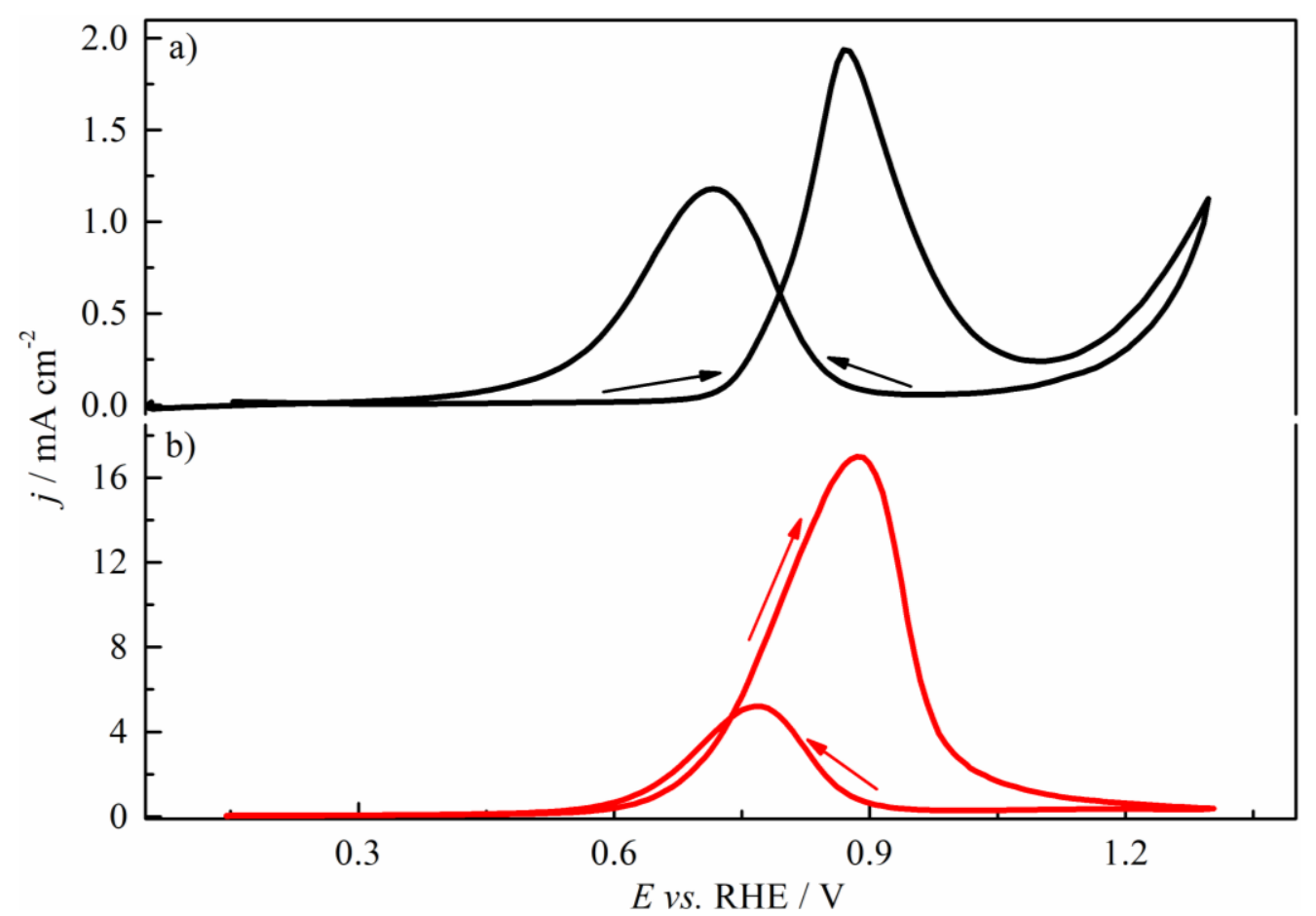

Consequently, it is not surprising, that the steady state voltammogram of $\mathrm{H}_{3} \mathrm{COH}$ oxidation on Pt (Figure 19) takes place exclusively in the potential region, where the surface oxidation is active, independently on the $\mathrm{pH}$. This fact is a striking difference to the oxidation of $\mathrm{HCOOH}$ (see Figure 16) and crucial to understand the oxidation mechanism. It should be especially noticed, that the change of the bulk solution $\mathrm{pH}$ has the contrary effect on the oxidation activity than it appears in formic acid oxidation and the current densities is found to be higher by one order of magnitude at pH 13 [89]. The oxidation mechanism in Figure 20 highlights the most important steps. The first initial steps consist of the cleavage of the C-H bonds and the adsorption of several, carbonaceous species, which lead to the formation of $\mathrm{CO}_{\mathrm{ad}}$ (dashed arrows). Adsorbed surface oxides can undergo either a place-exchange, as indicated in the left bottom or oxidize the formed adsorbates via Langmuir-Hinshelwood mechanism in the reaction steps 1-4, where the black arrows mark the direct and indirect pathway. In the dual pathway mechanism of methanol formyl $(\mathrm{CHO})$ and hydroxymethylidyne $(\mathrm{COH})$ are discussed in literature as crucial intermediates for both pathways [90-93]. These oxidation processes include the formation of the partially oxidized by-products formaldehyde (not shown) and formic acid (reaction step 1) in the interfacial double layer, from where they can diffuse either into the solution or back to the surface to become further oxidized (reaction 5). 
It should be especially noticed, that this reaction is the only one which does not include necessarily a oxygenated species as reaction partner via the direct oxidation of formic acid.

Figure 20: Reaction mechanism of the electro-oxidation of methanol. Copied from [94]

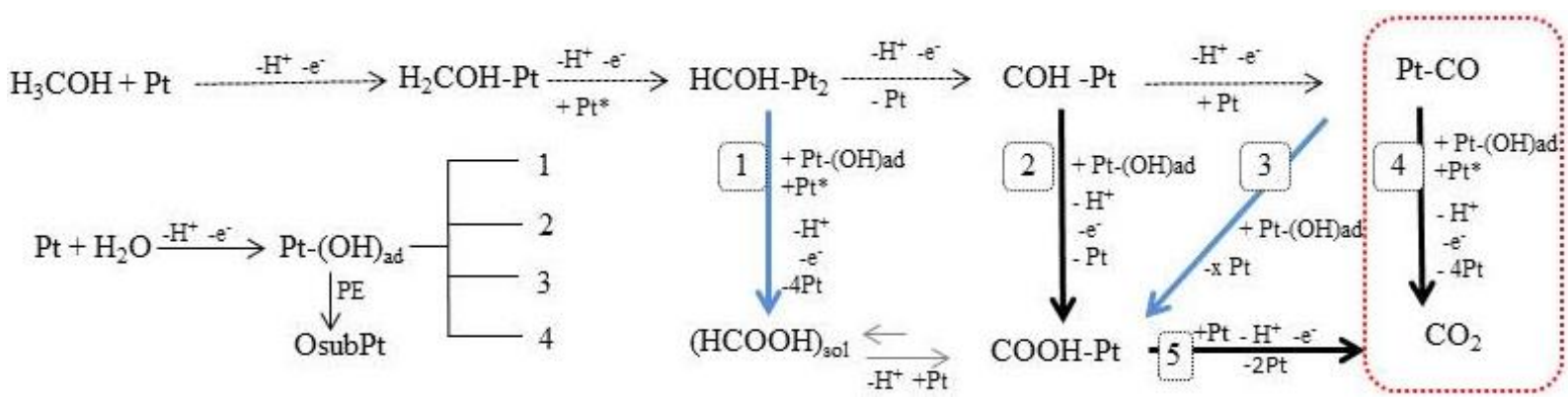

Due to the potential dependent water adsorption hidden by the adsorption of $\mathrm{CO}_{\mathrm{ad}}$ among others, the electro-oxidation of $\mathrm{H}_{3} \mathrm{COH}$ counts to the class of $\mathrm{HN}-\mathrm{NDR}$ oscillators as $\mathrm{HCOOH}$ oxidation [95]. Thus, potential oscillations in $\mathrm{H}_{3} \mathrm{COH}$ oxidation on $\mathrm{Pt}$, exemplary shown in Figure 21a) together with the $\mathrm{dEdt}^{-1}$ profile $v s$. E in Figure 21b), evolve by passing a supercritical Hopf bifurcation and at their end the collision of the limiting cycle with the stable branch of a saddle point [96-99].

Figure 21: a) potential oscillations of $1 \mathrm{M} \mathrm{H}_{3} \mathrm{COH}$ in $0.5 \mathrm{M} \mathrm{K}_{2} \mathrm{SO}_{4}(\mathrm{pH} 1.02)$, b) $\mathrm{dE} \mathrm{dt}^{-1} v s . \mathrm{E}$ of the oscillation pattern.
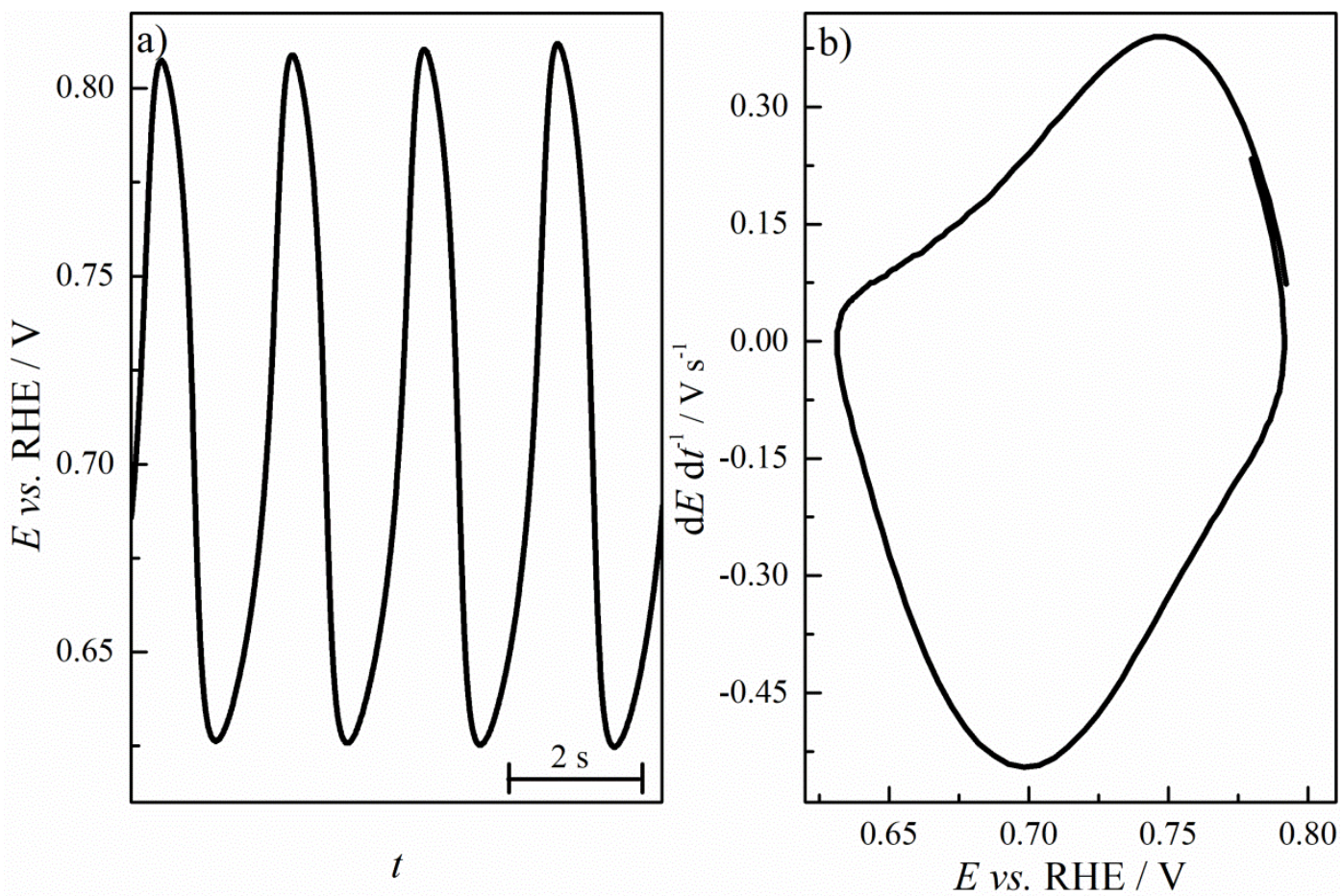

In that case, the oscillations die out the stable branch at lower overpotentials than $1 \mathrm{~V}$. 
Contrary to formic acid oxidation, the saddle point does not always lie in the oxygen evolution, that the end of the oscillations can be seen before the end of the potential time series in the oxygen evolution. Contrary to $\mathrm{HCOOH}$ oxidation, the potential can also show patterns different types of period-1 patterns, called S- and L-type, and of higher period than 1 as well, which usually evolve from period-1 oscillations [100,101]. The period-1 oscillation of $\mathrm{H}_{3} \mathrm{COH}$ oxidation at $\mathrm{pH} 1$ have a higher frequency by at least one order of magnitude and visit just a higher potential range, which lies in the region, where surface oxidation becomes active. This fact can be explained again by the requirement of oxygenated species in the methanol oxidation. The $\mathrm{dEdt}^{-1}$ profile also shows drastic differences to the one from Figure 19b), where the cycle appears more reversible and ten-fold lower poisoning and liberation rates. An analysis of the oscillation behaviour of $\mathrm{H}_{3} \mathrm{COH}$ oxidation and its comparison to HCOOH oxidation will be worked out in further detail in section 6 .

\subsection{The electro-oxidation of formic acid and methanol on Pt- based electrodes}

Pt electrodes are well reported in literature to show the best catalytic activity in the oxidation of small organic molecules. Yet, as the previous sections described, Pt suffers significant poisoning due to the adsorption of carbonaceous species, mainly $\mathrm{CO}_{\mathrm{ad}}$, which is one reason amongst others, that more research is to be done for an successful and cost-efficient application of fuel cells as energy converter. Thus, a vast amount of publications has already been reported on literature, which studied the oxidation of formic acid and methanol on biand ternary Pt electrodes [102-105], which goes beyond the scope of this work. Thus, a short introduction should be given here and a more theoretical approach in chapter 5.1 to introduce the application of PtAu alloyed nanoparticles in formic acid oxidation to review the literature on this topic briefly. In general, different approaches can be found in literature to enhance the activity of Pt anodes in the oxidation of small organic molecules: a) the alloying of Pt with more oxophilic metals, like Ruthenium, to facilitate the formation of surface oxides, that carbonaceous adsorbates can be removed more easily via Langmuir-Hinshelwood mechanism [106], b) the alloying with metal, that show less or no CO formation and are more selective to the direct oxidation pathway, such as Pd or Au [107,108], c) the treatment of Pt electrodes with metals, that facilitate and enhance the direct oxidation [109]. 


\section{Objectives}

This chapter presents the main objectives, which were addressed in this work. 
As it was mentioned in the previous section, recent studies on the $\mathrm{pH}$ dependence on formic acid oxidation by cyclic voltammetry could give a deeper understanding on the reaction mechanism and indicated weakly adsorbed formate as the most active species in the direct oxidation pathway. In this work the study of the steady-state voltammetry of formic acid oxidation was extended to a wide $\mathrm{pH}$ and temperature range and also by chronopotentiometry on $\mathrm{Pt}$ as well as on PtAu alloyed nanoparticles of different content. Furthermore formic acid oxidation was studied independence on these parameters under oscillating conditions in galvanodynamic and -static experiments, which have been able to give more insight in the active surface processes along the oxidation of small organic molecules, as stated above. The made interpretations could be verified by the analysis of the coverage of the Pt surface in oscillation mode by ATR-SEIRAS and differential reflectance spectroscopy. Besides the study of the electro-oxidation of formic acid, cyclic voltammograms and chronopotentiometry of methanol oxidation were also performed in $\mathrm{pH}$ and temperature range to get better understanding on this complex reaction network. Moreover measurements were also carried out with $\mathrm{H}_{3} \mathrm{COH}$ in the batch to study the solid/liquid interface of $\mathrm{HCOOH}$ oxidation in dependence on the temperature. Summarizing, both systems were studied under the mentioned conditions close and far from the thermodynamic equilibrium to get more information on all important surface processes and the influence of them on each other and pointed out the crucial impact of other processes which are not directly involved in the oxidation mechanism, like anion adsorption. 


\section{Materials and methods}

This chapter addresses all equipments and materials used in this work. 


\subsection{The electrochemical cell}

All voltammetric and galvanostatic measurements were carried out in two-compartment, three-electrode glass cell (Figure 22), equipped with two Pt foils of $0.30 \mathrm{~cm}^{-2}$ and $1.2 \mathrm{~cm}^{-2}$ as working (WE) and counter electrode (CE), respectively (roughness factor: 1.2, estimated by the charge of hydrogen monolayer, $210 \mu \mathrm{C} \mathrm{cm}^{-2}$ ), and an as prepared reversible hydrogen electrode (RHE) as reference (RE). In the $\mathrm{pH}$ range of 0-2 and 13-14 RE contained the same electrolyte as the electrochemical cell. For the other $\mathrm{pH}$ range a solution of $\mathrm{pH}$ around 0 or 14 used.

Figure 22: Schematic electrochemical cell used for all measurements.

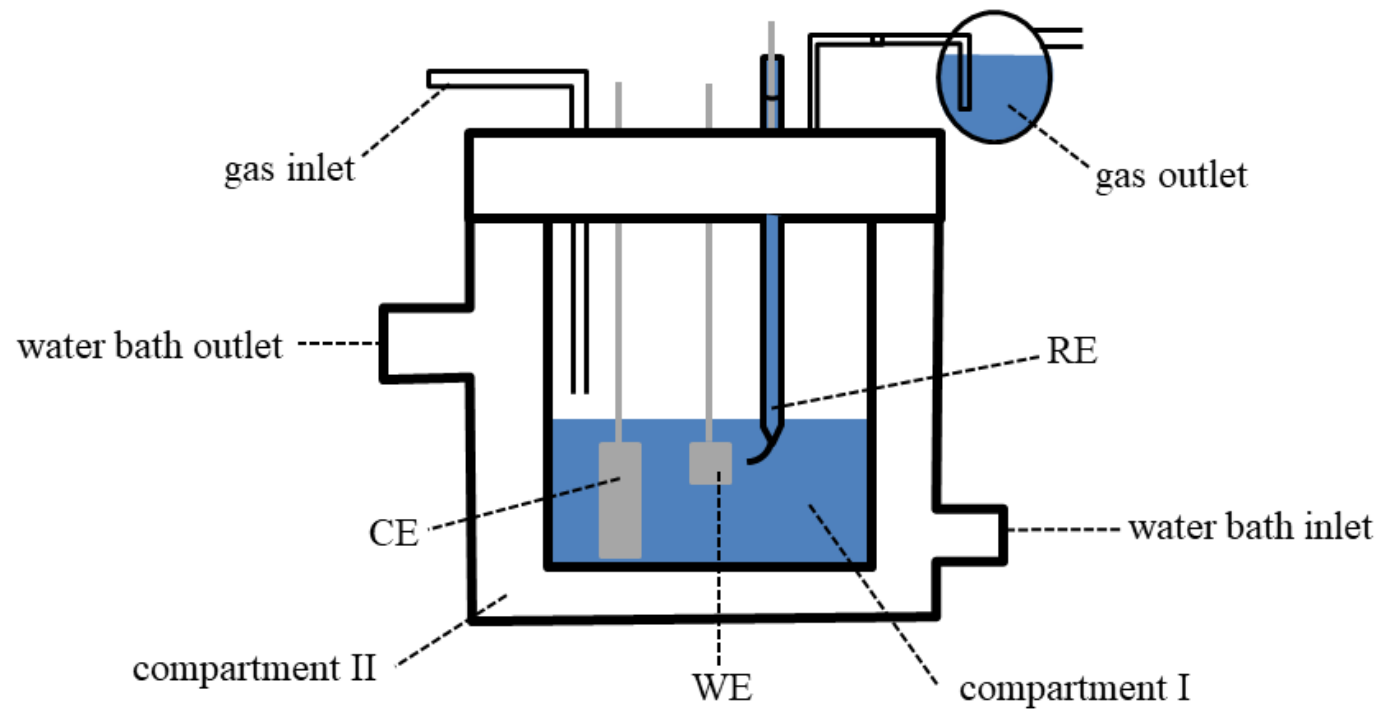

Before entering the cell WE and CE underwent flame annealing in a butane flame for about 30 s. Afterwards electrochemical annealing by cyclic voltammetry (CV) of at least 1000 cycles of $1 \mathrm{Vs}^{-1}$ in the basic electrolyte in the potential range between 0.05 and $1.45 \mathrm{~V}$ was used done to ensure the reproducibility of the surface. The initial characterization of the system was done in a $\mathrm{CV}$ at $0.05 \mathrm{Vs}^{-1}$ out in the same potential window. The measurements were carried out with an Autolab potentiostat/galvanostat PGSTAT 30, and the temperature controlled with a thermostat bath MA-184 by Marconi. Solutions were prepared using sulphuric acid (97.3\%, J.T. Baker), potassium hydroxide (99.99\%, Sigma-Aldrich), potassium sulphate (99.0\%, Sigma-Aldrich), formic acid (98\%, Sigma-Aldrich), methanol (99.97\%, J.T. Baker) and Milli-Q-water (18.2 $\mathrm{M} \Omega \mathrm{cm})$. The $\mathrm{pH}$ of each solution of electrolyte and RHE was 
determined with a $\mathrm{pH}$-meter Marconi MA-522. Before each experiment the solution was purged with argon (99.996\%, White Martins) for at least 5 minutes. Afterwards the electrode was put in a solution of $0.4 \mathrm{M} \mathrm{K}_{2} \mathrm{SO}_{4}$ with the identical $\mathrm{pH}$, containing $0.2 \mathrm{M} \mathrm{HCOOH}$ or $1 \mathrm{M}$ $\mathrm{H}_{3} \mathrm{COH}$. Another $\mathrm{CV}$ at $0.05 \mathrm{Vs}^{-1}$ was performed to check the reproducibility of the characteristic features the voltammogram of formic acid oxidation on platinum before any further procedure. All potentials in this work refer to the RHE scale and were corrected by the Nernst-equation:

$$
\mathrm{E}=\mathrm{E}^{0}+\frac{\mathrm{RT}}{\mathrm{nF}}\left(\frac{\mathrm{a}_{\mathrm{ox}}}{\mathrm{a}_{\text {red }}}\right)
$$

with $\mathrm{E}$ and $\mathrm{E}^{0}$ as potential and standard potential, $\mathrm{R}$ the ideal gas constant, $\mathrm{T}$ the temperature, $\mathrm{n}$ the transferred electrons, $\mathrm{F}$ the Faraday constant and a the activities of oxidized and reduced species. In the applied system the equation can be transformed to:

$$
\mathrm{E}=-0.059 \mathrm{pH}
$$

Since the potential also depends on the temperature as illustrated in equation 16 ,

$$
\left(\frac{\partial \mathrm{E}}{\partial \mathrm{T}}\right)_{\mathrm{p}}=\frac{\Delta \mathrm{S}_{\mathrm{H}}}{\mathrm{F}}
$$

with $\Delta \mathrm{S}_{\mathrm{H}}$ as the deposition entropy of hydrogen on platinum. Conway et al. determined this value as 83.6 and $6.7 \mathrm{~J} \mathrm{~mol}^{-1} \mathrm{~K}^{-1}$ in acidic and alkaline solution, that the potential temperature dependence is 0.84 and $0.07 \mathrm{mV} \mathrm{K}^{-1}$, respectively [110]. The potential displacement by the temperature can be corrected accordingly.

\subsection{Alloyed platinum-gold nanoparticles}

The synthesis and characterization of all applied PtAu NPs as well as the preparation of the working electrodes is reported elsewhere [111]. 


\subsection{Surface enhanced infrared adsorption spectroscopy in attenuated total reflection configuration (ATR-SEIRAS)}

As it is shown in Figure 23, the experimental set-up in the ATR-SEIRAS is slightly different to the conventional three electrode electrochemical cell. Meanwhile the CE was a Pt wire of significantly larger area than WE a similar RE was used, where the latter was linked via a Luggin capillary to the WE. WE was a Pt film $\left(26 \mathrm{~cm}^{-2}\right.$, roughness factor 6.5) deposited on a silicon $(\mathrm{Si})$ prism, as reported elsewhere $[112,113]$. In ATR configuration the IR beam comes from the source and passes polarisator, before being reflected by two mirrors and the WE on the way to the detector. Along the reflection on the electrode surface, the interaction of IR photons and adsorbates is amplified via an electromagnetic and chemical mechanism, according to the election rules [114]. Due to that fact, ATR-SEIRAS is a powerfull technique to probe the IR active species on and near the surface in a qualitative and quantitative way. Thus, the experiments were performed with a Nicolet 470 FTIR spectrometer equipped with an MCT detector, using unpolarised light. The background spectrum consisted of 100 interferograms taken in the bare electrolyte at $0.1 \mathrm{~V}$ before each measurement. Each measurement spectrum along the potential time series of formic acid oxidation consisted of a single interferogram, collected with a spectral resolution of $8 \mathrm{~cm}^{-1}$ in the kinetic mode, with a time resolution of $140 \mathrm{~ms}$.

Figure 23: Schematic set-up for the ATR-SEIRAS.

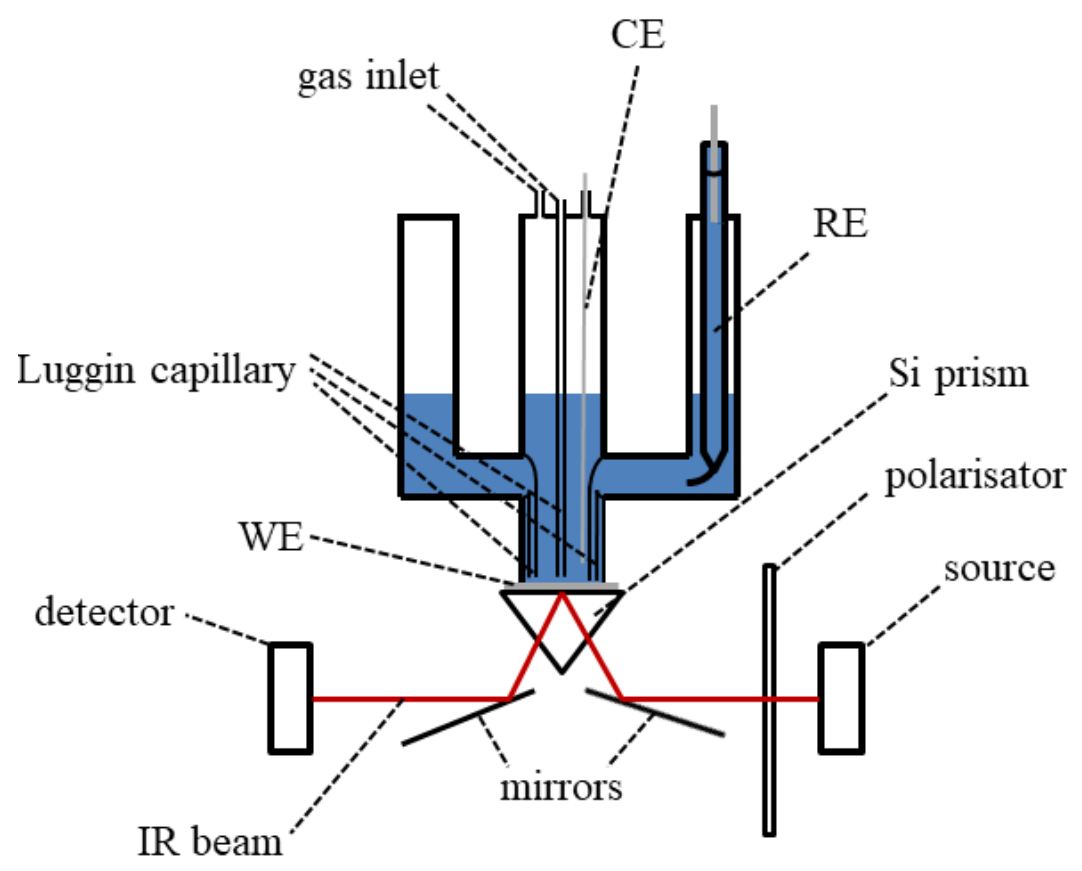


All preparation experiments were carried out with a EmStat 3 Potentiostat from PalmSens, meanwhile a galvano-/potentiostat from EG\&G Princeton Applied Research was used for the chronopotentiometric measurements.

\subsection{Differential reflectance spectroscopy}

The experimental set-up for the differential ultra-violet reflectance spectroscopy is demonstrated in Figure 24:

Figure 24: Schematic set-up for the differential UV reflectance spectroscopy.

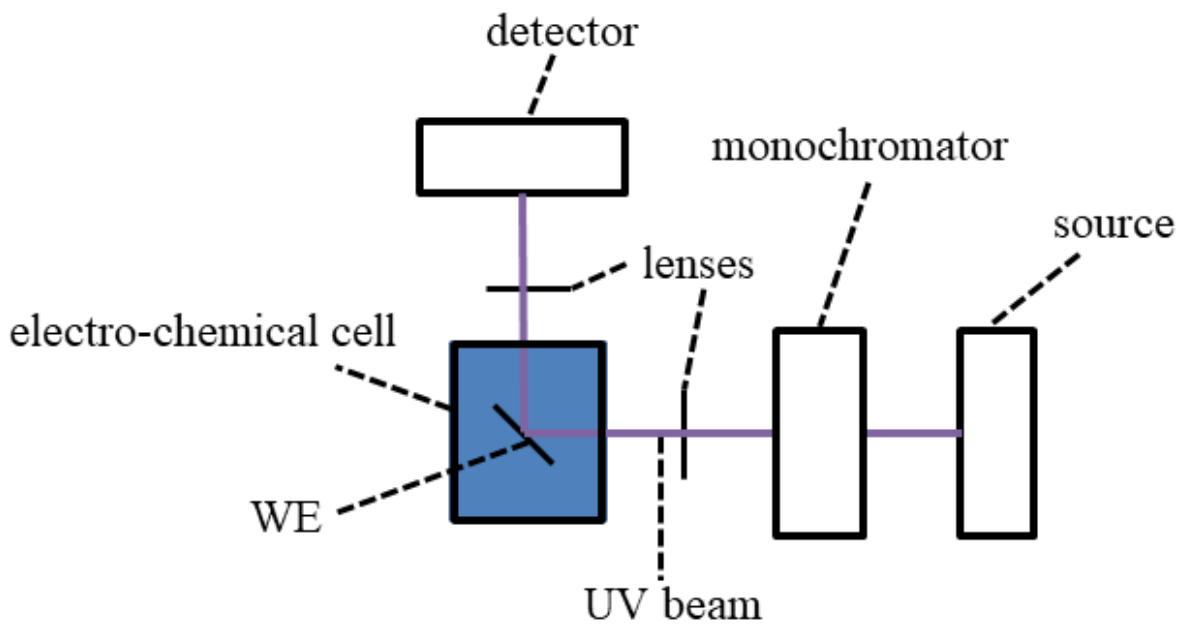

The UV photons come from the source (deuterium lamp, Hamamatsu, $150 \mathrm{~W}$ ) pass through a monochromator (PhotonTechnology International), which is fixed at the desired wavelength, and are reflected on the electrode surface, before they reach the detector. All shown measurements were performed with a $\operatorname{Pt}(111)$ single crystal and a wavelength of $250 \mathrm{~nm}$. To ensure a reproducible focus of the beam, the positions of electrode and detector were adjusted at a wavelength of $520 \mathrm{~nm}$ (tungsten lamp, Hewlett Packard, $100 \mathrm{~W}$ ). The differential spectra were calculated as $-\log \left(\mathrm{R}_{\text {sample }} / \mathrm{R}_{\text {reference }}\right)$, where $\mathrm{R}_{\text {reference }}$ and $\mathrm{R}_{\text {sample }}$ are the reference and sample spectra, respectively. 


\section{Electro-oxidation of}

\section{formic acid on PtAu}

nanoparticles (NPs)

This chapter shows the investigation of the electro-oxidation of formic acid on $\mathrm{Pt}$ nanoparticles alloyed with $\mathrm{Au}$ in different content by under voltammetric and oscillating conditions. Electronic and ensemble effects in the $\mathrm{Pt}_{\mathrm{x}} \mathrm{Au}_{\mathrm{y}}$ nanoparticles demonstrated a crucial influence on the oxidation activity. 


\subsection{Introduction}

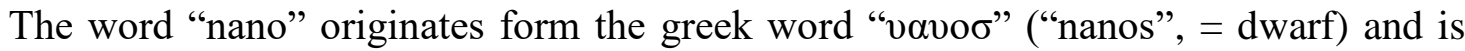
used as prefix in the metric system to denote a factor of one millionth. Thus, nanotechnology refers to the treatment of matter in the range of nanoscale in at least one dimension, typically 1 to $100 \mathrm{~nm}$. The application of nanomaterials has gained much importance in the last decades and also plays an important role in catalysis and energy conversion (see [115-118] and references in there), due to their high surface-to-volume ratio, less material consumption compared to bulk material and tunable properties [115]. Characteristic properties of the nanostructures strongly depend on the synthesis methods and parameters, which are not yet fully understood. This topic is beyond the scope of this work and shall not be discussed in further detail. As already mentioned, Pt and Pt-based catalysts are promising candidates for an application in fuel cells, but further studies are required to reduce the surface poisoning due to carbonaceous adsorbates and tailor a cost-effective electrode for the oxidation of hydrogen or small organic molecules. A possible way to enhance the performance of the electrode is to combine Pt with other metals, which can reduce the formation/adsorption of $\mathrm{CO}_{\mathrm{ad}}$

Generally an electron bound to an atom can be treated as a particle in a box, where the energy eigenvalues $\mathrm{E}$ of the distinct states in s-, p-, $\mathrm{d}$ - and f- orbitals can be calculated by the Schrödinger equation. The result is an energy diagram of all possible states as in Figure 25a). The combination of atoms in molecules, clusters and bulk material then leads to the addition of all states to the valence and conduction band, separated by the band gap (Figure 25b),c)). As in the case of metals at least the last occupied state by electrons, the Fermi level, lies in the energy range of unoccupied states, as in Figure 25d). Thus, the valence band overlaps with the conduction band and the electrons in the metal can move freely like a gas, what is the reason for the high conductivity of metals. The density of the electronic states and the Fermi level are characteristic features of a catalyst and are important to understand its activity. Since the dband electrons determine the chemistry of the transition metals, such as $\mathrm{Pt}$, the electronic structure of the valence band of the d-orbitals is crucial. $\mathrm{CO}$ adsorbs vertically via the $\mathrm{C}$ - atom on Pt and shows a strong interaction with its d-band via the $\sigma$-bonding and a back-donation from the metal to the antibonding $\pi^{*}$-Orbital of CO [119]. As it has been shown by Nørskov and co-workers, the electronic characteristics of the d-band of each metal can change significantly due to alloying with other metals and also the adsorption behaviour of $\mathrm{CO}$ $[120,121]$. Besides this electronic effect on the band structure each metal of the alloy will 
undergo strain effects changing the lattice parameters in the surface composition along the alloying process, which influence each other and the catalytic activity [121].

Figure 25: Energy level diagrams of a) an atom, b) molecule and the energy bands of multiatom compositions like in the case of c) a semiconductor and d) a metal.

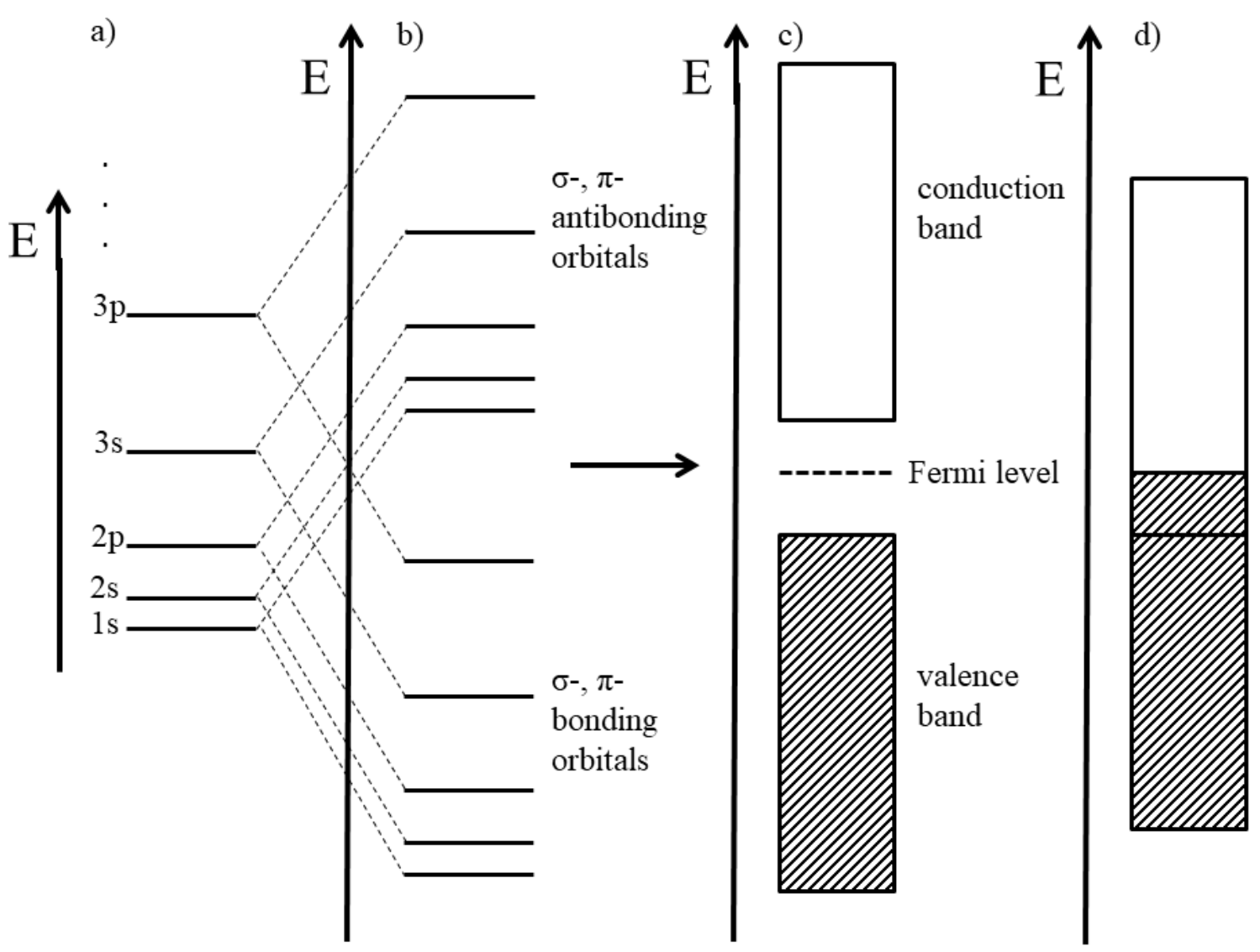

It is reported in literature, that the alloying of Pt with Au shifts the d-band centre of Pt from 2.25 to $-1.8 \mathrm{eV}$, what strengthens the adsorption bond of $\mathrm{CO}$ and results in higher overpotentials required for its oxidation [122]. Yet, one has to differentiate between the adsorption of $\mathrm{CO}$ from solution or the gas-phase and its formation along the oxidation of small organic molecules. As Cuesta reported, three contiguous $\mathrm{Pt}$ atoms are required as adsorption site for $\mathrm{CO}$ formation [77]. On the other hand the direct oxidation pathway requires less adsorption sites, that a decrease in the electro-active area of Pt adsorption sites has a lower impact on the active pathway. The adsorption of ad-atoms and alloying changes the surface composition of the electrode, which has an impact on the reactions in the double layer region, known as ensemble or third body effect [123]. Since Au is known to be selective to the direct oxidation pathway of the oxidation mechanism of formic acid and does not show any sign of $\mathrm{CO}$ formation [76], its alloying with $\mathrm{Pt}$ is a promising approach to enhance the 
catalytic activity of Pt-based electrodes [122,124,125]. Since Au impacts the $\mathrm{CO}$ and $\mathrm{OH}$ formation via electronic and ensemble effects, as described above, PtAu alloys have also demonstrated a promising performance in formic acid and methanol oxidation [124-126].

Yet, to the best of our knowledge, the performance of PtAu alloyed NPs has not been studied far from equilibrium, but might provide further insight in the surface processes in formic acid oxidation.

\subsection{Initial characterization and performance in $\mathrm{HCOOH}$ oxidation}

The structure characterization of the NPs can be found elsewhere [111]. Due to surface segregation the $\mathrm{Pt} / \mathrm{Au}$ ratio in the nanoparticle can differ at the surface, which will influence the electrochemical performance [127-130]. The obtained results from X-ray photoelectron spectroscopic (XPS) measurements showed an enrichment of Pt, which leads to a bigger $\mathrm{Pt} / \mathrm{Au}$ ratio at the surface (see Table 1) [111]:

Table 1: Estimated Pt/Au ratios from XPS.

\begin{tabular}{|c|c|c|c|c|}
\hline Pt/Au ratio & $\mathrm{Pt}_{3} \mathrm{Au}$ & $\mathrm{PtAu}$ & $\mathrm{PtAu}_{3}$ & $\mathrm{PtAu}_{9}$ \\
\hline determined & 5.56 & 1.75 & 0.39 & 0.14 \\
\hline nominal & 3 & 1 & 0.33 & 0.11 \\
\hline
\end{tabular}

XPS also revealed, that the binding energy of the $\mathrm{Pt} 4 \mathrm{f}_{7 / 2}$ core level decreases up to $0.7 \mathrm{eV}$ in dependence on the Au content, what may be the result of a charge transfer between Pt and $\mathrm{Au}$, probably due to an electronic effect, indicating an alloy formation, which could be verified by X-ray diffratometry [111].

Figure 26 shows the electrochemical response of the prepared electrodes with the different NPs in the steady state voltammograms in $0.5 \mathrm{M} \mathrm{H}_{2} \mathrm{SO}_{4}$. As it can be seen, the $\mathrm{Pt}$ NPs showed the well-known shape of the voltammogram with the underpotential deposition of hydrogen in the potential region I from 0 to $0.4 \mathrm{~V}$, the double layer region between 0.4 and $0.8 \mathrm{~V}$ and the surface oxidation $>0.8 \mathrm{~V}$, whose reduction takes place in Peak II. Meanwhile the double layer region did not change on all nanoparticles, due to low affinity of hydrogen to $\mathrm{Au}$, the electro-active area of the NPs decreases regarding the hydrogen adsorption and results in the diminishing peaks in region I. The peaks II and III at $\sim 0.7 \mathrm{~V}$ and $\sim 1.2 \mathrm{~V}$ stand for the 
reduction of the previously formed surface oxides at $>0.8$ and $>1.25 \mathrm{~V}$ on $\mathrm{Pt}$ and $\mathrm{Au}$, respectively, which also show a clear dependence on the relation of Pt and Au. In that way Peak II declines and Peak III increases in activity according to the increasing Au content, as it was reported earlier by Breiter and Woods, which corresponds to the sum of charges of both surface compositions [130,131]. Thus, the electro-active area of Pt can be calculated by integration of the hydrogen region I and a surface charge of $210 \mu \mathrm{C} \mathrm{cm}^{-2}$, which allowed the normalization of the measured currents to the active Pt area. The slightly negatively shifting peak potential of the $\mathrm{Pt}$ reduction suggests a stronger adsorption of oxygen on $\mathrm{Pt}$ due to an electronic effect of Au, as it was already indicated in the XPS. Due to the shift in the d-band centre (see above) closer to the Fermi level, adsorbates like $\mathrm{OH}$ and $\mathrm{CO}$ form stronger bonds on the surface and require more negative overpotentials for their cleavage.

Figure 26: Steady state voltammograms of the graphite-supported NPs in $0.5 \mathrm{M} \mathrm{H}_{2} \mathrm{SO}_{4}$. Scan rate $0.05 \mathrm{~V} \mathrm{~s}^{-1}$

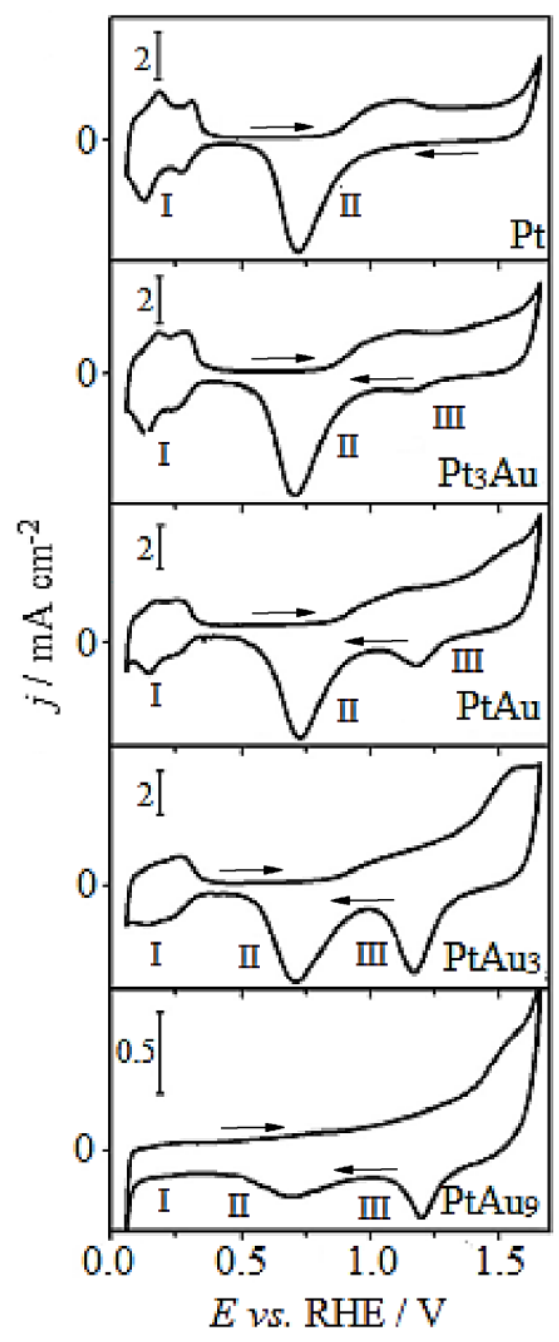


Yet, the potentiodynamic profiles of the NPs in Figure 27 show an ambiguous behaviour in formic acid oxidation. On the one hand the poor activity of $\mathrm{Au}$ in formic acid oxidation causes a decrease of the catalytic activity, since the electro-active area diminishes. On the other hand the alloying of Au with Pt demonstrates an ensemble and electronic effect, which can improve the performance of the electrode due to an enhancement of the direct oxidation pathway, as the changing profile in Figure 27 demonstrates [125,132]. The steady state voltammogram of formic acid oxidation over the Pt NPs in Figure 27 shows the well-known profile of formic acid oxidation, as it is known from Pt bulk electrodes and described in section 2.1, which also is clearly discernible on $\mathrm{Pt}_{3} \mathrm{Au}[66,76]$. It depicts the strong inhibition of $\mathrm{HCOOH}$ oxidation by $\mathrm{CO}_{\mathrm{ad}}$, manifesting itself in the seen hysteresis. As the lower steady state voltammograms in Figure 27 demonstrate, the alloying of $\mathrm{Au}$ has a significant impact on formic acid oxidation, which results in the increasing activity at Peak I. Thus, the current density increases with the presence of $\mathrm{Au}$, where the $\mathrm{PtAu}_{3}$ showed the highest values. The overall poor activity of formic acid oxidation on $\mathrm{PtAu}_{9}$ is an indication, that the alloying effects are not the determining factor anymore, but rather the small electro-active area on the low Pt surface atom content.

Figure 27: Steady state voltammograms of the graphite-supported NPs in $0.5 \mathrm{M} \mathrm{H}_{2} \mathrm{SO}_{4}+0.05$ $\mathrm{M} \mathrm{HCOOH}$. Scan rate $0.05 \mathrm{~V} \mathrm{~s}^{-1}$. The asterisks indicate the onset potential of the formic acid oxidation, defined as the potential (see text).

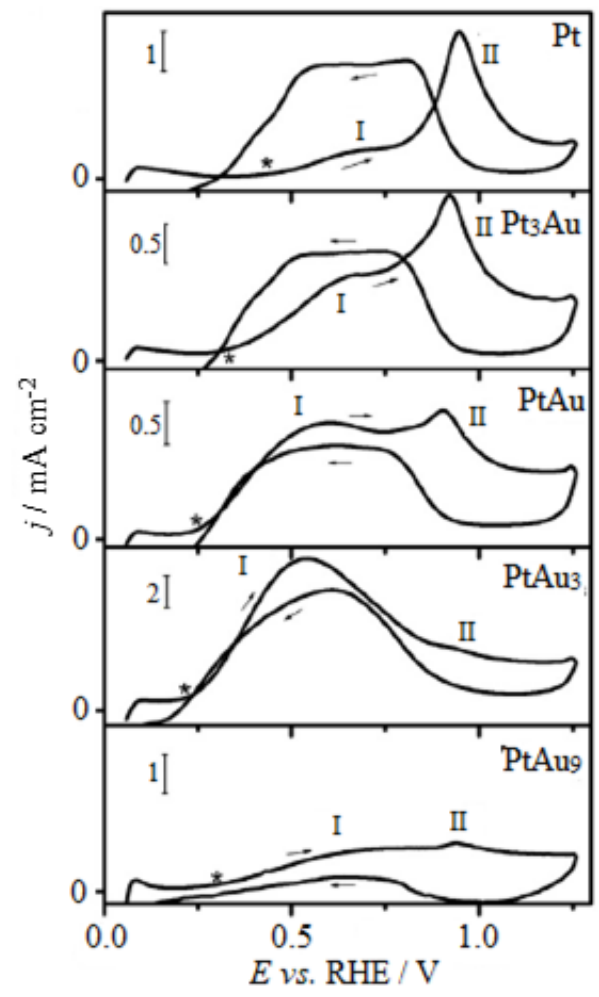


The higher oxidation rates of formic acid at Peak I are concomitant with a decreasing current density of Peak II due to the consequently lower presence of $\mathrm{HCOOH}$ in the electrochemical double layer in this potential range. Yet, the occurrence of Peak II in each profile indicates $\mathrm{CO}$ adsorption, blocking active surface sites, which are freed by the beginning Pt oxidation. Summarizing, these results suggest the effective suppression the dehydaration (indirect) oxidation pathway by the ensemble effect of $\mathrm{Au}$ in the PtAu alloys, which decreases the availability of required adsorption site for $\mathrm{CO}_{\mathrm{ad}}$ formation. This interpretation finds further confirmation in the declining hysteresis with increasing amount of $\mathrm{Au}$ and the more reversible formic acid oxidation. The onset potential of formic acid oxidation was calculated as the potential, where the current density exceeds $5 \%$ of the baseline, which is illustrated with the asterisks in Figure 27. Its exact values are noted in Table 2:

Table 2: Estimated onset potentials under the conditions applied $\left([\mathrm{HCOOH}]=0.05 \mathrm{~mol} \mathrm{l}^{-1}\right.$,

$$
\left.\left[\mathrm{H}_{2} \mathrm{SO}_{4}\right]=0.5 \mathrm{~mol} \mathrm{l}^{-1}, 25^{\circ} \mathrm{C}\right) \text {. }
$$

\begin{tabular}{|c|c|c|c|c|c|}
\hline $\mathrm{E}_{\text {equilibrium }} / \mathrm{V}$ & 0.038 & & & & \\
\hline & $\mathrm{Pt}$ & $\mathrm{Pt}_{3} \mathrm{Au}$ & $\mathrm{PtAu}$ & $\mathrm{PtAu}_{3}$ & $\mathrm{PtAu}_{9}$ \\
\hline $\mathrm{E}_{\text {onset }} / \mathrm{V}$ & 0.445 & 0.348 & 0.258 & 0.218 & 0.297 \\
\hline
\end{tabular}

The found negative shift of over $0.2 \mathrm{~V}$ is another, clear evidence for the enhanced formic acid oxidation due to two reasons. Firstly, the afore mentioned, stronger interaction with adsorbates by an electronic effect may be relevant for the adsorption of the active intermediate in the direct oxidation pathway. Thus, the rate-determining step in that pathway is facilitated, that a lower overpotential is required for a successful oxidation. The electronic effects may have further influences, which put the dehydrogenation (direct) pathway in favour, but the results do not allow more conclusions in that point. Secondly, hydrogen underpotential deposition requires a pure Pt adsorption site with at least 2 other Pt atoms, which decreases because of the ensemble effect in the $\mathrm{Pt}_{\mathrm{x}} \mathrm{Au}_{\mathrm{y}}$ alloys [133]. Since formic acid oxidation can take place on a $\mathrm{Pt}-\mathrm{Au}$ site, this effect is less pronounced here.

\subsection{Chronopotentiometry}

As the results from the potentiodynamic and surface characterization pointed out, the $\mathrm{Au}$ presence in the alloys influences the electro-oxidation of formic acid in various ways. These were further analysed by galvanostatic measurements. The distinct current densities 
were determined by the normalization of the oscillating region, as reported elsewhere [82]. Figure 28 displays the potential time series of all applied nanoparticles in $0.2 \mathrm{M} \mathrm{HCOOH}+$ $0.5 \mathrm{M} \mathrm{H}_{2} \mathrm{SO}_{4}$, carried out with 0.2 as normalized current density. As it can be seen, the increasing presence of Au causes a drastic decrease in the time scale of the series. This effect is related to the diminishing active Pt surface sites, which sustain the applied current density via the direct oxidation pathway of formic acid oxidation and maintain the potential oscillations via the afore described mechanism until the surface is completely deactivated by the described place-exchange and inhibiting adsorption processes.

Figure 28: Potential time series of the NPs (a) Pt, b) $\mathrm{Pt}_{3} \mathrm{Au}, \mathrm{c}$ ) PtAu, d) $\mathrm{PtAu}_{3}$, e) $\mathrm{PtAu}_{9}$ ) in 0.2 $\mathrm{M} \mathrm{HCOOH}+0.5 \mathrm{M} \mathrm{H}_{2} \mathrm{SO}_{4}$ with the highlighted first (red) and last, complete oscillation cycle (green) and f)- h) their corresponding derivatives against the measured potential on the right.

Applied, normalized current density 0.2.

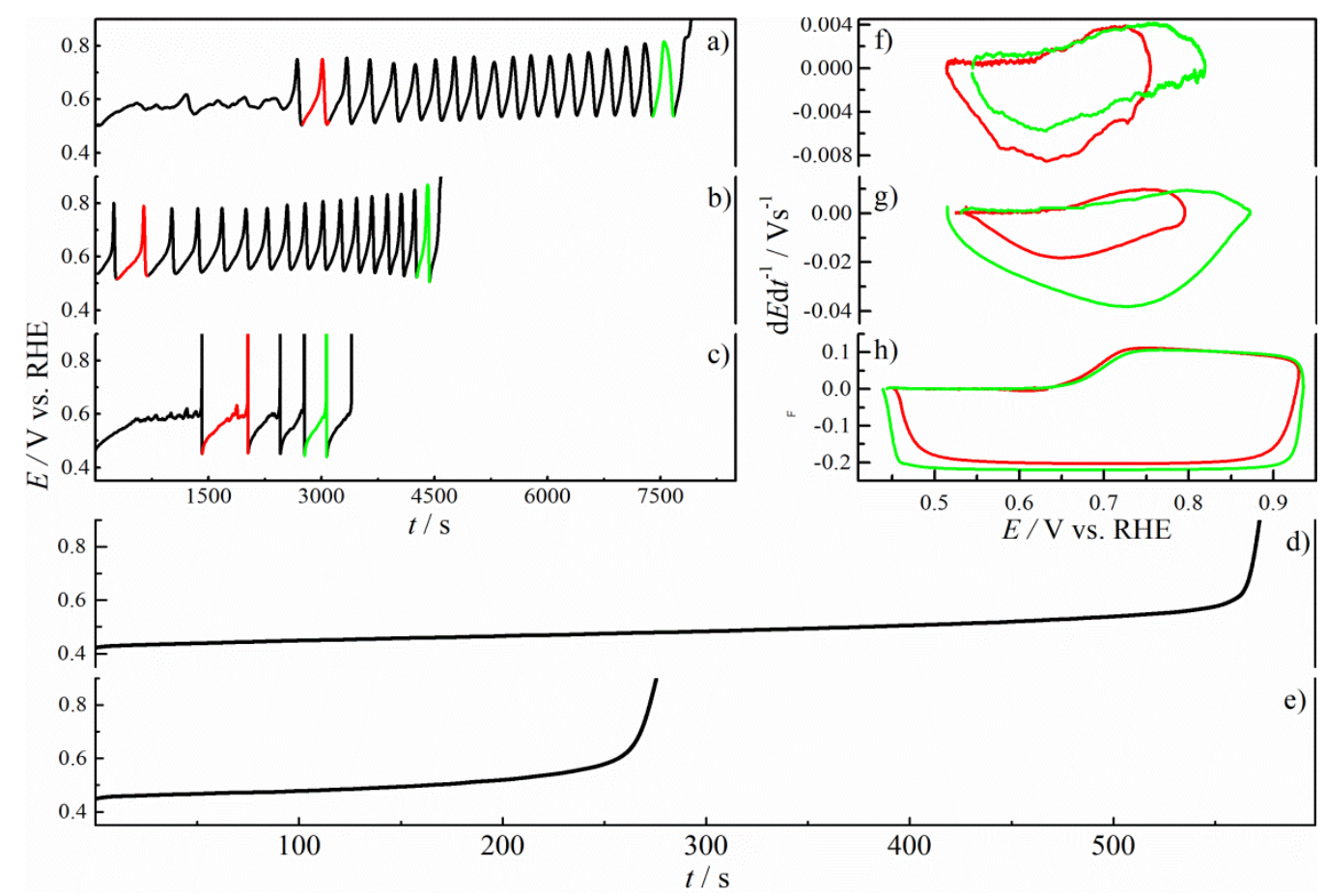

At that point the potential increases rapidly to overpotentials above $1.2 \mathrm{~V}$, where oxygen evolution accomplishes the demanded charge transfer. Since the electrode can suffer severe damage by its underlying processes, the measurement was cut at that potential. Due to surface segregation and the consequent enrichment of Pt at the surface, which was indicated by XPS, potential oscillations on $\mathrm{Pt}_{3} \mathrm{Au}$ appear with a similar profile like on the Pt NPs, as it was described in the introduction and is well-known from literature [16]. Some differences were found, which become even more clearly visible on PtAu. Characteristic values of the all found oscillations are shown in Table 3. 
Table 3: Oscillation parameters obtained from Figure 28.

\begin{tabular}{|c|c|c|c|}
\hline & $\mathrm{Pt}$ & $\mathrm{Pt}_{3} \mathrm{Au}$ & $\mathrm{PtAu}$ \\
\hline Amplitude / V & $0.54-0.81$ & $0.54-0.86$ & $0.44-0.87$ \\
\hline Frequency / $\mathrm{mHz}$ & 3.9 & 4.8 & 2.4 \\
\hline Size of the oscillation region / s & 5200 & 4600 & 1700 \\
\hline Min/Max dE dt ${ }^{-1} / \mathrm{mV} \mathrm{s}^{-1}$ & $-4.0 / 5.4$ & $-8.3 / 22$ & $-150 / 360$ \\
\hline
\end{tabular}

The increasing amplitude, where especially the upper potential limit shifts more positively, which is related to the electronic effect of $\mathrm{Au}$ and causes a stronger adsorption of carbonaceous and oxygenated species. A higher overpotential is required to activate their reaction via Langmuir-Hinshelwood mechanism. Once a sufficiently high potential is reached, the surface liberation becomes more effective and faster and leads to a steeper change from high to low potentials. The derivatives in Figure 28f)-h) emphasize the potential change dE/dt against the measured potential $\mathrm{E}$ along the oscillation cycle, where a positive and negative values reflect poisoning and liberation rates of the surface, respectively. The increasing amplitude can be seen here very well in the widening of the circle due to the positive potential shift of the maximum potential and the higher potentials of the maximum rates on $\mathrm{Pt}_{3} \mathrm{Au}$, which increase by one order of magnitude. Besides these effects, the potential oscillations on PtAu also show a significant, negative shift of the oscillation minimum by $0.1 \mathrm{~V}$, which increases the amplitude further, and must be related to the ensemble effect of $\mathrm{Au}$ in the alloys. The lower $\mathrm{CO}_{\mathrm{ad}}$ coverages ease the oxidation of formic acid, that a lower overpotential is needed to sustain the applied current density. It should be especially noted the changing profile of the oscillations, where a significant poisoning just takes place in a very short time scale and at least 25 times faster auto-cleaning rates on PtAu compared to Pt, which clearly show up the enhanced catalytic activity of Pt due to the alloying of Au. Due to the more pronounced ensemble effect with an increasing Au presence, no oscillations were found anymore on $\mathrm{PtAu}_{3}$ and $\mathrm{PtAu}_{9}$. As it has been reported previously, the mean potential in the oscillation pattern is dislocated positively slowly along the time series [50,52], what has been assigned a place-exchange process of adsorbed oxygenated species to the subsurface, as described by Conway [28]. Oxide formation is negligible on $\mathrm{Au}$ in the visited potential range, that mainly Pt surface atoms undergo this process and become deactivated. Since the Pt on the surface is less present at higher Au content, this phenomenon is less present in the oscillations on alloyed NPs. Yet, the poor catalytic activity of $\mathrm{Au}$ regarding formic acid oxidation also 
diminishes the electro-active area that the oscillation region collides earlier with the unstable branch of the HN-NDR and ends up faster in the oxygen evolution. The oscillation frequency can give an idea about the rates in the effective interaction of adsorbed carbonaceous and

oxygenated species, but in the comparison of the alloyed with the Pt NPs no clear trend could be observed, what may be related to the complex influence of various processes and effects. The oscillation on Pt and PtAu showed an induction period, which is the time in the time series until the oscillations start, which, surprisingly, was not found on the $\mathrm{Pt}_{3} \mathrm{Au} \mathrm{NPs}$.

\subsection{Partial conclusions}

Bimetallic NPs of PtAu alloys of different ratio were investigated for the catalytic electro-oxidation of formic acid under voltammetric and oscillatory conditions. The NP characterization by XPS, steady state voltammetry and CO stripping (not shown, but reported in reference [103]) suggest an active electronic effect in the alloyed NPs, which strengthens the bondings of adsorbates and leads to potential shift of $\mathrm{CO}_{\mathrm{ad}}$ oxidation by $0.2 \mathrm{~V}$ more positively. Nevertheless, the alloying of $\mathrm{Au}$ showed a significant enhancement of the NP performance, particularly of PtAu and $\mathrm{PtAu}_{3}$ NPs, which manifests itself in higher current densities and smaller onset potentials in formic acid oxidation. Both can be attributed to the electronic and ensemble effect, which leads to an improved adsorption of the active intermediate in the direct oxidation pathway on the Pt surface atoms and an effective suppression of $\mathrm{CO}_{\mathrm{ad}}$ formation via the indirect pathway, respectively. The profile of potential oscillations on $\mathrm{Pt}, \mathrm{Pt}_{3} \mathrm{Au}$ and $\mathrm{PtAu}$ with an increasing amplitude, a diminishing oscillation region and the changing limiting cycle as well as their missing on $\mathrm{PtAu}_{3}$ and $\mathrm{PtAu}$ confirmed

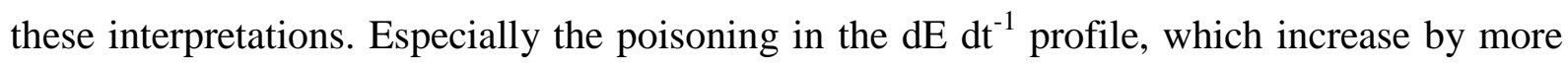
than one order of magnitude on PtAu compared to Pt reflect the electronic effect of $\mathrm{Au}$, meanwhile reactivation rates increased due to the ensemble effect. Therefore, all results point out an improved, long lasting, stable performance of the Pt surface due to the presence of $\mathrm{Au}$ and give further information about the required characteristics of a tailored catalyst for a successful application in fuel cells and energy conversion. 


\section{Temperature and $\mathrm{pH}$}

dependencies of voltammetric

\section{response and oscillations}

In this chapter the studies of the electro-oxidation of formic acid and methanol on $\mathrm{Pt}$ in a wide range of the bulk solution temperature and $\mathrm{pH}$ are discussed. The principle result was the indication, that formic acid is oxidized via three independent pathways, where the oxidation in the most active pathway takes place via weakly adsorbed formate. It could be revealed, that this mechanism also has a crucial role in the electrooxidation of methanol. The existence of potential patterns strongly depends on the activity of that main pathway, besides the $\mathrm{pH}$ and temperature dependent formation and interaction of carbonaceous and oxygenated adsorbates. 


\subsection{Introduction}

As was mentioned briefly in section 2, much endeavours have been done to better understand the mechanisms of the oxidation of small organic molecules and make an application in fuel cells profitable. Thus, a vast amount of publications on this topic exists in literature, as found in web of knowledge:

Table 4: Publications with the oxidation of the relevant molecule in the title and fuel cell as topic, listed in the database "web of science" in all years.

\begin{tabular}{|c|c|c|c|c|c|c|c|}
\hline Molecule & $\begin{array}{c}\text { Meth- } \\
\text { anol }\end{array}$ & $\begin{array}{c}\text { Eth- } \\
\text { anol }\end{array}$ & $\begin{array}{c}\text { Formic } \\
\text { acid }\end{array}$ & $\begin{array}{c}\text { Formal- } \\
\text { dehyde }\end{array}$ & $\begin{array}{c}\text { Ethylene } \\
\text { glycol }\end{array}$ & $\begin{array}{c}\text { Acetic } \\
\text { acid }\end{array}$ & $\begin{array}{c}\text { Acetal- } \\
\text { dehyde }\end{array}$ \\
\hline $\begin{array}{c}\text { Number of } \\
\text { publications }\end{array}$ & 2408 & 998 & 561 & 50 & 132 & 4 & 4 \\
\hline
\end{tabular}

As Table 4 highlights, the majority of the literature is focused in methanol and ethanol oxidation, which may be the most promising candidates. Studies on the other, listed molecules amongst others have their relevance, since they appear as intermediates in the oxidation mechanisms of the formers and the understanding of their oxidation mechanism will help to give further insight or can be applied as fuel as well. Especially formic acid oxidation is investigated for this reason. Yet, most of the data have been carried out in acidic media and few literature existed on another $\mathrm{pH}$ range [89,134-138]. Systematic studies on the electrooxidation of formic acid in a wide $\mathrm{pH}$ range were just published recently and allowed a deeper understanding $[70,72,74,75]$. But to the best of our knowledge, no study on the oscillatory regime of small organic molecules had been published regarding the $\mathrm{pH}$ effect.

\subsection{Formic acid oxidation}

The steady state voltammograms of formic acid oxidation on $\mathrm{Pt}$ in $0.4 \mathrm{M} \mathrm{K}_{2} \mathrm{SO}_{4}+\mathrm{x} \mathrm{M}$ $\mathrm{H}_{2} \mathrm{SO}_{4} / \mathrm{KOH}+0.2 \mathrm{M} \mathrm{HCOOH}(\mathrm{pH}=1.02$ and 13.12) are plotted in dependence on the bulk solution temperature in Figure 29. The characteristic profile, as described in section 2.1, can be seen at all temperatures with an increasing current density in all peaks. This behaviour is common for most of chemical and biological systems due to an enhanced diffusion and 
mobility. Thus, the reaction rate is known to increase 2-4 times with the temperature. In the same way the seen NDR region increases in $\mathrm{pH} \mathrm{13,} \mathrm{especially} \mathrm{at} \mathrm{higher} \mathrm{temperatures.} \mathrm{The}$ small hysteresis in $\mathrm{pH} 13$ and the shifting peak maximum to lower overpotentials indicates a minor role of the dehydration pathway and $\mathrm{CO}_{\mathrm{ad}}$ formation and the more determining adsorption of water, whose potential dependent adsorption is responsible for that phenomena (see also section 1.3). A similar behaviour was found above on the PtAu alloyed NPs and thus, related to the same reasons, although the origin is completely different. To verify this effect, measurements were carried out in a wide $\mathrm{pH}$ range, where its change was negligible.

Figure 29: Positive (notation 1) and negative (notation 2) sweeps of the steady state voltammogram in (a) $0.4 \mathrm{~K}_{2} \mathrm{SO}_{4}+\mathrm{x} \mathrm{M} \mathrm{H} 2 \mathrm{SO}_{4}$ ( $\mathrm{pH} 0.25$ ), and (b) y $\mathrm{M} \mathrm{KOH}$ (pH 13.86); with formic acid concentration of $0.2 \mathrm{M}$ in the temperature range between 10 and $50{ }^{\circ} \mathrm{C}$. Scan rate $0.05 \mathrm{~V} \mathrm{~s}^{-1}$

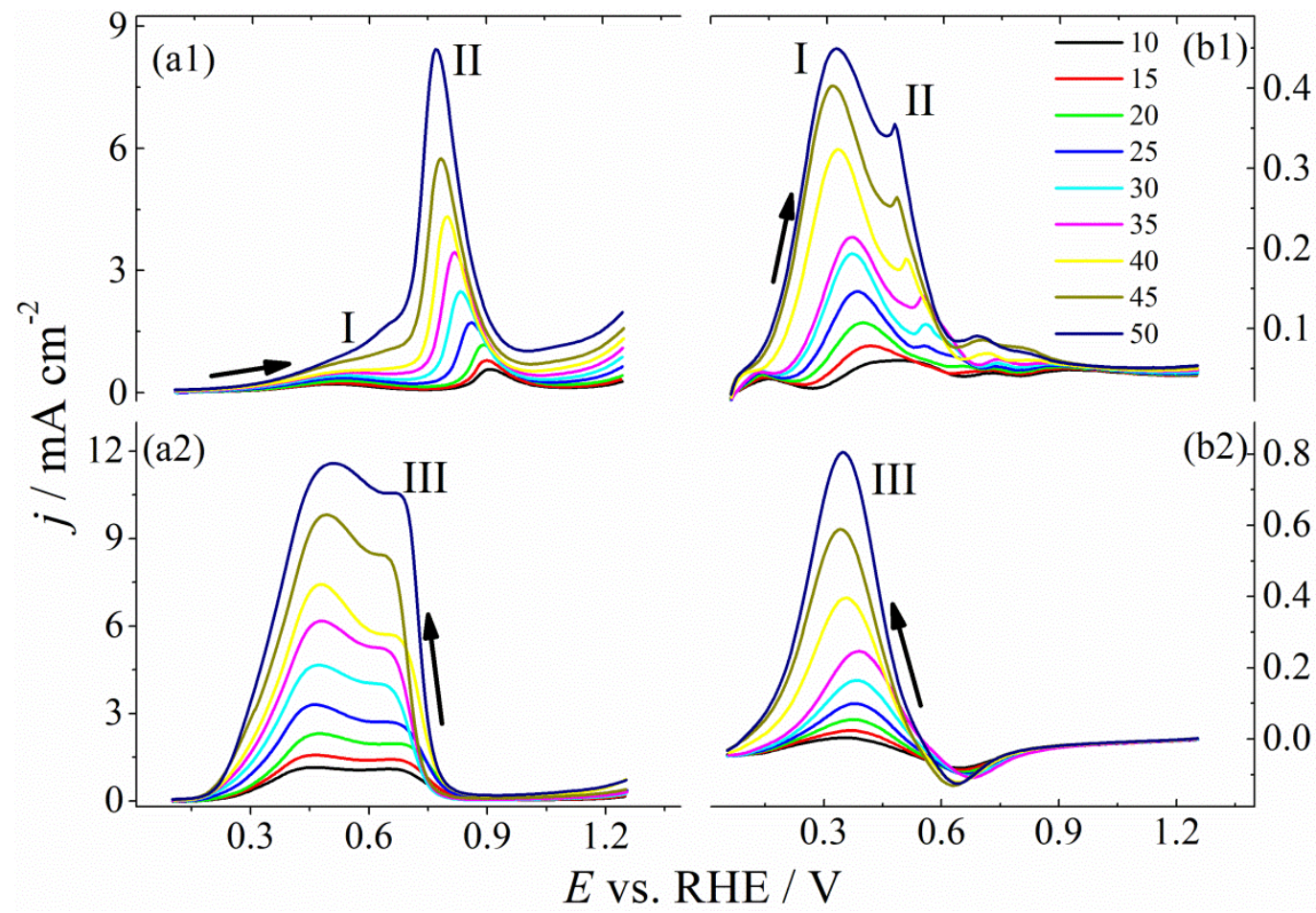

The maximum current densities of all characteristic peaks from the voltammetric response of formic acid oxidation on $\mathrm{Pt}$ are plotted in Figure 30 together with the molar fractions of formic acid and formate against the bulk solution $\mathrm{pH}$. As the Figure depicts, the current density of all peaks follow the profile of molar fraction of formate in very good agreement until $\mathrm{pH} \sim 12$, where its oxidation is strongly inhibited by adsorbed water and oxides. As such, as the $\mathrm{pH}$ increases from $\mathrm{pH} 0$ on, the current density increases slightly until the $\mathrm{pK}_{\mathrm{A}}$ of 
formic acid/formate at 3.75. At that point all currents become several times higher compared to $\mathrm{pH} 0$, which can be seen especially in the cathodic scan, where the peak current increase by almost one order of magnitude and reaches an adumbrated plateau in the $\mathrm{pH}$ range of 5 to 11 , where measurements were just partly possible due to the non-negligible changing $\mathrm{pH}$ in the interface caused by the produced protons from the oxidation. This dependence is consistent with the recent literature and strongly suggests formate as the main active species in the dehydrogentation pathway even under acidic conditions, where it occurs in minor molar fraction $[72,73,75]$. Surprisingly the activity in the back scan also revealed a linear slope of $1.18+/-0.08 \mathrm{~mA} \mathrm{~cm}^{-2}$ per $\mathrm{pH}$ unit in the region $0-4$. This part does not fit exactly the $\mathrm{pH}$ dependence of the concentration of formate, which just changes slightly and nonlinearly and leads to the conclusion of an active side pathway. The current data do not allow any interpretation on the nature of active species, but it can be assumed, that formic acid and/or bridge-bonded formate may have a crucial role, which are very present under that conditions. Since bridge-bonded formate always is present under conditions, where formic acid oxidation takes place, it has been considered as a candidate as an intermediate $[59,66,68,69,76,111,139$ 142]. As Kibler et al. found, bridge-bonded formate adsorbs on $\mathrm{Au}(111)$ in chains and show a phase transition, as the coverage is 0.25 monolayer. At this point a current jump in the cyclic voltammogram was observed, which can be attributed to a catalytic effect due to formate adsorption [37]. Recently, Gao et al. reported DFT calculations, which reveal a monodentate form of adsorbed formate as a possible, active species in the oxidation mechanism of formic acid, which has been confirmed by Vilaplana et al., where the neighbouring adsorbed formates play a stabilizing role and catalyse the oxidation of that species to $\mathrm{CO}_{2}[59,69,73]$. It seems likely, that the oxidation via monodentate formate is the active side pathway, which is especially visible in the acidic $\mathrm{pH}$ range, where solvated formate is only present in very low concentration. An additional effect may be attributed to the more unfavoured sulphate adsorption in the $\mathrm{pH}$ range from 0 to 4 and the higher competition with the adsorption of oxygenated species, which lead to lower sulphate coverages and more available active Pt sites for the direct oxidation pathway [143]. It should also be noticed, that currents of peak I overcome peak II at pH 11, which suggest the constantly decline of the CO coverage. Several reasons may play a role here: Firstly, due to the favoured direct pathway, less formic acid/formate is available to undergo the indirect oxidation. Secondly, the formation of $\mathrm{HCOO}_{\mathrm{B}}$ also decreases, which is seen as precursor for $\mathrm{CO}$ and may be strongly related to thirdly, the more negative surface charge at higher $\mathrm{pH}$. A more negatively charged surface repels the negative oxygen atoms of formate, may be responsible for the slower $\mathrm{HCOO}_{\mathrm{B}}$ and 
$\mathrm{CO}_{\mathrm{ad}}$ formation and forces formate in $\mathrm{C}-\mathrm{H}$ down configuration, which is considered to be the active one in the direct pathway [72,73].

Figure 30: Influence of the solution $\mathrm{pH}$ on the current peaks described in Figure 29: I (triangles, forward sweep), II (circles, forward sweep), and III (squares, backward sweep). Molar fractions of solution $\mathrm{HCOOH}$ and $\mathrm{HCOO}^{-}$are also given in right y-axis. Grey areas depict the $\mathrm{pH}$ windows where potential oscillations were found (see below). Remaining conditions as in Figure 29.

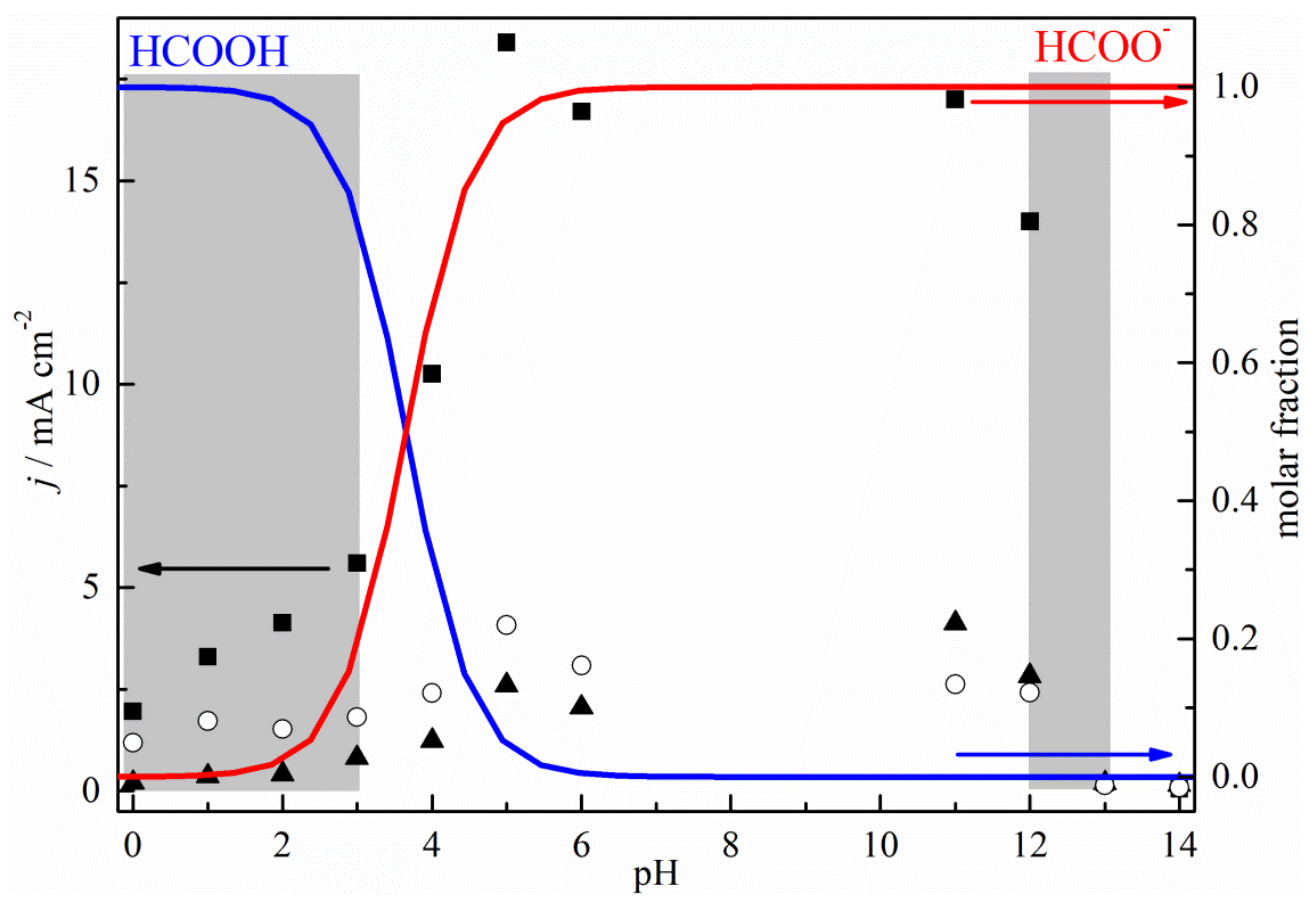

Formic acid oxidation was further analysed by galvanodyamic measurements in each applied solution to probe the existence of potential oscillations, which are shown in Figure 31.Potential oscillations were found in acidic media between $\mathrm{pH} 0$ and 4 , where it should be especially noted that this is the $\mathrm{pH}$ region below the $\mathrm{pK}_{\mathrm{A}}$. This result suggests, that formic acid is the responsible precursor for the appearance of oscillations in that media, which appear in the known shape, at similar current density range and after a short induction period until the potential rises sharply to high overpotentials. Unexpectedly, potential oscillations also occurred under those conditions in the solution of $\mathrm{pH} 12$ (Figure 31) at lower potentials and just at the beginning of the measurement. It can also be seen, that at $\mathrm{pH} 11$ and 12 higher current densities can be applied where the potential remains between 0.5 and $0.8 \mathrm{~V}$, what indicates a more active formate oxidation sustaining the applied current and confirms the afore made interpretations. On the other hand only low currents can be applied in strong, 
alkaline media, where the potential meets the oxygen evolution very fast. This behaviour demonstrates the poor activity of formate oxidation under those conditions due to the strong inhibition.

Figure 31: Galvanodynamic measurements of $5 \mu \mathrm{A} \mathrm{s}^{-1}$ of $0.2 \mathrm{M} \mathrm{HCOOH}$ in $0.4 \mathrm{M} \mathrm{K}_{2} \mathrm{SO}_{4}$ of different $\mathrm{pH}$.

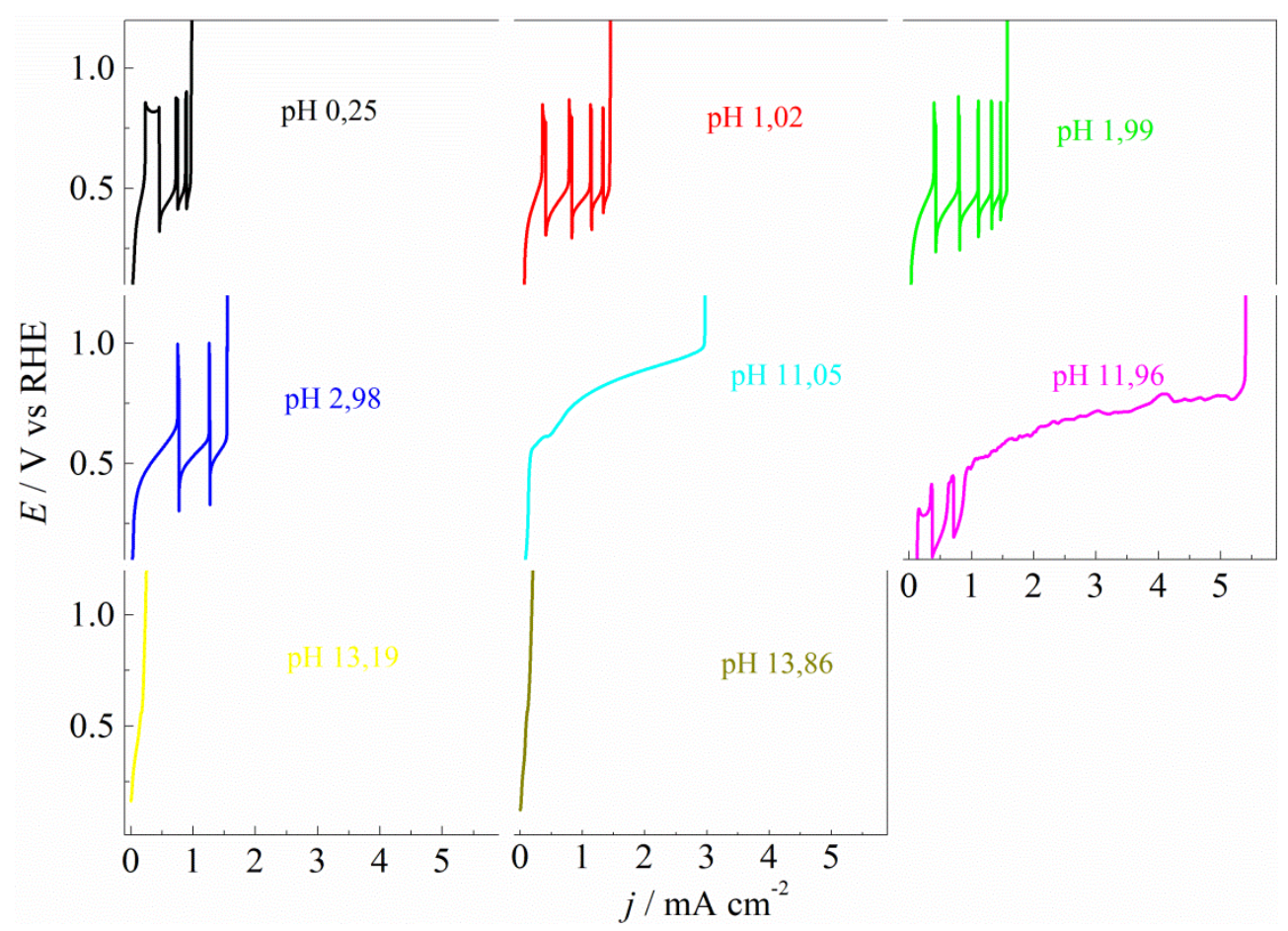

Figure 32 shows galvanodynamic measurements of formic acid oxidation with different scan rates between 1 and $500 \mu \mathrm{A} \mathrm{s}^{-1}$ at $\mathrm{pH} 1$ and 13. As it has been reported earlier by Feliu and co-workers, the scan rate can have a significant influence on formic acid oxidation and allowed further insight in its oxidation mechanism [142]. Thus, it was found, that a faster potentiodynamic scan rate results in more pronounced adsorption processes due to the lower probability of a successful oxidation of formic acid in the changing time window in each voltammetric cycle. Yet, under galvanodynamic conditions the system is constantly far away from equilibrium independently on the scan rate, which cannot be compared to the previous publication. To the best of our knowledge no results have been published, which study the influence of the scan rate on formic acid oxidation in galvanodynamic measurements, which drives the system away from equilibrium in a different time scale. As Figure 32 shows, the scanning velocity also is a crucial parameter under galvanodynamic conditions and has a strong influence on the oscillation characteristics. Thus, the number of oscillation cycles decreases at faster scan rates and can even cause their disappearance, as seen in alkaline 
media (Figure 32b)) and the oscillation frequency in both media. Besides this effect, the visited current range changes drastically, which is an important point to consider, since the galvanodynamic measurement is used for the normalization of the oscillation region and the determination of applied currents for further studies in chronopotentiometry [82].

Figure 32: Galvanodynamic measurements of $0.2 \mathrm{M} \mathrm{HCOOH}$ in $0.4 \mathrm{M} \mathrm{K}_{2} \mathrm{SO}_{4}$ of a) $\mathrm{pH} 1.02$ and b) $\mathrm{pH} 13$ of different scan rates.

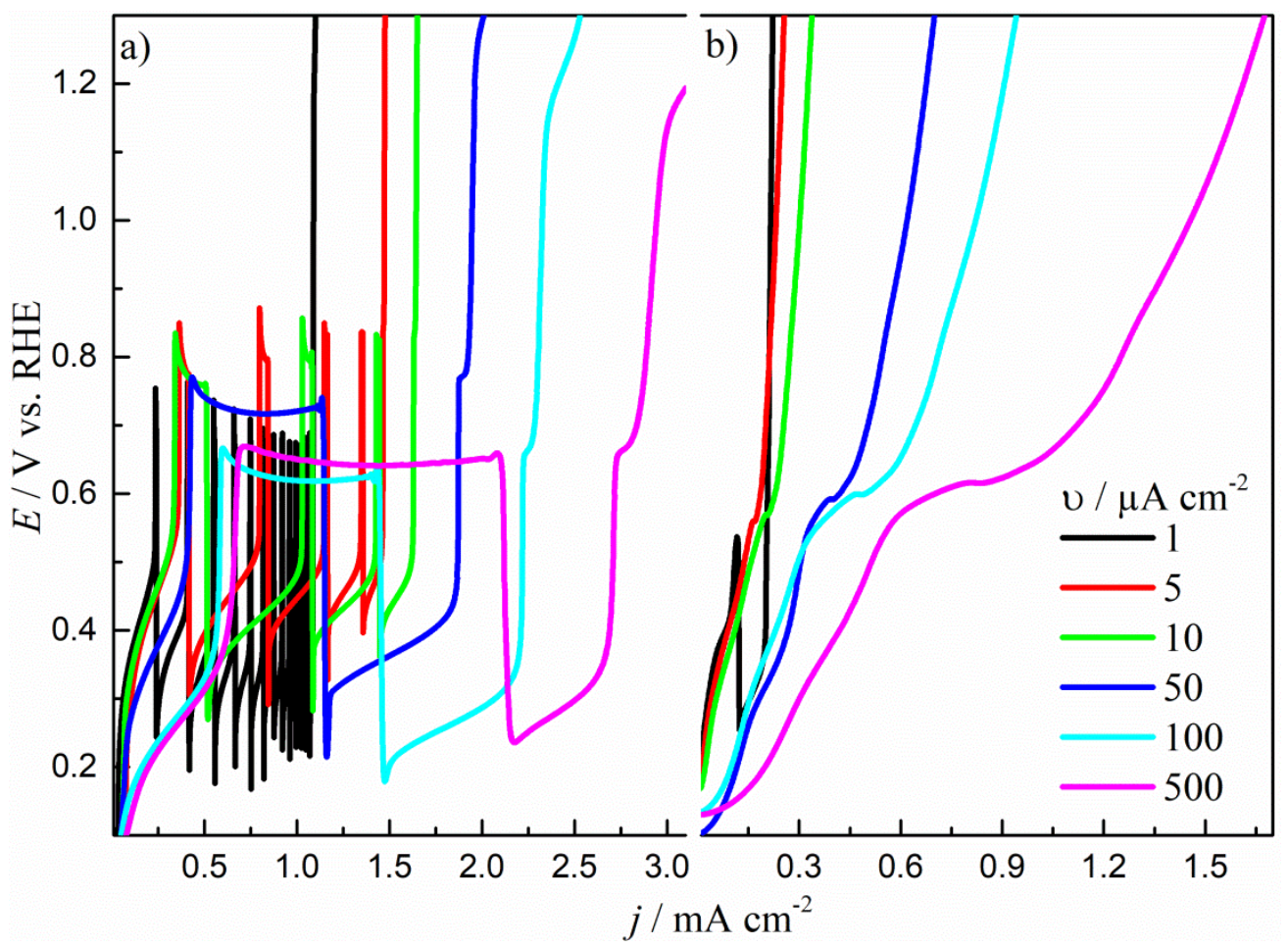

From the mechanistic point of view, a high oscillation frequency stands for a faster adsorption of $\mathrm{CO}_{\mathrm{ad}}$ and $(\mathrm{H})_{\mathrm{x}} \mathrm{O}_{\mathrm{ad}}$ as well as an effective interaction of these adsorbates and their removal. Consequently, the highest frequency can be found at $1 \mu \mathrm{A} \mathrm{s}^{-1}$, where the longest time scale is visited. As the scan rate increases, the system is forced to maintain higher currents in a shorter time window and the main active surface process is put in favour. In that case this reaction is the direct oxidation pathway of formic acid oxidation, which is responsible for the most charge transfer. With a more active direct pathway the adsorbed species and their reaction become less pronounced, what explains the lower frequencies and the longer high and low potential parts in one oscillation cycle. The more active dehydrogenation of formic acid can provide more charge and allows higher current densities to be applied. Since CO is less produced in alkaline solutions, the disappearance of the oscillations at faster rates is the consequence. The lack of $\mathrm{CO}$ enhanced not only the direct pathway, but also the adsorption of $(\mathrm{H})_{\mathrm{x}} \mathrm{O}_{\mathrm{ad}}$. So $(\mathrm{H})_{\mathrm{x}} \mathrm{O}_{\mathrm{ad}}$ accumulates fast on the Pt surface besides the formate oxidation without 
a noticeable removal what causes a fast increase of the potential to a small plateau at $\sim 0.6 \mathrm{~V}$ and a faster end of the profile in the oxygen evolution, compared to $\mathrm{pH} 1$.

To study the $\mathrm{pH}$ effect on the oscillation regime of formic acid oxidation, the oscillation region in a galvanodynamic measurement of $5 \mu \mathrm{A} \mathrm{s}^{-1}$ was normalized in each solution. $100 \%$ of the oscillation region was considered as the current region, where the potential visited the range between $0.4 \mathrm{~V}$ and the last oscillation cycle. After the chronopotentiometric profile was carried out at 0.1 (black), 0.5 (red) and 0.9 (green) normalized current densities. The potential time series are shown for $\mathrm{pH}$ 1, 3 and 12 in Figure 33. All series were performed for $750 \mathrm{~s}$, except for $\mathrm{pH} 12$, if the limiting cycle was not reached before, where the potential was cut off at $1.2 \mathrm{~V}$. Since Figure 33a) and b) show the known profile of potential oscillation along formic acid oxidation, the instabilities are supposed to come from the described surface reactions in section 2.1. At $\mathrm{pH} 1$ and 3 an increase of the applied current density results in a lower time scale, higher mean potential and oscillation frequency (in the case of $\mathrm{pH} 3$ even the lack of potential oscillations). This effect was already found in the galvanodynamic studies and attributed to a more active formic acid oxidation, the concomitantly smaller $\mathrm{CO}$ adsorption and a faster coverage of the Pt surface by oxides.

Figure 33: Galvanostatic time-series for the electro-oxidation of formic acid in $0.4 \mathrm{~K}_{2} \mathrm{SO}_{4}+$ $0.2 \mathrm{M} \mathrm{HCOOH}+\mathrm{x} \mathrm{M} \mathrm{H}_{2} \mathrm{SO}_{4} / \mathrm{M} \mathrm{KOH}$ solution at (a) $\mathrm{pH}$ 1, (b) $\mathrm{pH} 3$, and (c) $\mathrm{pH} 12$.

Temperature $25{ }^{\circ} \mathrm{C}$. Normalized current density 0.1 (black), 0.5 (red) and 0.9 (green).

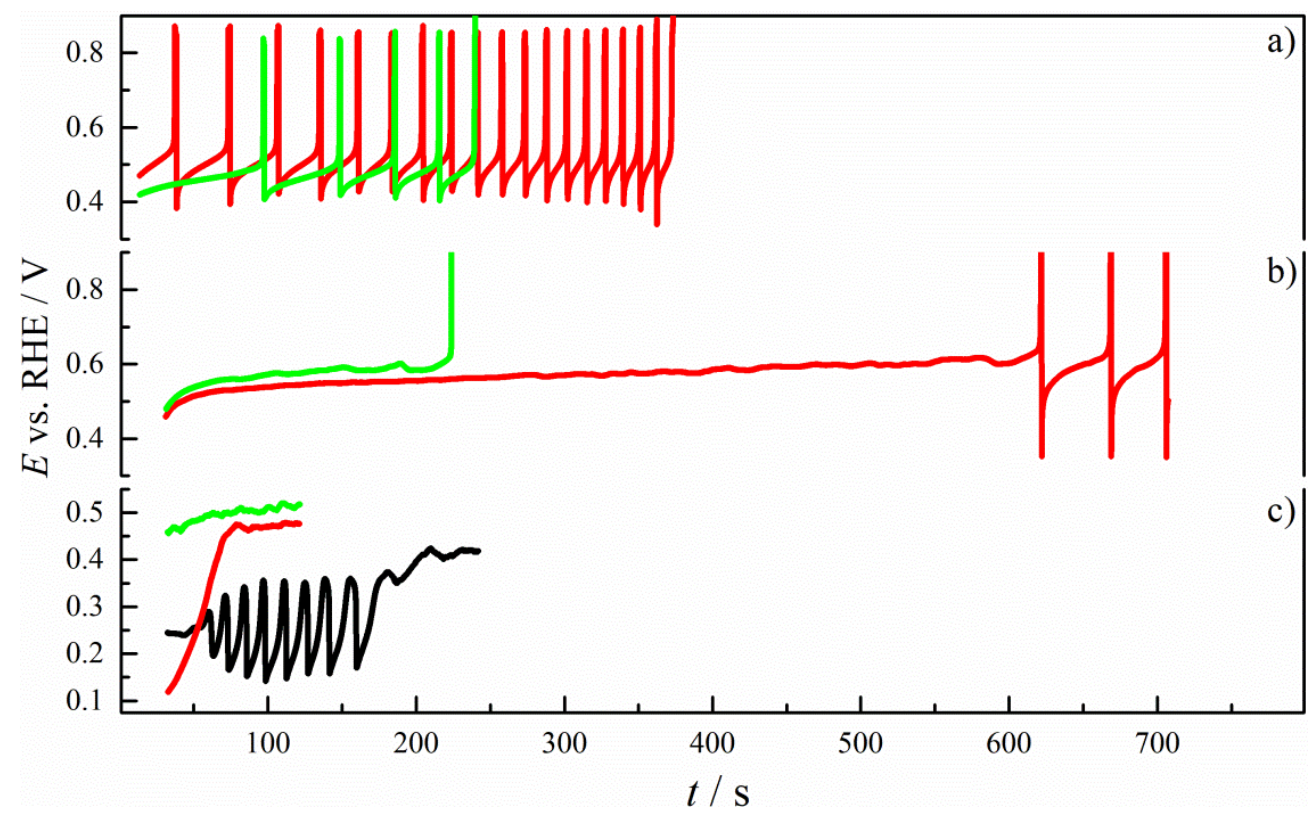


Consequently the known potential oscillations were just found after a long induction time or are not present at all at high applied currents. Surprisingly, another family of potential oscillation of lower amplitude between 0.1 and $0.4 \mathrm{~V}$ occurred in $\mathrm{pH} 12$. The conditions to find this family seem to be unstable, that their oscillation region does not last long and their profile undergoes a constant transition from a small to a more pronounced high potential part. To the best of our knowledge, this type of oscillation has not been reported in literature yet and there is no information about the underlying mechanism. The small amplitude suggests a small change in the electrochemical interface like the oxide coverage for example by a slightly active $\mathrm{CO}$ formation. Other candidates for such a change might be formate or produced protons, which could react with $(\mathrm{H})_{\mathrm{x}} \mathrm{O}_{\mathrm{ad}}$-species via Eley-Rideal mechanism. Deeper insight in the $\mathrm{pH}$ effect on the potential oscillations is shown in Figure 34. As the graphs demonstrate, the known potential oscillations are limited to $\mathrm{pH} 0-4$, whose oscillation region decreases and frequency increases from $\mathrm{pH} 0$ to 2 . Both facts can be attributed to the facilitated oxide formation by the higher $\mathrm{pH}$. The behaviour changes dramatically at $\mathrm{pH} 3$, where potential oscillations are hardly present and are not found at any other acidic $\mathrm{pH}$ studied. The reason for that effect lies in the changing molar fraction of formate beyond the $\mathrm{pH}$ region $\mathrm{pK}_{\mathrm{A}}$, which also was the reason for the several times more active formic acid oxidation and smaller coverage of $\mathrm{CO}_{\mathrm{ad}}$ (see above). Figure 34e) and f) display representative oscillations in alkaline media, which are of lower frequency and amplitude than in acidic solutions. It can also be seen, that the oscillation characteristics and the profile is very susceptible to changes in the applied parameters, like bulk solution temperature and $\mathrm{pH}$ or the applied current. This result points out the strong influence of all applied parameters on the complex electrochemical interface, which seems to change from $\mathrm{pH} 12$ to 13 , where oscillations show lower frequency and amplitude. A detailed overview of the temperature and $\mathrm{pH}$ effect is given in Figure 35, where the oscillation frequency is plotted as function of the temperature for all solutions of different $\mathrm{pH}$ in a) and vice versa in b). As the graph depicts, all found oscillations in the low $\mathrm{pH}$ range increase in frequency in a wide temperature range, whereupon overcompensation is found at high temperatures in $\mathrm{pH}$. This phenomena has been reported previously for $0.5 \mathrm{M} \mathrm{H}_{2} \mathrm{SO}_{4}$ and was related to the different dependence of adsorbed surface oxides in the parallel pathways of $\mathrm{CO}$ oxidation and the place exchange process on the temperature [50,82]. Since the adsorption of carbonaceous and oxygenated species depends strongly on the applied parameters, such as surface orientation and defects, concentration of organic and ionic species amongst others, it is likely, that the 
overcompensation region was not visited in the applied range and may occur at higher temperatures under these studied conditions $[83,85,144,145]$.

Figure 34: Potential time-traces for the electro-oxidation of formic acid in $0.4 \mathrm{M} \mathrm{K}_{2} \mathrm{SO}_{4}+0.2$ $\mathrm{M} \mathrm{HCOOH}+x \mathrm{M} \mathrm{H}_{2} \mathrm{SO}_{4}$ of normalized current density 0.5 and $25^{\circ} \mathrm{C}$ with $\mathrm{pH}$ (a) 0.25 , (b) 1.02, (c) 1.99, and (d) 2.98; and x M KOH, and (e) pH 11.96, normalized current density 0.1, $25^{\circ} \mathrm{C}$, and (f) $\mathrm{pH} 13.12$, normalized current density $0.5, \mathrm{~T}=50^{\circ} \mathrm{C}$.
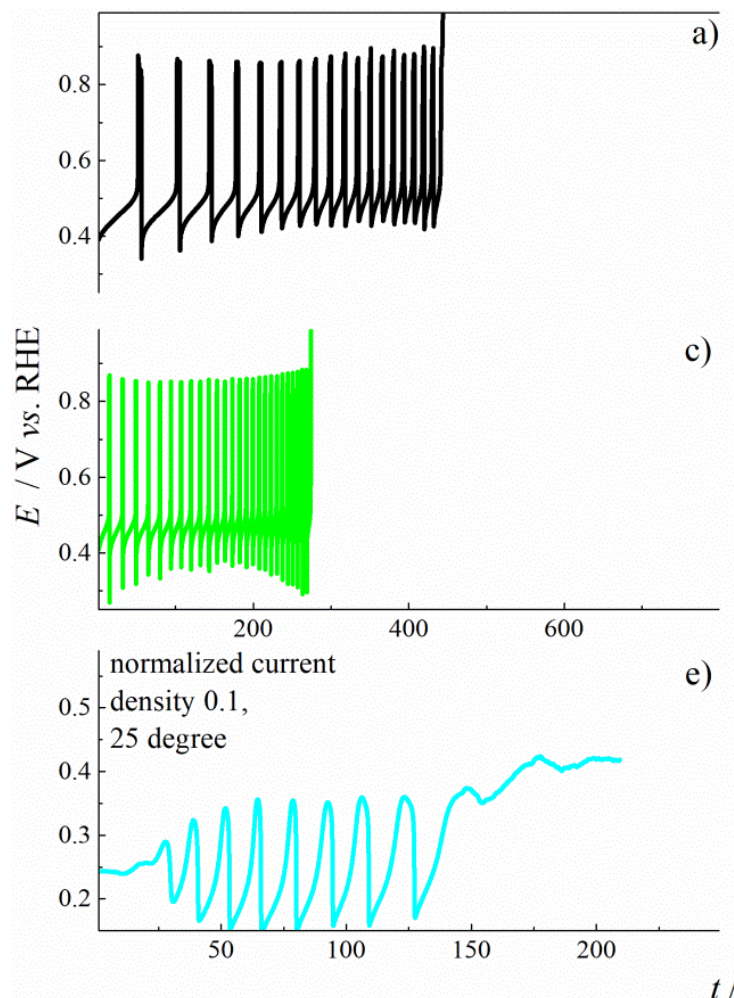

a)
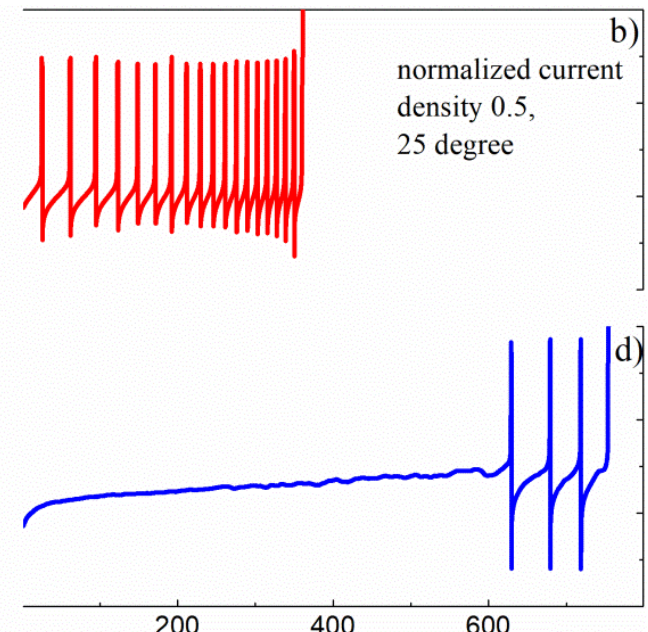

density 0.5 ,

50 degree

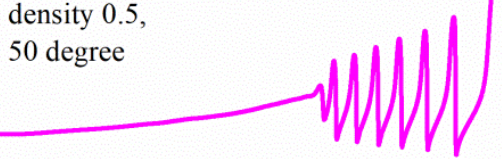

It should also be noted, that the found potential oscillations in alkaline media appear instable and are limited to low and high temperatures at $\mathrm{pH} 12$ and 13, respectively. As Figure 35b) shows, the frequency increases to the maximum at $\mathrm{pH} \mathrm{2.} \mathrm{Although} \mathrm{the} \mathrm{steady} \mathrm{state}$ voltammograms at all $\mathrm{pH}$ showed the characteristic hysteresis to some extent, indicating the presence of site blocking adsorbates like $\mathrm{CO}$, which was reported earlier as well, no oscillations were found between $\mathrm{pH} 3$ and 12 [72]. Potential oscillations in alkaline $\mathrm{pH}$ appear to be rather independent on the temperature, what may be related to the rather inactive $\mathrm{CO}$ formation at the studied temperatures. The frequencies lie on the same scale as for $\mathrm{pH} 0$, where the surface is heavily blocked by adsorbed anions, $\mathrm{CO}$ and bridge-bonded formate. 
Figure 35: Oscillation frequency (a) versus temperature for different $\mathrm{pH}$ values, and (b) versus $\mathrm{pH}$ for different temperatures. Normalized current density was 0.5 in all cases, except for $\mathrm{pH}$ 11.96, which it was 0.1 .
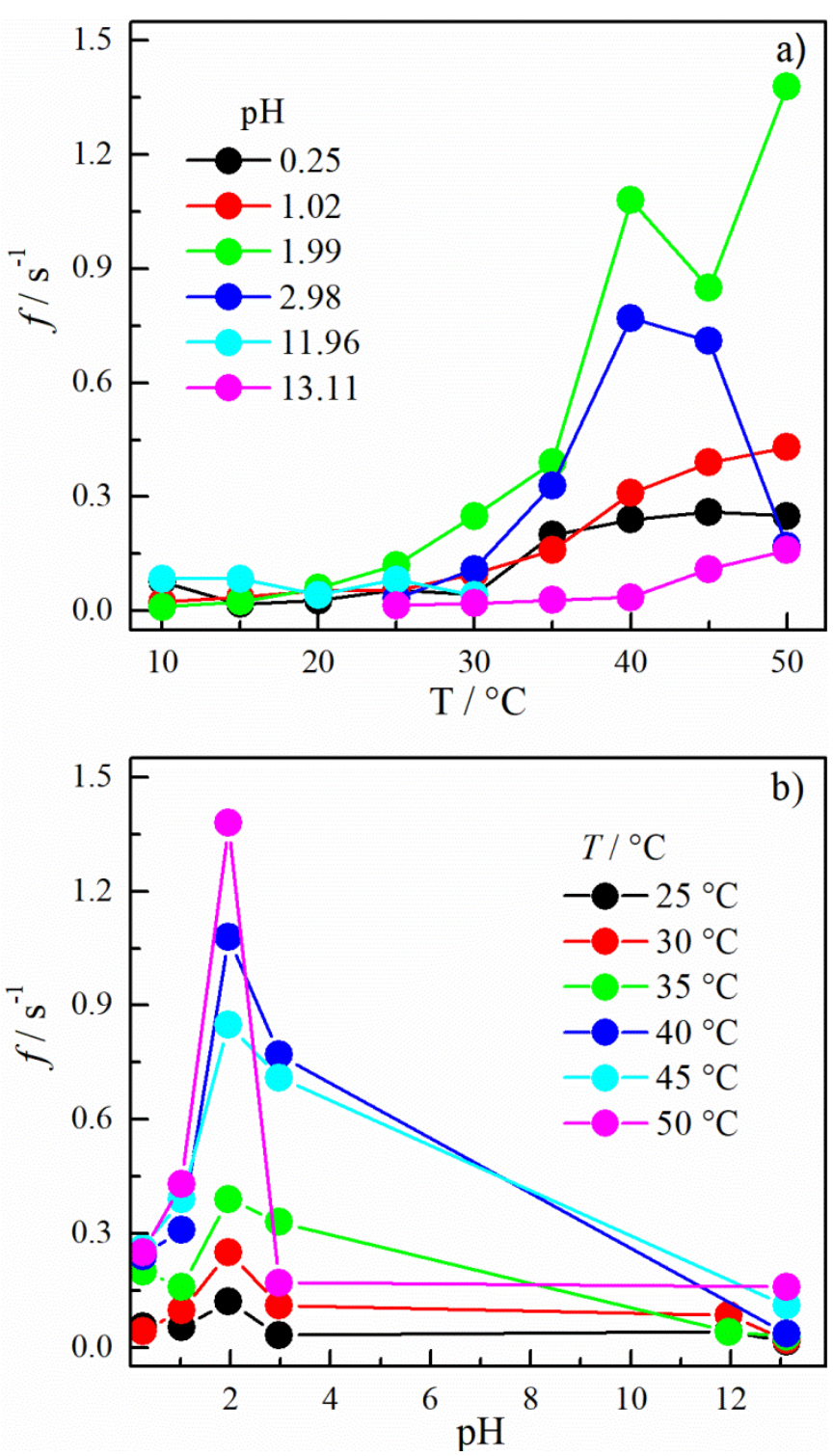

At high $\mathrm{pH}$ values it was found that formic acid oxidation is heavily suppressed by surface (hydr)oxides and water adsorption, whose ample coverage far from equilibrium may be responsible for the potential instabilities. Thus, as it was mentioned before, the oscillation frequency is a measure for the interaction in the Langmuir-Hinshelwood mechanism, where high values represent a fast formation and removal of the involved species. If the involved species have to compete with other molecules or one exceeds the other in great amount, independently on the nature of the adsorbates, the oscillation frequency will decline. The dE/dt profiles in Figure 36 visualize the poisoning and liberation rates of the Pt surface in positive and negative values against the measured potential E, respectively. Thus, the positive 
poisoning rates follow the $\mathrm{pH}$ dependence of the frequency, where the maximum rates are seen at $\mathrm{pH} 2$ and decrease at $\mathrm{pH} 3$ and $\mathrm{pH}$ 13. This dependence confirms the afore made interpretations and highlights the ambiguous behaviour of oxygenated species as inhibiting and freeing part in the oxidation mechanism of formic acid. Somehow, this behaviour cannot be seen for the negative part of the cycles, which might be related to somehow chaotic conditions in the liberation of the Pt surface and includes a significant error.

Figure 36: dE/dt $v s$. E for the first oscillatory cycle of the potential oscillations from Figure $34(\mathrm{a})-(\mathrm{d})$. Insert in (a) is a zoom view of results in a) for $\mathrm{pH}=13.11$.

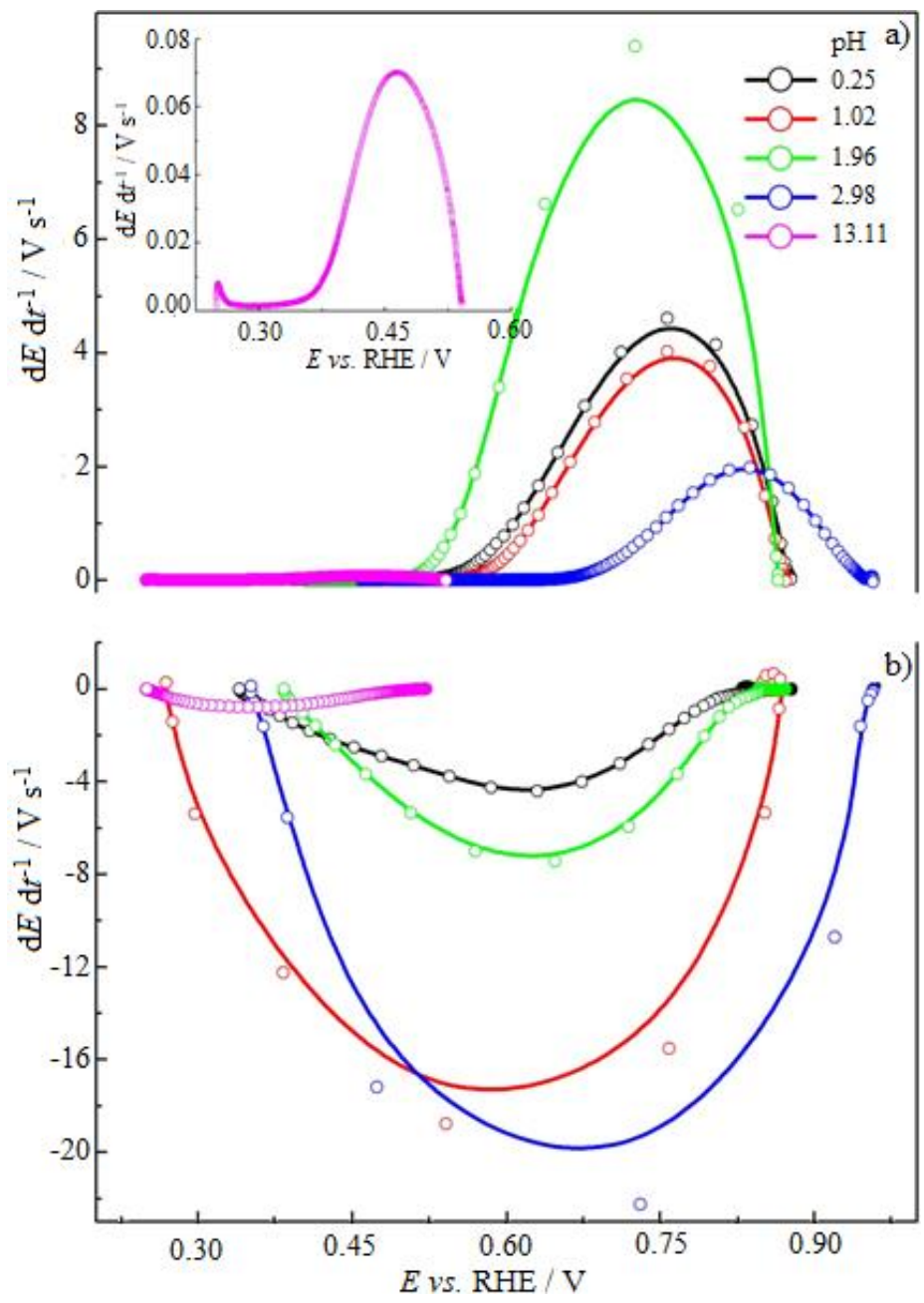

The performed measurements in a wide temperature range at all used solutions of different $\mathrm{pH}$ allow the calculations of the activation energy $\mathrm{E}_{\mathrm{A}}$, which is plotted in dependence on the bulk solution $\mathrm{pH}$ in Figure 37. It has to be stressed, that the activation energies are apparent, which include processes, which are not related to formic acid oxidation. Thus, a relation of each energy to a process in the oxidation mechanism is difficult. Yet, 45 and $50 \mathrm{~kJ} \mathrm{~mol}^{-1}$, obtained from the maximum current densities in anodic and cathodic scan 
direction at $\mathrm{pH} 0$ and 1 , are in good agreement with the literature $[50,82,146]$. Since the peak maximum in both scan directions lie in a potential region, where $\mathrm{CO}$ coverage is rather low due to its oxidation or slow formation, these values may represent the activation energy of the direct, dehydrogenation pathway under the apparent conditions. The dependence of the activation energy in the back scan decreases to an indicated plateau at $33 \mathrm{~kJ} \mathrm{~mol}^{-1}$ in the $\mathrm{pH}$ range from 4 to 12 and significantly higher values in strong alkaline media, what reflects the results in Figure 30 and highlights the eased direct oxidation pathway in the medium $\mathrm{pH}$ range via formate as well as its inhibition at $\mathrm{pH} 13$ and 14. On the other hand the anodic scan reveals a quite constantly increasing energy to $\sim 60 \mathrm{~kJ} \mathrm{~mol}^{-1}$ at $\mathrm{pH} 11$ and 12 , what can be attributed to a more blocked formic acid oxidation by a higher concentration of oxides, being less removed by the decreasing $\mathrm{CO}$ formation. In contrast to voltammetric activation energies, the estimated ones under oscillating conditions undergo a great variation and show erratic behaviour especially at the borders of the region at $\mathrm{pH} 3$ and 12 .

Figure 37: Apparent activation energy for the electro-oxidation of formic acid $v s$. bulk solution pH. Data obtained from the maximum currents at peak II (red circles), III (black squares) and from the oscillatory frequency (green triangles). Remaining conditions as in

Figure 29 and 35.

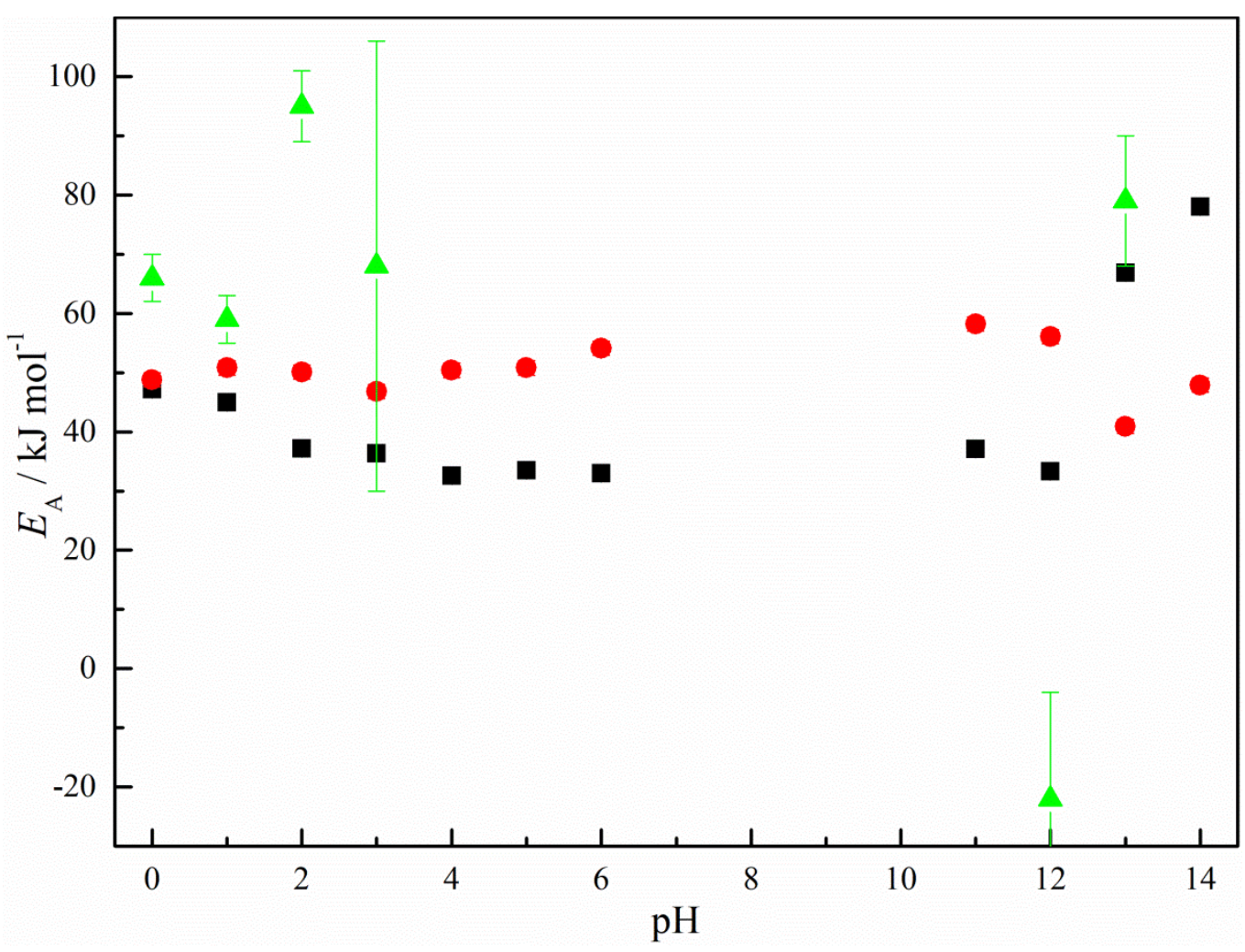


Since along the potential oscillations the system undergoes, differently to steady state voltammetry, a constant change in the non-stationary surface condition and several surface processes are probed simultaneously, an erratic behaviour can be hardly avoided. Yet, some conclusions seem possible. The values between $60-100 \mathrm{~kJ} \mathrm{~mol}^{-1}$ in acidic solutions and $80 \mathrm{~kJ}$ $\mathrm{mol}^{-1}$ at $\mathrm{pH} 13$ lie clearly above the energies of formic acid oxidation under voltammetric conditions. Due to the high applied current densities and the consequent oxidation far from equilibrium formic acid is oxidized under the influence of a significant surface coverage of either $\mathrm{CO}_{\mathrm{ad}}$ or $(\mathrm{H})_{\mathrm{x}} \mathrm{O}_{\mathrm{ad}}$, that this result seems reasonable. Especially the negative activation energy of $-20 \mathrm{~kJ} \mathrm{~mol}^{-1}$ at $\mathrm{pH} 12$ is a clear indication of the contribution of other processes than the oxidation pathways of formic acid oxidation to the apparent activation energy and is the consequence of the instable oscillations in alkaline solution.

\subsection{Methanol oxidation}

As it was done for formic acid, methanol oxidation was studied in a wide temperature range in acidic and alkaline solutions (see also section 2.2) by steady state voltammetry and chronopotentiometry. Figure 38a) displays the steady state voltammograms of $\mathrm{Pt}$ in $2 \mathrm{M}$ $\mathrm{H}_{3} \mathrm{COH}+0.5 \mathrm{M} \mathrm{H}_{2} \mathrm{SO}_{4}$ between 10 and $50{ }^{\circ} \mathrm{C}$, which show the well-known profile with one main oxidation peak anodic and cathodic sweep with peak maxima at $\sim 0.9$ and $\sim 0.8 \mathrm{~V}$, respectively, of increasing current density in dependence on the temperature [89]. In particular the small shoulder right before the peak in positive scan direction should be noticed, which is present in all voltammograms, but becomes clearly visible at high temperatures. The potential hysteresis between the peak maxima decreases with the temperature by $2.67+/-0.2$ $\mathrm{mV}{ }^{\circ} \mathrm{C}^{-1}$ and can be attributed to a more reversible and favoured de-/adsorption of oxygenated species at high temperatures. This fact allows a more effective methanol oxidation at lower overpotentials in the anodic sweep and an earlier lifting of the Pt oxide layer at more positive potentials in the negative scan. Both leads to a smaller peak separation, as it is found in Figure 38a). A deeper analysis of the temperature dependence of methanol oxidation is shown in the Arrhenius plots in Figure 38b) with special focus on potential range before the main oxidation peak in positive scan direction at 0.7 and $0.8 \mathrm{~V}$, which also is the region, where potential oscillation can appear under galvanostatic conditions. The data at $0.8 \mathrm{~V}$ fit the indicated linear behaviour very well and refer to an apparent activation energy $E_{\text {app }}$ of $65 \mathrm{~kJ} \mathrm{~mol}^{-1}$, which is in 
good agreement to previously reported values and may represent the overall activation energy of the direct oxidation pathway under the apparent conditions $[89,147]$.

Figure 38: (a) The effect of temperature on the cyclic voltammograms of the electro-oxidation of methanol on platinum, (b) Arrhenius plots derived from the current densities at 0.70 (black circles) and $0.80 \mathrm{~V}$ (red triangles) of Figure 38a).
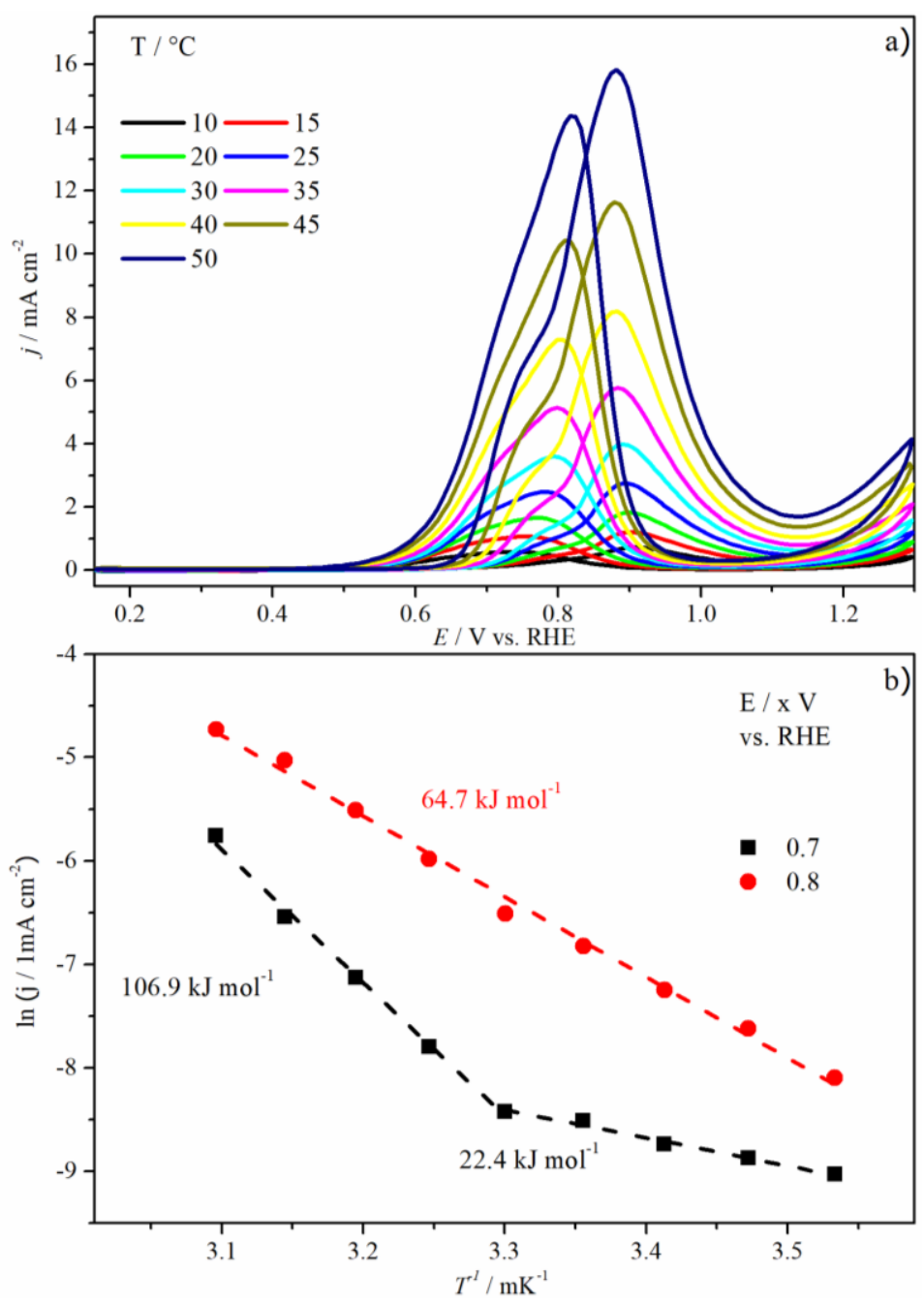

On the other hand the plotted currents at $0.7 \mathrm{~V}$ display two clearly separated linear regions with the fast transition at $30{ }^{\circ} \mathrm{C}$, which fit to an apparent activation energy of 107 and $22 \mathrm{~kJ}$ $\mathrm{mol}^{-1}$. Such a drastic change in the activation energy must be the result of a change in the ratedetermining step triggered by the temperature, which were suggested earlier in literature $[148,149]$. Meanwhile, small activation energies are rather related to diffusion processes, the high value of over $100 \mathrm{~kJ} \mathrm{~mol}^{-1}$ represents a sluggish process, which in that case is probably the electro-oxidation $\mathrm{CO}_{\mathrm{ad}}[150,151]$. Geng et al. related this increase to a diminishing $\mathrm{CO}$ coverage, which consequently becomes more important at higher temperatures [152]. Since it 
is concomitant with the removal of $\left(\mathrm{H}_{\mathrm{x}}\right) \mathrm{O}_{\mathrm{ad}}$, which also acts as site-blocking species in the methanol oxidation, a slower formation of $\mathrm{CO}_{\mathrm{ad}}$ leads to a more blocked direct pathway by the oxides. This interpretation is supported by the decreasing peak distance in the cyclic voltammograms and can be seen in the calculated oxide coverage of $\mathrm{Pt}$ in $0.5 \mathrm{M} \mathrm{H}_{2} \mathrm{SO}_{4}$ in Figure 39.

Figure 39: Temperature-dependent coverage of platinum oxides estimated by cyclic voltammetry in $0.5 \mathrm{M} \mathrm{H}_{2} \mathrm{SO}_{4}$. $\theta_{\mathrm{OH}}$ calculated by the ratio between the charge associated to the oxide formation and hydrogen UPD charge $\left(\mathrm{q}_{\mathrm{OH}} / 2 \mathrm{q}_{\mathrm{H}}\right)$ as suggested in [152].

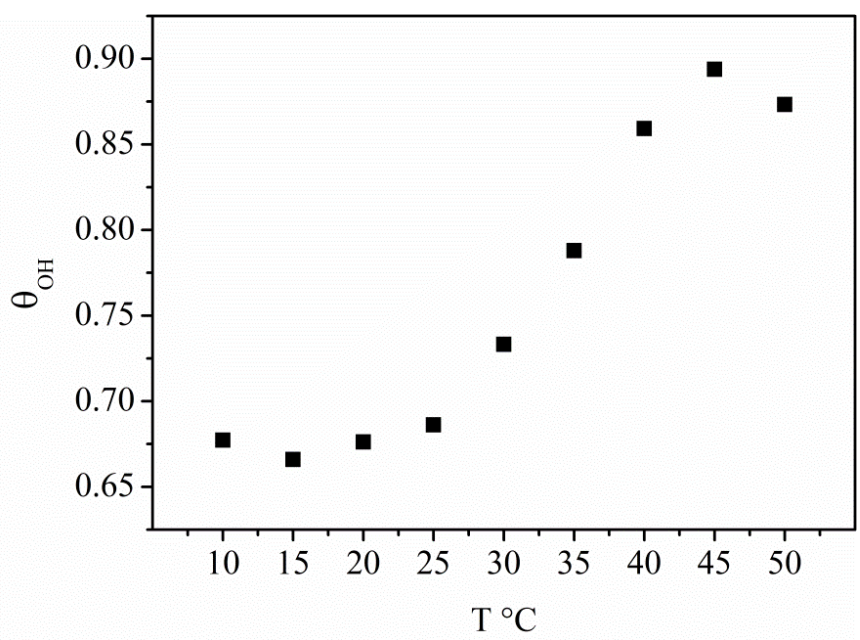

Figure 40a)-c) gives a good insight in the charge distribution in distinct anodic scan in the range of 0.50 to $1.10 \mathrm{~V}$ from Figure $38 \mathrm{a}$ ), where the deconvolution peaks I, II and III fit the profile in very good agreement. As it can be seen in Figure $40 \mathrm{~g}$ ), the peaks are located at different potentials. Thus, although all surface processes of methanol oxidation can be assumed as active in that potential range, peak I may represent the effective removal of $\mathrm{CO}_{\mathrm{ad}}$ besides other carbonaceous adsorbates via the indirect pathway, meanwhile peak II and III can be attributed to the direct oxidation an the interaction of methanol with surface oxides, respectively. The different contribution of each process in dependence on the temperature is emphasized in Figure 40f), which shows the major part coming from peak III at low temperatures. On the other hand, above $30^{\circ} \mathrm{C}$ peak I and II grow in importance and the main charge is delivered via peak II. The same behaviour is found in Figure 40d), showing the kinetic rates as current density in the temperature range studied, where peak I comes from a rather sluggish reaction and peak II shows the most activity besides peak III, particularly at high temperatures. The derived apparent activation energies at the peak maxima, obtained 
from the Arrhenius plot in Figure 40e), are for peak I, II and III result in $88 \mathrm{~kJ} \mathrm{~mol}^{-1}, 67 \mathrm{~kJ}$ $\mathrm{mol}^{-1}$ and $40 \mathrm{~kJ} \mathrm{~mol}^{-1}$, respectively, in good agreement with the literature [89].

Figure 40: a) -c): Deconvolution analysis of the main oxidation voltammetricpeak in the forward scan for three typical temperatures. Fitted peaks I (in red), II (in black) and III (in blue) are presented along with the cumulative fitted peak (dashed line). Original voltammetric peak is presented by the continuous black line. d) Current densities for the sub-peaks at different temperatures and the corresponding, e) Arrhenius plots. Temperature dependence on f) the distribution of charge, in percentage of the total charge of the original peak, and on $g$ ) the potential in which individual peaks are centred, $E_{p e a k}$.
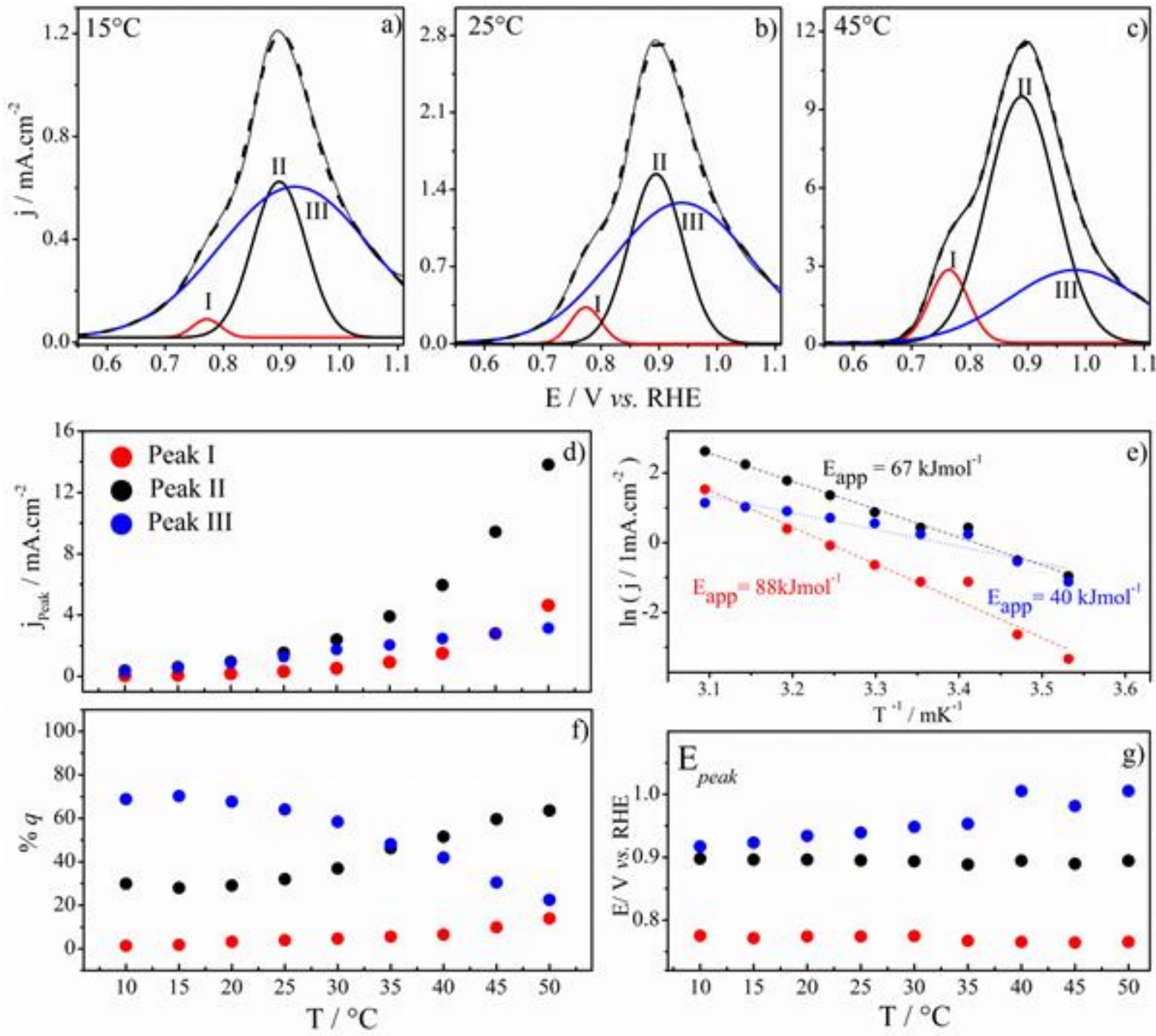

All demonstrated data confirm the made interpretation on the role of adsorbed oxygenated species in the oxidation mechanism of methanol and show the deconvolution peaks and the attributed processes as rate-determining steps at the particular potentials. The cyclic 
voltammograms of methanol oxidation are plotted in Figure 41 for various $\mathrm{pH}$, where the characteristic response on $\mathrm{Pt}$ is found in all profiles in similar shape.

Figure 41: Steady state voltammograms of $\mathrm{Pt}$ in $0.4 \mathrm{M} \mathrm{K}_{2} \mathrm{SO}_{4}+1 \mathrm{M} \mathrm{H}_{3} \mathrm{COH}$ of different $\mathrm{pH}$.

a) 0.37 , b) 1.02 , c) 2.04 , d) 3.03 , e) 12.97 , f) 13.76 .

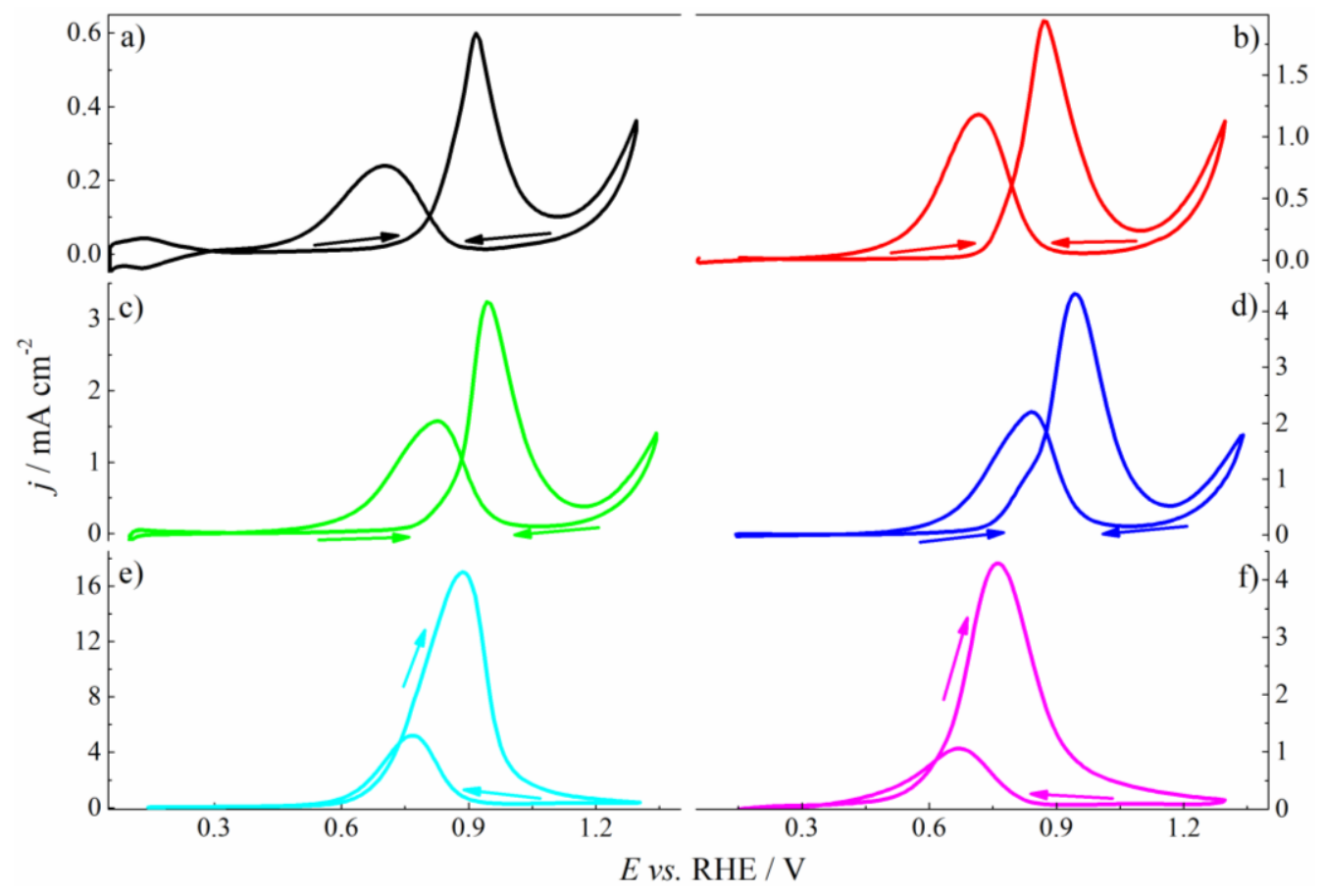

Figure 42: maximum current density in anodic (black squares) and cathodic scan (red circles) vs. bulk solution $\mathrm{pH}$.

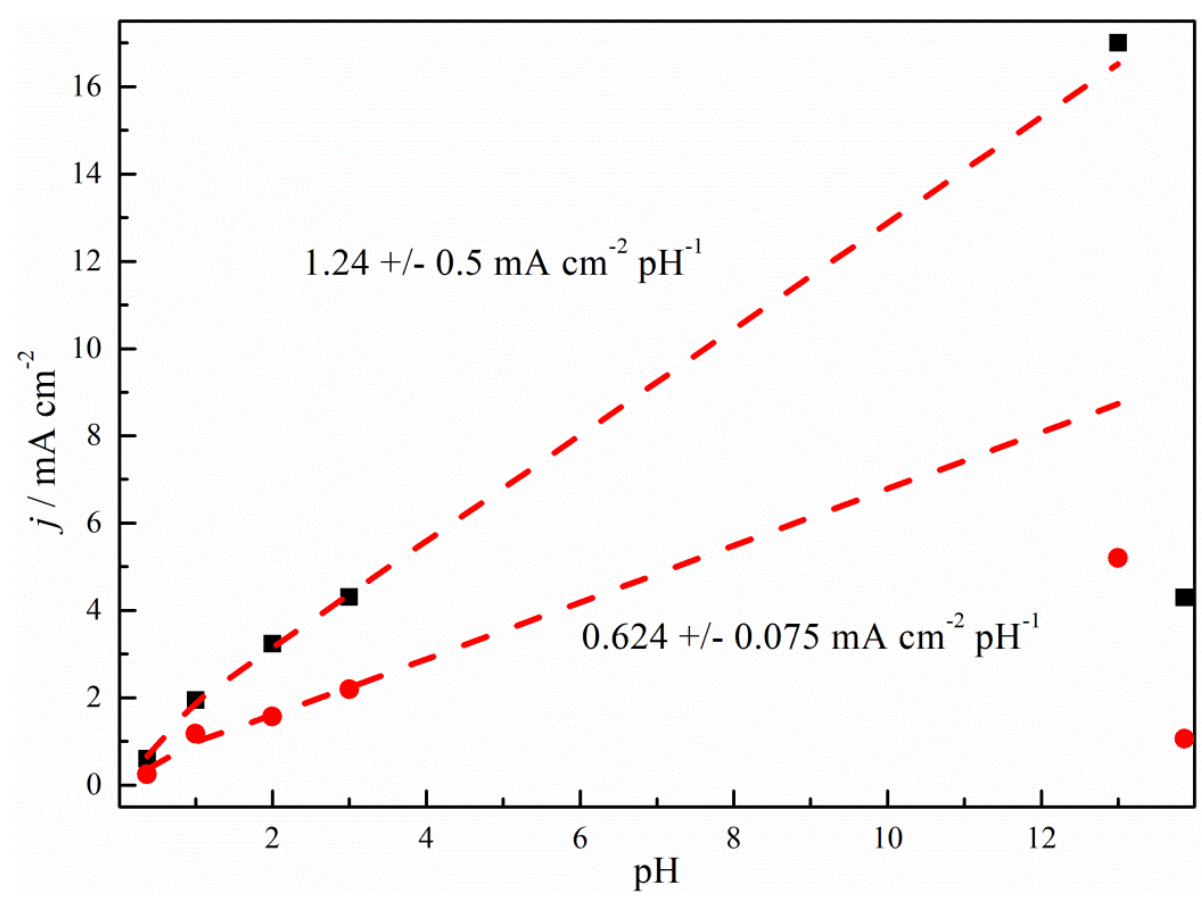


As the different current density scales indicate, methanol oxidation strongly depends on the present bulk solution $\mathrm{pH}$ and increases in activity by two orders of magnitude from $\mathrm{pH} 0$ to 13. This dependence is highlighted in Figure 42, where the maximum current density in both sweeps undergoes a linear ascent of 1.24 and $0.624 \mathrm{~mA} \mathrm{~cm}^{-2} \mathrm{pH}^{-1}$. Just in the most alkaline solution the current density does not fit the behaviour due to the high presence of hydroxide in the electrochemical interface. This dependence is in great contrast to formic acid oxidation (see Figure 30) and suggests significant differences in the oxidation mechanism. The constant increase until $\mathrm{pH} 13$ also points out the great importance of active surface oxides in the methanol oxidation mechanism, which play a crucial role in the removal of strongly adsorbed inhibiting species, but as well in the direct oxidation pathway. For the initial characterization of potential oscillation region of methanol oxidation in dependence on the $\mathrm{pH}$ and temperature galvanodynamic measurements are plotted in Figure 43a) and b). As the graph depicts, the oscillation dynamics are conspicuously more complex than in formic acid oxidation. Meanwhile at the most acidic $\mathrm{pH}$ the existence of instabilities was just slightly visible, potential oscillations were found in the $\mathrm{pH}$ range from 1 to 3 , where the size of the oscillating region $\mathrm{S}_{\mathrm{OSC}}$, the frequency $\mathrm{f}$ and the shape of the oscillation cycle changes continuously. A very significant difference to formic acid oxidation is the fact that the oscillations do not

Figure 43: Galvanodynamic measurements of $5 \mu \mathrm{A} \mathrm{s}^{-1}$ in a) $0.4 \mathrm{M} \mathrm{K}_{2} \mathrm{SO}_{4}+1 \mathrm{M} \mathrm{H}_{3} \mathrm{COH}$ of different $\mathrm{pH}$ at $25{ }^{\circ} \mathrm{C}$, b) $0.5 \mathrm{M} \mathrm{H}_{2} \mathrm{SO}_{4}+2 \mathrm{M} \mathrm{H}_{3} \mathrm{COH}$ in a wide temperature range ( $\mathrm{pH} 0.72$ ).
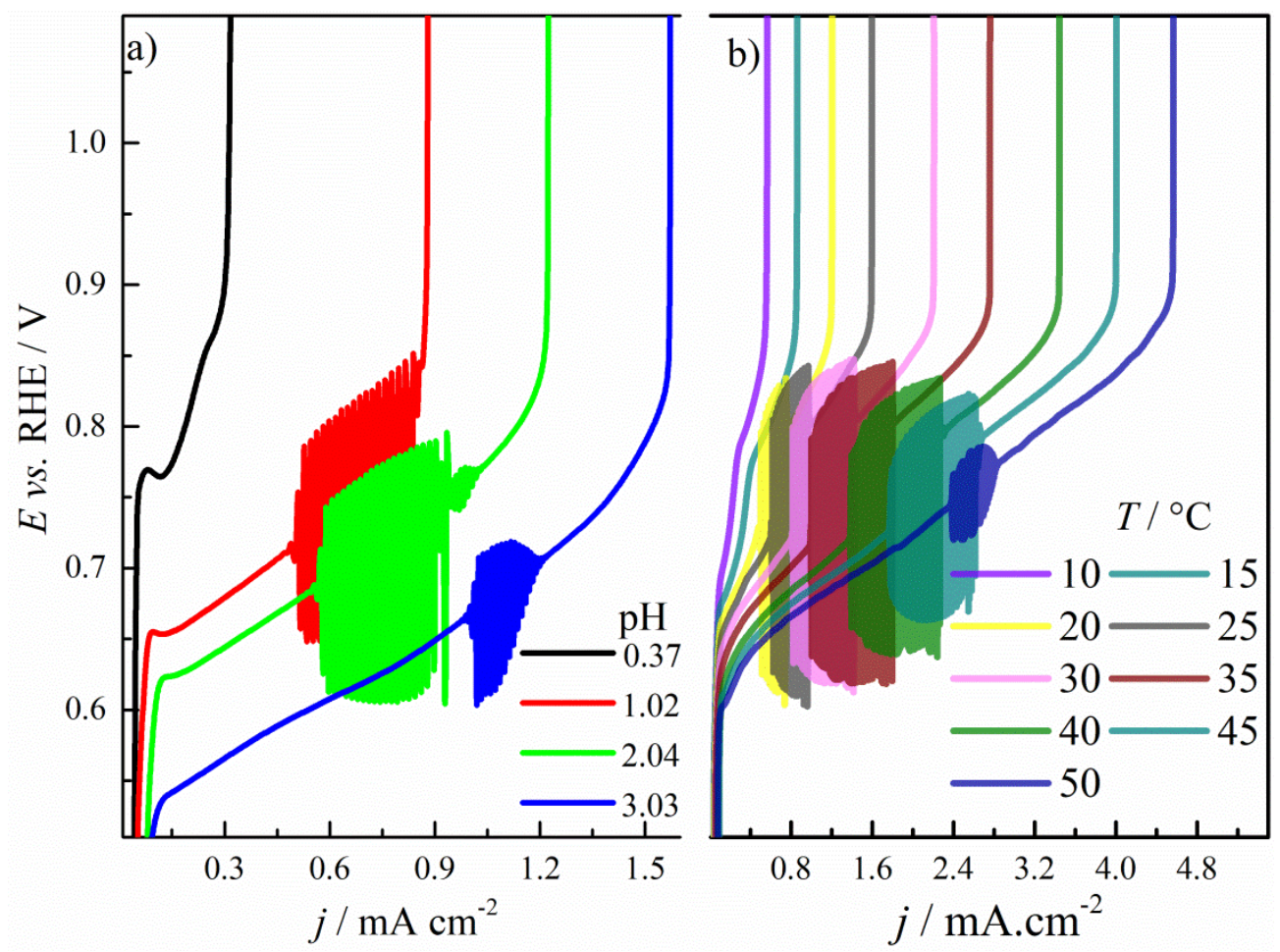
necessarily end by the collision of the limiting cycle with the instable branch of the HN-NDR region and is not followed by the rapid potential increase to the region of oxygen evolution above $1.2 \mathrm{~V}$. Instead the oscillations can also cease by a second supercritical Hopf bifurcation on the stable branch, as it was briefly mentioned in the introduction. In that case, the potential increases steadily until the end of the stable potential region. Since potential oscillations along methanol oxidation occur in the potential range of $\sim 0.5$ to $0.9 \mathrm{~V}$ in various types, which depend strongly on the applied current density chosen and might not appear in the galvanodynamics of Figure 43 due to their slow establishment, the current region in between these potentials was chosen as possible oscillation region for the normalization [82]. All oscillation patterns were found in the temperature range between 10 and $45{ }^{\circ} \mathrm{C}$, the upper limit for the appearance of potential oscillations under the applied conditions, which are plotted in Figure 44. In general, potential oscillations can emerge in a great variety of families, which have been denoted previously as L- and S-type (see section 2.2). The latter is more present and classified in period-n $\left(1^{\mathrm{n}}\right)$ oscillations with $\mathrm{n}$ as the number of subcycles in one period, where along the galvanostatic electro-oxidation of methanol mainly period-1 oscillations emerge and eventually of higher period at the end of the instability region $[101,153,154]$.

Figure 44: Effect of temperature in the galvanostatic electro-oxidation of methanol (normalized current density 0.5). Electrolyte: $0.5 \mathrm{M} \mathrm{H}_{2} \mathrm{SO}_{4}+2 \mathrm{M} \mathrm{H}_{3} \mathrm{COH}$ solution.

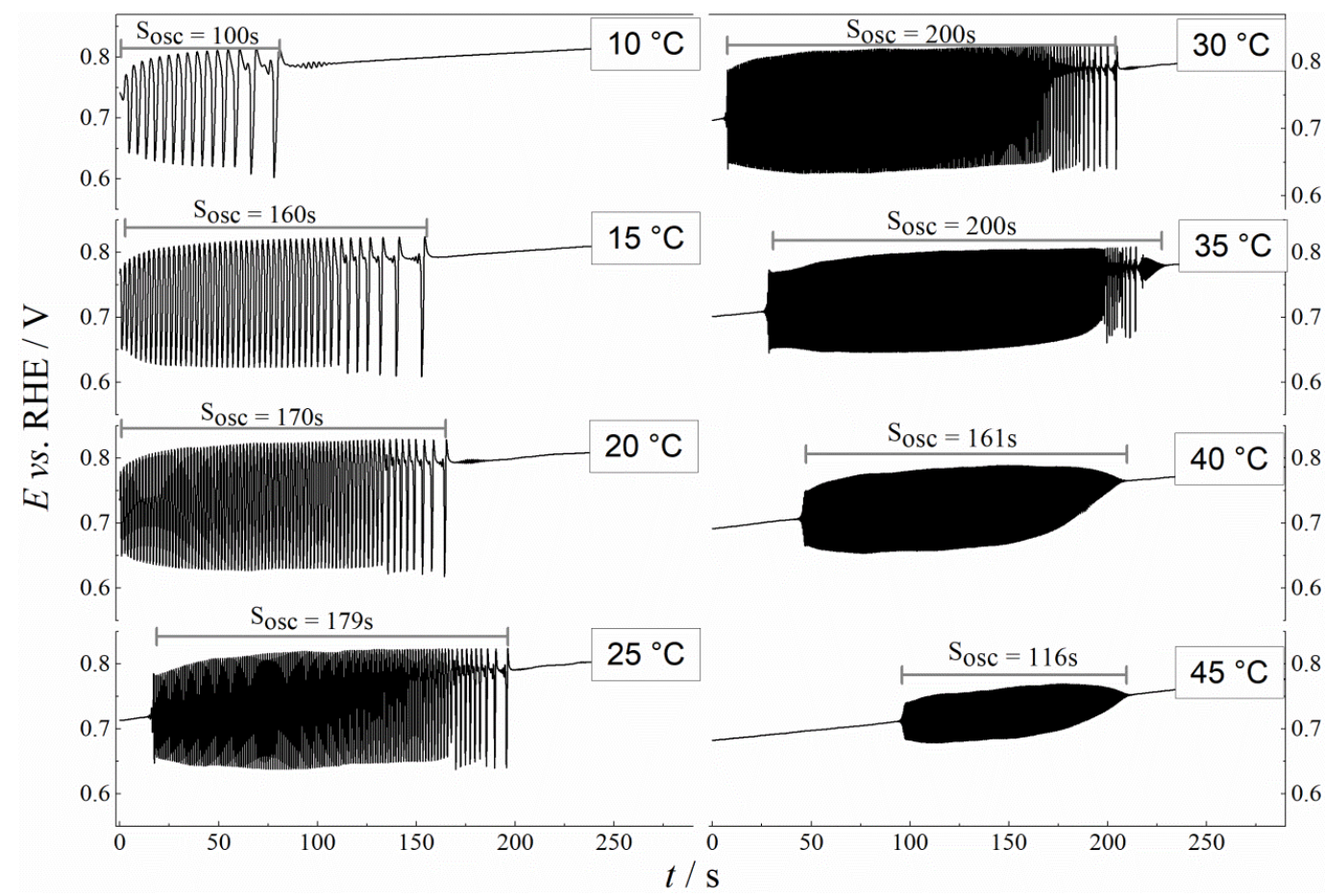


In that way, an increment in the temperature results in a higher frequency in the complete range and longer lasting oscillations until 30 degree. Beyond that distinctive temperature oscillations appear less and of smaller amplitude, which are indications, that the conditions for potential instabilities are diminishing and extinct at $45{ }^{\circ} \mathrm{C}$ under our applied conditions. Further details about the temperature impact are plotted in Figure 45 in the limiting cycles of the rates $\mathrm{d} E \mathrm{~d} t^{-1}$ together with the maximum and minimum values and potentials visited in one distinct, characteristic cycle. Meanwhile the potential limits are barely affected at the low range, $30{ }^{\circ} \mathrm{C}$ is again a crucial temperature, where the maxima and minima converge and confirm the poor conditions for oscillations at high temperatures and their decreasing amplitude. The comparison of Figure 45a) and b) shows, that the cycles become symmetric, what is equal to an improved reversibility, by the shift of the positive maxima to lower overpotentials.

Figure 45: a) and b) rates of $\mathrm{d} E \mathrm{~d} t^{-1}$ as a function of $E$ at different temperatures as indicated; c) upper (upward triangles, $E_{\max }$ ) and lower limits (downward triangles, $E_{\min }$ ) of electrode potential and d) the maximum (upward triangles) and minimum (downward triangles) rates of $\mathrm{d} E \mathrm{~d} t^{-1}$, during the oscillatory electro-oxidation of methanol as function of temperature. Data derived from Figure 44.
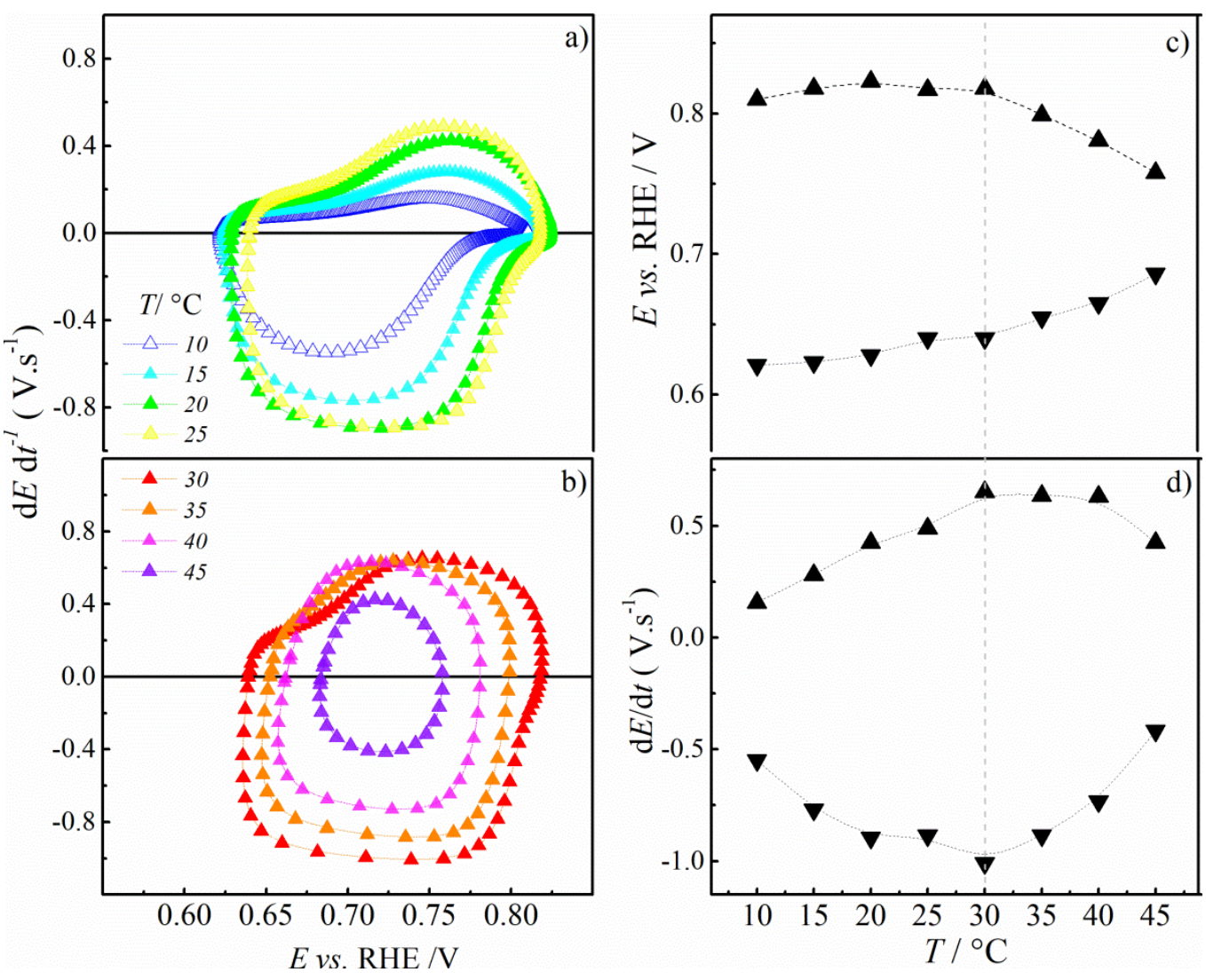
The maximum and minimum rates in the oscillation cycle increase until $30{ }^{\circ} \mathrm{C}$, which is evident for an improving balance of surface poisoning and autocatalytic self-cleaning on the Pt surface. This behaviour can be explained by an increasing activity of all adsorption process, which play a role in the galvanostatic oxidation mechanism of methanol, mainly the formation of carbonaceous adsorbates. Yet, as it is emphasized in Figure 39 , beyond $30{ }^{\circ} \mathrm{C}$ the surface oxidation becomes more important The result is a constant poisoning rate due to the higher coverage of oxides and a sharply declining negative rate, due to the lack of $\mathrm{C}$-species, which get removed effectively in the more active, direct oxidation pathway and do not allow the formation of $\mathrm{CO}_{\mathrm{ad}}$ along the indirect pathway, necessary for the establishment of potential oscillations. Figure 46 compares the temperature effect on $\mathrm{S}_{\mathrm{OSC}}$ and $\mathrm{f}$ together with the maximum current densities for methanol and formic acid oxidation from reference 73.

Figure 46: The effect of temperature on $S_{\text {osc }}$ (full circles), $f$ (full squares) and current densities obtained in voltammetric conditions (forward scan at $0.80 \mathrm{~V}$ vs. RHE) for the (a) the methanol galvanostatic oxidation and (b) formic acid galvanostatic oxidation[8] at $\mathrm{IN}_{\mathrm{N}}=0.5$.

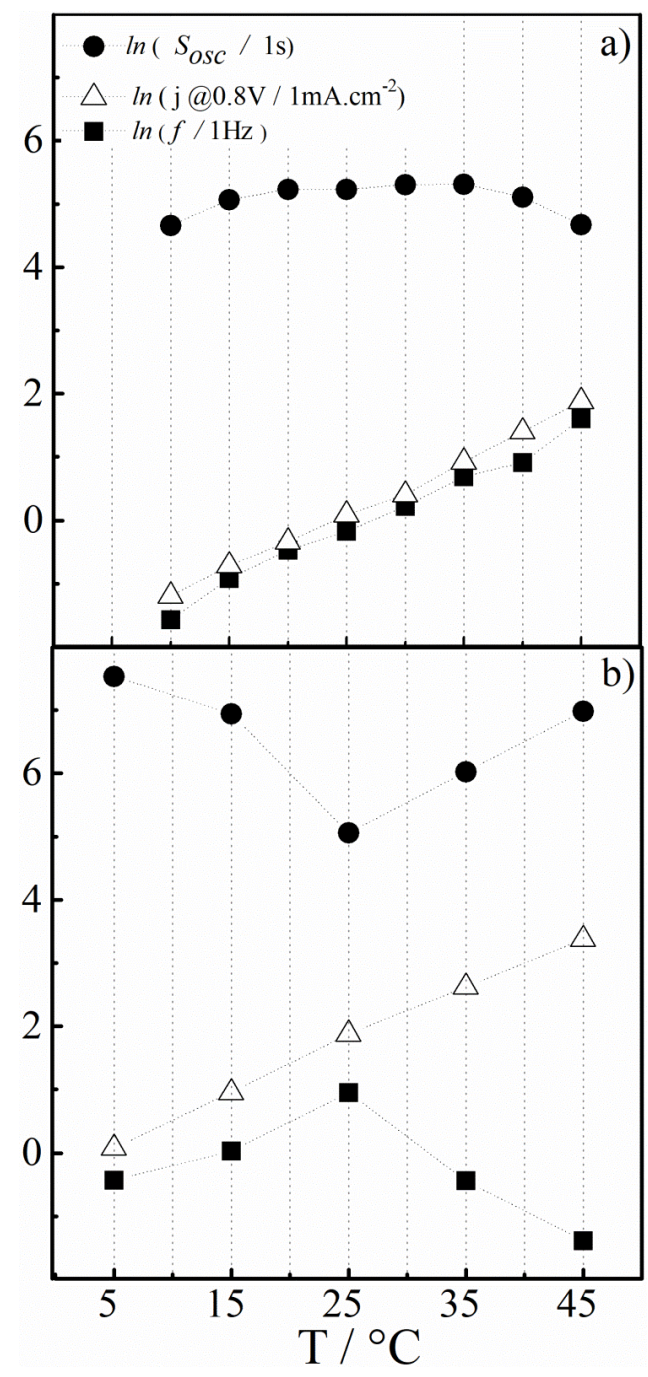


The Figure highlights significant differences between the oscillating oxidation processes, such as lower activity, shorter chronopotentiometric series and smaller activation energy from 5 to $25{ }^{\circ} \mathrm{C}$ and rather independent $\mathrm{S}_{\mathrm{OSC}}$. Yet the most drastic difference is the characteristic (over)compensation along formic acid oxidation, which was attributed to different temperature dependencies of oxide and $\mathrm{CO}$ adsorption on $\mathrm{Pt}$ and the changing impact of the surface deactivation by place-exchange processes [50]. The lack of any compensation along methanol oxidation is even more emphasized by the very similar temperature evolution of voltammetric current and oscillation frequency and apparent activation energies of 63 and 68 $\mathrm{kJ} \mathrm{mol}^{-1}$, which suggests similar rate-determining steps under potentiodynamic and galvanostatic conditions, which is in obvious contrast to formic acid oxidation. This behaviour is related to the fact, that $\mathrm{H}_{3} \mathrm{COH}$ oxidation requires the adaption of an oxygen atom and its previous adsorption in any case and is active in the oxidation of various carbonaceous species to partially oxidized side products, meanwhile in formic acid oxidation is just a reaction partner in the second step of the indirect dehydration pathway. This general fact makes surface oxides rather spectator and inhibiting adsorbate along formic acid and active species in methanol oxidation.

Further studies were carried out on this topic in the oscillating methanol oxidation in dependence on the bulk solution $\mathrm{pH}$, which is plotted in Figure 47 for a normalized current density of 0.5 . As the temperature, the $\mathrm{pH}$ also is an important parameter that determines the existence and characteristics of the potential oscillations in the electro-oxidation of methanol. Thus, the concomitant increment of hydroxide with the $\mathrm{pH}$ also results in a more active surface oxidation, what results in higher frequencies and the disappearance of oscillations before the end of the time series as seen in $\mathrm{pH} 2$ or the complete lack of any oscillation at $\mathrm{pH}$ 3. Differently to formic acid, no potential instabilities were found in alkaline media. Yet, since methanol has a poor acidic character, the concentration profile of methanol/methanoate has the same profile as the water/hydroxide equilibrium and the equivalence point at $\mathrm{pH} 7$, what cannot explain the lack of oscillations at $\mathrm{pH} 3$. On the other hand it conspicuous, that all oscillation parameters as well as their disappearance is very similar to the found dependence of formic acid oxidation, which suggests a crucial role of formic acid/formate in the oxidation mechanism of methanol, whose oxidation may be part of the direct pathway. Very similar results have been reported recently in phosphoric acid, but showed a more complex oscillation pattern, what may be related to the strong competition of phosphates with other species for adsorption sites [155]. 
Figure 47: Potential time series of methanol oxidation in acidic $0.4 \mathrm{M} \mathrm{K}_{2} \mathrm{SO}_{4}+1 \mathrm{M} \mathrm{H}_{3} \mathrm{COH}$ at $25^{\circ} \mathrm{C}$. a) $\mathrm{pH} 0.37$, b) 1.02 , c) 2.04 , d) 3.03 .

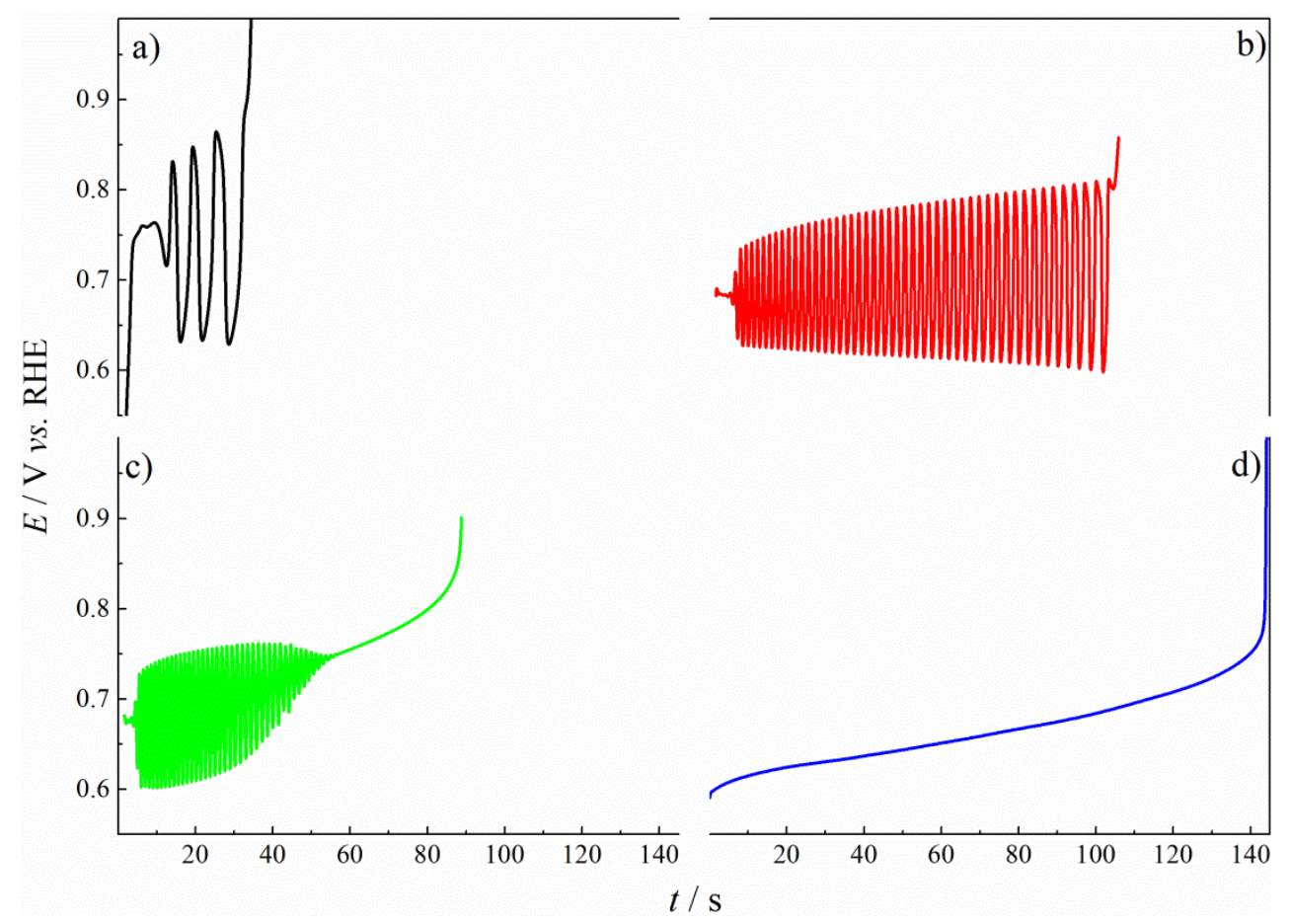

The $\mathrm{dE} / \mathrm{dt}$ profiles of the above time series are plotted against the visited potential in Figure 48. Meanwhile the limiting cycles at $\mathrm{pH} 0$ evolve slowly in time, what suggest barely changing coverages of poisoning species and their removal comparing each cycle, at $\mathrm{pH} 1$ the rates increase fast and constantly (as indicated by the arrows) to their maximum at the end of the time series. In situ ATR-SEIRAS revealed a decline in the $\mathrm{CO}_{\mathrm{ad}}$ coverage in time [47]. Thus, the place-exchange of adsorbed oxides becomes more pronounced in time and may be responsible for the evolving patterns [51]. This behaviour is also found at $\mathrm{pH} \mathrm{2,} \mathrm{that} \mathrm{similar}$ initial conditions in this $\mathrm{pH}$ range can be assumed, but the $\mathrm{dE} / \mathrm{dt}$ values decrease after their maximum and follow the decreasing trend as it was already found in the potential time-series and let anticipate the absence of any potential instability at $\mathrm{pH} 3$. This result can be attributed again to changing conditions in general, not allowing the formation of oscillating behaviour, which is again very similar to formic acid oxidation. It leads to the conclusion, that formic acid is accumulated in the electrochemical interface, may impact the oxidation dynamics and put the direct oxidation pathway in favour. Since formic acid, at pH 2 in higher presence as formate than at $\mathrm{pH} 1$ and 0 , is produced by methanol oxidation at the surface, diffusion effects are less important than it may be the case in a bulk solution of formic acid, that a smaller surface concentration of formate may be sufficient to react via the most active pathway, as it was the case for formic acid oxidation as well. 
Figure 48: dE/dt versus E profiles depicted in Figure 47 for $\mathrm{pH}$ a) 0.37, b) 1.02 and c) 2.04 .

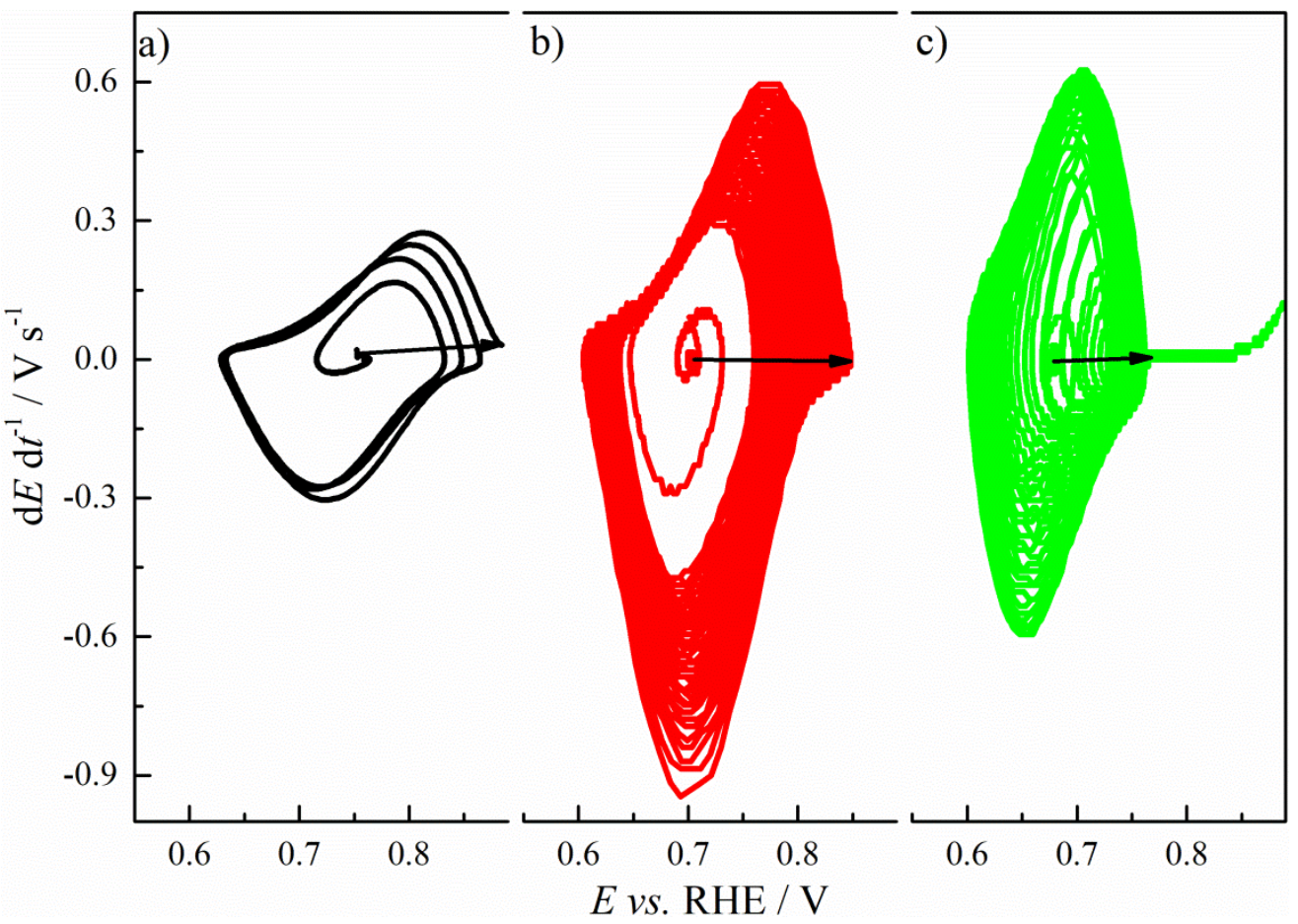

It should be pronounced, that the lack of oscillations was assigned to the oxidation of formate in $\mathrm{C}-\mathrm{H}$-down configuration, which does not form $\mathrm{CO}_{\mathrm{ad}}$ and is oxidized rapidely to $\mathrm{CO}_{2}$ instead. The analysis of the frequencies of all found oscillations along methanol oxidation is shown in Figure 49 on the temperature scale. Firstly it should be noticed, that no indication of any compensation effects was found in methanol oxidation in the studied $\mathrm{pH}$ range, differently to formic acid and the oscillation frequency undergoes a linear increase with the temperature, what emphasizes again the partially different role of oxygenated species in the two oxidation mechanisms. It can also be seen very clearly, that $\mathrm{pH}$ and temperature have a significant effect on the frequency and the existence of pattern formation as well. Thus, oscillations were just found at high and low temperatures in a solution of $\mathrm{pH} 0$ and 2 or 3 , respectively. Yet, in the complete $\mathrm{pH}$ and temperature range a constant increase in the oscillating frequency can be seen, what highlights the importance of diffusion of water for an effective surface oxidation and of methanol in the formation of poisoning adsorbates and active side products. This behaviour differs from the reported results in phosphoric acid solutions, where a decreasing frequency was found independently on the present bulk solution $\mathrm{pH}$. As the authors suggest, a more pronounced impact of a stronger adsorption of phosphates may be the reason for the differences. 
Figure 49: Frequencies of the oscillations of $1 \mathrm{M} \mathrm{H}_{3} \mathrm{COH}$ in solutions of $0.4 \mathrm{M} \mathrm{K}_{2} \mathrm{SO}_{4}$ of $\mathrm{pH}$ 0.3 (black), 1.02 (red), 2.04 (green) and 3.03 (blue) against the temperature. Normalized current density $=0.5$.

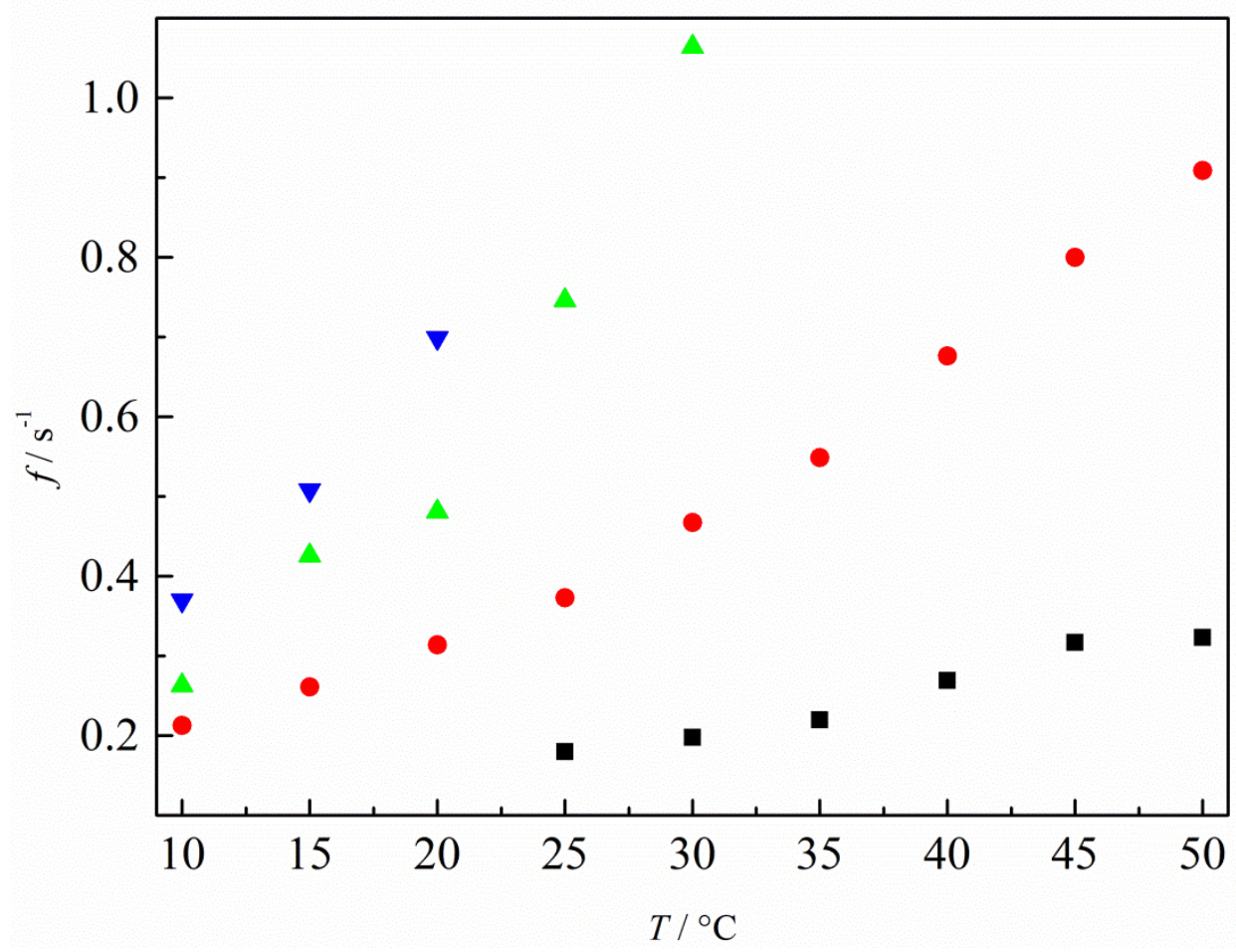

The apparent activation energies derived from peak maxima and oscillation frequencies are summarized in Figure 50. Besides high energies at $\mathrm{pH} 0$, the values are in the range between 30 to $50 \mathrm{~kJ} \mathrm{~mol}^{-1}$, which are in range of reported values ([89] and references in there). The data show a constant incline in anodic scan direction, which was already found for formic acid oxidation in a distinct $\mathrm{pH}$ range and attributed to the more pronounced blockage of surface sites by the enhanced adsorption of oxides. The decreasing energy between $\mathrm{pH} 1$ to 13 for the cathodic scan can be seen in formic acid in the same range between $\mathrm{pH} 0$ to 4 and related to the discussed, mechanistic aspects. It is not surprising, that these similarities appear here again and confirm the afore made interpretations of the important role of formic acid in the electro-oxidation of methanol. The fact, that the activation energy changes slower than for formic acid can be explained by the additional adsorption of other carbonaceous species than $\mathrm{CO}_{\mathrm{ad}}$ and the probably different mechanism of $\mathrm{CO}$ formation. On the other hand the apparent activation energies under oscillating conditions lie below the ones from steady state voltammetry, which is in absolute contrast to formic acid. This fact is again a sign, that the more active surface oxidation far from equilibrium eases the methanol oxidation, since the surface oxides act more as reaction partner than site-blocking species [49]. It should also be 
noticed the smaller erratic behaviour comparing methanol and formic acid oxidation, which may result from the more independent and less susceptible surface coverage on the bulk solution $\mathrm{pH}$ and temperature.

Figure 50: Apparent activation energy for the methanol oxidation $v$ s. bulk solution $\mathrm{pH}$. Data obtained from the maximum currents at in anodic (red circles), and cathodic sweep (black squares) and from the oscillatory frequency (green triangles). Remaining conditions as in

Figure 41.

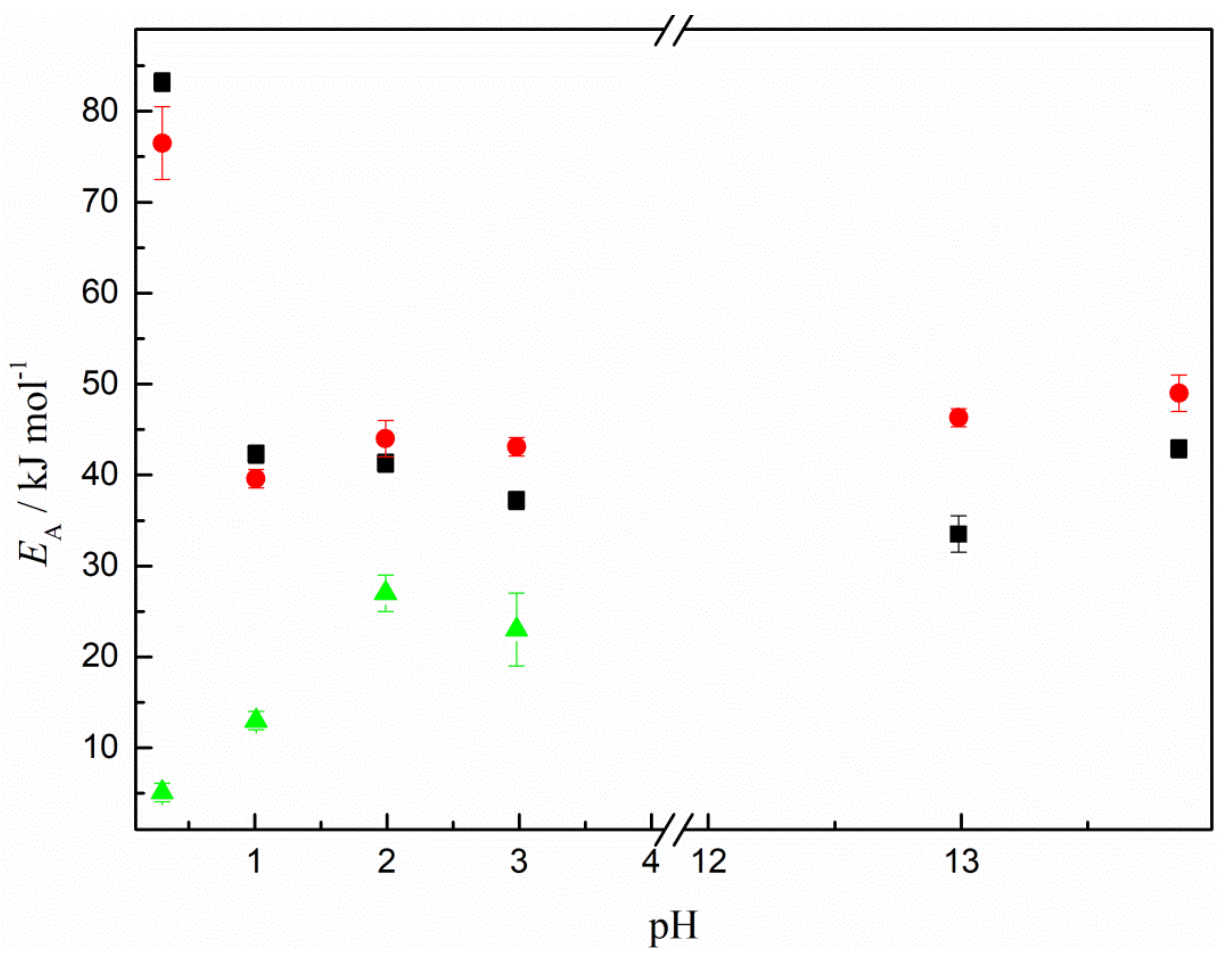

\subsection{Partial Conclusions}

The study of the electro-oxidation of formic acid and methanol in a wide temperature and $\mathrm{pH}$ range allowed a deep analysis of the catalytic response of both mechanisms. Formic acid oxidation showed a $\mathrm{pH}$ dependence which is in good agreement with the literature and indicated mechanistic change around the $\mathrm{pK}_{\mathrm{A}}$ of formic acid. Thus, the same intermediates can be assumed to be present and are found under oscillating and voltammetric conditions, as the following section shows and whose coverage depends on the applied parameters. This fact and the consideration of all obtained results lead to the conclusion, that solvated formate in the solid-liquid phase boundary is the reacting intermediate in the most active reaction pathway of both molecules. Besides a side pathway may be active, which showed a linear $\mathrm{pH}$ 
dependence in acidic solutions, and may take place via the oxidation of bridge-bonded formate. It should be emphasized very much, that all data suggest a very important role of these pathways along methanol oxidation. These conclusions are supported by the $\mathrm{pH}$ dependent oscillation regime, which are limited to acidic solutions with a $\mathrm{pH}$ smaller than the $\mathrm{pK}_{\mathrm{A}}$, where $\mathrm{CO}$ adsorption plays a major role. The similar $\mathrm{pH}$ dependence of the activation energies in acidic solutions draw that conclusion as well. On the other hand, steady state voltammetry also depicted significant differences, such as the lack of oscillation patterns in alkaline media along methanol oxidation and the different dependence of the potentiodynamic profiles in basic solutions. This fact must be clearly related to the different role of surface oxides, which are obligatory for methanol oxidation to $\mathrm{CO}_{2}$ via direct and indirect pathway, meanwhile a successful formic acid oxidation does not require a reaction partner. Consequently, oxygenated species are just necessary to oxidize $\mathrm{CO}_{\mathrm{ad}}$ to allow an efficient direct pathway of formic acid oxidation. Due to the diminishing presence of $\mathrm{CO}$ at $\mathrm{pH}>3$, the character of surface oxides changes to an exclusively inhibiting adsorbate in that system. Yet, questions remains, like the origin of the newly found oscillation dynamics of formate oxidation in strongly alkaline solutions, which take place under the high coverages of $(\mathrm{H})_{\mathrm{x}} \mathrm{O}$ and low presence of $\mathrm{CO}_{\mathrm{ad}}$ or $\mathrm{HCOO}_{\mathrm{B}}$. 


\section{Potentiostatic}

impedance spectroscopy

In this chapter formic acid and methanol oxidation on Pt were studied in solutions of $\mathrm{pH} 1$ and 13 by electrochemical impedance spectroscopy. In general the data confirmed the different dependence of formic acid and methanol on the $\mathrm{pH}$ and the concluded, different mechanistic aspects. 


\subsection{Introduction}

Generally, impedance spectroscopy is a powerful technique to study the electrical properties of the charge flow in solid and liquid materials and their interface [156]. Basic contributions were introduced for electronic circuits by Nyquist and Bode and extended to electrochemical systems by de Levie et al. [157-159]. Although Koper et al. could apply electrochemical impedance spectroscopy for the stability analysis in electrochemical systems, few works have been published about the study of the potential region of the HN-NDR and oscillations of formic acid and methanol oxidation [42,160,161]. A electrochemical impedance spectra (EIS) of the electro-oxidation of formic acid and methanol can be found in $[148,162]$ and references in there, where Harrington and co-workers could relate mechanistic elements to the equivalent circuits in a wide potential range including the HN-NDR region. A direct comparison of the oxidation of formic acid and methanol has been performed by Wang et al., reporting different, potential dependent rate-determining steps and mechanisms [149]. The following sections show the detailed study of EIS in at distinct potentials in the oscillating regime of formic acid and methanol and in a wide $\mathrm{pH}$ range.

\subsection{Formic acid oxidation}

Steady state voltammograms of formic acid oxidation at $\mathrm{pH} 1$ and 13 on $\mathrm{Pt}$ are plotted together with the potentiostatic impedance spectra in the insets at various potentials in Figure 51 , indicated by the arrows. It was found, that spectra at more negative potentials than the peak maximum show a semicircle with initially first quadrant behaviour tending to the second quadrant, as the frequency increases. This result can be attributed to the availability of free surface sites, where the dehydrogenation of formic acid can take place and manifests itself in a positive slope in the voltammogram until $0.5 \mathrm{~V}$, which is in agreement with the literature [162]. Yet differently to Harrignton and co-workers, who reported an increasing current until the peak maximum, the profile passes a maximum and a decreasing current until the main oxidation peak [162]. Formic acid oxidation depends on many applied parameters, which may be responsible, that the exact profile differs in that point. All impedance spectra demonstrate a very similar semicircle in this potential range, which tends more rapidly to the second quadrant, as the potential approximates the main anodic oxidation peak, that no significant changes in the electrochemical interface can be assumed in that potential region. Since higher 
frequency cause a faster response in the system, adsorption processes overcome slower oxidation reactions, that in that case $\mathrm{CO}$ and $\mathrm{H}_{2} \mathrm{O}$ coverages increase blocking active Pt sites. Thus, the flip to the second quadrant is not surprising, establishing a negative impedance. It is a clear sign for the $\mathrm{HN}-\mathrm{NDR}$ region, where the potential dependent adsorption of $\mathrm{H}_{2} \mathrm{O}$ is responsible and hidden by the concomitant $\mathrm{CO}$ adsorption. On the positive side of the main oxidation peak of formic acid oxidation in presence of a highly oxidized Pt surface the semicircle flips back to the first quadrant also entering the fourth quadrant suggesting the influence of an inductor, which has been reported previously as well [162]. The same features for $\mathrm{pH} 1$ in Figure 51a) are plotted for $\mathrm{pH} 13$ in Figure 51b). As the insets show, all impedance spectra are dominated by positive resistance, revealing a tendency to the second quadrant at the lowest potentials studied. Thus, the existence of the hidden HN-NDR and the presence of $\mathrm{CO}_{\mathrm{ad}}$ is indicated by these results as well, but playing a minor role as discussed above.

Figure 51: Steady state voltammogram of $\mathrm{Pt}$ in $0.4 . \mathrm{M} \mathrm{K}_{2} \mathrm{SO}_{4}+0.2 \mathrm{M} \mathrm{HCOOH}$ with impedance spectra carried out under potentiostatic conditions at the indicated potentials. $\mathrm{pH}$ a) 1.01, b) 13.05 .
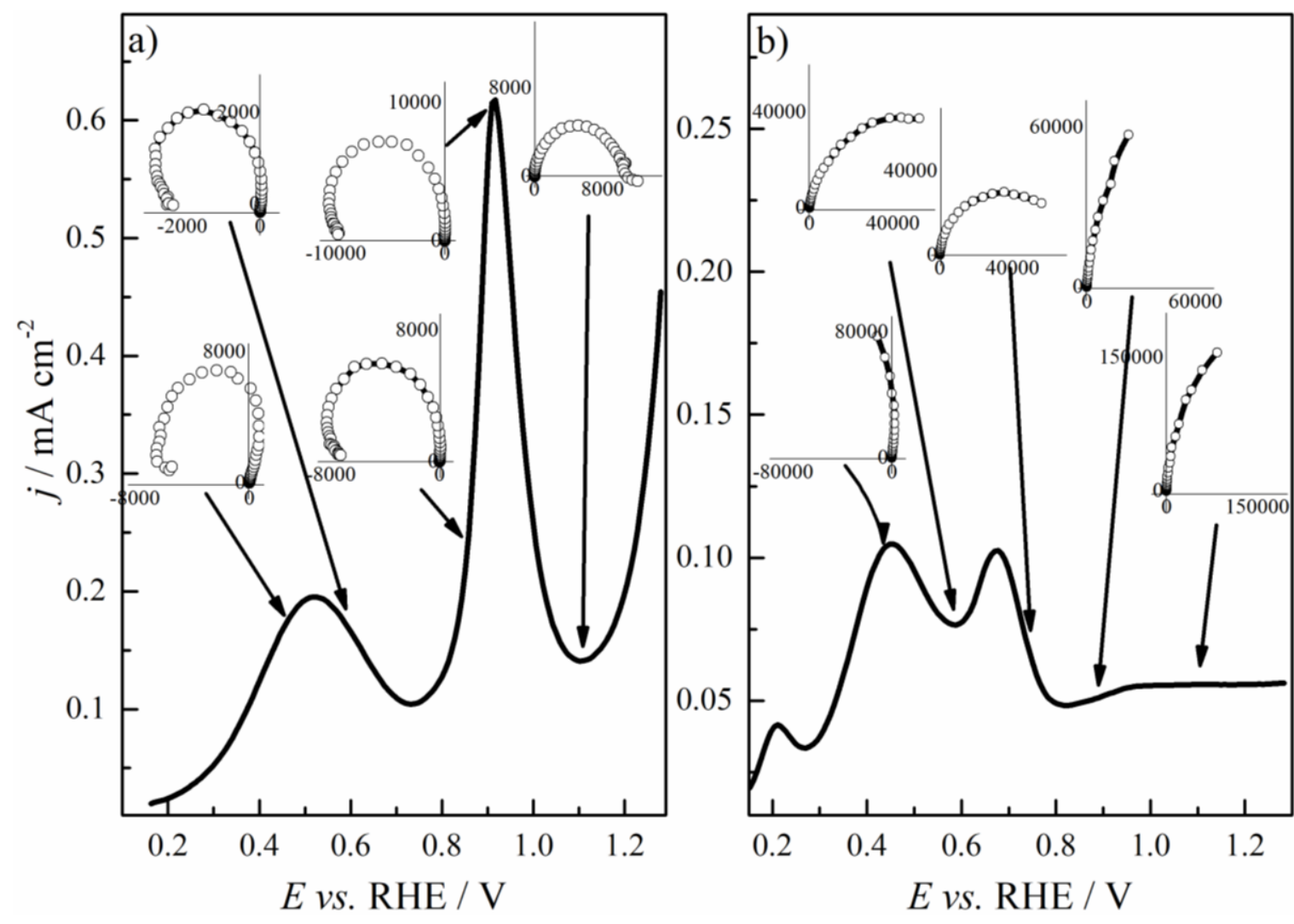
As the potential increases, the spectra remain solely in the first quadrant with no tendency to the second one. This fact is in very good agreement to the found galvanostatic profiles in alkaline media, plotted in Figure 34e) and f), where formic acid oxidation undergoes instable pattern formation in at potentials between 0.2 and $0.5 \mathrm{~V}$. Additionally to that, the $\mathrm{pH}$ dependent voltammetric formic acid oxidation showed significant changes in activity and a transition in the anodic sweep, as well as the ceasing of oscillation patterns, which must be related to that (see Figure 30 and 34).

\subsection{Methanol oxidation}

As Seland et al. reported for methanol oxidation, the impedance spectra can scatter and change the quadrant due to erratic behaviour, which is found in our data as well. Yet, the spectra seem in agreement and show a reasonable tendency [148]. Thus, on the cathodic side of the oxidation peak, all spectra show first quadrant behaviour and may enter the fourth, again indicating the influence of an inductor. In the anodic branch of the oxidation peak, the spectra were found to flip to the second quadrant until the oxide coverage plays a dominant role above 1 V [148]. Surprisingly, no negative impedance could be found, although it could be expected, since methanol oxidation is known to undergo potential oscillations in this potential range and also includes a HN-NDR region. Yet, as mentioned, in this potential region a non-negligible error may occur, that an entry of the spectra is possible, but cannot be seen in all experiments [148]. At $1.1 \mathrm{~V}$ the impedance turns back to positive values, which is also the case for our data. The same data, carried out in alkaline media, show very similar results to acidic media, which is again in great contrast to formic acid and can be explained by the above made conclusions. On the other hand, the spectra at mid potentials demonstrate the negative impedance as well, confirming the existence of a $\mathrm{HN}-\mathrm{NDR}$, propably more pronounced at $\mathrm{pH} 13$ due to the more active reactions by one order of magnitude, suggesting the possibility of potential oscillations under that conditions, which were not found in any chronopotentiogram of methanol oxidation in alkaline solutions. Since the impedance appears to be instable and potential oscillations were found to be susceptible for any change in the applied conditions, it could be possible, that the potential instabilities could not be meet due to not suitable parameters, like current density or $\mathrm{pH}$. The Comparison of the impedance spectra of formic acid and methanol oxidation has already been reported previously, which revealed significant contrast due to different rate determining steps, labelling formic acid 
oxidation as the more active reaction [149], which could be reproduced in these studies (see Figure 51 and 52).

Figure 52: Steady state voltammogram of Pt in $0.4 . \mathrm{M} \mathrm{K}_{2} \mathrm{SO}_{4}+0.2 \mathrm{M} \mathrm{HCOOH}$ with impedance spectra carried out under potentiostatic conditions at the indicated potentials. $\mathrm{pH}$ a) $1.01, \mathrm{~b}) 13.05$.
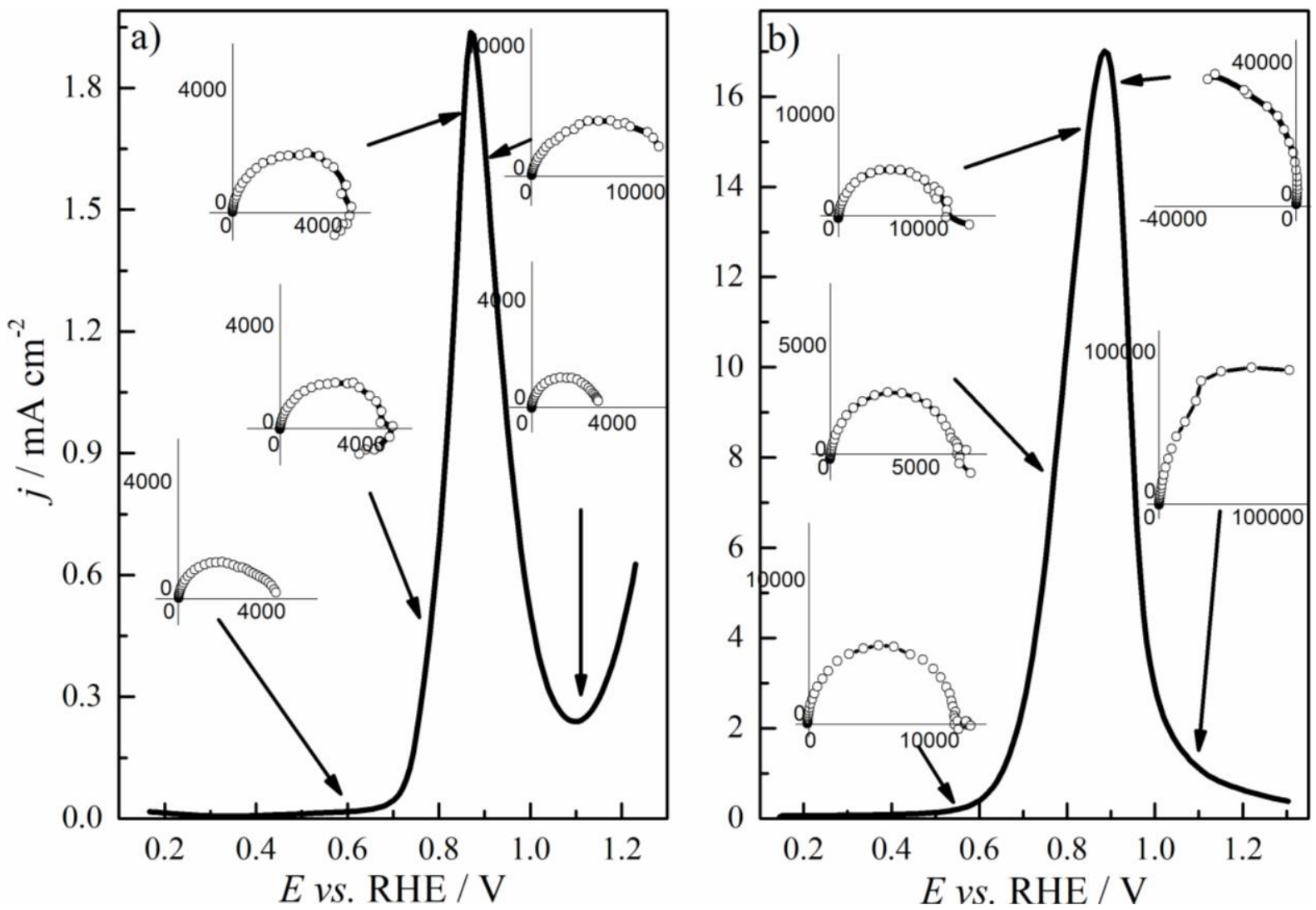

Yet, their existence, as it was the case for formic acid oxidation may be possible in the $\mathrm{pH}$ range above 14. The $\mathrm{pH}$ dependent impedance spectra at 0.9 and $1.1 \mathrm{~V}$ in Figure 53 also suggest that possibility.

\subsection{Partial conclusions}

As Wang et al. found, the electrochemical impedance spectra of formic acid and methanol oxidation demonstrate important differences [149]. Seland et al. attributed these results to the importance of two species in formic acid oxidation, namely $\mathrm{CO}_{\mathrm{ad}}$ and surface oxides, meanwhile the formation of $\mathrm{CO}$ is the rate-determining process in methanol oxidation $[148,162]$. Since the afore displayed spectra could reproduce the reported behaviour, the made 
conclusions can be assumed to be valid in this work as well. The spectra following the found dependence of formic acid and methanol oxidation under voltammetric and galvanostatic conditions and the interpretation from the literature confirming the drawn ones above in good agreement are other signs for the accuracy. Consequently, the changes in the spectra due to the bulk solution $\mathrm{pH}$ can be related to the $\mathrm{pH}$ dependent formation of $\mathrm{CO}$ and $(\mathrm{H})_{\mathrm{x}} \mathrm{O}$, which have already explained the ceasing of potential oscillations at $\mathrm{pH} 3$ and the significant changes of the activity for the oxidation of both molecules. 


\section{ATR-SEIRAS and differential reflectance}

In this chapter are discussed the simultaneously recorded ATR-SEIRA and differential reflectance spectra along the galvanostatic oxidation of formic acid on Pt. The data reveal a complex dependence of formic acid oxidation on all surface process taking place in the electrochemical interface, namely the three indicated pathways and the adsorption of the active intermediates and their precursors, anion adsorption and the formation of surface oxides. 


\subsection{Introduction}

As it was mentioned in the introduction, in situ infrared spectroscopy is a powerful technique to probe the present species absorbed on the surface and the electrochemical interface, which fit in the selection rules (see for example [163] and references in there). Yet, most of the studies were carried out by an infrared reflection spectroscopy. This technique uses an electrochemical cell in a thin layer configuration with a electrolyte of $10 \mu \mathrm{m}$ to avoid any contributions of the solution in the spectra as much as possible. In that case diffusion and other mass transport processes are limited and can cause misleading conclusions in the data analysis [163]. Such limitations can be decreased by performing measurements in a cell in attenuated total reflection configuration. The infrared photons are reflected on the opposite side of the surface, which is deposited on a silicon prism (see Figure 23). Diffusion limitation can also be cut off by applying a flow cell, as it has been reported by Behm and co-workers, which allows an uninfluenced diffusion of reactants, solution species and (by-)products from and to the surface $[68,80]$. It also has to be considered, that this setup is less sensitive to reactive intermediates and has a non-negligible effect on the oxidation of methanol and formic acid. Since the present study focused on a free mass transport and high sensitivity, a stationary bulk solution was preferred. It is well established, that bridge-bonded formate and $\mathrm{CO}_{\mathrm{ad}}$ are found in the IR spectra as adsorbates in formic acid and methanol oxidation, which may have a crucial role in the oxidation mechanism, as discussed above $[26,47,66,72,76,80,81,164]$. Recent literature also mentioned monodentate formate adsorbed on the surface as possible active intermediate, which could not be detected or cannot be differentiated from $\mathrm{HCOO}_{\mathrm{B}}[59,69,73]$. It should also be noted, IR spectroscopy is less sensitive regarding the detection of solution species like adsorbed anions and adsorbed oxygenated species, which can be better analysed by differential reflectance spectroscopy [165-173], but has not been studied under oscillating conditions far from equilibrium to the best of our knowledge. Thus, the influence of the two latter species can be studied in the potential oscillation regime, to find further information on the impact of these adsorbates on in the reaction network of the electro-oxidation of formic acid. 


\subsection{Formic acid oxidation under potentiodynamic conditions accompanied by differential reflectance spectroscopy}

Figure 53 displays the steady state voltammograms of formic acid oxidation in a) sulphuric acid and b) perchloric acid in the well-known profile, respectively, together with the corresponding differential reflectance. As the data clearly show, the reflectance varies around a constant baseline in the low overpotential range and decreases drastically in the potential region, where the surface oxidation is the dominant process. It should also be noted, that the reflectance in sulphuric acid already shows the decline $\sim 0.1 \mathrm{~V}$ earlier than in perchloric acid, which is a clear sign for the influence of sulphate adsorption on the reflective response of the Pt surface. In backward scan direction the reflectance remains low until $\sim 0.9 \mathrm{~V}$ in both electrolytes, where the lifting of the oxide layer takes place, followed by a steep incline to the baseline. The level of the baseline may deviate slightly due to changes in the surface morphology caused by place-exchange processes, but will not be further discussed in here.

Figure 53: Steady state voltammograms of Pt(111) single-crystal disk (black) and the simultaneously recorded differential reflectance on the $\mathrm{Pt}(111)$ surface in a) $0.5 \mathrm{M} \mathrm{H}_{2} \mathrm{SO}_{4}+1$

$\mathrm{M} \mathrm{HCOOH}$ and b) $0.5 \mathrm{M} \mathrm{HClO}_{4}+1 \mathrm{M} \mathrm{HCOOH}$.
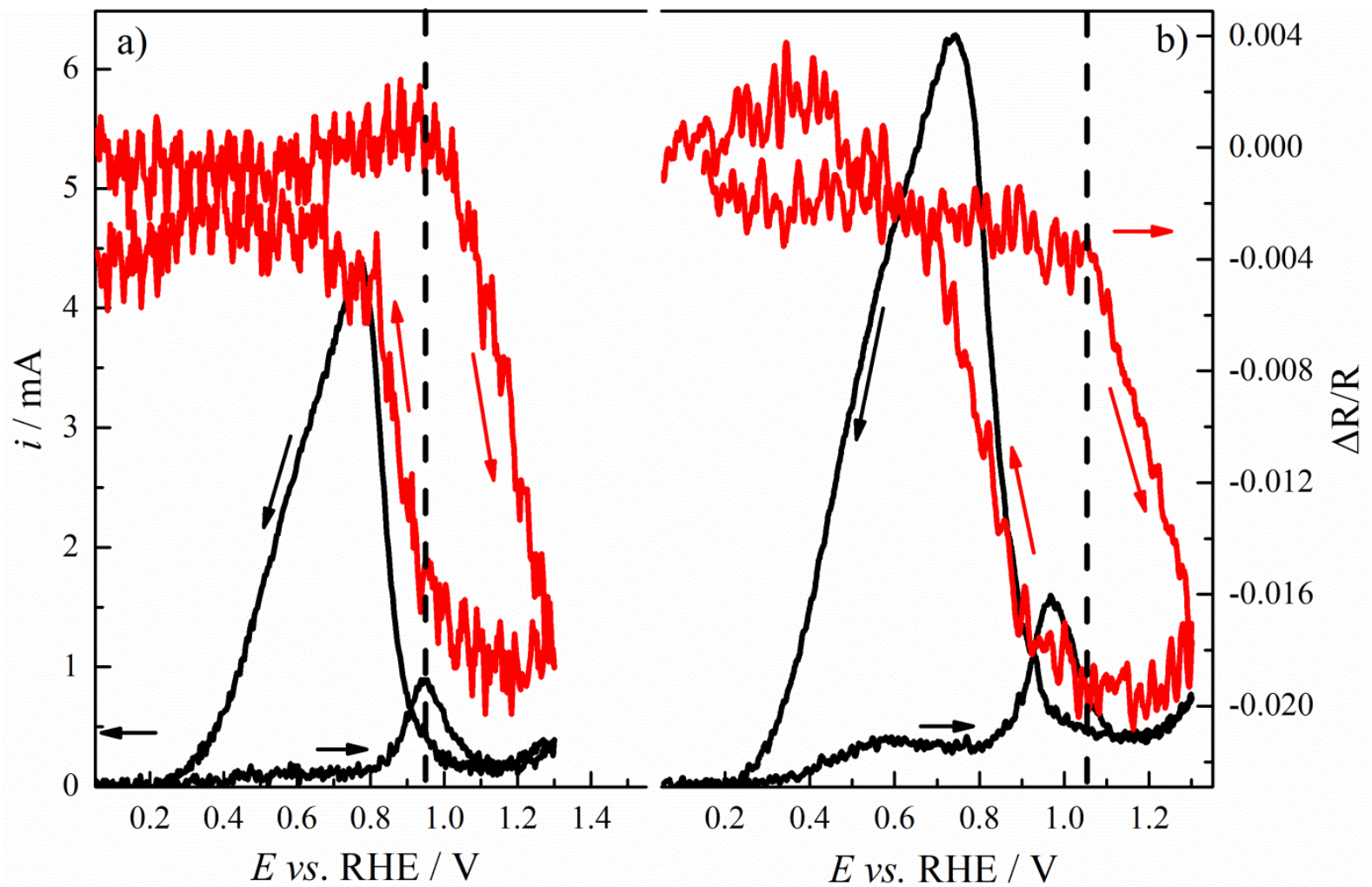
Concluding, no other surface processes than sulphate and oxide adsorption have an effect and formic acid oxidation and $\mathrm{CO}$ formation have no influence on the reflectance, which is in good agreement with the literature and highlights the advantage over IR spectroscopy. Yet, the latter processes have a potential dependent influence on the coverage of sulphate and $(\mathrm{H})_{\mathrm{x}} \mathrm{O}$, which was studied in chronopotentiometry and will be discussed in the following together with the ATR-SEIRAS data in acidic solution.

\subsection{Oscillating surface coverages of $\mathrm{CO}, \mathrm{HCOO}_{\mathrm{B}}$, surface oxides and adsorbed sulphate at acidic pH along the galvanostatic formic acid oxidation}

Figure 54: Potential oscillation pattern of formic acid oxidation on a Pt single-crystal disk immersed in $0.3 \mathrm{M} \mathrm{K}_{2} \mathrm{SO}_{4}+0.1 \mathrm{M} \mathrm{H}_{2} \mathrm{SO}_{4}+0.4 \mathrm{M} \mathrm{HCOOH}$ for an applied current of a) $1 \mathrm{~mA}$ $\mathrm{cm}^{-2}$, b) $2 \mathrm{~mA}$ and c) $2.5 \mathrm{~mA}$ and the simultaneously recorded relative change in the reflectance of the $\operatorname{Pt}(111)$ face at $\lambda=250 \mathrm{~nm}$.

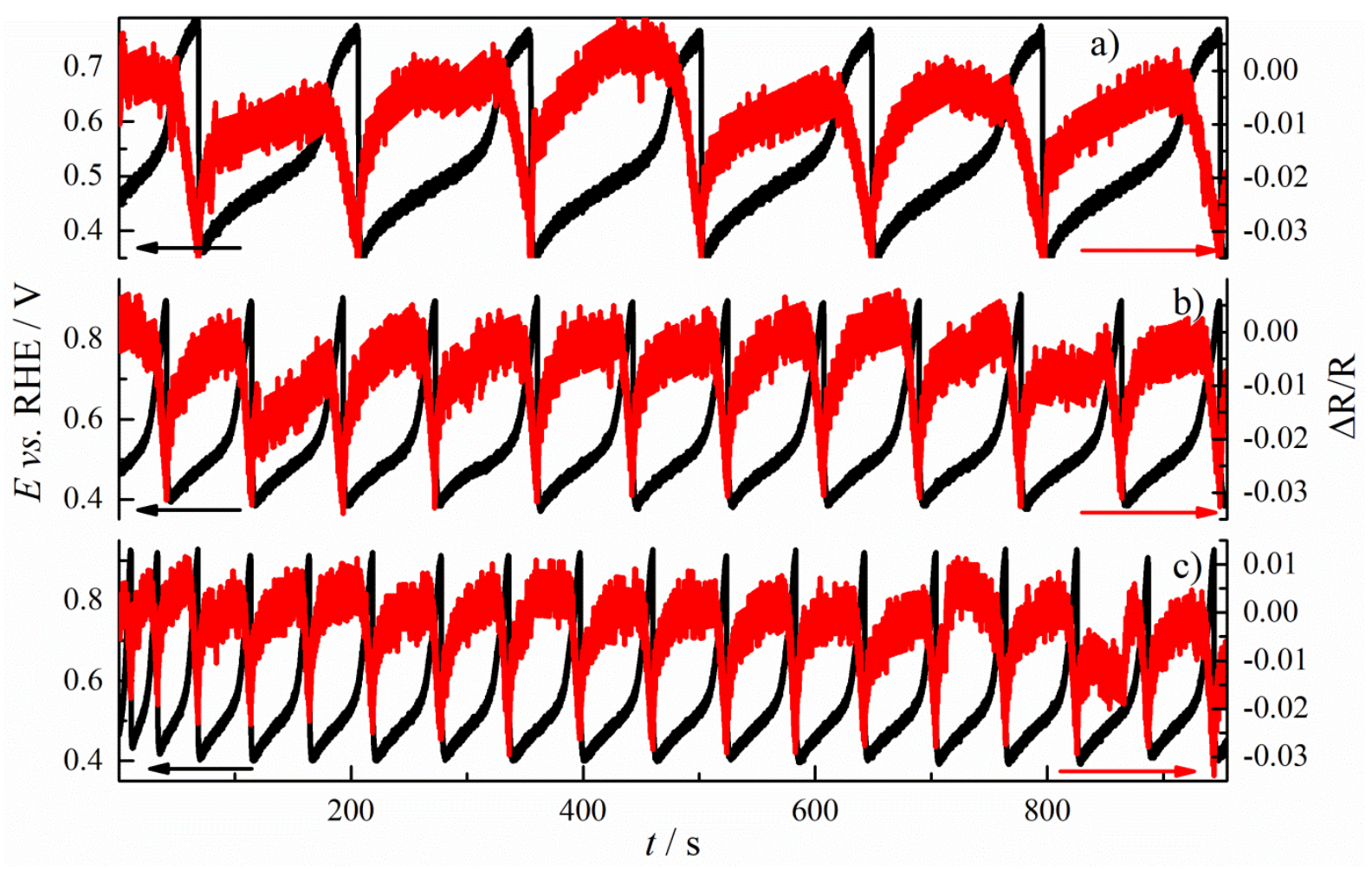

The potential time series of a solution of $0.4 \mathrm{M} \mathrm{HCOOH}$ in $0.5 \mathrm{M} \mathrm{H}_{2} \mathrm{SO}_{4}$ and an applied current of $1 \mathrm{~mA}, 2 \mathrm{~mA}$ and $2.5 \mathrm{~mA}$ are plotted together with the simultaneously recorded reflectance of the $\operatorname{Pt}(111)$ plane of the disk electrode in Figure 54a), b) and c), which was 
used for the sake of simplicity, respectively. The graph shows a perfect overlap of a drop in the differential reflectance with the potential increase in each oscillation cycle. A deep insight in one oscillation cycle of the series of $2 \mathrm{~mA}$ is given in Figure 55, which emphasizes the synchronous changes of potential and reflectance. Thus, it can be clearly seen, that the reflectance drops after the initial potential increase, where the Pt surface is mostly covered by $\mathrm{CO}_{\mathrm{ad}}$, to the minimum. The reflectance minimum coincides with the potential maximum, where the adsorbed oxides and specially sulphate are very present as well. The following potential decrease is very steep, meanwhile the reflectance changes slower. This can be seen in particular in the inset, where the derivative of the differential reflectance is plotted together with the potential oscillation cycle.

Figure 55: Expanded scale of Figure 54b) between 600 and 700 s. The inset shows a potential oscillation (black) and the derivative of the synchronous reflectance oscillation (red).

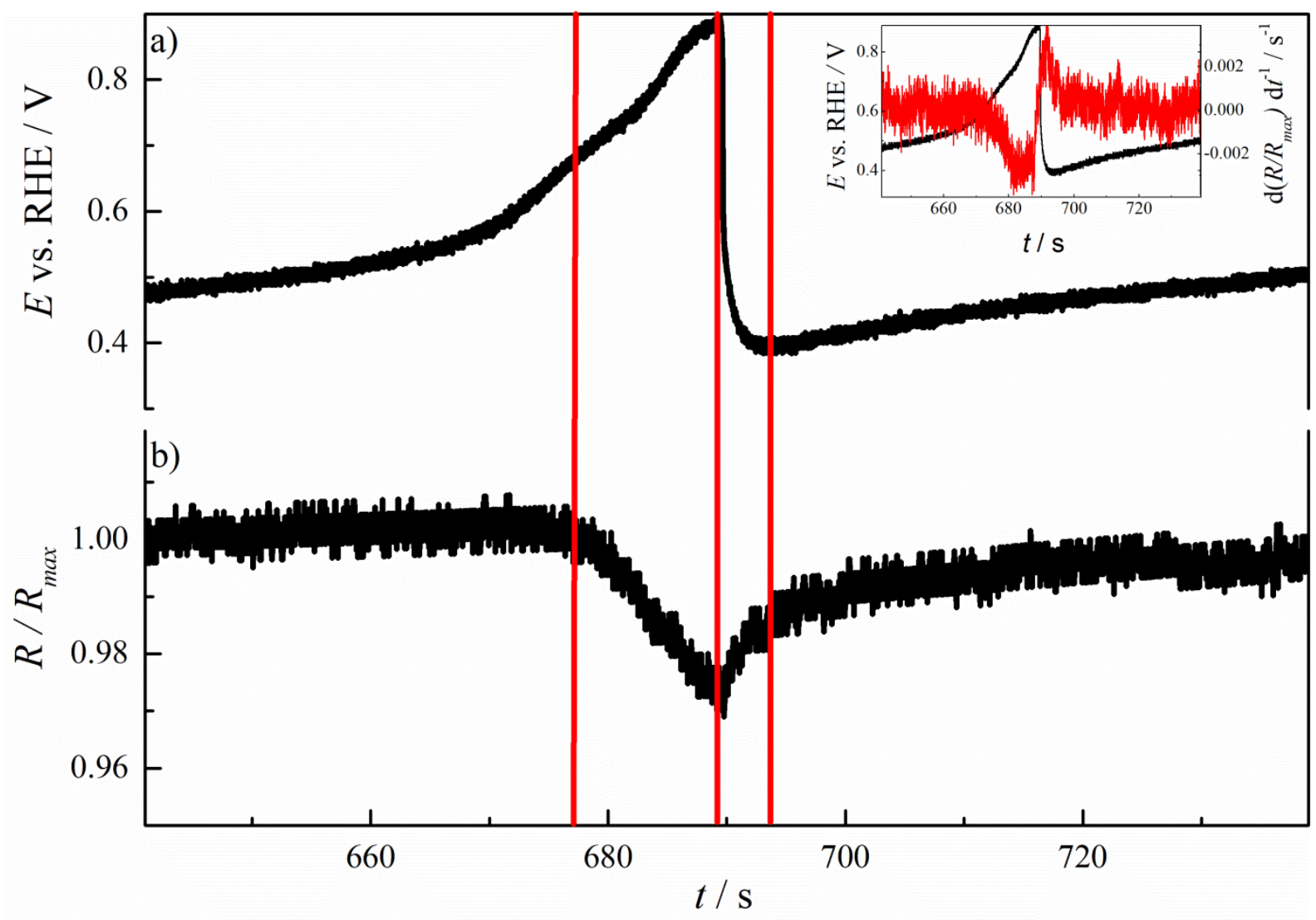

Figure 56 shows typical ATR-SEIRA spectra carried out along the time series at distinct points of the potential cycle, as indicated. As it was previously found by Samjeské et al., $\mathrm{CO}_{\mathrm{ad}}$ and $\mathrm{HCOO}_{\mathrm{B}}$ are the only detected species on the surface related to formic acid oxidation and oscillate in dependence on the potential along the chronopotentiometric time series (see [81] and references in there). The derived spectra in Figure 56 are in good 
agreement to their publications. Figure 57 demonstrates a complete chronopotentiogram together with the simultaneously measured band intensities of linear adsorbed $\mathrm{CO}\left(\mathrm{CO}_{\mathrm{L}}\right)$ at $2070 \mathrm{~cm}^{-1}$ and $\mathrm{HCOO}_{\mathrm{B}}$ at $1320 \mathrm{~cm}^{-1}$, which clearly show the changing intensities of both species during every potential oscillation.

Figure 56: Typical SEIRA spectra of $0.3 \mathrm{M} \mathrm{K}_{2} \mathrm{SO}_{4}+0.1 \mathrm{M} \mathrm{H}_{2} \mathrm{SO}_{4}+0.4 \mathrm{M} \mathrm{HCOOH}$ on Pt carried out at $364 \mathrm{~s}$ (red) $367 \mathrm{~s}$ (red) of the chronopotentiogram as indicated in the inset.

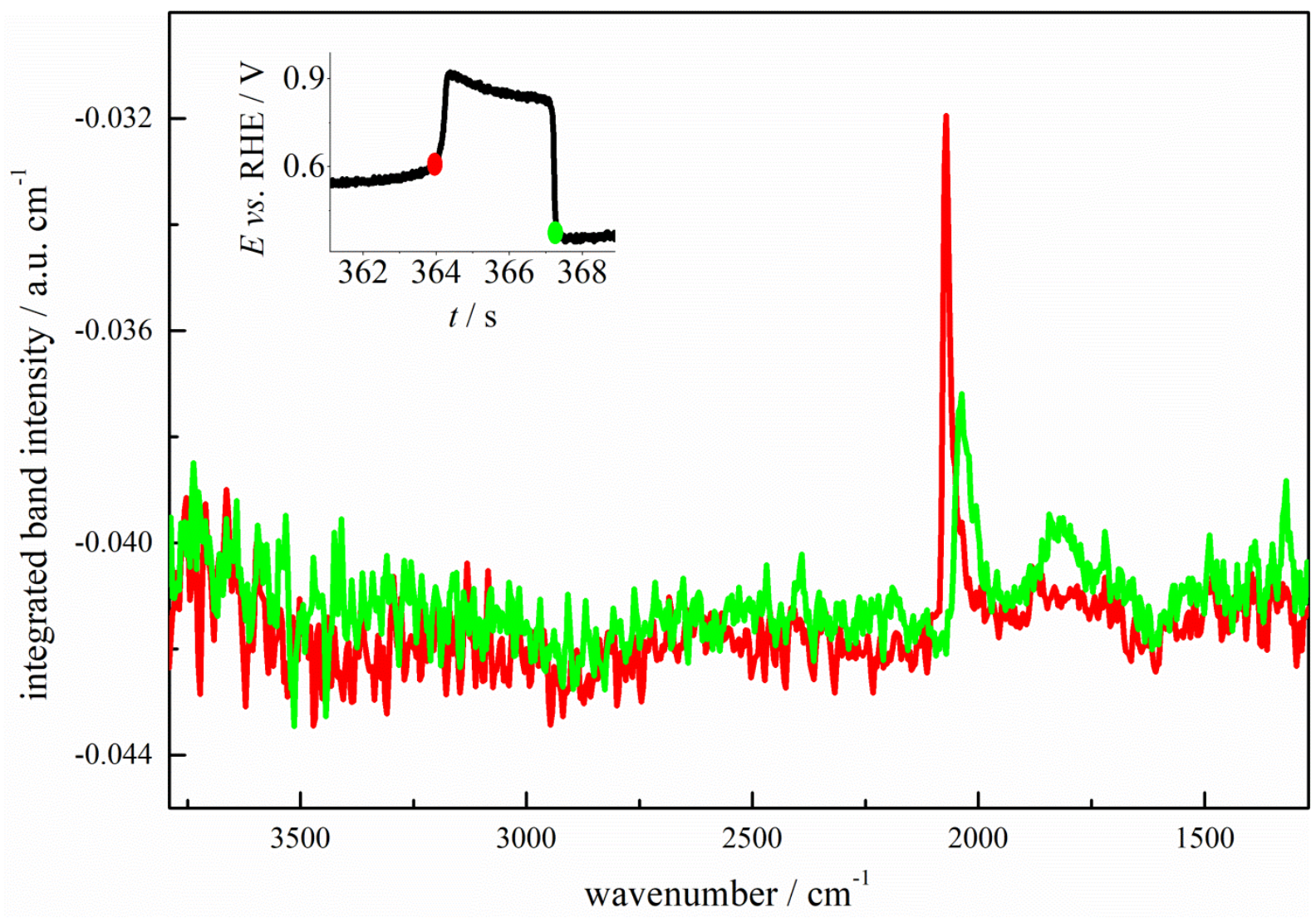

The panels on the right side of Figure 57 give a deeper insight in the content of the adlayer on the Pt surface at each potential of the oscillation pattern. Thus, it is found, that the CO band intensity $\left(\mathrm{I}_{\mathrm{CO}}\right)$ decreases at the potential spike concomitant with an increase of band of $\mathrm{HCOO}_{\mathrm{B}}\left(\mathrm{I}_{\mathrm{HCOO}}\right)$, what is again in good agreement with previously published results [81]. At that point the potential decreases slightly and $\mathrm{I}_{\mathrm{CO}}$ remains constant, until the potential and $\mathrm{I}_{\mathrm{CO}}$ decrease sharply to their minimum, which again coincide. Meanwhile $\mathrm{I}_{\mathrm{CO}}$ increases rapidly to a constant level until the next spike, the potential has a constant but steady incline. $\mathrm{I}_{\mathrm{HCOO}}$ responds accordingly and increases first rapidly then more slowly, where $\mathrm{I}_{\mathrm{CO}}$ is on a lower level and decreases as well in intensity before the spike. Here it is worth to mention, that $\mathrm{I}_{\mathrm{HCOO}}$ can be assumed to be proportional to the coverage of $\mathrm{HCOO}_{\mathrm{B}}\left(\theta_{\mathrm{HCOO}}\right)$, while the $\mathrm{I}_{\mathrm{CO}}$ has been shown to be proportional to the $\mathrm{CO}_{\mathrm{ad}}$ coverage $\left(\theta_{\mathrm{CO}}\right)$ only at sufficiently low coverages 
$[141,174]$. Similar behaviour was found in the series of other applied current densities, which confirm the interpretation. As the UV reflectance data show, adsorbed anions like sulphate can impact the changes in the adlayer by occupying and blocking adsorptions sites, which may be the reason, that $\theta_{\mathrm{CO}}$ does not drop immediately to its minimum with the potential, but shows a delay of an intermediate level for a few seconds.

Figure 57: Potential oscillation pattern for a current density of $0.15 \mathrm{~mA} \mathrm{~cm}^{-2}$ applied to a $\mathrm{Pt}$ film deposited on a Si prism (a) and integrated band intensities of $\mathrm{CO}_{\mathrm{L}}(\mathrm{b})$ and $\mathrm{HCOO}_{\mathrm{B}}$ (c) obtained from a simultaneously recorded series of ATR-SEIRA spectra. The electrolyte was a $0.3 \mathrm{M} \mathrm{K}_{2} \mathrm{SO}_{4}+0.1 \mathrm{M} \mathrm{H}_{2} \mathrm{SO}_{4}+0.4 \mathrm{M} \mathrm{HCOOH}$ solution. The panel on the right is an expanded view of the oscillation between 820 and $850 \mathrm{~s}$. The background spectrum was recorded at $0.10 \mathrm{~V}$ in the absence of formic acid.
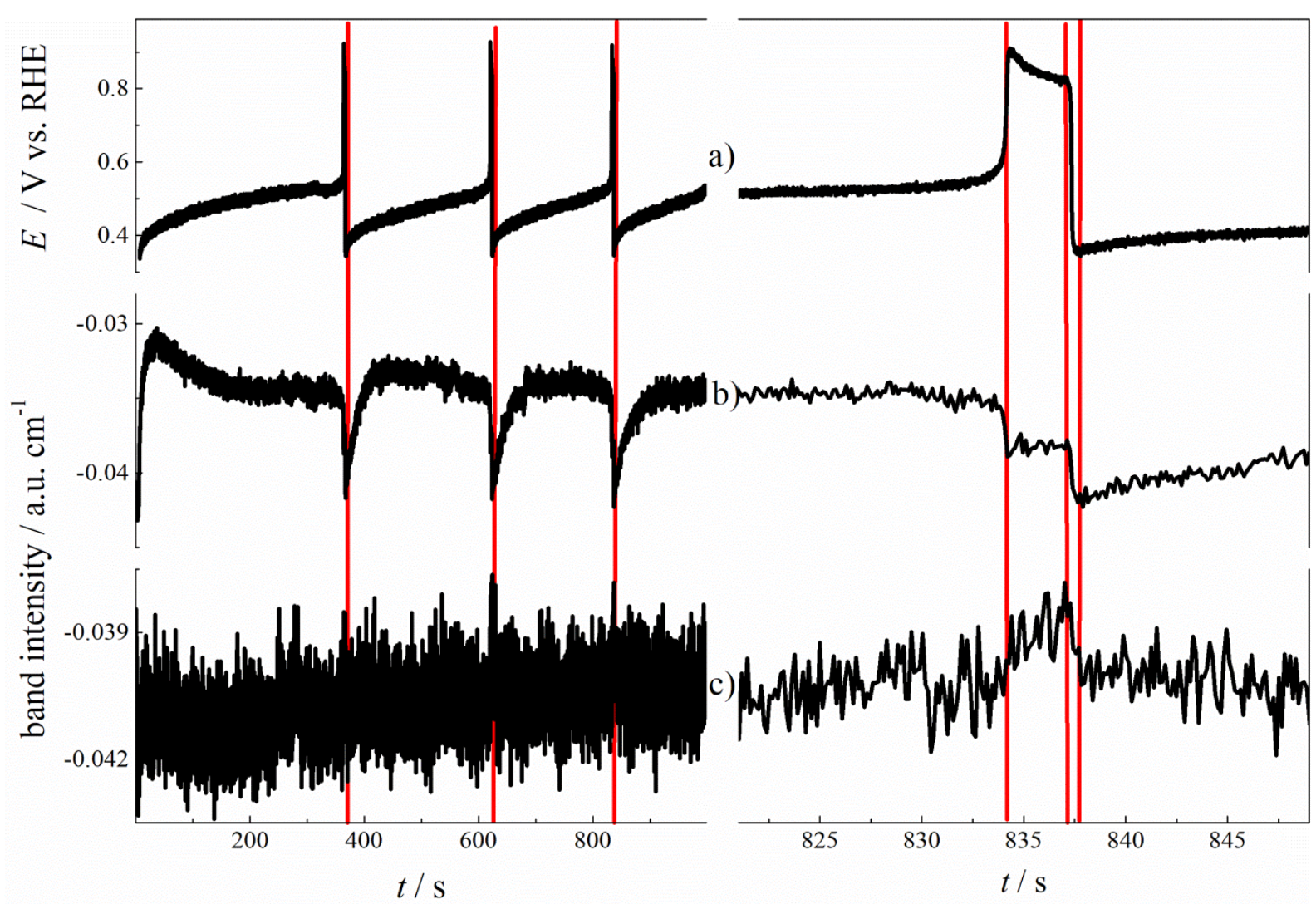

Taking the interpretations of UV reflectance and ATR-SEIRAS data in account, it is possible to give a more detailed insight in the processes in the oscillating regime of formic acid oxidation, than it has been done before $[81,175]$. Thus, all spectroscopic data show constant behaviour in the low potential part of the oscillation pattern, where the potential increase slightly, but steadily. In first sight this facts contradict each other, since a potential increase must result from a decrease of the available, active surface due to higher blockage by the 
adsorption of site-blocking species like $\mathrm{CO}_{\mathrm{ad}}$ and/or sulphate. Since the coverage of $\mathrm{CO}$ is high at the lower overpotentials of the oscillation and increasing, it may be beyond the linear relation to the IR signal, that a further increase is not monitored by ATR-SEIRAS, but visible in the increase of the potential. Along this auto-inhibiting process the potential visits the range of surface oxidation, where $\mathrm{CO}$ can be removed from the surface, what is indicated by the drop of $\mathrm{I}_{\mathrm{CO}}$ at the potential spike. The increasing band of $\mathrm{HCOO}_{\mathrm{B}}$ suggests the partial replacement of $\mathrm{CO}$ by that species, but is too less to be the only adsorbing species in that potential range. Additionally the reflectance data just changes drastically in the profile, where the CO coverage can be assumed to decline, that free surface sites become occupied mainly by sulphate and partially $(\mathrm{H})_{\mathrm{x}} \mathrm{O}$ than $\mathrm{HCOO}_{\mathrm{B}}$. Right after the sharp potential increase, the potential changes slower, but the $\mathrm{R} / \mathrm{R}_{\max }$ decreases fast, what also suggests a rapid sulphate adsorption, that perturbs the $\mathrm{CO}$ oxidation via Langmuir-Hinshelwood mechanism, This interpretation explains the intermediate level of the $\mathrm{CO}$ coverage and the not immediate drop until surface oxides and $\mathrm{CO}_{\mathrm{ad}}$ are removed, where the steep decrease of potential and band intensities as well as the increasing reflectance are found. The latter also suggests the replacement of sulphate by $\mathrm{CO}$. It should also be mentioned, that $\mathrm{CO}$ is assumed to form from $\mathrm{HCOO}_{\mathrm{ad}}$, whose coverage consequently cannot be zero.

Considering the newly received information about the surface coverage under galvanostatic control at $\mathrm{pH} \mathrm{1,} \mathrm{the} \mathrm{studies} \mathrm{were} \mathrm{extended} \mathrm{to} \mathrm{the} \mathrm{same} \mathrm{measurements} \mathrm{at} \mathrm{pH} 3$ and 13 (see Figure 58 and 60, respectively). As it is shown in Figure 54 very well in agreement to Figure 31 and 33, the possibility to find oscillation patterns with low frequency in this $\mathrm{pH}$ range exists and can be visited, if the applied parameters allow the establishment of the necessary instability. It can also be seen, that no changes in the band intensity of $\mathrm{CO}_{\mathrm{L}}$ are found in the absence of pattern formation. Yet surprisingly, comparing Figure 58 and 33 the dependence on the applied current density is the contrary, which may be related to the different range of applied currents and to different time windows. Meanwhile Figure 33 displays the potential oscillations disappearing at higher currents, Figure 58 demonstrates the beginning of the oscillation regime at higher currents. It is likely, that the slightly different system parameters and here mainly the greater area of the working electrode by one order of magnitude in the case of the ATR-SEIRAS have a crucial impact here. However, the data clearly explain the behaviour at $\mathrm{pH} \mathrm{3}$, since both cases show that $\mathrm{CO}$ formation is not favoured in this $\mathrm{pH}$ range, because of the faster and more dominant direct pathway or $\mathrm{CO}$ formation is too slow to block the Pt surface sufficiently, as seen in Figure 58. Thus, it can 
occur, that the time series ends too early due to the concomitantly uninhibited adsorption of $(\mathrm{H})_{\mathrm{x}} \mathrm{O}$ and the place-exchange or the time window is not visited to find possible oscillations, respectively.

Figure 58: Potential oscillation pattern for a current density of $0.4 \mathrm{~mA} \mathrm{~cm}{ }^{-2}$ (left panels) and $0.8 \mathrm{~mA} \mathrm{~cm}^{-2}$ (right panels) applied to a Pt film deposited on a Si prism (a) and integrated band intensities of $\mathrm{CO}_{\mathrm{L}}(\mathrm{b})$ and $\mathrm{HCOO}_{\mathrm{B}}(\mathrm{c})$ obtained from a simultaneously recorded series of ATR-SEIRA spectra. The electrolyte was a $0.3 \mathrm{M} \mathrm{K}_{2} \mathrm{SO}_{4}+0.4 \mathrm{M} \mathrm{HCOOH}$ solution (pH 3).

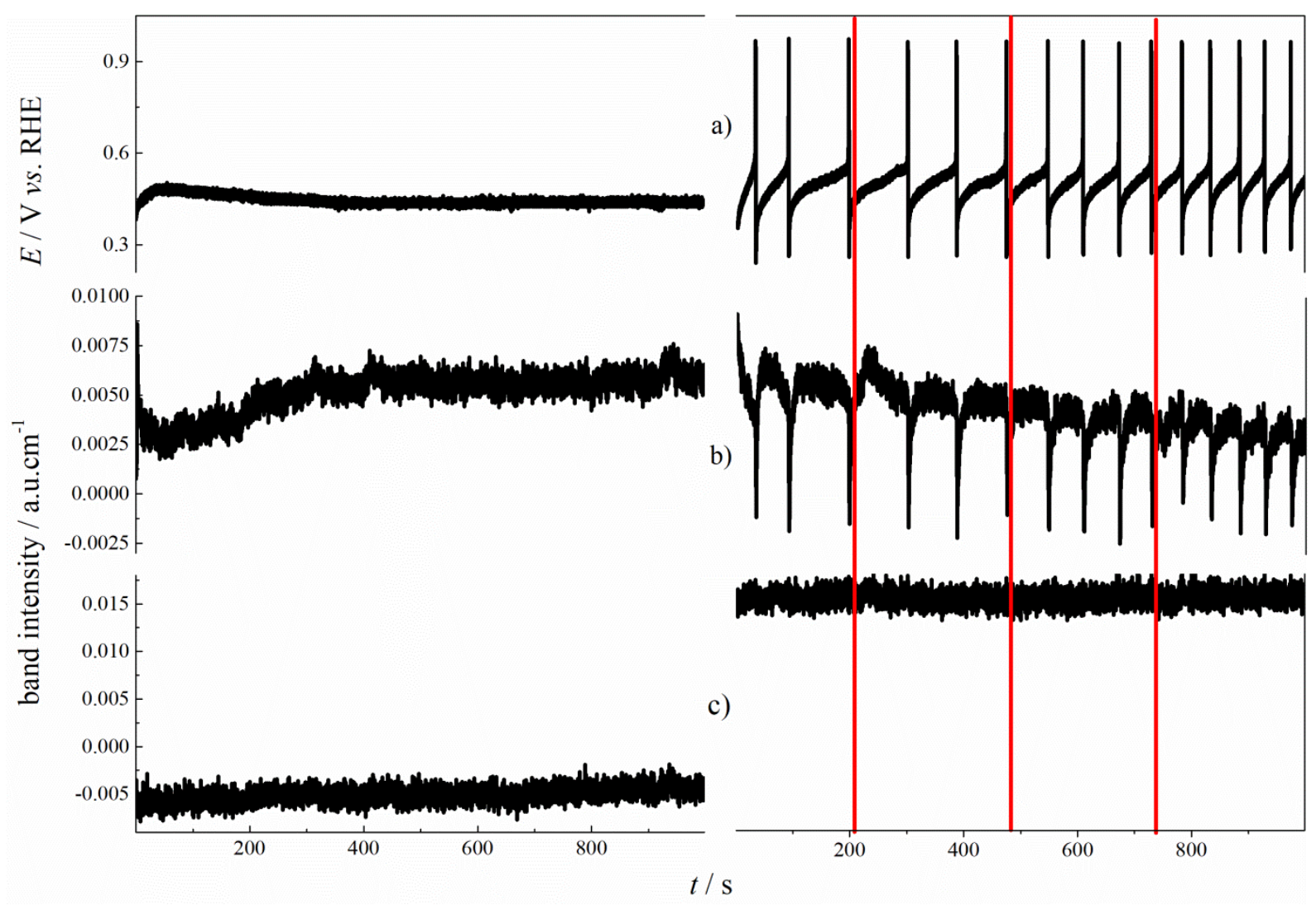

It should also be noted, that the band intensity of $\mathrm{HCOO}_{\mathrm{B}}$ in both cases remains quite constant, but on different levels. It leads to the conclusion, that the coverage of bridge-bonded formate is very small, since its formation is slow and is the intermediate in the $\mathrm{CO}$ formation. Different baselines in the IR spectra are seen here, which depends on the more active anion adsorption and the different reflectivity of the Pt surface (see above). This fact will be discussed in further detail with the results of the ATR-SEIRAS data of $\mathrm{pH} 13$ in Figure 59 and 64. The newly found oscillation patterns of formic acid oxidation in alkaline media could be reproduced on the deposited Pt layer along the ATR-SEIRAS, which allowed the simultaneous study of the adsorbates in the complete time series. Although the profile of the oscillation cycle is different (compare Figure 60 with Figure 34), which may not be related to 
different mechanistic processes, but spatial coupling, the comparison and some conclusions are possible [176]. Figure 59 shows two representative ATR-SEIRA spectra recorded at distinct points in the chronopotentiogram, as indicated in the inset. Both spectra only show the known broad water bands at 1600-1700 and 3000-3700 $\mathrm{cm}^{-1}$ and a band at $\sim 1450 \mathrm{~cm}^{-1}$, which may be related to formate in the solid-liquid interface [26]. It should be especially pronounced, that no $\mathrm{CO}$ or $\mathrm{HCOO}_{\mathrm{B}}$ bands were detected above the trace level, which suggests a very different adsorption layer than in the acidic $\mathrm{pH}$ range.

Figure 59: Typical SEIRA spectra of $0.3 \mathrm{M} \mathrm{K}_{2} \mathrm{SO}_{4}+0.4 \mathrm{M} \mathrm{HCOOH}(\mathrm{pH} 13)$ on Pt carried out at $364 \mathrm{~s}$ (red) $367 \mathrm{~s}$ (red) of the chronopotentiogram as indicated in the inset

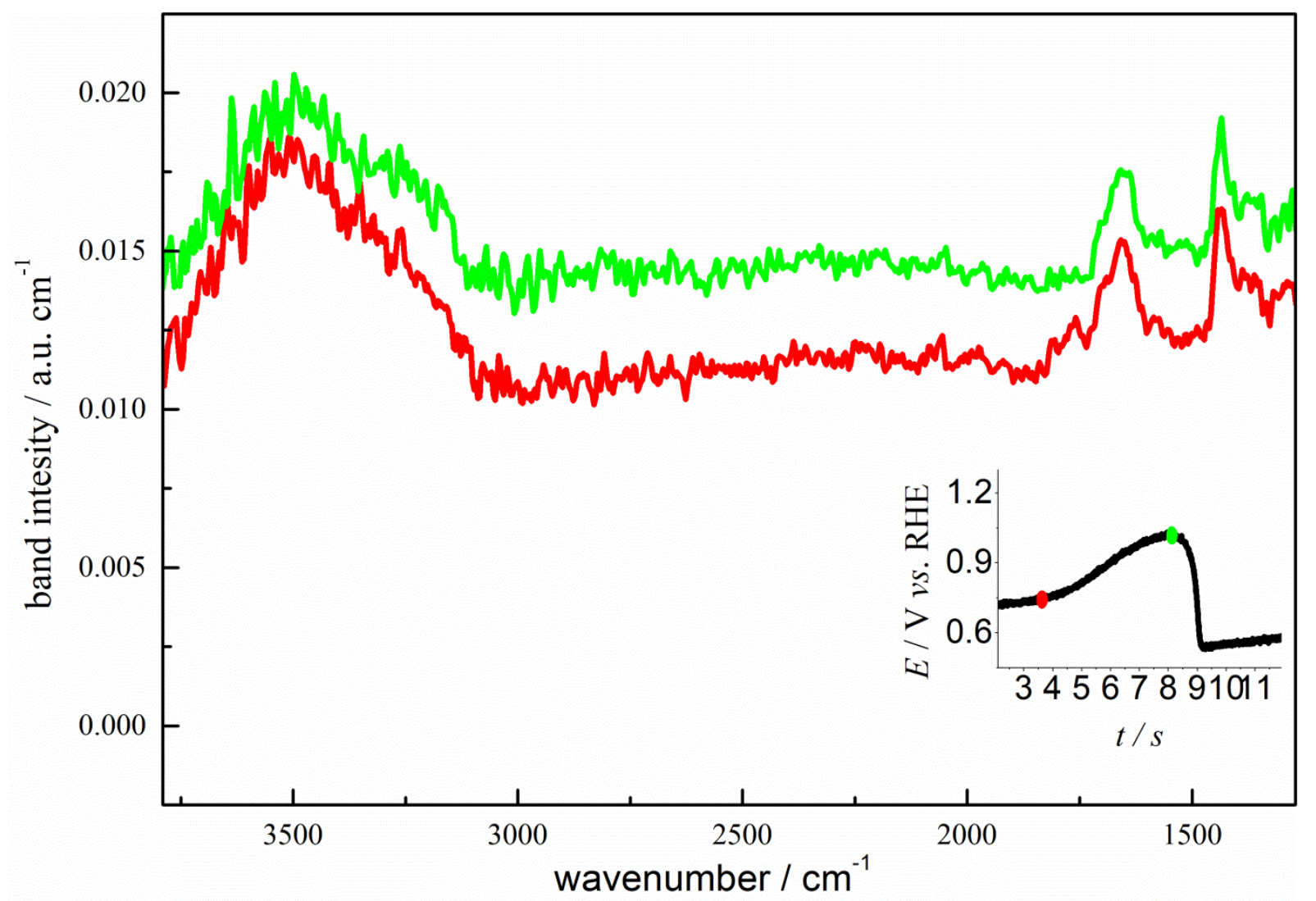

As the comparison of the spectra above show, the baseline of the spectra strongly depends on the current potential and as the potential increases, the complete spectra shifts upwards. This behaviour was already found partly in the spectra at $\mathrm{pH} 3$ and can be related to the changing reflectance due to anion adsorption in dependence on the potential. In Figure 60 the galvanostatic measurement is plotted together with the simultaneously recorded band intensity at 1630 and $2070 \mathrm{~cm}^{-1}$, which show a perfectly synchronous dependence in phase. As the reflectance and IR data show, water species and sulphate are adsorbed to a dominant coverage in alkaline media, which are responsible for changes in the reflectivity of the Pt surface. As it 
has been reported by Osawa and co-workers, $\mathrm{CO}_{\mathrm{ad}}$ and $\mathrm{HCOO}_{\mathrm{B}}$ just appeared with lower coverages in media with $\mathrm{pH}$ beyond 6 , which explains the higher activity of formic acid oxidation and the visible N-NDR region as it is discussed above [72]. As the demonstrated data along the time series under conditions far from equilibrium show, none of the both species can be detected, but yet may be present in very low coverages. In the visited potential range surface oxidation may not be the most active process, but rather the adsorption of an ions, as it was argued in the discussion of the differential reflectance results, that in great contrast to acidic media an oscillating adsorption layer of sulphate anions in phase with the potential is found, which is removed slowly by the surface oxidation.

Figure 60: Potential oscillation pattern for a current density of $0.12 \mathrm{~mA} \mathrm{~cm}^{-2}$ (left panels) and $0.33 \mathrm{~mA} \mathrm{~cm}^{-2}$ (right panels) applied to a Pt film deposited on a Si prism (a) and integrated band intensities of $\mathrm{CO}_{\mathrm{L}}(\mathrm{b})$ and $\mathrm{HCOO}_{\mathrm{B}}(\mathrm{c})$ obtained from a simultaneously recorded series of ATR-SEIRA spectra. The electrolyte was a $0.3 \mathrm{M} \mathrm{K}_{2} \mathrm{SO}_{4}+0.4 \mathrm{M} \mathrm{HCOOH}$ solution ( $\mathrm{pH} 13$ ).

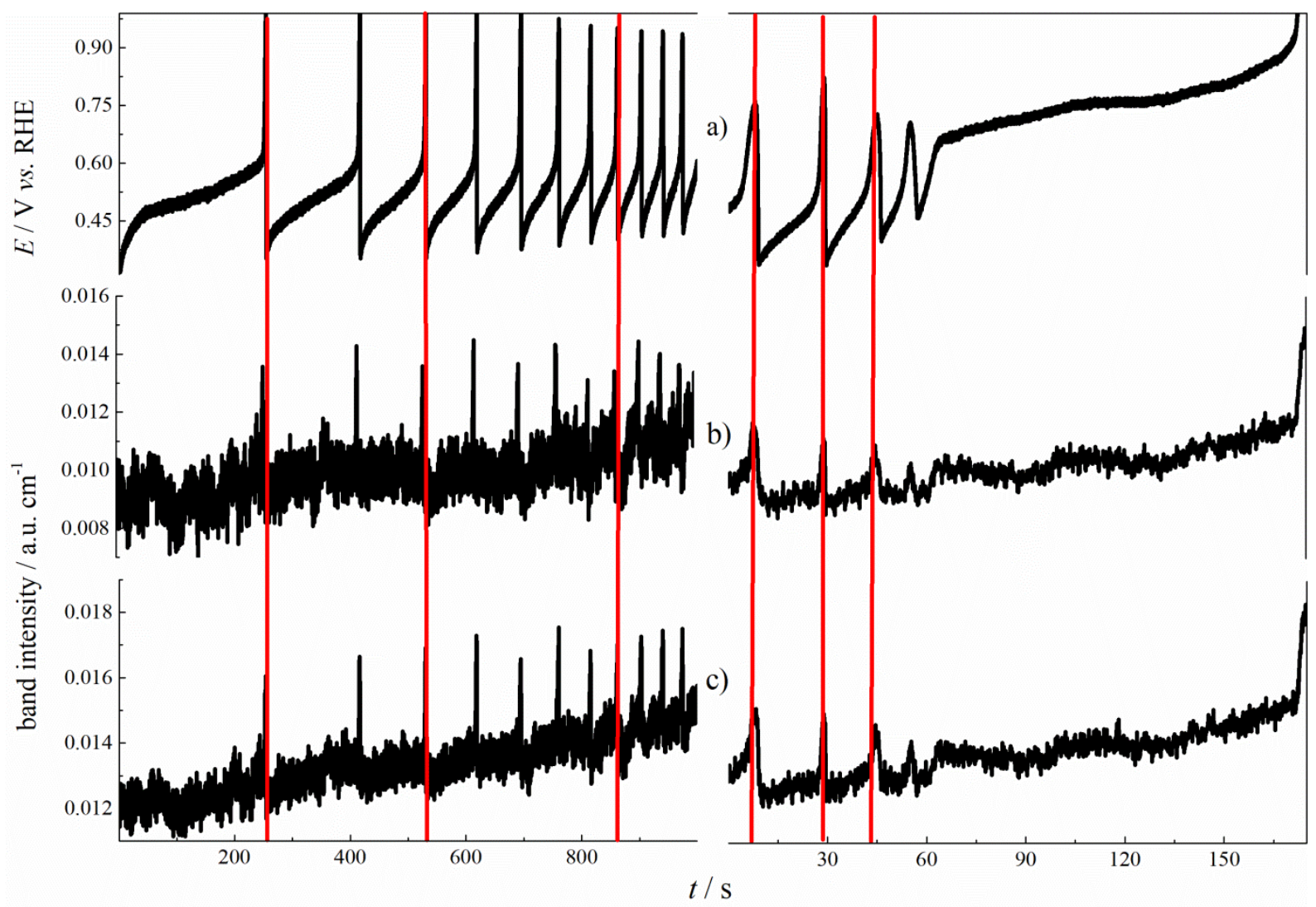

Thus, the open question remains, which species is active in the negative feedback loop in absence of $\mathrm{CO}_{\mathrm{ad}}$, that establishes conditions for pattern formation and self-organization. All data do not give a clear evidence for any species, that just assumptions can be made. As the ATR-SEIRA spectra in Figure 59 suggests, formate is very present in the electrochemical 
interface weakly adsorbed on the Pt surface, which is the precursor in the most active pathway in formic acid/formate oxidation (see section 6.2). Consequently a fast oxidation of these present active species can be assumed, which is concomitant to the formation of $\mathrm{H}^{+}$on the surface, which can interact with sulphate or water/oxygenated species and cause a shift in the interfacial $\mathrm{pH}$. In both ways the adsorption equilibrium of sulphate anions can be influenced [143].

\subsection{Partial Conclusions}

The simultaneous study of formic acid oxidation by chronopotentiometry with ATR-SEIRAS and differential reflectance spectroscopy allowed a deep insight in the adsorption layer along the autocatalytic evolution of potential oscillations, which showed a complex interaction of adsorbed carbonaceous species, namely $\mathrm{CO}_{\mathrm{ad}}$ and $\mathrm{HCOO}_{\mathrm{B}}$, sulphate, and oxygenated species. It was found, that the adsorption of anions such as sulphate in this case pertubes the reaction of $\mathrm{CO}_{\mathrm{ad}}$ and surface oxides in the high potential range of the oscillating formic acid oxidation, what results in an intermediate $\mathrm{CO}$ coverage at higher overpotentials a delay in its complete removal. The coverage of all named species depends strongly on the applied bulk solution $\mathrm{pH}$. Thus, the $\mathrm{pH}$ has a crucial impact in the existence of potential oscillations, as well as their characteristics, which are differentiate fundamentally in alkaline and acidic solutions. In acidic media pattern formation occurs due to the oscillating coverages of the above mentioned adsorbates, where $\mathrm{CO}_{\mathrm{ad}}$ is clearly present and its coverage synchronously oscillating out-ofphase in relation to the potential. Yet, in alkaline solutions, oscillation patterns occur along the evolving ocverage of absorbed oxide and anions, where $\mathrm{CO}_{\mathrm{ad}}$ and $\mathrm{HCOO}_{\mathrm{B}}$ could not be detected. Consequently it remains hidden, which species is responsible for the removal of the oxides and the negative feedback loop, which is essential condition for pattern formation. It can be assumed, that formate or protons in the solid/liquid interface may have a crucial role here. 


\section{Synergy of formic acid and methanol electro-oxidation}

This chapter demonstrates the simultaneous oxidation of formic acid and methanol with different content over $\mathrm{Pt}$ studied by steady state voltammetry and chronopotentiometry. The voltammetric profiles showed a synergetic oxidation, where the highest activity was found in the solution containing a molar fraction of 0.8 for formic acid and 0.2 of methanol, and a transition from formic acid profile to methanol. The same transition was found in the oscillating regime. All data lead to the conclusion, that carbonaceous species formed by methanol blocked surface sites for $\mathrm{CO}$ formation and thus, enhance the direct oxidation of formic acid. 


\subsection{Introduction}

In the recent decades, enormous work has been done and a vast literature exists to find a costeffective catalyst for the application in fuel cells. Yet, in the recent time some groups reported an enhancing effect of small alcohols added to the formic acid solution [177-181]. This promotion was attributed by El-Deab et al. to the adsorption of carbonaceous species, that inhibit the formation of $\mathrm{CO}_{\mathrm{ad}}$ for a more active direct pathway in formic acid oxidation [177]. On the other hand Behm and co-workers discovered a synergetic effect of the partly oxidized byproducts, namely formaldehyde and formic acid, on the methanol oxidation $[182,183]$. Thus, a systematic study of solutions containing formic acid and methanol with different composition were performed under voltammetric and galvanostatic conditions.

\subsection{Steady state voltammetry}

The steady state voltammograms of methanol and formic acid oxidation are plotted in Figure 61a) and c), respectively, in the temperature range of 10 to 50 degree. Both reactions show their well-known profile, as it is described in the previous sections and reported in literature $[66,89]$. The graph highlights the characteristic similarities, namely and increasing activity in the potential region of surface oxidation, a potential hysteresis and the (partially) hidden $\mathrm{N}$ NDR due to the potential dependent adsorption of water [25].

Figure 61: CVs of Pt in $0.5 \mathrm{M} \mathrm{H}_{2} \mathrm{SO}_{4}+$ a) $2 \mathrm{M} \mathrm{H}_{3} \mathrm{COH}$, b) $1 \mathrm{M} \mathrm{H}_{3} \mathrm{COH} / 1 \mathrm{M} \mathrm{HCOOH}$ and c) $2 \mathrm{M} \mathrm{HCOOH}$ at various temperatures. Scan rate $0.05 \mathrm{~V} \mathrm{~s}^{-1}$.
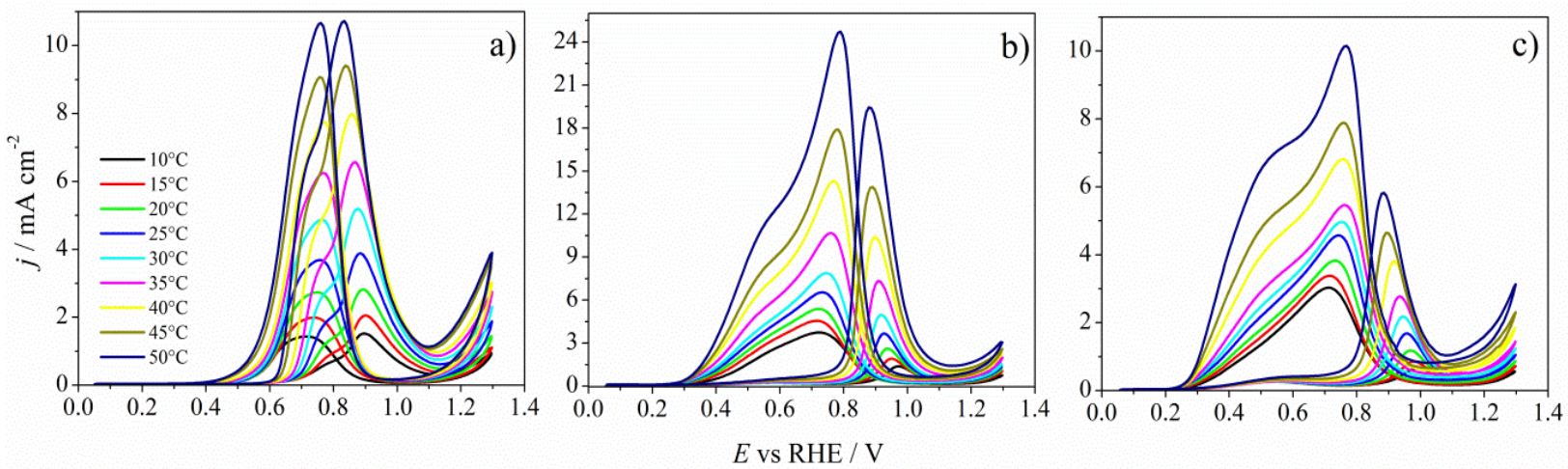

Yet, there can also be seen drastic differences like similar currents in positive and negative scan direction with a shoulder before the anodic peak for the electro-oxidation of methanol, meanwhile formic acid oxidation shows higher currents in the cathodic sweep, which remain 
above the anodic one until the hydrogen region [94]. Figure 61b) displays the potentiodynamic curves of $\mathrm{Pt}$ in a solution of equal concentration of methanol and formic acid and otherwise the same conditions, which indicate the transition from one to the other profile. Yet, it should be especially noted, that the maximum current densities in both scan directions are found to be significantly higher as each species separately [177]. Figure 62a) and b) shows the steady state voltammograms of all applied solutions of different contents at 25 degree. Meanwhile the addition of small concentrations of methanol did not show any significant differences in the shape of the potentiodynamic curve, except an increase in the current density, as seen in Figure 62a), the addition of $10 \%$ of formic acid changes the profile significantly, which manifests itself in a potential shift of the main anodic oxidation peak and reveals the characteristic features of formic acid oxidation.

Figure 62: steady state voltammograms of $\mathrm{HCOOH} / \mathrm{H}_{3} \mathrm{COH}$ (x/y M) a) 2/0, 1.8/0.2 and $1.6 / 0.4$, b) $1.4 / 0.6-0 / 2$ in $0.5 \mathrm{M} \mathrm{H}_{2} \mathrm{SO}_{4}$, c) peak maximum current densities. Temperature 25 ${ }^{\circ} \mathrm{C}$. d) apparent activation energy vs $\mathrm{x}\left(\mathrm{H}_{3} \mathrm{COH}\right)$. c), d) anodic (black) and cathodic sweep (red).
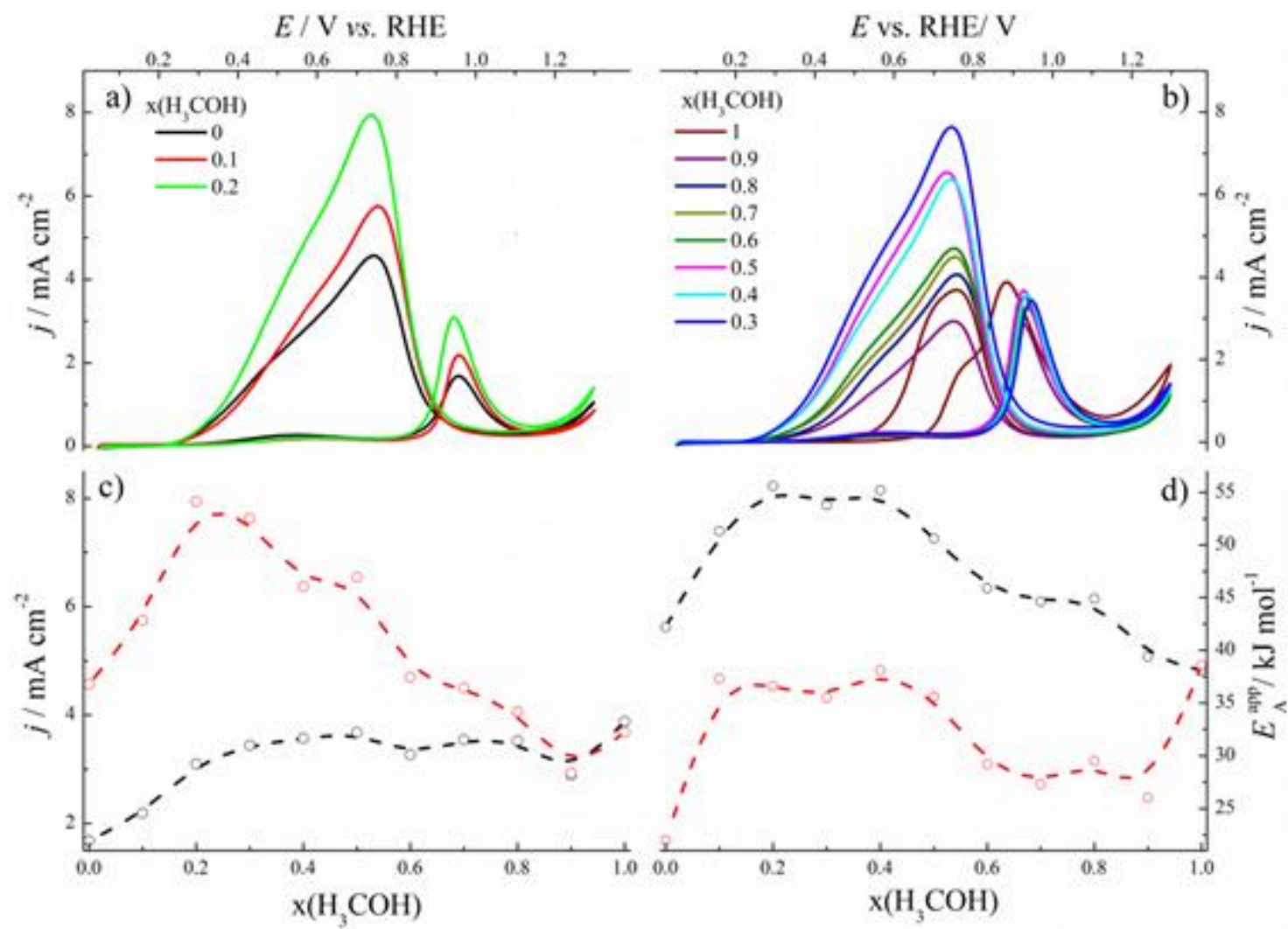

These results emphasizes a non-additive behaviour of both oxidation processes, and labels formic acid not surprisingly as the more active reaction species, as the activation energies 
indicated (see above). Reichert et al. reported the same effect for already smaller concentrations of formic acid on methanol oxidation and attributed it to the a changing $\mathrm{CO}$ coverage $[182,183]$. Figure 62c) and d) emphasize the changing peak current maxima at $25{ }^{\circ} \mathrm{C}$ and activation energies of positive and negative sweeps in dependence on the solution composition. Both graphs depict the mentioned differences of current densitiy and activation energy in both sweeps for solutions of high formic acid concentration, which diminishes, as the presence of methanol increases. It was also found that the current evolves differently in anodic scan direction, where it reaches a plateau at a molar fraction of $20 \%$ of methanol, meanwhile the overall highest currents were found at this solution composition in the cathodic sweep declining to higher and lower concentrations of methanol. The activation energy on the other hand shows a very similar evolution in both scan directions in dependence for a molar fraction of methanol from 0 to 0.9 , where it increases to higher plateau from 0.2 to 0.5 and a lower one from 0.6 to 0.9 molar fraction of methanol. Thus, it is surprising, that the highest activities found take place under conditions, which reveal a similar high activation energy as a the $2 \mathrm{M}$ methanol solution for both sweeps. As it was mentioned in the mechanistic discussion of section 6.2 and 6.3, methanol oxidation requires the presence of adsorbed oxygenated species for a successful oxidation to $\mathrm{CO}_{2}$ in direct and indirect reaction pathway, that its activity is limited to high overpotentials. On the other hand, the active dehydrogenation pathways of formic acid oxidation do not show this behaviour, that high activities are possible in a wider potential range, but are inhibited by the adsorption of $\mathrm{CO}$ in the anodic sweep. Thus, again changes in the $\mathrm{CO}$ coverage may be responsible for the changing current and activation energy. A deeper analysis of the voltammetric profiles was done by deconvolution in 3 peaks, shown in Figure 63a)-c) fitting all voltammograms in good agreement, as it has been reported earlier for the steady state voltammogram of $\mathrm{Pt}$ in $2 \mathrm{M} \mathrm{H}_{3} \mathrm{COH}$ [94]. Since deconvolution peak II results from the overall most active process, it can be attributed to the direct oxidation pathway of formic acid and methanol oxidation. Peak III propably results from the same processes, but may contain a contribution of the surface deactivation by oxide formation. This interpretation is supported by the independent peak potential of peak II and III, as shown in Figure 63f). The deconvoluted peak I on the other hand is to be seen differentiated, since the potential of the peak maximum strongly depends on the solution composition and undergoes a constant increase with the molar fraction methanol. The detailed analysis gives a deep insight in differences and similarities of the electro-oxidation of methanol and formic acid and the influence of both molecules on each other. Thus, it was found, that the peak maximum potential of deconvolution peak II and III above $0.9 \mathrm{~V}$ 
decreases slightly (see Figure 63f), as methanol becomes more present, which is not surprising, since the surface processes take place in the presence of surface oxides.

Figure 63: Deconvoluted sweeps of positive scan direction from the steady state voltammograms of $x / y \mathrm{M} \mathrm{HCOOH} / \mathrm{H}_{3} \mathrm{COH}$ in $0.5 \mathrm{M} \mathrm{H}_{2} \mathrm{SO}_{4}$ (a) 2/0, b) $1 / 1$, c) $0 / 2$ ) and the derived d) charge distribution, e) peak maximum current density and f) peak maximum potential vs. molar fraction of $\mathrm{H}_{3} \mathrm{COH}$.
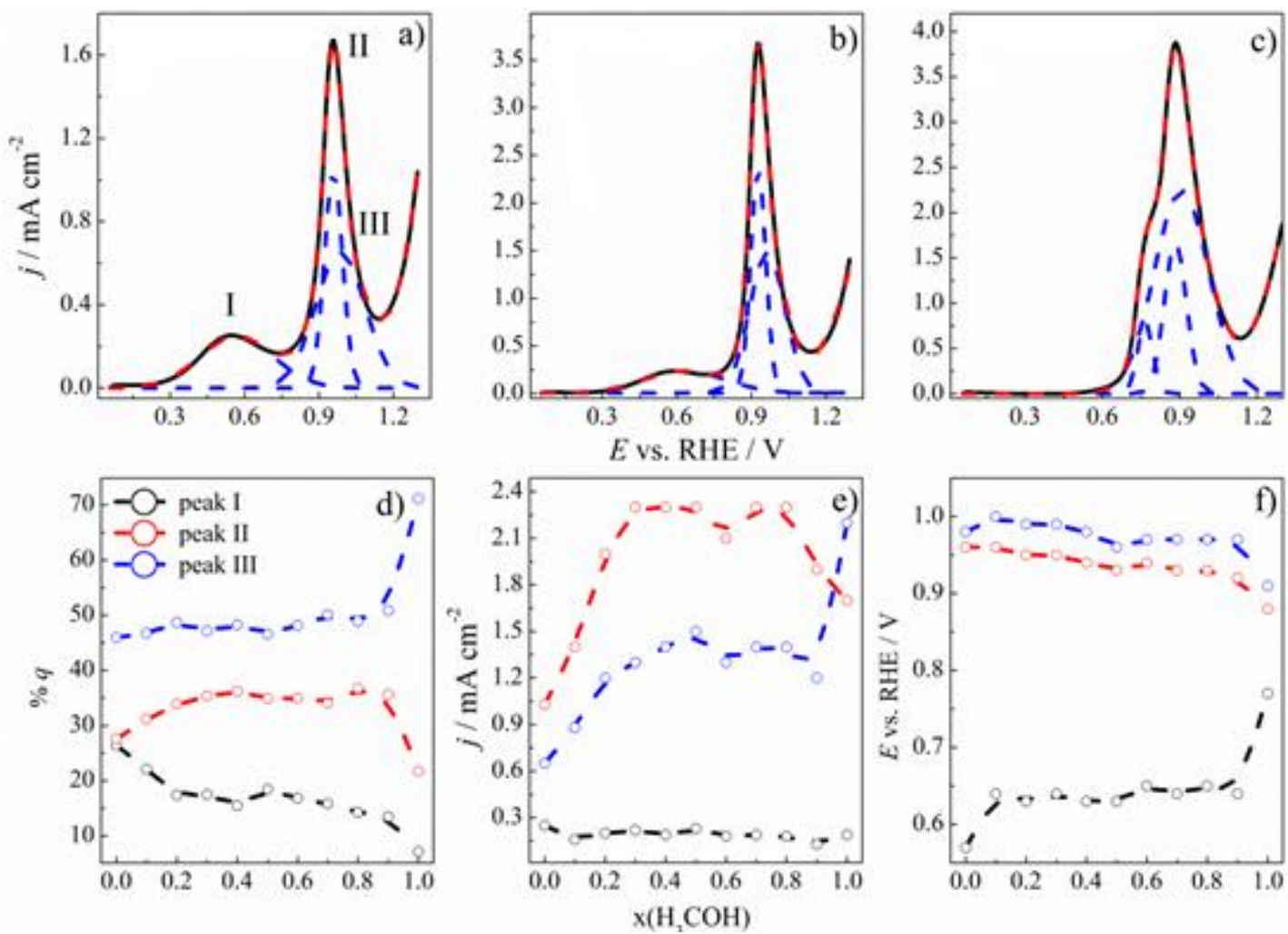

As mentioned various times above, adsorbed oxygenated species have more site-blocking character for the direct pathway of formic acid oxidation, which is the most active reaction in the system and responsible for the major charge transfer in the electrochemical interface, even if it is just present in small concentration. On the other hand, the peak potential of peak maximum I shifts more positively already at a molar fraction of $10 \%$ of methanol and increases slightly until $90 \%$, followed by a sharp increase of more than $0.1 \mathrm{~V}$. This behaviour indicates, that the deconvolution peak I at $2 \mathrm{M}$ formic acid solution is represented by the direct oxidation pathway under the influence of $\mathrm{CO}_{\mathrm{ad}}$. The positive shift by adding methanol indicates, that the same pathway takes place in presence of more adsorbed carbonaceous species than $\mathrm{CO}_{\mathrm{ad}}$, as it was reported by El-Deab et al. and peak I is solely represented by the oxidation of these adsorbates by $(\mathrm{H})_{\mathrm{x}} \mathrm{O}_{\mathrm{ad}}$ in $2 \mathrm{M} \mathrm{H}_{3} \mathrm{COH}$, as found earlier [94,177]. These interpretations get support in the transferred charge of all peaks in dependence on the molar 
fraction of methanol, which is plotted in Figure 63d). The maximum current densities of each deconvolution peak are shown in Figure 63e), which show the same tendency, as it was found in the steady state voltammograms and it appears, that methanol enhances the formic acid oxidation via the dehydrogenation pathway, reaching the highest currents at 0.3 molar fraction of methanol [177]. Surprisingly, the maximum current density of peak II remains at this level until the molar fraction of 0.8, which differs from the results in Figure 62c).

\subsection{Oscillations}

For further insight, the influence of methanol on formic acid oxidation was studied under galvanostatic conditions at a normalized current density of 0.5 at all temperatures. Since several surface reactions are probed at the same time and take place in a complex network, solutions containing both species showed a great variety of S- and L-patterns were found, that made a deep analysis difficult. Figure 64 shows 5 oscillations cycles of a time series in each solution for $25^{\circ} \mathrm{C}$, where a complex influence of methanol is found under oscillating conditions, which manifests itself especially in the strongly changing time scale. The oscillations in mixed solutions show a constant transition from the formic acid- to the methanol-type, which will be discussed in detail along Figure 65 and 66.

Figure 64: Time series of characteristic potential oscillations in dependence on the molar fraction of methanol and formic acid in $0.5 \mathrm{M} \mathrm{H}_{2} \mathrm{SO}_{4}+\mathrm{x} / \mathrm{y} \mathrm{M} \mathrm{HCOOH} / \mathrm{H}_{3} \mathrm{COH}$ at $25{ }^{\circ} \mathrm{C}$. Normalized current density $=0.5$.
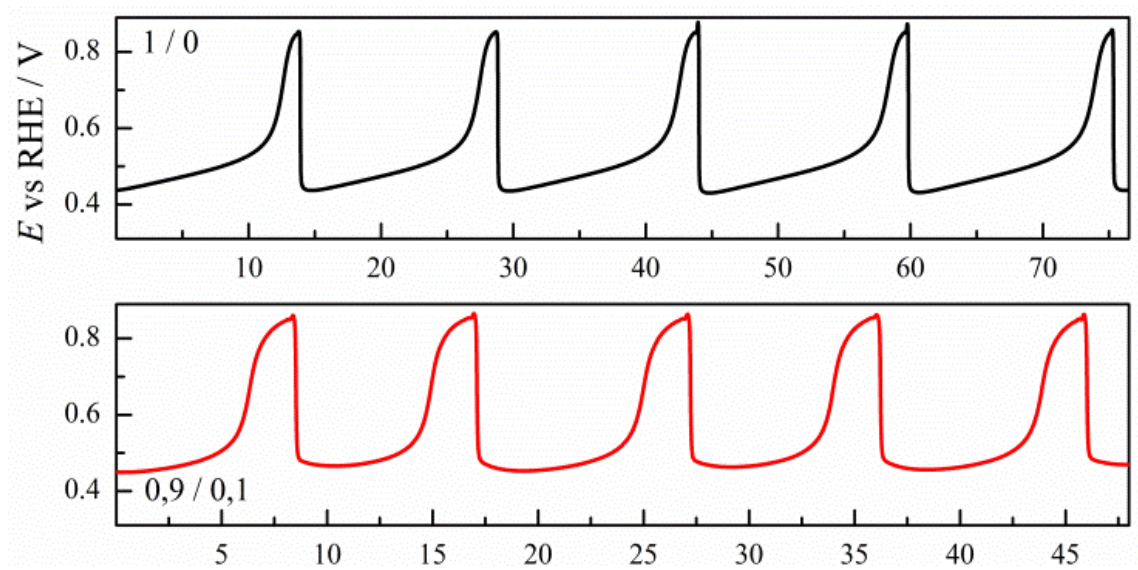

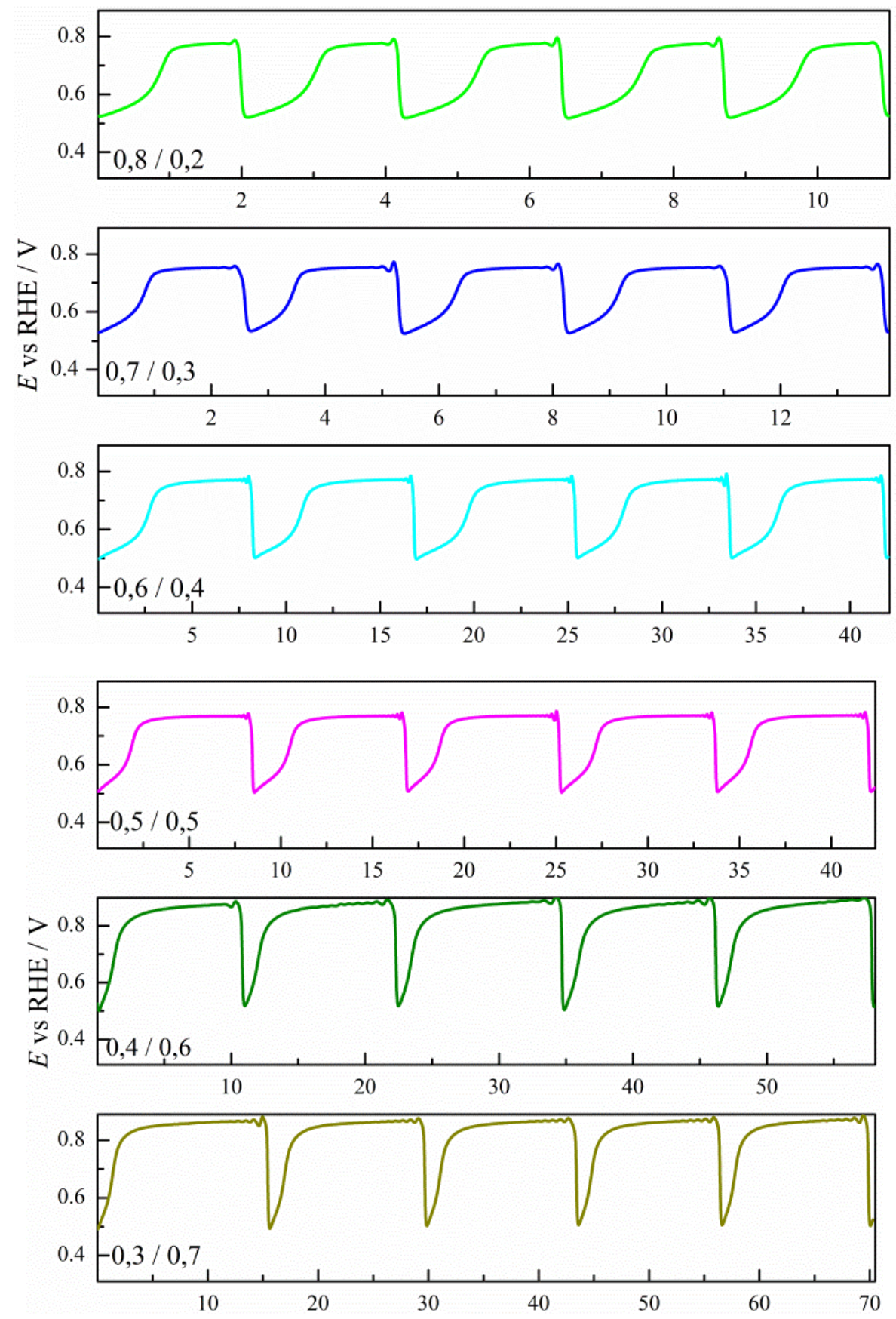

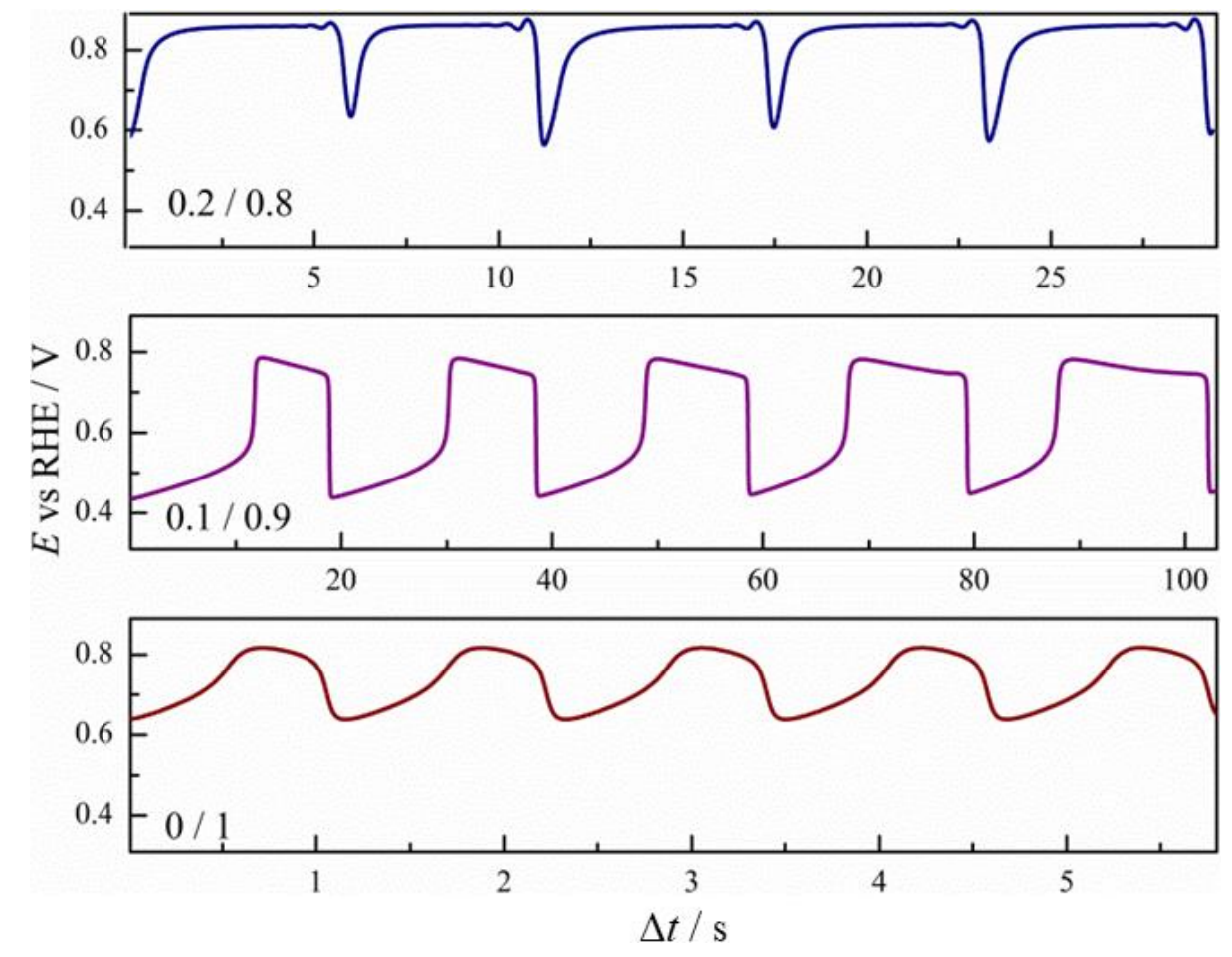

Meanwhile the potential oscillations for formic acid and methanol oxidation show the wellknown profile, as it has been described in section 2.1 and 2.2., the high potential part in each oscillation cycle becomes more pronounced in the oscillations in mixed solutions, as the molar fraction of methanol increases until 0.8.

Figure 65: a) dE/dt profiles of characteristic oscillation cycles vs. electrode potential in solutions containing different molar fractions of methanol and b) high and low limits of the cycles vs. $\mathrm{x}\left(\mathrm{H}_{3} \mathrm{COH}\right) . x\left(\mathrm{H}_{3} \mathrm{COH}\right) . x\left(\mathrm{H}_{3} \mathrm{COH}\right)$ : 0 (black), 0.2 (red), 0.5 (green), 0.8 (blue), 1

(light blue).

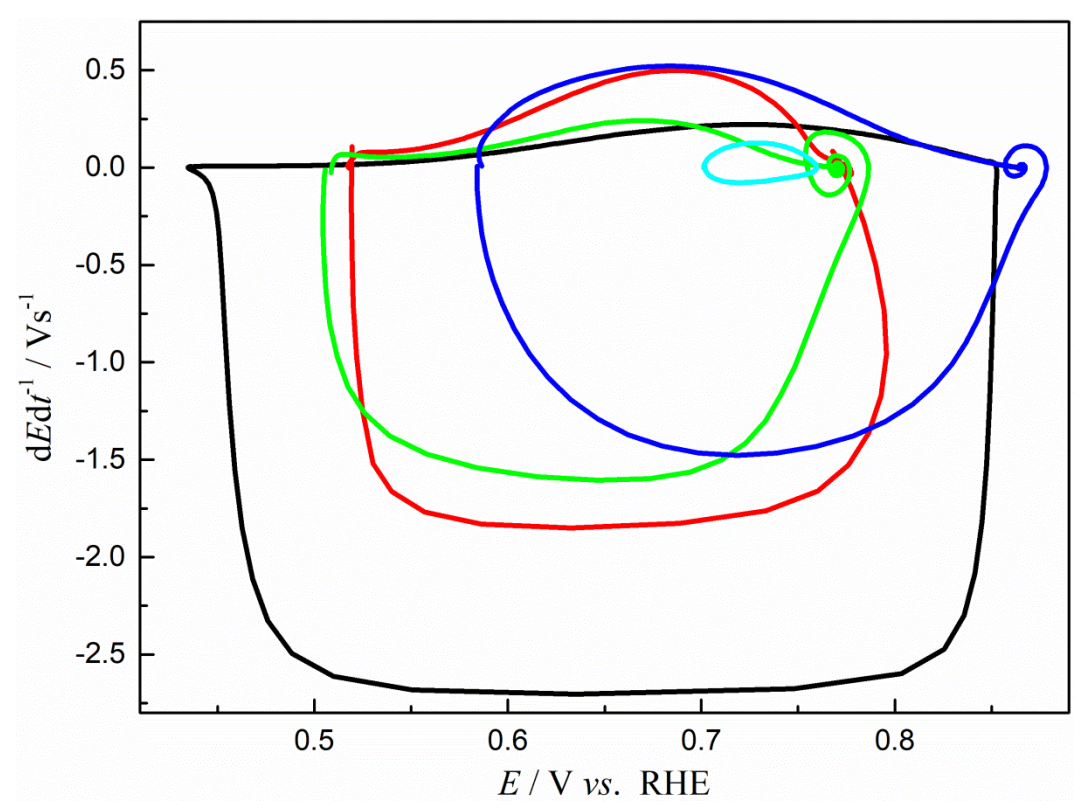


It can also be seen, that the oscillation profile remains in the formic acid-type until the molar fraction of 0.8 , which labels formic acid oxidation again as the more active and dominant process also under galvanostatic conditions, sustaining the majority of the applied current. This result is in good agreement with the ones from the steady state voltammetry, which again indicates a higher coverage of carbonaceous species, that require high overpotentials for oxidation, as the conclusion. All characteristic oscillation variables will be discussed in detail along Figure 65 and 66. Figure 65 shows some representative $\mathrm{dEdt}^{-1}$ profiles for different molar fractions of methanol and formic acid, summarizing the mentioned influence of methanol on formic acid oxidation, such as a positive shift of the visited potential and the transition of the shape. Thus, the potential dependent oscillation derivative evolves slowly in the positive part of the cycle, meaning slow surface poisoning, followed by a steep change to negative values, meaning a fast removal of inhibiting species. The presence of methanol leads to a more reversible cycle by a diminishing difference of the extrema of potential and derivative, where the general trend is highlighted in Figure 66a) and b). Thus, it can be seen, that the potential of the maximum poisoning rate is the highest for the solution of methanol, which confirms the most active formation of carbonaceous site-blocking adsorbates from methanol, which also are effectively removed.

Figure 66: a) potential of the maximum $\mathrm{dEdt}^{-1}$ rate and b) $\mathrm{dEdt}^{-1}$ of the positive part of the derivatives from Figure 65.

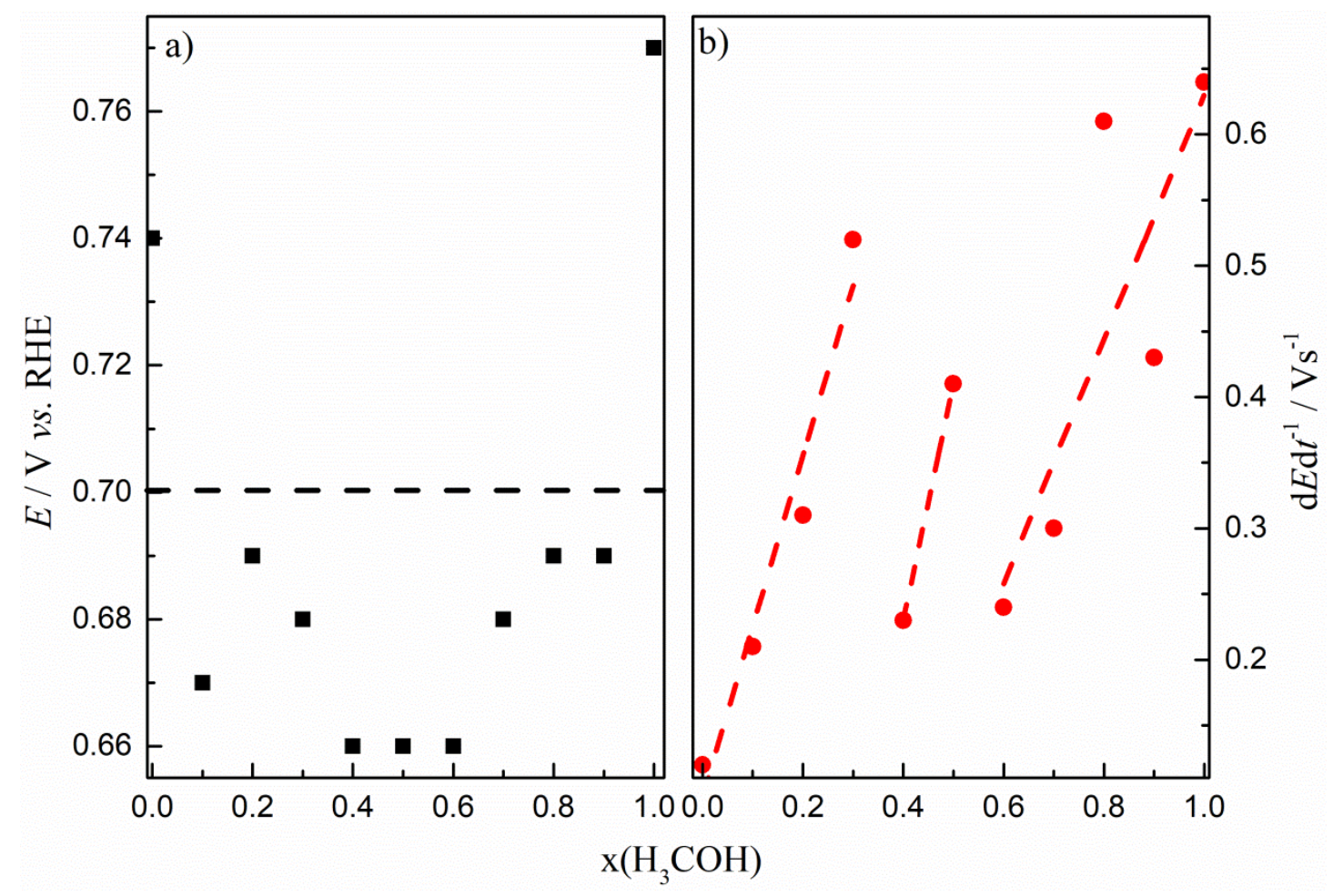


This fact is not surprising, since direct and indirect pathway share partially the same intermediates and an active formation of oxygenated species on the surface in the visited potential rage in the oscillation cycle, which are responsible for the main charge transfer sustaining the applied current density and establish the oscillation patterns. The maximum poisoning rate in formic acid solution is found at a close potential, since the initial potential increase due to $\mathrm{CO}_{\mathrm{ad}}$ leads to oxide adsorption. The formed oxides cannot free the surface effectively and also have rather site-blocking character, that the highest poisoning rate lies in that potential range. On the other hand, the mixed solutions show the maximal surface poisoning in a similar range below $0.7 \mathrm{~V}$, which is at least $0.05 \mathrm{~V}$ lower than for formic acid and methanol, which indicates a faster formation of the carbonaceous species. This point can be seen in the oscillation profiles, where the high potential part becomes more pronounced with presence of methanol. This conclusion gets further support in the higher poisoning rates compared to formic acid, again showing an incline seen in Figure 66b), which increase from almost 0 to $0.6 \mathrm{Vs}^{-1}$. Yet, it seems surprising, that the maxima of the derivative maxima indicate three different levels in dependence on the molar fraction of methanol, namely from 0 to $0.3,0.6$ to 1 and a medium branch from 0.4 and 0.5 , where the latter unfortunately just consists of 2 points. This behaviour emphasizes strongly the non-additive oxidation of formic acid and methanol, a complex network of formation and oxidation of adsorbates in various surface processes far from equilibrium, what makes it difficult to find a clear mechanistic explanation for this behaviour. A similarly complex behaviour is display for the oscillation frequency for 3 different temperatures in Figure 67. As expectable, methanol oxidation showed the overall highest oscillation frequency, which diminishes, as the temperature increases and leads to the absence of any oscillation pattern at $50{ }^{\circ} \mathrm{C}$, as it has been discussed above and reported by our group [94]. This might also be the reason for the higher oscillation frequency at a molar fraction of 0.8 and 0.9 than 0.7 . This suggests, that although formic acid is the more active process as seen in the oscillation profiles and steady state voltammetry, methanol oxidation takes place non-negligible under conditions far from equilibrium and high presence as well, which is again confirmed by the longer oscillation cycle at high overpotentials. Yet, it can also be seen, that there is a local maximum in the range from 0.2 to 0.3 molar fraction of methanol at all temperatures (at $50{ }^{\circ} \mathrm{C}$ a global maximum). The steady state voltammetry also showed the highest activities in that region, that again a high activity and an efficient oxidation of methanol and especially formic acid can be assumed here. The oscillatory regime has already been reported to be the more effective region for the electrooxidation of small organic molecules, that those interpretations are reasonable [49]. 
Figure 67: Oscillation frequencies, against the molar fraction of methanol for a) 10, b) 25 and c) $50{ }^{\circ} \mathrm{C}$. Other parameters are the same as in Figure 65.

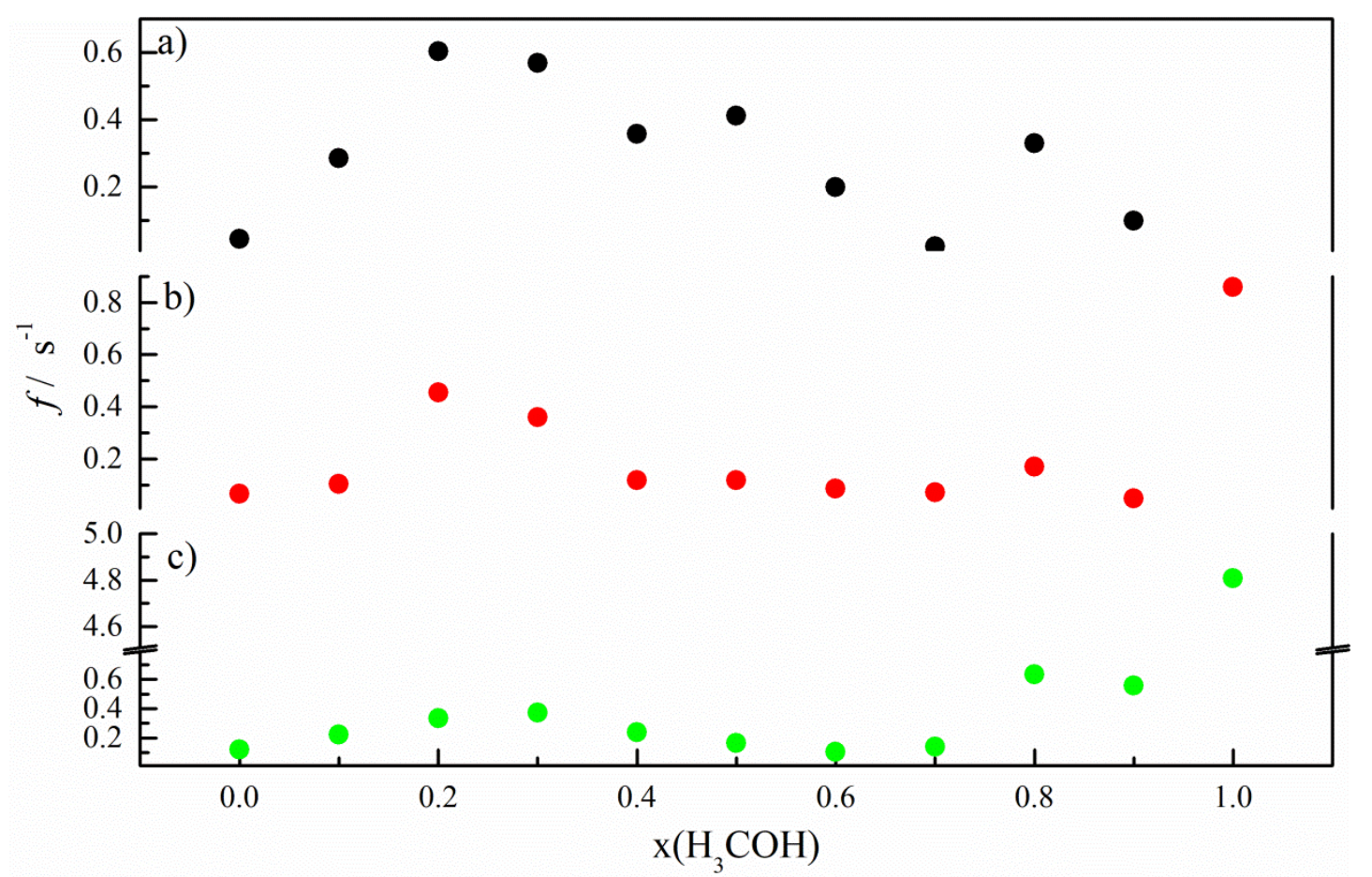

A high oscillation frequency can be seen as indicator for fast formation of carbonaceous surface poisoning, coinciding with an active oxidation via direct pathways, and also fast adsorption of oxygenanted species, what guarantees a good interaction via LangmuirHinshelwood mechanism and the consequently fast removal.

\subsection{Partial Conclusions}

Table 4 highlights the importance of methanol and formic acid, whose oxidation received much attention in literature. Their application in fuel cells shows advantages and disadvantages and lead to the study of their simultaneous oxidation (see reference 169 and references in there). As it has been reported earlier, this worked showed a synergetic, nonadditive oxidation of formic acid and methanol, where the highest activity was found for a solution containing 1.6 M HCOOH and $0.4 \mathrm{M} \mathrm{H}_{3} \mathrm{COH}[177,182,183]$. The systematic study of the electrochemical response in all solutions by chronopotentiometry confirm the supporting effect of methanol for formic acid oxidation, where the solution containing a molar faction of 0.2 and 0.3 showed the highest oscillation frequency besides the solutions of high methanol content. In general, steady state voltammetry and potential oscillations show a 
constant transition between the profiles of purely containing methanol and formic acid solutions and label the latter as the more active process. The deeper analysis of the deconvoluted voltammograms and derivatives of oscillation cycles indicate, that methanol influences formic acid oxidation via the adsorption of other carbonaceous species than just $\mathrm{CO}_{\mathrm{ad}}$, which may inhibit $\mathrm{CO}$ formation, consume adsorbed oxygenated species and thus, allow a more active formic acid oxidation via its direct oxidation pathway, as previously reported by El-Deab et al. [177]. Yet, the potential time series in all mixed solutions showed various patterns in different time scales, which suggests a complex response and interaction of all surface processes, that makes a deep understanding and insight difficult. 


\section{Concluding remarks}

This section summarizes the results and the corresponding conclusions, which were achieved in this work 
The principal objective of this work was the detailed study of formic acid and methanol oxidation in dependence on temperature and $\mathrm{pH}$ in a wide range, which was done by steady state voltammetry, impedance spectroscopy and with special focus on the oscillatory regime under galvanostatic conditions. Aside these investigations formic acid oxidation was studied on PtAu alloys of different contents and under the simultaneous electro-oxidation of methanol. Thus, the following conclusions could be achieved:

- Results from literature in the $\mathrm{pH}$ dependent, potentiodynamic oxidation of formic acid could be reproduced and indicated weakly adsorbed formate as main active species in the direct oxidation pathway. Besides this fact, formic acid oxidation showed a linear dependence of the peak maximum current in the cathodic voltammetric sweep indicating a possible third pathway with a non-negligible contribution in the acidic $\mathrm{pH}$ range beyond the $\mathrm{pK}_{\mathrm{a}}$. Bridge-bonded formate is a possible active intermediate in this third reaction pathway.

- The pH dependence of methanol oxidation demonstrated a linear behaviour of the peak maximum current density in the complete range, which can be related to a crucial role of formic acid as active side product in the afore mentioned mechanism in the overall oxidation of methanol.

- Potential oscillations in the known form from literature are limited for both molecules to the $\mathrm{pH}$ range from 0 to 3 , which are governed particularly by the $\mathrm{pH}$ dependent adsorption of $\mathrm{CO}_{\mathrm{ad}}$ and $\mathrm{HCOO}_{\mathrm{B}}$, but also anion adsorption and surface oxidation, as it was found in ATR-SEIRA and differential reflectance spectroscopy. Different oscillation patterns were newly found along formic acid oxidation in alkaline media, where the simultaneous recorded SEIRA spectra showed an oscillating coverage of water species. Yet, the complete oscillation mechanism in this $\mathrm{pH}$ range remained hidden.

- The results of $\mathrm{pH}$ and temperature dependent voltammetric and galvanostatic oxidation of formic acid and methanol could give more insight in the role of oxygenated species in the reaction mechanism, that must be seen differentiated and labels surfaces oxides either as active adsorbate or site-blocking inhibitor.

- Formic acid oxidation on Au-alloyed Pt nanoparticles and in presence of methanol demonstrated an enhanced activity, where an effective $\mathrm{CO}_{\mathrm{ad}}$ suppression can be assumed by ensemble effects or the adsorption of other carbonaceous species. 
- The simultaneous electro-oxidation of methanol and formic acid reveal an enhancing effect, due to the adsorption of carbonaceous spieces, that can inhibit $\mathrm{CO}$ formation and contribute to the overall oxidation current. Under oscillating conditions a more effective interaction of carbonaceous and oxygenated species is found, but requires higher overpotentials because of the faster surface poisoning than in absence of methanol.

Summarizing, the electro-oxidation of formic acid and methanol oxidation take place in a complex network of various, directly or indirectly related adsorption processes, each of them being sensitive to the applied parameters, such as potential, current density, temperature, $\mathrm{pH}$, surface configuration and time amongst others. 


\section{Perspective and outlook}

This chapter is meant to highlight the mechanistic insight that can be given by studying electrochemical systems far from equilibrium and give a short outlook to possible future works. This is also done by the brief discussion of other oscillating systems, which have been studied in the oscillating regime in parallel to this work, namely the electro-oxidation of formaldehyde over $\mathrm{Pt}_{\mathrm{x}} \mathrm{Au}_{\mathrm{y}}$ nanoparticles of different composition and formic acid oxidation over A Pd bulk electrode. 


\subsection{Introduction}

Recent studies in steady state and far from equilibrium, in theory and experiment, from our group and other institutes could deepen the understanding of the surface processes on Ptbased electrodes and their role in the electro-oxidation mechanism of methanol and formic acid (see references). Yet, there remain several challenges to face, that allow a successful application of fuel cells as a sustainable, commercially profitable alternative of high performance to other energy converters. Especially the lack of long term stability, efficiency, fuel availability and product management are to mention here amongst others. This section should give a concise overview on briefly studied systems regarding the electro-oxidation of small organic molecules.

\subsection{Galvanostatic oxidation of $\mathrm{HCOH}$ on $\mathrm{Pt}_{\mathrm{x}} \mathrm{Au}_{\mathrm{y}}$}

The applied PtAu alloyed nanoparticles on formic acid oxidation (see section 5) were also used to study the electro-oxidation of formaldehyde by steady state voltammetry (performed by the collaborators from Universidade Federal de São Carlos and not shown) and chronopoteniometric measurements, which are shown in Figure 68. Previous publications on galvanostatic oxidation of formaldehyde over Pt showed several types of potential oscillation, including the displayed patterns in Figure 68a), which thus, were used as reference for the alloying effect of $\mathrm{Au}[16,18,51,184-190]$. Yet, the literature reported mixed mode oscillations of higher period along the galvanostatic formaldehyde oxidation, where the surface coverage changes accordingly, depending on the applied parameters and time [18,51]. In our case, just period-1 oscillations could be observed, propably due to the greater electro-acitve area on $\mathrm{Pt}$ nanoparticles than conventional bulk electrodes. Generally, formaldehyde is known to get oxidized via the described dual-pathway mechanism, forming $\mathrm{CO}_{2}$, where the indirect reaction pathway takes place via the inhibiting intermediate $\mathrm{CO}_{\mathrm{ad}}$ and just becomes oxidized by activated oxygenated species at high overpotentials. On the other hand the intermediate in the direct pathway still remains under discussion, where the hydrated form of formaldehyde $\mathrm{CH}_{2}(\mathrm{OH})_{2}$ is thought to be active. It is likely, that formic acid, formed as sideproduct has an influence on both pathways, as it was described above for methanol oxidation. Consequently, potential instabilities occur due to the afore described mechanism for methanol and formic acid oxidation. As Figure 68b)-e) and Table 5 highlight, the alloying with Au has impacts in 
the same fashion on the potential oscillations of formaldehyde oxidation on the alloyed nanoparticles, as it was found for formic acid oxidation, namely an increasing amplitude and oscillation frequency and a diminishing time scale. Also as for formic acid oxidation, no potential oscillations were found on the nanoparticles of high Au content. So the same ligand and electronic effects can be assumed to be active, which suppress $\mathrm{CO}$ formation, leading to a higher oxidation efficiency via the direct pathway. Yet, differently to the oscillations in Figure 28, the oscillation profiles show a more pronounced part on $\mathrm{Pt}_{3} \mathrm{Au}$ and $\mathrm{PtAu}$ than for Pt. Since the measurements were carried out under similar experimental parameters, this behaviour must have its origin in mechanistic differences between formaldehyde and formic acid and suggests the adsorbance of other carbonaceous species than $\mathrm{CO}$ on the surface, which require higher overpotential for their removal via the oxidation by surface oxides. This has already been reported and described above for methanol oxidation as well as formaldehyde, where $\mathrm{HCO}$ and $\mathrm{COH}$ were suggested as possible candidates [16,18,93]. As Figure 68b)-e) and Table 5 highlight, the alloying with Au has impacts in the same fashion on the potential oscillations of formaldehyde oxidation on the alloyed nanoparticles, as it was found for formic acid oxidation, namely an increasing amplitude and oscillation frequency and a diminishing time scale.

Figure 68: Potential time series of $\mathrm{HCOH}$ oxidation on nanoparticles of a) $\mathrm{Pt}$, b) $\mathrm{Pt}_{3} \mathrm{Au}$, c) PtAu, d) $\mathrm{PtAu}_{3}$ and e) PtAu . The panels on right in Figure a), b) and c) show an expanded view of the oscillation patterns. Applied normalized current density 0.2.

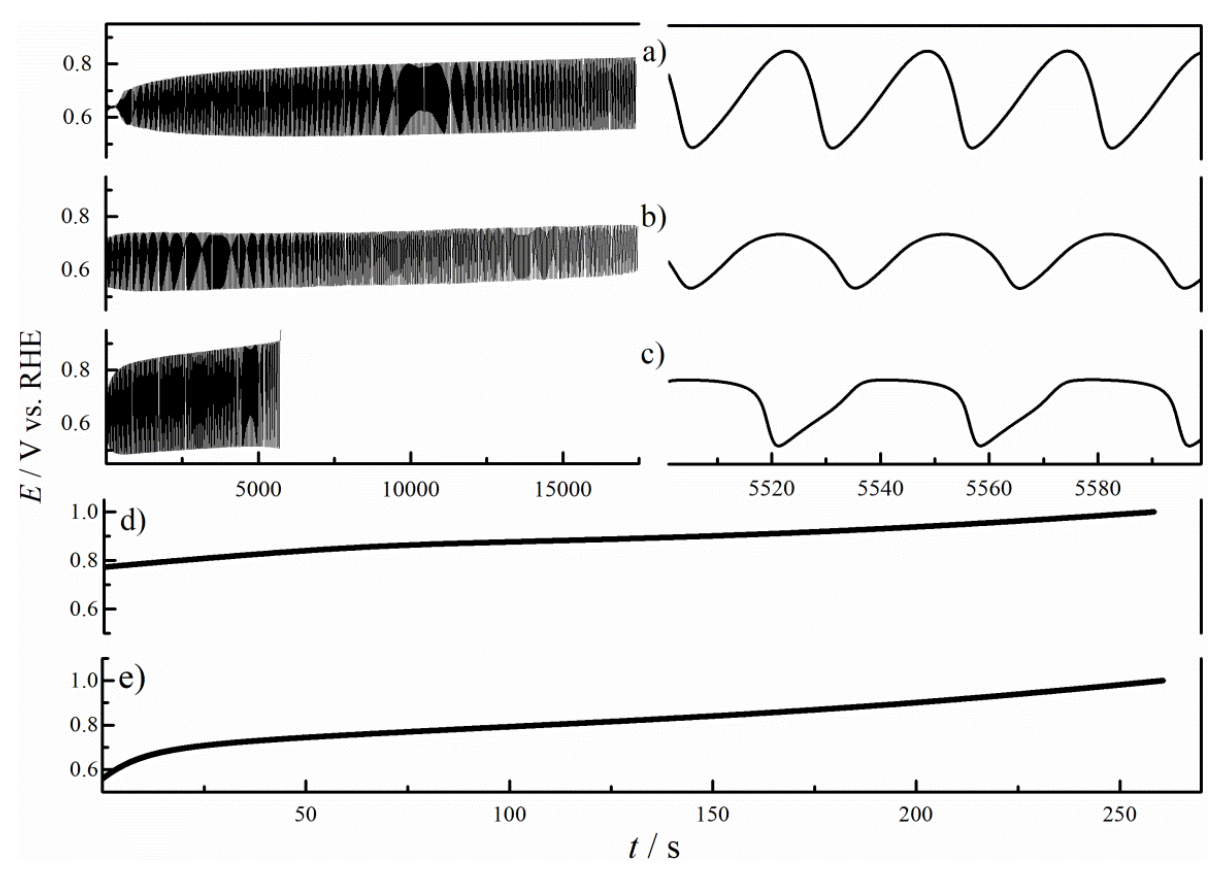


Table 5: Oscillation parameters obtained from Figure 68.

\begin{tabular}{|c|c|c|c|}
\hline & $\mathrm{Pt}$ & $\mathrm{Pt}_{3} \mathrm{Au}$ & $\mathrm{PtAu}$ \\
\hline Amplitude / V & $0.53-0.78$ & $0.53-0.74$ & $0.51-0.91$ \\
\hline Frequency / $\mathrm{mHz}$ & 38 & 33 & 26 \\
\hline Min/Max dE dt ${ }^{-1} / \mathrm{mV} \mathrm{s}^{-1}$ & $-0.07 / 0.02$ & $-0.03 / 0.02$ & $-0.12 / 0.03$ \\
\hline
\end{tabular}

Also as for formic acid oxidation, no potential oscillations were found on the nanoparticles of high Au content. So the same ligand and electronic effects can be assumed to be active, which suppress CO formation, leading to a higher oxidation efficiency via the direct pathway. Yet, differently to the oscillations in Figure 28, the oscillation profiles show a more pronounced part on $\mathrm{Pt}_{3} \mathrm{Au}$ and $\mathrm{PtAu}$ than for Pt. Since the measurements were carried out under similar experimental parameters, this behaviour must have its origin in mechanistic differences between formaldehyde and formic acid and suggests the adsorbance of other carbonaceous species than $\mathrm{CO}$ on the surface, which require higher overpotential for their removal via the oxidation by surface oxides. This has already been reported and described above for methanol oxidation as well as formaldehyde, where $\mathrm{HCO}$ and $\mathrm{COH}$ were suggested as possible candidates $[16,18,93]$.

Figure 69: Derivatives of distinct oscillation cycles from Figure 68 against the measured potential. Pt (black), $\mathrm{Pt}_{3} \mathrm{Au}$ (red), $\mathrm{PtAu}$ (green).

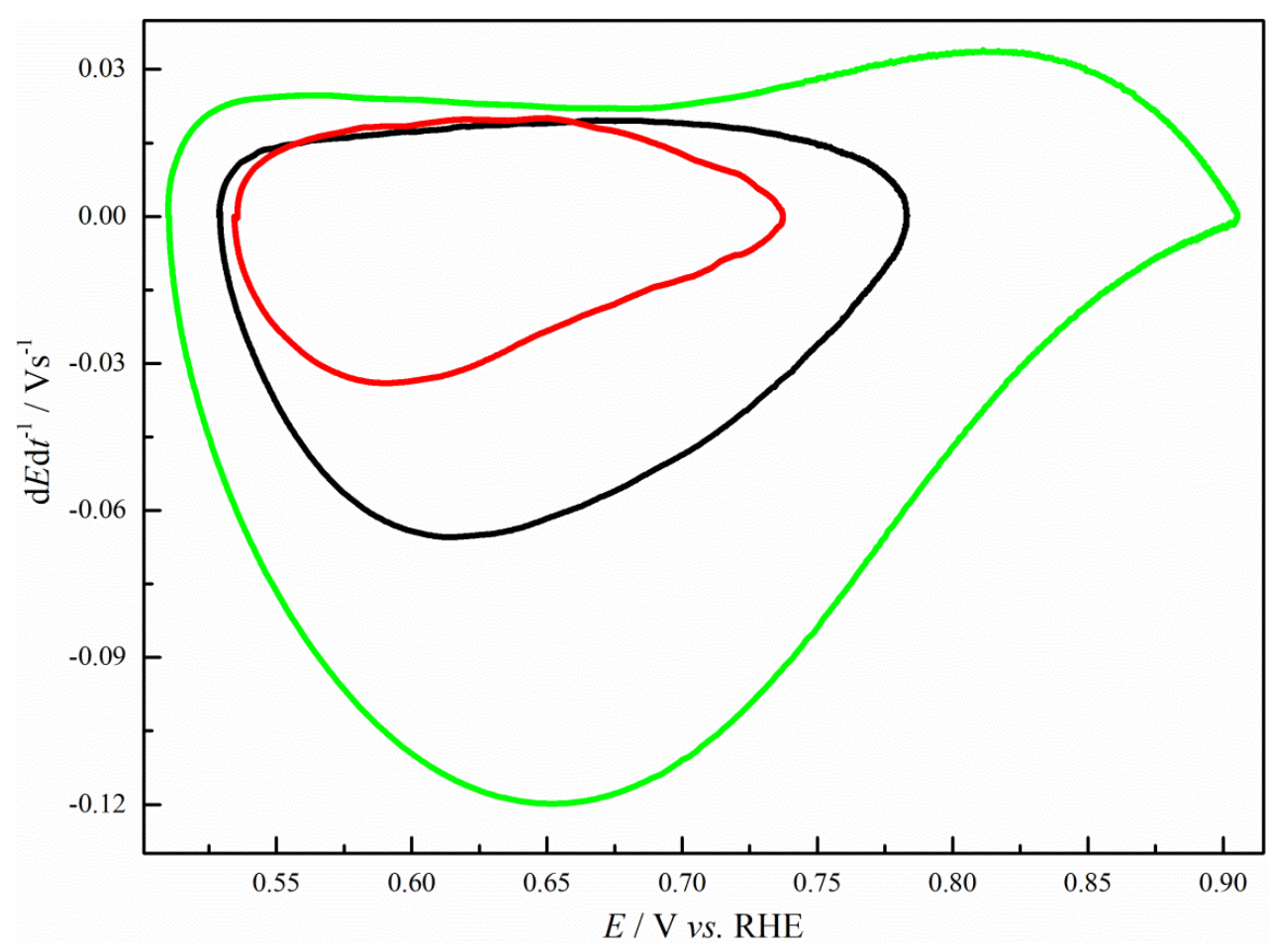


The derivatives of distinct oscillation cycles on $\mathrm{Pt}, \mathrm{Pt}_{3} \mathrm{Au}$ and $\mathrm{PtAu}$ are plotted in Figure 69, which show a double sided effect of Au, similar as for formic acid oxidation. Thus, the oscillations $\mathrm{Pt}_{3} \mathrm{Au}$ visit a smaller range of potentials and the decreasing cycle in the negative half, meanwhile the positive part remains the same shape. This result suggests, that the smaller active area due to the presence of $\mathrm{Au}$ has a more pronounced influence than ligand and electronic effects and leads to a faster surface poisoning and a slower autocleaning process. On the other hand on PtAu a wider potential amplitude can be seen besides higher poisoning rates in a higher potential range and significantly more efficient removal of poisoning species in the negative half of the cycle, which again indicate a successful suppression of $\mathrm{CO}$ formation on the PtAu nanoparticles. Interestingly, the profile of the limiting cycle for PtAu adjusts to the shape of formic acid oxidation, as it is demonstrated in Figure 17b). The importance of formic acid as reactive side product has already been discussed for methanol oxidation and may surface here as well and finds its relevance here along formaldehyde oxidation as well.

\subsection{HCOOH oxidation on Pd}

Since Palladium shows besides Pt the highest activites in hydrogen evolution and oxidation, Pd-based catalysts are considered as a promising candidates for an application as anode in fuel cells. Considering the higher availability and less costs in production, Pd electrodes may be the favoured, noble metal compared to Pt. Yet, to the best of my knowledge there are no studies on the electro-oxidation of small organic molecules on $\mathrm{Pd}$ in the oscillatory regime, except few for formic acid [84,191,192]. The steady state voltammograms of a Pd bulk electrode in 0.5 and $2 \mathrm{M} \mathrm{HCOOH}+0.5 \mathrm{H}_{2} \mathrm{SO}_{4}$ are plotted in Figure 70 . As it can be clearly seen, the potentiodynamic profiles differ drastically from the ones of Pt. Formic acid oxidation is active in the complete double layer region between 0.2 and 0.8 , where it is limited by the underpotential deposition of hydrogen and surface oxidation, respectively. Contrary to $\mathrm{Pt}$, the voltammograms reveal one main oxidation peak with its maximum between 0.3 and $0.5 \mathrm{~V}$ and a shoulder at more positive potentials between 0.7 and $0.8 \mathrm{~V}$ in dependence on the formic acid concentration in good agreement to earlier studies $[84,191,192]$. Meanwhile the main peak may represent the active formic acid oxidation via the direct pathway, the side peak may be related to oxidation of trace $\mathrm{CO}_{\mathrm{ad}}$, which suggests a minor activity of the indirect pathway. This interpretation is supported by the slight hysteresis 
between anodic and cathodic scan, suggesting a highly reversible, almost uninhibited formic acid oxidation as it is found on Au electrodes [76]. This behaviour also is reported in literature and highlights the catalytic advantages of Pd over Pt [192].

Figure 70: Steady state voltammograms of $\mathrm{Pd}$ in 0.5 (black) and 2 (red) $\mathrm{M} \mathrm{HCOOH}+0.5 \mathrm{M}$ $\mathrm{H}_{2} \mathrm{SO}_{4}$.

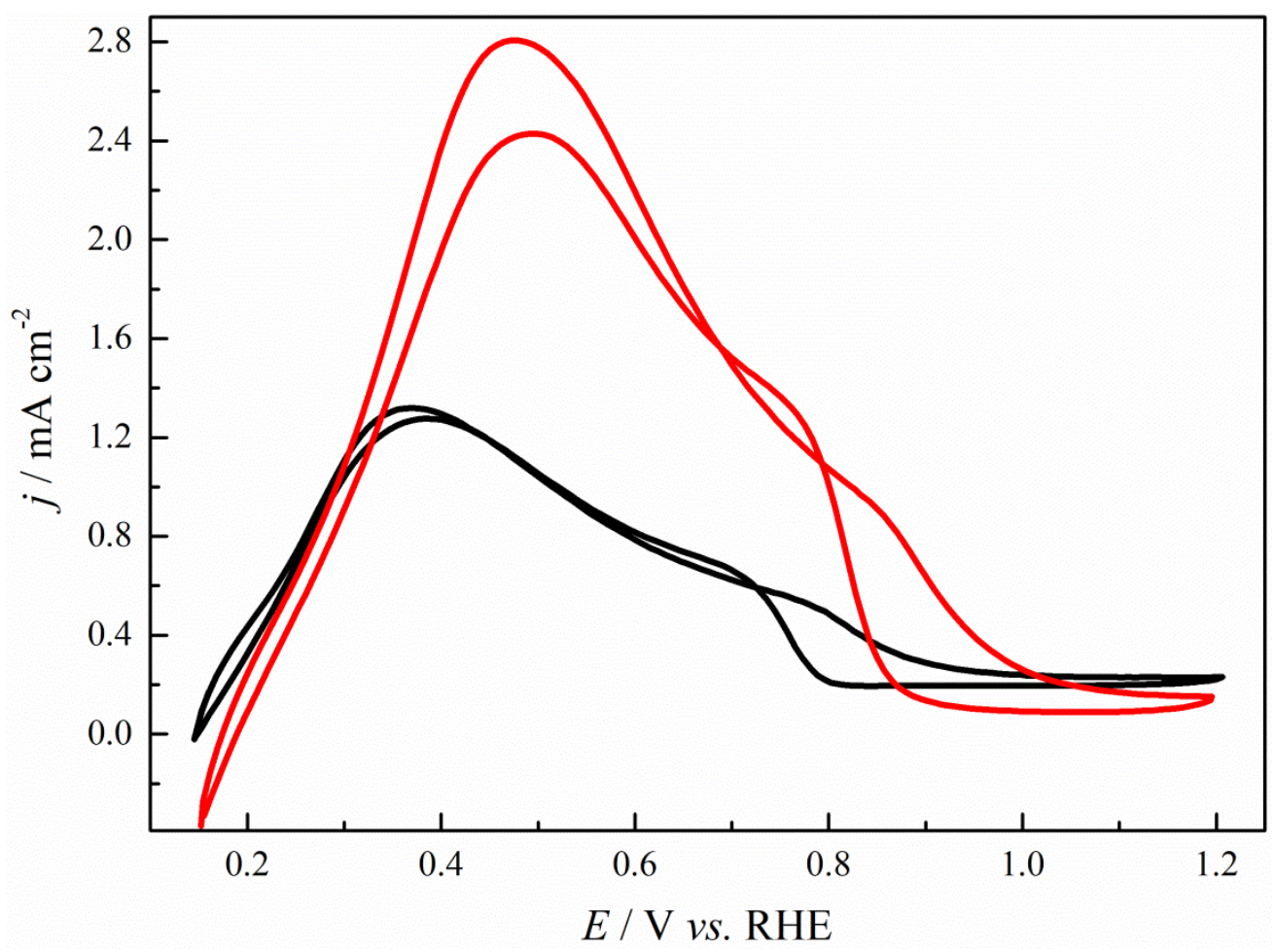

The performed galvanostatic measurements for the oscillatory analysis of formic acid oxidation on Pd are plotted in Figure 71a) and b) for both applied concentrations, which confirm the interpretations from the steady state voltammetry. At $0.5 \mathrm{M} \mathrm{HCOOH}$ only some potential instabilities can be seen at $0.2 \mathrm{~mA} \mathrm{~cm}^{-2}$, which show a chaotic and aperiodic behaviour and could not be found at $0.33 \mathrm{~mA} \mathrm{~cm}^{-2}$. Again this behaviour indicates, that the formation of $\mathrm{CO}_{\mathrm{ad}}$ is present, but not sufficient to block the dehydrogenation pathway and just require overpotentials around $0.6 \mathrm{~V}$, where the surface oxidation on Pd starts, to be removed. Yet, by increasing the formic acid bulk concentration, periodic oscillations could also be found, which show a wide amplitude between 0.25 and $1 \mathrm{~V}$ and period 200-300 s. Both parameters are significantly higher than on Pt. The absence of any oscillation pattern at higher applied current densities and the oscillating behaviour are in good agreement to the literature and are sign again, that $\mathrm{CO}$ formation is not a highly active process like on $\mathrm{Pt}$ and the surface is faster covered by oxygenated species, leading to a fast increase to potentials in the oxygen evolution [84,192]. 
Figure 71: Potential time series of a) $0.5 \mathrm{M} \mathrm{HCOOH}+0.5 \mathrm{M} \mathrm{H}_{2} \mathrm{SO}_{4}$ with applied current densities of 0.2 (black) and $0.33 \mathrm{~mA} \mathrm{~cm}^{-2}$ (red) and b) $0.5 \mathrm{M} \mathrm{HCOOH}+0.5 \mathrm{M} \mathrm{H}_{2} \mathrm{SO}_{4}$ with applied current densities of 0.13 (black) and $0.2 \mathrm{~mA} \mathrm{~cm}^{-2}$ (red).

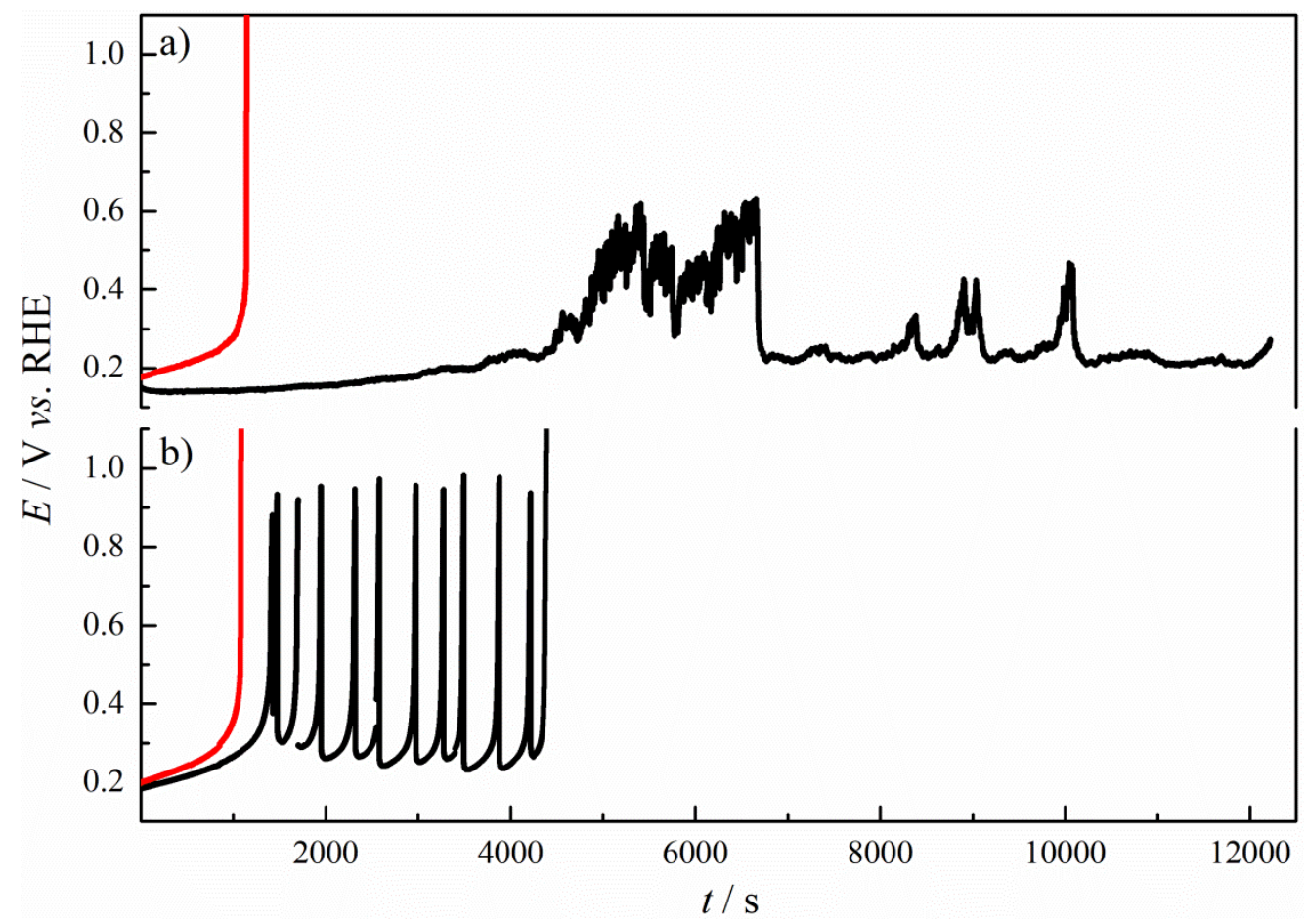

As it has been shown in this work and others, the oscillatory regime can allow another point of view on the electro-oxidation of small organic molecules and shed more light in the complex reaction mechanism and related processes. Meanwhile the efforts of the last decades may have revealed the most important facts on the oxidation mechanism of formic acid and other C1-species to some extend, many problems for an effective application of fuel cells need to be solved, such as the tailoring of a cheap and efficient anode catalyst. There already is a vast literature on bi- and ternary Pt-alloy catalysts (see for example reference [193] and references in there), but few studies were done far from equilibrium [44,45,111]. As it also has been shown, there are possibilities in tailoring the solution characteristics, that allow an enhancement in effectivity $[177,181]$. Since the oxidation under oscillating conditions was proven to be the more effective one compared to conventional stationary methods, it may be a promising field for further studies with the power to solve the energy problem of our time. 


\section{References}

This sections contains all references cited in this work. 
[1] K. Leong, A. Sung, A review of spatio-temporal pattern analysis approaches on crime analysis, Int. E-Journal Crim. Sci. 9 (2015) 1-33.

[2] H. Meng, W.-J. Xie, Z.-Q. Jiang, B. Podobnik, W.-X. Zhou, H.E. Stanley, Systemic risk and spatiotemporal dynamics of the US housing market, Sci. Rep. 4 (2014) 3655.

[3] R.E. Wilson, Mechanisms for spatio-temporal pattern formation in highway traffic models, Philos. Trans. R. Soc. London A Math. Phys. Eng. Sci. 366 (2008) 2017-2032.

[4] J.A.S. Kelso, Dynamic Patterns: The Self-Organization of Brain and Behavior (Complex Adaptive Systems), The MIT Press, 1995.

[5] H. Ringsdorf, B. Schlarb, J. Venzmer, Molecular Architecture and Function of Polymeric Oriented Systems: Models for the Study of Organization, Surface Recognition, and Dynamics of Biomembranes, Angew. Chemie Int. Ed. English. 27 (1988) 113-158.

[6] E. Şahin, Swarm Robotics: From Sources of Inspiration to Domains of Application BT - Swarm Robotics, in: E. Şahin, W.M. Spears (Eds.), Springer Berlin Heidelberg, Berlin, Heidelberg, 2005: pp. 10-20.

[7] A.M. Zhabotinsky, Periodic oxidizing reactions in the liquid phase, Dokl. Akad. Nauk SSSR. 157 (1964) 392-395.

[8] Z. Zhang, Y. Wang, Z. Qi, W. Zhang, J. Qin, J. Frenzel, Generalized Fabrication of Nanoporous Metals (Au, Pd, Pt, Ag, and $\mathrm{Cu}$ ) through Chemical Dealloying, J. Phys. Chem. C. 113 (2009) 12629-12636. doi:10.1021/jp811445a.

[9] P.-A. Geslin, I. McCue, B. Gaskey, J. Erlebacher, A. Karma, Topology-generating interfacial pattern formation during liquid metal dealloying, Nat. Commun. 6 (2015) 8887. http://dx.doi.org/10.1038/ncomms9887.

[10] J. Yang, Y. Song, H. Varela, I.R. Epstein, W. Bi, H. Yu, Y. Zhao, Q. Gao, The effect of chloride on spatiotemporal dynamics in the electro-oxidation of sulfide on platinum, Electrochim. Acta. 98 (2013) 116-122. doi:https://doi.org/10.1016/j.electacta.2013.03.042.

[11] W. Bi, Y. He, M.F. Cabral, H. Varela, J. Yang, R. Jiang, Q. Gao, Oscillatory electrooxidation of thiosulfate on gold, Electrochim. Acta. 133 (2014) 308-315. 
doi:https://doi.org/10.1016/j.electacta.2014.04.055.

[12] T. Matsuda, H. Hommura, Y. Mukouyama, S. Yae, Y. Nakato, New Current and Potential Oscillations for Reduction Reactions on Platinum Electrodes in Acid Solutions Containing High Concentration Hydrogen Peroxide, J. Electrochem. Soc. . 144 (1997) 1988-1994. doi:10.1149/1.1837733.

[13] S. Nakanishi, Y. Mukouyama, K. Karasumi, A. Imanishi, N. Furuya, Y. Nakato, Appearance of an Oscillation through the Autocatalytic Mechanism by Control of the Atomic-Level Structure of Electrode Surfaces in Electrochemical H2O2 Reduction at Pt Electrodes, J. Phys. Chem. B. 104 (2000) 4181-4188. doi:10.1021/jp993961c.

[14] Y. Mukouyama, S. Nakanishi, H. Konishi, K. Karasumi, Y. Nakato, Observation of two stationary states of low and high $\mathrm{H} 2 \mathrm{O} 2$-reduction currents at a Pt electrode $\{$, arising from the occurrence of a positive feedback mechanism including solutionstirring by gas evolution, Phys. Chem. Chem. Phys. 3 (2001) 3284-3289. doi:10.1039/B101077H.

[15] S. Chen, M. Schell, Bistability and excitability in the electrochemical oxidation of ethanol, Electrochim. Acta. 44 (1999) 4773-4780. doi:https://doi.org/10.1016/S00134686(99)00263-7.

[16] M. Schell, F.N. Albahadily, J. Safar, Y. Xu, Characterization of oscillatory states in the electrochemical oxidation of formaldehyde and formate/formic acid, J. Phys. Chem. 93 (1989) 4806-4810. doi:10.1021/j100349a025.

[17] H. Okamoto, N. Tanaka, M. Naito, Chaos in the Oxidation of Formaldehyde and/or Methanol, J. Phys. Chem. A. 101 (1997) 8480-8488. doi:10.1021/jp971858m.

[18] H. Okamoto, N. Tanaka, M. Naito, Chaotic and Periodic Potential Oscillations in Formaldehyde Oxidation, J. Phys. Chem. A. 102 (1998) 7343-7352. doi:10.1021/jp981292h.

[19] M. Schell, Y. Xu, Z. Zdraveski, Mechanism for the Electrocatalyzed Oxidation of Glycerol Deduced from an Analysis of Chemical Instabilities, J. Phys. Chem. 100 (1996) 18962-18969. doi:10.1021/jp961195t.

[20] M.G.T. FECHNER, Zur Elektrochemie, Ueber Umkehrungen der Polarität der 
einfachen Kette, J. Chem. Phys. 53 (1828) 129-151.

[21] E. Ticianelli, E.R. Gonzalez, princípios e aplicações, in: Eletroquímica, Edusp, São Paulo, 2002: p. 224.

[22] M. Naderian, A. Groß, From single molecules to water networks: Dynamics of water adsorption on Pt(111), J. Chem. Phys. 145 (2016) 094703. doi:10.1063/1.4961870.

[23] A. Michaelides, Density functional theory simulations of water-metal interfaces: waltzing waters, a novel 2D ice phase, and more, Appl. Phys. A. 85 (2006) 415-425. doi:10.1007/s00339-006-3695-9.

[24] S. Meng, E.G. Wang, S. Gao, Water adsorption on metal surfaces: A general picture from density functional theory studies, Phys. Rev. B. 69 (2004) 195404. doi:10.1103/PhysRevB.69.195404.

[25] T. Gojuki, Y. Numata, Y. Mukouyama, H. Okamoto, Hidden negative differential resistance in the oxidation of formic acid on platinum, Electrochim. Acta. 129 (2014) 142-151. doi:https://doi.org/10.1016/j.electacta.2014.02.102.

[26] M. Osawa, M. Tsushima, H. Mogami, G. Samjeské, A. Yamakata, Structure of Water at the Electrified Platinum-Water Interface: A Study by Surface-Enhanced Infrared Absorption Spectroscopy, J. Phys. Chem. C. 112 (2008) 4248-4256. doi:10.1021/jp710386g.

[27] B. V Tilak, B.E. Conway, H. Angerstein-Kozlowska, The real condition of oxidized pt electrodes: Part III. Kinetic theory of formation and reduction of surface oxides, J. Electroanal. Chem. Interfacial Electrochem. 48 (1973) 1-23. doi:https://doi.org/10.1016/S0022-0728(73)80290-6.

[28] B.E. Conway, Electrochemical oxide film formation at noble metals as a surfacechemical process, Prog. Surf. Sci. 49 (1995) 331-452. doi:https://doi.org/10.1016/0079-6816(95)00040-6.

[29] H. Angerstein-Kozlowska, B.E. Conway, B. Barnett, J. Mozota, The role of ion adsorption in surface oxide formation and reduction at noble metals: General features of the surface process, J. Electroanal. Chem. Interfacial Electrochem. 100 (1979) $417-$ 446. doi:https://doi.org/10.1016/S0022-0728(79)80176-X. 
[30] N.M. Marković, T.J. Schmidt, B.N. Grgur, H.A. Gasteiger, R.J. Behm, P.N. Ross, Effect of Temperature on Surface Processes at the Pt(111)-Liquid Interface: Hydrogen Adsorption, Oxide Formation, and CO Oxidation, J. Phys. Chem. B. 103 (1999) 85688577. doi:10.1021/jp991826u.

[31] D. Strmcnik, Kodama, D. van der Vliet, J. Greeley, V.R. Stamenkovic, N.M. Marković, The role of non-covalent interactions in electrocatalytic fuel-cell reactions on platinum, Nat. Chem. 1 (2009) 466-472. http://dx.doi.org/10.1038/nchem.330.

[32] M.C. Santos, D.W. Miwa, S.A.S. Machado, Study of anion adsorption on polycrystalline Pt by electrochemical quartz crystal microbalance, Electrochem. Commun. 2 (2000) 692-696.

[33] P.W. Faguy, N. Markovic, R.R. Adzic, C.A. Fierro, E.B. Yeager, A study of bisulfate adsorption on $\mathrm{Pt}(111)$ single crystal electrodes using in situ Fourier transform infrared spectroscopy, J. Electroanal. Chem. Interfacial Electrochem. 289 (1990) 245-262. doi:https://doi.org/10.1016/0022-0728(90)87220-E.

[34] F.C. Nart, T. Iwasita, M. Weber, Sulfate adsorption on well-defined $\operatorname{Pt(100)~electrodes,~}$ Electrochim. Acta. 39 (1994) 2093-2096. doi:https://doi.org/10.1016/00134686(94)85094-1.

[35] A. Kolics, A. Wieckowski, Adsorption of Bisulfate and Sulfate Anions on a Pt(111) Electrode, J. Phys. Chem. B. 105 (2001) 2588-2595. doi:10.1021/jp003536f.

[36] T. Fujitani, Y. Choi, M. Sano, Y. Kushida, J. Nakamura, Scanning Tunneling Microscopy Study of Formate Species Synthesized from CO2 Hydrogenation and Prepared by Adsorption of Formic Acid over Cu(111), J. Phys. Chem. B. 104 (2000) 1235-1240. doi:10.1021/jp9920242.

[37] L.A. Kibler, M. Al-Shakran, Adsorption of Formate on Au(111) in Acid Solution: Relevance for Electro-Oxidation of Formic Acid, J. Phys. Chem. C. 120 (2016) 1623816245. doi:10.1021/acs.jpcc.6b02044.

[38] S.H. (Steven H. Strogatz, Nonlinear dynamics and chaos : with applications to physics, biology, chemistry, and engineering, Second edition. Boulder, CO : Westview Press, a member of the Perseus Books Group, [2015], n.d. https://search.library.wisc.edu/catalog/9910223127702121. 
[39] K. Krischer, H. Varela, Oscillations and other dynamic instabilities, in: Handb. Fuel Cells, John Wiley \& Sons, Ltd, 2010. doi:10.1002/9780470974001.f206052.

[40] M. Orlik, Self-Organization in Electrochemical Systems I: General Principles of Selforganization. Temporal Instabilities, Springer Berlin Heidelberg, 2012. https://books.google.com.br/books?id=T7P4TzbPZdEC.

[41] M. Koper, Non-linear phenomena in electrochemical systems, J. Chem. Soc. Faraday Trans. 94 (1998) 1369-1378.

[42] M.T.M. Koper, J.H. Sluyters, Instabilities and oscillations in simple models of electrocatalytic surface reactions, J. Electroanal. Chem. 371 (1994) 149-159. doi:https://doi.org/10.1016/0022-0728(93)03248-N.

[43] R. Nagao, D.A. Cantane, F.H.B. Lima, H. Varela, The dual pathway in action: decoupling parallel routes for $\mathrm{CO} 2$ production during the oscillatory electro-oxidation of methanol, Phys. Chem. Chem. Phys. 14 (2012) 8294-8298. doi:10.1039/C2CP00037G.

[44] N. Perini, E. Sitta, A.C.D. Angelo, H. Varela, Electrocatalytic activity under oscillatory regime: The electro-oxidation of formic acid on ordered Pt3Sn intermetallic phase, Catal. Commun. 30 (2013) 23-26. doi:https://doi.org/10.1016/j.catcom.2012.10.019.

[45] N. Perini, B.C. Batista, A.C.D. Angelo, I.R. Epstein, H. Varela, Long-Lasting Oscillations in the Electro-Oxidation of Formic Acid on PtSn Intermetallic Surfaces, ChemPhysChem. 15 (2014) 1753-1760. doi:10.1002/cphc.201301186.

[46] E.G. Machado, H. Varela, Complex Dynamics in the Electro-Oxidation of Formic Acid Assisted by Hydrazine in Acidic Media, J. Electrochem. Soc. . 163 (2016) H186-H191. doi:10.1149/2.0671603jes.

[47] E. Boscheto, B.C. Batista, R.B. Lima, H. Varela, A surface-enhanced infrared absorption spectroscopic (SEIRAS) study of the oscillatory electro-oxidation of methanol on platinum, J. Electroanal. Chem. 642 (2010) 17-21. doi:https://doi.org/10.1016/j.jelechem.2010.01.026.

[48] M.V.F. Delmonde, M.A. Nascimento, R. Nagao, D.A. Cantane, F.H.B. Lima, H. Varela, Production of Volatile Species during the Oscillatory Electro-oxidation of 
Small Organic Molecules, J. Phys. Chem. C. 118 (2014) 17699-17709. doi:10.1021/jp5044915.

[49] M.V.F. Delmonde, L.F. Sallum, N. Perini, E.R. Gonzalez, R. Schlögl, H. Varela, Electrocatalytic Efficiency of the Oxidation of Small Organic Molecules under Oscillatory Regime, J. Phys. Chem. C. 120 (2016) 22365-22374. doi:10.1021/acs.jpcc.6b06692.

[50] A.A. Zülke, H. Varela, The effect of temperature on the coupled slow and fast dynamics of an electrochemical oscillator, Sci. Rep. 6 (2016) 24553.

[51] M.F. Cabral, R. Nagao, E. Sitta, M. Eiswirth, H. Varela, Mechanistic aspects of the linear stabilization of non-stationary electrochemical oscillations, Phys. Chem. Chem. Phys. 15 (2013) 1437-1442. doi:10.1039/C2CP42890C.

[52] M.A. Nascimento, R. Nagao, M. Eiswirth, H. Varela, Coupled slow and fast surface dynamics in an electrocatalytic oscillator: Model and simulations, J. Chem. Phys. 141 (2014) 234701. doi:10.1063/1.4903172.

[53] H.M. James, A.S. Coolidge, The Ground State of the Hydrogen Molecule, J. Chem. Phys. 1 (1933) 825-835. doi:10.1063/1.1749252.

[54] W. Kolos, L. Wolniewicz, Lower Bound for the Dissociation Energy of the Hydrogen Molecule, J. Chem. Phys. 51 (1969) 1417-1419. doi:10.1063/1.1672189.

[55] J.K. Nørskov, T. Bligaard, A. Logadottir, J.R. Kitchin, J.G. Chen, S. Pandelov, U. Stimming, Trends in the Exchange Current for Hydrogen Evolution, J. Electrochem. Soc. . 152 (2005) J23-J26. doi:10.1149/1.1856988.

[56] J.R. Rostrup-Nielsen, Catalytic Steam Reforming BT - Catalysis: Science and Technology, in: J.R. Anderson, M. Boudart (Eds.), Springer Berlin Heidelberg, Berlin, Heidelberg, 1984: pp. 1-117. doi:10.1007/978-3-642-93247-2_1.

[57] A. Capon, R. Parson, The oxidation of formic acid at noble metal electrodes: I. Review of previous work, J. Electroanal. Chem. Interfacial Electrochem. 44 (1973) 1-7. doi:https://doi.org/10.1016/S0022-0728(73)80508-X.

[58] K. P. C. Vollhardt, K. E. Shore, Carboxylic Acids, in: Org. Chem., 6th ed., W. H. Freeman and Company, New York, 2011: pp. 871-924. 
[59] W. Gao, J.A. Keith, J. Anton, T. Jacob, Theoretical Elucidation of the Competitive Electro-oxidation Mechanisms of Formic Acid on Pt(111), J. Am. Chem. Soc. 132 (2010) 18377-18385. doi:10.1021/ja1083317.

[60] C. Yan-Xia, H. Martin, J. Zenonas, B.R. Jürgen, Kinetic Isotope Effects in Complex Reaction Networks: Formic Acid Electro-Oxidation, ChemPhysChem. 8 (2007) 380385. doi:10.1002/cphc.200600520.

[61] A. Capon, R. Parsons, The oxidation of formic acid on noble metal electrodes: II. A comparison of the behaviour of pure electrodes, J. Electroanal. Chem. Interfacial Electrochem. 44 (1973) 239-254. doi:https://doi.org/10.1016/S0022-0728(73)80250-5.

[62] A. Capon, R. Parsons, The oxidation of formic acid at noble metal electrodes Part III. Intermediates and mechanism on platinum electrodes, J. Electroanal. Chem. Interfacial Electrochem. 45 (1973) 205-231. doi:https://doi.org/10.1016/S0022-0728(73)80158-5.

[63] B. Beden, A. Bewick, C. Lamy, A study by electrochemically modulated infrared reflectance spectroscopy of the electrosorption of formic acid at a platinum electrode, $\mathrm{J}$. Electroanal. Chem. Interfacial Electrochem. 148 (1983) 147-160. doi:https://doi.org/10.1016/S0022-0728(83)80137-5.

[64] K. Kunimatsu, Infrared spectroscopic study of methanol and formic acid adsorbates on a platinum electrode: Part I. Comparison of the infrared absorption intensities of linear $\mathrm{CO}$ (a) derived from $\mathrm{CO}, \mathrm{CH} 3 \mathrm{OH}$ and $\mathrm{HCOOH}$, J. Electroanal. Chem. Interfacial Electrochem. 213 (1986) 149-157. doi:https://doi.org/10.1016/0022-0728(86)80604-0.

[65] K. Kunimatsu, H. Kita, Infrared spectroscopic study of methanol and formic acid absorbates on a platinum electrode: Part II. Role of the linear $\mathrm{CO}(\mathrm{a})$ derived from methanol and formic acid in the electrocatalytic oxidation of $\mathrm{CH} 3 \mathrm{OH}$ and $\mathrm{HCOOH}, \mathrm{J}$. Electroanal. Chem. Interfacial Electrochem. 218 (1987) 155-172. doi:https://doi.org/10.1016/0022-0728(87)87013-4.

[66] G. Samjeské, A. Miki, S. Ye, M. Osawa, Mechanistic Study of Electrocatalytic Oxidation of Formic Acid at Platinum in Acidic Solution by Time-Resolved SurfaceEnhanced Infrared Absorption Spectroscopy, J. Phys. Chem. B. 110 (2006) 1655916566. doi:10.1021/jp0618911.

[67] S.G. Sun, J. Clavilier, A. Bewick, The mechanism of electrocatalytic oxidation of 
formic acid on Pt (100) and Pt (111) in sulphuric acid solution: an emirs study, J. Electroanal. Chem. Interfacial Electrochem. 240 (1988) 147-159.

doi:https://doi.org/10.1016/0022-0728(88)80319-X.

[68] Y.-X. Chen, M. Heinen, Z. Jusys, R.J. Behm, Bridge-Bonded Formate: Active Intermediate or Spectator Species in Formic Acid Oxidation on a Pt Film Electrode?, Langmuir. 22 (2006) 10399-10408. doi:10.1021/la060928q.

[69] G. Wang, S.E. Hong, J. Qing, J. Timo, Revealing the Active Intermediates in the Oxidation of Formic Acid on Au and Pt(111), Chem. - A Eur. J. 20 (2014) 1100511012. doi:10.1002/chem.201402737.

[70] J. Joo, T. Uchida, A. Cuesta, M.T.M. Koper, M. Osawa, Importance of Acid-Base Equilibrium in Electrocatalytic Oxidation of Formic Acid on Platinum, J. Am. Chem. Soc. 135 (2013) 9991-9994. doi:10.1021/ja403578s.

[71] K.A. Schwarz, R. Sundararaman, T.P. Moffat, T.C. Allison, Formic acid oxidation on platinum: a simple mechanistic study, Phys. Chem. Chem. Phys. 17 (2015) 2080520813. doi:10.1039/C5CP03045E.

[72] J. Joo, T. Uchida, A. Cuesta, M.T.M. Koper, M. Osawa, The effect of pH on the electrocatalytic oxidation of formic acid/formate on platinum: A mechanistic study by surface-enhanced infrared spectroscopy coupled with cyclic voltammetry, Electrochim. Acta. 129 (2014) 127-136. doi:10.1016/j.electacta.2014.02.040.

[73] A. Ferre-Vilaplana, J. V Perales-Rondon, C. Buso-Rogero, J.M. Feliu, E. Herrero, Formic acid oxidation on platinum electrodes: a detailed mechanism supported by experiments and calculations on well-defined surfaces, J. Mater. Chem. A. 5 (2017) 21773-21784. doi:10.1039/C7TA07116G.

[74] J. V Perales-Rondón, S. Brimaud, J. Solla-Gullón, E. Herrero, R. Jürgen Behm, J.M. Feliu, Further Insights into the Formic Acid Oxidation Mechanism on Platinum: $\mathrm{pH}$ and Anion Adsorption Effects, Electrochim. Acta. 180 (2015) 479-485. doi:http://dx.doi.org/10.1016/j.electacta.2015.08.155.

[75] S. Brimaud, J. Solla-Gullón, I. Weber, J.M. Feliu, R.J. Behm, Formic Acid Electrooxidation on Noble-Metal Electrodes: Role and Mechanistic Implications of $\mathrm{pH}$, Surface Structure, and Anion Adsorption, ChemElectroChem. 1 (2014) 1075-1083. 
doi:10.1002/celc.201400011.

[76] A. Cuesta, G. Cabello, M. Osawa, C. Gutiérrez, Mechanism of the Electrocatalytic Oxidation of Formic Acid on Metals, ACS Catal. 2 (2012) 728-738. doi:10.1021/cs200661z.

[77] A. Cuesta, At Least Three Contiguous Atoms Are Necessary for CO Formation during Methanol Electrooxidation on Platinum, J. Am. Chem. Soc. 128 (2006) 13332-13333. doi:10.1021/ja0644172.

[78] W. Zhong, D. Zhang, New insight into the CO formation mechanism during formic acid oxidation on Pt(111), Catal. Commun. 29 (2012) 82-86. doi:https://doi.org/10.1016/j.catcom.2012.09.002.

[79] W. Zhong, J. Jiang, New Insight into CO Formation during HCOOH Oxidation on Pt(111): Intermolecular Dehydration of HCOOH Dimers, J. Phys. Chem. C. 119 (2015) 19287-19296. doi:10.1021/acs.jpcc.5b06569.

[80] Y.X. Chen, M. Heinen, Z. Jusys, R.J. Behm, Kinetics and Mechanism of the Electrooxidation of Formic Acid-Spectroelectrochemical Studies in a Flow Cell, Angew. Chemie Int. Ed. 45 (2006) 981-985. doi:10.1002/anie.200502172.

[81] G. Samjeské, A. Miki, S. Ye, A. Yamakata, Y. Mukouyama, H. Okamoto, M. Osawa, Potential Oscillations in Galvanostatic Electrooxidation of Formic Acid on Platinum: A Time-Resolved Surface-Enhanced Infrared Study, J. Phys. Chem. B. 109 (2005) 23509-23516. doi:10.1021/jp055220j.

[82] R. Nagao, I.R. Epstein, E.R. Gonzalez, H. Varela, Temperature (Over)Compensation in an Oscillatory Surface Reaction, J. Phys. Chem. A. 112 (2008) 4617-4624. doi:10.1021/jp801361j.

[83] P. Strasser, M. Eiswirth, G. Ertl, Oscillatory instabilities during formic acid oxidation on $\mathrm{Pt}(100), \operatorname{Pt}(110)$ and $\mathrm{Pt}(111)$ under potentiostatic control. II. Model calculations, J. Chem. Phys. 107 (1997) 991-1003. doi:10.1063/1.474451.

[84] M. Tian, B.E. Conway, Phenomenology of oscillatory electro-oxidation of formic acid at $\mathrm{Pd}$ : role of surface oxide films studied by voltammetry, impedance spectroscopy and nanogravimetry, J. Electroanal. Chem. 581 (2005) 176-189. 
doi:https://doi.org/10.1016/j.jelechem.2004.12.029.

[85] B.E.K. Swamy, C. Vannoy, J. Maye, F. Kamali, D. Huynh, B.B.L. II, M. Schell, Potential oscillations in formic acid oxidation in electrolyte mixtures: Efficiency and stability, J. Electroanal. Chem. 625 (2009) 69-74. doi:https://doi.org/10.1016/j.jelechem.2008.10.001.

[86] E.G. Machado, M.V.F. Delmonde, H. Varela, Spectrometric Evidence of the Synergy between Formic Acid and Hydrazine on Their Electro-Oxidation, J. Electrochem. Soc. . 164 (2017) H647-H650. doi:10.1149/2.1291709jes.

[87] J. Dumas, E. Péligot, Mémoire sur l’Esprit de Bois et sur les divers Composés Ethérés qui en proviennent, in: J.L. Gay-Lussac, F. Arago (Eds.), Ann. Chim. Phys., 58th ed., Chez Crochard, Paris, 1835: pp. 5-74.

[88] K. P. C. Vollhardt, K. E. Shore, Hydroxy Functional Group: Alcohols, in: Org. Chem., 6th ed., W. H. Freeman and Company, New York, 2011: pp. 287-332.

[89] J.L. Cohen, D.J. Volpe, H.D. Abruna, Electrochemical determination of activation energies for methanol oxidation on polycrystalline platinum in acidic and alkaline electrolytes, Phys. Chem. Chem. Phys. 9 (2007) 49-77. doi:10.1039/B612040G.

[90] L. Árnadóttir, E.M. Stuve, H. Jónsson, The effect of coadsorbed water on the stability, configuration and interconversion of formyl $(\mathrm{HCO})$ and hydroxymethylidyne $(\mathrm{COH})$ on platinum (111), Chem. Phys. Lett. 541 (2012) 32-38. doi:https://doi.org/10.1016/j.cplett.2012.05.024.

[91] S. Kandoi, J. Greeley, M.A. Sanchez-Castillo, S.T. Evans, A.A. Gokhale, J.A. Dumesic, M. Mavrikakis, Prediction of Experimental Methanol Decomposition Rates on Platinum from First Principles, Top. Catal. 37 (2006) 17-28. doi:10.1007/s11244006-0001-1.

[92] S. Sakong, A. Groß, The Importance of the Electrochemical Environment in the Electro-Oxidation of Methanol on Pt(111), ACS Catal. 6 (2016) 5575-5586. doi:10.1021/acscatal.6b00931.

[93] Z. Jusys, R.J. Behm, Adsorption and oxidation of formaldehyde on a polycrystalline Pt film electrode: An in situ IR spectroscopy search for adsorbed reaction intermediates, 
Beilstein J. Nanotechnol. 5 (2014) 747-759. doi:10.3762/bjnano.5.87.

[94] F. Hartl, A. Aragon Zulke, B. J. Fonte, H. Varela, Temperature dependence of the evolving oscillations along the electrocatalytic oxidation of methanol, 2016. doi:10.1016/j.jelechem.2016.11.032.

[95] P. Strasser, M. Eiswirth, M.T.M. Koper, Mechanistic classification of electrochemical oscillators — an operational experimental strategy, J. Electroanal. Chem. 478 (1999) 50-66. doi:https://doi.org/10.1016/S0022-0728(99)00412-X.

[96] S. Sauerbrei, M.A. Nascimento, M. Eiswirth, H. Varela, Mechanism and model of the oscillatory electro-oxidation of methanol, J. Chem. Phys. 132 (2010) 154901. doi:10.1063/1.3368790.

[97] L. Li, Z. Wei, X. Qi, C. Sun, G. Yin, Chemical oscillation in electrochemical oxidation of methanol on Pt surface, Sci. China Ser. B Chem. 51 (2008) 322-332. doi:10.1007/s11426-007-0110-0.

[98] J. Lee, C. Eickes, M. Eiswirth, G. Ertl, Electrochemical oscillations in the methanol oxidation on Pt, Electrochim. Acta. 47 (2002) 2297-2301. doi:https://doi.org/10.1016/S0013-4686(02)00075-0.

[99] H. Herzel, P. Plath, P. Svensson, Experimental evidence of homoclinic chaos and typeII intermittency during the oxidation of methanol, Phys. D Nonlinear Phenom. 48 (1991) 340-352. doi:https://doi.org/10.1016/0167-2789(91)90092-N.

[100] R. Nagao, D.A. Cantane, F.H.B. Lima, H. Varela, Influence of Anion Adsorption on the Parallel Reaction Pathways in the Oscillatory Electro-oxidation of Methanol, J. Phys. Chem. C. 117 (2013) 15098-15105. doi:10.1021/jp4028047.

[101] Y. MUKOUYAMA, O. FURUYAMA, Y. BUNDO, H. OKAMOTO, Separate Current Range for Appearance of Potential Oscillation during Methanol Oxidation on Platinum, Electrochemistry. 82 (2014) 573-577. doi:10.5796/electrochemistry.82.573.

[102] J. Wang, B. Li, T. Yersak, D. Yang, Q. Xiao, J. Zhang, C. Zhang, Recent advances in Pt-based octahedral nanocrystals as high performance fuel cell catalysts, J. Mater. Chem. A. 4 (2016) 11559-11581. doi:10.1039/C6TA02748B.

[103] Z. Peng, H. Yang, Designer platinum nanoparticles: Control of shape, composition in 
alloy, nanostructure and electrocatalytic property, Nano Today. 4 (2009) 143-164. doi:https://doi.org/10.1016/j.nantod.2008.10.010.

[104] E. Antolini, J.R.C. Salgado, E.R. Gonzalez, The methanol oxidation reaction on platinum alloys with the first row transition metals: The case of $\mathrm{Pt}-\mathrm{Co}$ and $-\mathrm{Ni}$ alloy electrocatalysts for DMFCs: A short review, Appl. Catal. B Environ. 63 (2006) 137149. doi:https://doi.org/10.1016/j.apcatb.2005.09.014.

[105] C. Rice, S. Ha, R.I. Masel, A. Wieckowski, Catalysts for direct formic acid fuel cells, J. Power Sources. 115 (2003) 229-235. doi:10.1016/S0378-7753(03)00026-0.

[106] F. Liu, Q. Yan, W.J. Zhou, X.S. Zhao, J.Y. Lee, High Regularity Porous Oxophilic Metal Films on Pt as Model Bifunctional Catalysts for Methanol Oxidation, Chem. Mater. 18 (2006) 4328-4335. doi:10.1021/cm0606023.

[107] H. Miyake, T. Okada, G. Samjeské, M. Osawa, Formic acid electrooxidation on Pd in acidic solutions studied by surface-enhanced infrared absorption spectroscopy, Phys. Chem. Chem. Phys. 10 (2008) 3662-3669. doi:10.1039/B805955A.

[108] A. Cuesta, Formic Acid Oxidation On Metal Electrodes, in: Encycl. Interfacial Chem. Surf. Sci. Electrochem., 2018: pp. 620-632.

[109] J.V. Perales-Rondón, A. Ferre-Vilaplana, J.M. Feliu, E. Herrero, Oxidation Mechanism of Formic Acid on the Bismuth Adatom-Modified Pt(111) Surface, J. Am. Chem. Soc. 136 (2014) 13110-13113. doi:10.1021/ja505943h.

[110] B.E. Conway, H. Angerstein-Kozlowska, W.B.A. Sharp, Temperature and pressure effects on surface processes at noble metal electrodes. Part 1.-Entropy of chemisorption of $\mathrm{H}$ at Pt surfaces, J. Chem. Soc. Faraday Trans. 1 Phys. Chem. Condens. Phases. 74 (1978) 1373-1389. doi:10.1039/F19787401373.

[111] G. Cabello, R.A. (2009) (PNPD) Davoglio, F.W. Hartl, J.F. Marco, E.C. Pereira, S.R. Biaggio, H. Varela, A. Cuesta, Microwave-Assisted Synthesis of Pt-Au Nanoparticles with Enhanced Electrocatalytic Activity for the Oxidation of Formic Acid, A1 - 4,798 Electrochim. ACTA. 224 (2017) 56-63. doi:10.1016/j.electacta.2016.12.022.

[112] A. Miki, S. Ye, M. Osawa, Surface-enhanced IR absorption on platinum nanoparticles: an application to real-time monitoring of electrocatalytic reactions, Chem. Commun. 
(2002) 1500-1501. doi:10.1039/B203392E.

[113] A. Miki, S. Ye, T. Senzaki, M. Osawa, Surface-enhanced infrared study of catalytic electrooxidation of formaldehyde, methyl formate, and dimethoxymethane on platinum electrodes in acidic solution, J. Electroanal. Chem. 563 (2004) 23-31. doi:https://doi.org/10.1016/j.jelechem.2003.09.014.

[114] O. Masatoshi, C.J. M., Surface-Enhanced Infrared Absorption Spectroscopy, Handb. Vib. Spectrosc. (2006). doi:doi:10.1002/0470027320.s0603.

[115] S. Konstantin, F.G. Miguel, How Nanotechnology Can Change the Concrete World, in: Prog. Nanotechnol., Wiley-Blackwell, 2014: pp. 113-116. doi:10.1002/9780470588260.ch16.

[116] W. Zhang, L. Xianmao, Morphology control of bimetallic nanostructures for electrochemical catalysts, Nanotechnol. Rev. 2 (2013) 487. doi:10.1515/ntrev-20130022 .

[117] C.-J. Zhong, J. Luo, B. Fang, B. Wanjala, P. Njoki, R. Loukrakpam, J. Yin, Nanostructured catalysts in fuel cells, 2010. doi:10.1088/0957-4484/21/6/062001.

[118] Y. Qiao, C. Li, Nanostructured catalysts in fuel cells, J. Mater. Chem. 21 (2011) 4027. http://dx.doi.org/10.1039/c0jm02871a.

[119] N.K. Ray, A.B. Anderson, Molecular orbital study of co chemisorption and oxidation on a Pt(111) surface, Surf. Sci. 119 (1982) 35-45. doi:https://doi.org/10.1016/00396028(82)90185-6.

[120] E. Christoffersen, P. Liu, A. Ruban, H.L. Skriver, J.K. Nørskov, Anode Materials for Low-Temperature Fuel Cells: A Density Functional Theory Study, J. Catal. 199 (2001) 123-131. doi:https://doi.org/10.1006/jcat.2000.3136.

[121] A. Ruban, B. Hammer, P. Stoltze, H.L. Skriver, J.K. Nørskov, Surface electronic structure and reactivity of transition and noble metals1Communication presented at the First Francqui Colloquium, Brussels, 19-20 February 1996.1, J. Mol. Catal. A Chem. 115 (1997) 421-429. doi:https://doi.org/10.1016/S1381-1169(96)00348-2.

[122] Z. Peng, H. Yang, PtAu bimetallic heteronanostructures made by post-synthesis modification of Pt-on-Au nanoparticles, Nano Res. 2 (2009) 406-415. 
doi:10.1007/s12274-009-9040-9.

[123] A. Cuesta, Atomic Ensemble Effects in Electrocatalysis: The Site-Knockout Strategy, ChemPhysChem. 12 (2011) 2375-2385. doi:10.1002/cphc.201100164.

[124] J.B. Xu, T.S. Zhao, Z.X. Liang, Carbon supported platinum-gold alloy catalyst for direct formic acid fuel cells, J. Power Sources. 185 (2008) 857-861. doi:https://doi.org/10.1016/j.jpowsour.2008.09.039.

[125] M.D. Obradović, A. V Tripković, S.L. Gojković, The origin of high activity of Pt-Au surfaces in the formic acid oxidation, Electrochim. Acta. 55 (2009) 204-209. doi:https://doi.org/10.1016/j.electacta.2009.08.038.

[126] M.W. Breiter, Reactivity and Surface Composition. Anodic Methanol Oxidation on Platinum—Gold Alloys, J. Phys. Chem. 69 (1965) 3377-3383. doi:10.1021/j100894a025.

[127] E. Irissou, F. Laplante, S. Garbarino, M. Chaker, D. Guay, Structural and Electrochemical Characterization of Metastable PtAu Bulk and Surface Alloys Prepared by Crossed-Beam Pulsed Laser Deposition, J. Phys. Chem. C. 114 (2010) 2192-2199. doi:10.1021/jp908524u.

[128] B.N. Wanjala, J. Luo, R. Loukrakpam, B. Fang, D. Mott, P.N. Njoki, M. Engelhard, H.R. Naslund, J.K. Wu, L. Wang, O. Malis, C.-J. Zhong, Nanoscale Alloying, PhaseSegregation, and Core-Shell Evolution of Gold-Platinum Nanoparticles and Their Electrocatalytic Effect on Oxygen Reduction Reaction, Chem. Mater. 22 (2010) 42824294. doi:10.1021/cm101109e.

[129] S.D. Wolter, B. Brown, C.B. Parker, B.R. Stoner, J.T. Glass, The effect of gold on platinum oxidation in homogeneous Au-Pt electrocatalysts, Appl. Surf. Sci. 257 (2010) 1431-1436. doi:https://doi.org/10.1016/j.apsusc.2010.08.062.

[130] R. Woods, The surface composition of platinum-gold alloys, Electrochim. Acta. 16 (1971) 655-658. doi:https://doi.org/10.1016/0013-4686(71)85177-0.

[131] M.W. Breiter, Formation and reduction of the oxygen layer on cold-worked platinumgold alloys in acid solutions, Electrochim. Acta. 10 (1965) 543-547. doi:https://doi.org/10.1016/0013-4686(65)87056-6. 
[132] J. Zhang, D.N. Oko, S. Garbarino, R. Imbeault, M. Chaker, A.C. Tavares, D. Guay, D. Ma, Preparation of PtAu Alloy Colloids by Laser Ablation in Solution and Their Characterization, J. Phys. Chem. C. 116 (2012) 13413-13420. doi:10.1021/jp302485g.

[133] F. Maroun, F. Ozanam, O.M. Magnussen, R.J. Behm, The Role of Atomic Ensembles in the Reactivity of Bimetallic Electrocatalysts, Science (80-. ). 293 (2001) 1811 LP1814. doi:10.1126/science.1061696.

[134] J.L. Haan, R.I. Masel, The influence of solution $\mathrm{pH}$ on rates of an electrocatalytic reaction: Formic acid electrooxidation on platinum and palladium, Electrochim. Acta. 54 (2009) 4073-4078. doi:https://doi.org/10.1016/j.electacta.2009.02.045.

[135] H. Kita, T. Katagiri, K. Kunimatsu, Electrochemical oxidation of HCOONa on Pt in acidic solutions, J. Electroanal. Chem. Interfacial Electrochem. 220 (1987) 125-138. doi:https://doi.org/10.1016/0022-0728(87)88008-7.

[136] R.R. Adić, M.I. Hofman, D.M. Draić, Oxidation of formates on a platinum electrode in neutral solutions, J. Electroanal. Chem. Interfacial Electrochem. 110 (1980) 361-368. doi:https://doi.org/10.1016/S0022-0728(80)80390-1.

[137] R.P. Buck, L.R. Griffith, Voltammetric and Chronopotentiometric Study of the Anodic Oxidation of Methanol, Formaldehyde, and Formic Acid, J. Electrochem. Soc. . 109 (1962) 1005-1013. doi:10.1149/1.2425226.

[138] G. Crépy, C. Lamy, S. Maximovitch, Oxydation de l'acide formique sur électrode d'or, J. Electroanal. Chem. Interfacial Electrochem. 54 (1974) 161-179. doi:https://doi.org/10.1016/S0022-0728(74)80388-8.

[139] A. Cuesta, G. Cabello, C. Gutierrez, M. Osawa, Adsorbed formate: the key intermediate in the oxidation of formic acid on platinum electrodes, Phys. Chem. Chem. Phys. 13 (2011) 20091-20095. doi:10.1039/C1CP22498K.

[140] A. Cuesta, G. Cabello, F.W. Hartl, M. Escudero-Escribano, C. Vaz-Domínguez, L.A. Kibler, M. Osawa, C. Gutiérrez, Electrooxidation of formic acid on gold: An ATRSEIRAS study of the role of adsorbed formate, Catal. Today. 202 (2013) 79-86. doi:https://doi.org/10.1016/j.cattod.2012.04.022.

[141] O. Masatoshi, K. Kei-ichi, S. Gabor, U. Taro, I. Tamio, C. Angel, G. Claudio, The 
Role of Bridge-Bonded Adsorbed Formate in the Electrocatalytic Oxidation of Formic Acid on Platinum, Angew. Chemie Int. Ed. 50 (2010) 1159-1163.

doi:10.1002/anie.201004782.

[142] G. Vitali, V.F. J., H. Enrique, F.J. M., Adsorption of Formate and Its Role as Intermediate in Formic Acid Oxidation on Platinum Electrodes, ChemPhysChem. 12 (2011) 1641-1644. doi:10.1002/cphc.201100257.

[143] N. Garcia-Araez, V. Climent, P. Rodriguez, J.M. Feliu, Thermodynamic analysis of (bi)sulphate adsorption on a $\mathrm{Pt}(111)$ electrode as a function of $\mathrm{pH}$, Electrochim. Acta. 53 (2008) 6793-6806. doi:https://doi.org/10.1016/j.electacta.2007.12.086.

[144] S. Chen, T. Noles, M. Schell, Effects of anions on chemical instabilities in the oxidation of formic acid, Electrochem. Commun. 2 (2000) 171-174. doi:https://doi.org/10.1016/S1388-2481(99)00163-0.

[145] S. Chen, T. Noles, M. Schell, Differences in Oscillations and Sequences of Dynamical States Caused by Anion Adsorption in the Electrochemical Oxidation of Formic Acid, J. Phys. Chem. A. 104 (2000) 6791-6798. doi:10.1021/jp001066j.

[146] J. V Perales-Rondón, E. Herrero, J.M. Feliu, On the activation energy of the formic acid oxidation reaction on platinum electrodes, J. Electroanal. Chem. 742 (2015) 9096. doi:https://doi.org/10.1016/j.jelechem.2015.02.003.

[147] E.A. Carbonio, R. Nagao, E.R. Gonzalez, H. Varela, Temperature effects on the oscillatory electro-oxidation of methanol on platinum, Phys. Chem. Chem. Phys. 11 (2009) 665-670. doi:10.1039/B811636A.

[148] F. Seland, R. Tunold, D.A. Harrington, Impedance study of methanol oxidation on platinum electrodes, Electrochim. Acta. 51 (2006) 3827-3840. doi:https://doi.org/10.1016/j.electacta.2005.10.050.

[149] Z.-B. Wang, Y.-Y. Chu, A.-F. Shao, P.-J. Zuo, G.-P. Yin, Electrochemical impedance studies of electrooxidation of methanol and formic acid on Pt/C catalyst in acid medium, J. Power Sources. 190 (2009) 336-340. doi:https://doi.org/10.1016/j.jpowsour.2009.01.008.

[150] E. Herrero, B. Álvarez, J.M. Feliu, S. Blais, Z. Radovic-Hrapovic, G. Jerkiewicz, 
Temperature dependence of the COads oxidation process on $\operatorname{Pt}(111), \operatorname{Pt}(100)$, and $\operatorname{Pt}(110)$ electrodes, 2004. doi:10.1016/j.jelechem.2003.12.019.

[151] E. Herrero, J.M. Feliu, S. Blais, Z. Radovic-Hrapovic, G. Jerkiewicz, Temperature Dependence of CO Chemisorption and Its Oxidative Desorption on the $\operatorname{Pt}(111)$ Electrode, Langmuir. 16 (2000) 4779-4783. doi:10.1021/la9907432.

[152] B. Geng, J. Cai, S. Liang, S.X. Liu, M.F. Li, Y.-X. Chen, Temperature effects on CO adsorption/desorption at Pt film electrodes: an electrochemical in situ infrared spectroscopic study, Phys. Chem. Chem. Phys. 12 (2010) 10888-10895. doi:10.1039/C002665D.

[153] A.L. Martins, B.C. Batista, E. Sitta, H. Varela, Oscillatory instabilities during the electrocatalytic oxidation of methanol on platinum, J. Braz. Chem. Soc. 19 (2008) 679687. http://www.scielo.br/scielo.php?script=sci_arttext\&pid=S0103$50532008000400011 \&$ nrm=iso.

[154] R. Nagao, E. Sitta, H. Varela, Stabilizing Nonstationary Electrochemical Time Series, J. Phys. Chem. C. 114 (2010) 22262-22268. doi:10.1021/jp109554r.

[155] G.B. Melle, F.W. Hartl, H. Varela, E. Sitta, The Effect of Solution pH on the Oscillatory Electro-Oxidation of Methanol, J. Electroanal. Chem. submitted (2018).

[156] J.R. Macdonald, W.B. Johnson, Fundamentals of Impedance Spectroscopy, in: E. Barsoukov, J.R. Macdonald (Eds.), Impedance Spectrosc., 3rd ed., Wiley, New Jersey, 2018: pp. 1-20.

[157] N. H., Regeneration Theory, Bell Syst. Tech. J. 11 (2018) 126-147. doi:10.1002/j.1538-7305.1932.tb02344.x.

[158] H.W. Bode, Network analysis and feedback amplifier design, Van Nostrand, New York, 1945.

[159] R. de Levie, On the electrochemical oscillator, J. Electroanal. Chem. 25 (1970) 257273.

[160] M. T. M. Koper, Non-linear phenomena in electrochemical systems, J. Chem. Soc. $\{$, Faraday Trans. 94 (1998) 1369-1378. doi:10.1039/A708897C. 
[161] M.T.M. Koper, Stability study and categorization of electrochemical oscillators by impedance spectroscopy, J. Electroanal. Chem. 409 (1996) 175-182. doi:https://doi.org/10.1016/0022-0728(95)04391-8.

[162] F. Seland, R. Tunold, D.A. Harrington, Impedance study of formic acid oxidation on platinum electrodes, Electrochim. Acta. 53 (2008) 6851-6864. doi:https://doi.org/10.1016/j.electacta.2007.12.021.

[163] T. Iwasita, F.C. Nart, In situ infrared spectroscopy at electrochemical interfaces, Prog. Surf. Sci. 55 (1997) 271-340. doi:https://doi.org/10.1016/S0079-6816(97)00032-4.

[164] Y.X. Chen, A. Miki, S. Ye, H. Sakai, M. Osawa, Formate, an Active Intermediate for Direct Oxidation of Methanol on Pt Electrode, J. Am. Chem. Soc. 125 (2003) 36803681. doi:10.1021/ja029044t.

[165] M.A. Barrett, R. Parsons, Reflectance studies of adsorption on a platinum electrode, Symp. Faraday Soc. 4 (1970) 72-84. doi:10.1039/SF9700400072.

[166] A. Cuesta, C. Gutiérrez, Confirmation by differential reflectance spectroscopy of the transition at $270 \mathrm{~nm}$ of $\mathrm{CO}$ chemisorbed on $\mathrm{Pt}$ in an acid medium, J. Electroanal. Chem. 383 (1995) 195-197. doi:https://doi.org/10.1016/0022-0728(94)03760-Z.

[167] I. Fromondi, D. Scherson, (Bi)Sulfate Adsorption on Quasiperfect Pt(111) Facets from Acidic Aqueous Electrolytes as Monitored by Optical Techniques, J. Phys. Chem. C. 111 (2007) 10154-10157. doi:10.1021/jp073330f.

[168] I. Fromondi, D. Scherson, Surface dynamics at well-defined single crystal microfacetted Pt(111) electrodes: in situ optical studies, Faraday Discuss. 140 (2009) 59-68. doi:10.1039/B805040F.

[169] I. Fromondi, D.A. Scherson, Oxidation of Adsorbed CO on Pt(111) in CO-Saturated Perchloric Acid Aqueous Solutions: Simultaneous In Situ Time-Resolved Reflectance Spectroscopy and Second Harmonic Generation Studies, J. Phys. Chem. B. 110 (2006) 20749-20751. doi:10.1021/jp0653095.

[170] I. Fromondi, H. Zhu, D.A. Scherson, In Situ Spectroscopy at the Quasi-Perfect Pt(111) Single-Crystal Facet|Aqueous Electrolyte Interface, J. Phys. Chem. C. 116 (2012) 19613-19624. doi:10.1021/jp3024414. 
[171] I. Fromondi, A.L. Cudero, J. Feliu, D.A. Scherson, In Situ UV-Visible Reflectance Spectroscopy on Single Crystal Pt(111) Microfacets, Electrochem. Solid-State Lett. . 8 (2005) E9-E11. doi:10.1149/1.1830396.

[172] M. Hachkar, B. Beden, C. Lamy, Oscillating electrocatalytic systems: Part I. Survey of systems involving the oxidation of organics and detailed electrochemical investigation of formaldehyde oxidation on rhodium electrodes, J. Electroanal. Chem. Interfacial Electrochem. 287 (1990) 81-98. doi:https://doi.org/10.1016/0022-0728(90)87161-C.

[173] M. Hachkar, M.C. de Martinez, A. Rakotondrainibe, B. Beden, C. Lamy, Oscillating electrocatalytic systems: Part II. "In situ" UV-visible reflectance spectroscopic investigation of formaldehyde oxidation on rhodium in alkaline medium, J. Electroanal. Chem. Interfacial Electrochem. 302 (1991) 173-189. doi:https://doi.org/10.1016/0022-0728(91)85039-R.

[174] M. Heinen, Y.X. Chen, Z. Jusys, R.J. Behm, In situ ATR-FTIRS coupled with on-line DEMS under controlled mass transport conditions-A novel tool for electrocatalytic reaction studies, Electrochim. Acta. 52 (2007) 5634-5643. doi:https://doi.org/10.1016/j.electacta.2007.01.055.

[175] G. Samjeské, M. Osawa, Current Oscillations during Formic Acid Oxidation on a Pt Electrode: Insight into the Mechanism by Time-Resolved IR Spectroscopy, Angew. Chemie Int. Ed. 44 (2005) 5694-5698. doi:10.1002/anie.200501009.

[176] J. Christoph, M. Eiswirth, Theory of electrochemical pattern formation, Chaos An Interdiscip. J. Nonlinear Sci. 12 (2002) 215-230. doi:10.1063/1.1449956.

[177] M.S. El-Deab, G.A. El-Nagar, A.M. Mohammad, B.E. El-Anadouli, Fuel blends: Enhanced electro-oxidation of formic acid in its blend with methanol at platinum nanoparticles modified glassy carbon electrodes, J. Power Sources. 286 (2015) 504509. doi:https://doi.org/10.1016/j.jpowsour.2015.04.004.

[178] G.A. El-Nagar, A.M. Mohammad, M.S. El-Deab, B.E. El-Anadouli, Novel fuel blends facilitating the electro-oxidation of formic acid at a nano-Pt/GC electrode, RSC Adv. 6 (2016) 29099-29105. doi:10.1039/C6RA00118A.

[179] G.A. El-Nagar, M.S. El-Deab, A.M. Mohammad, B.E. El-Anadouli, Promoting Effect of Hydrocarbon Impurities on the Electro-Oxidation of Formic Acid at Pt 
Nanoparticles Modified GC Electrodes, Electrochim. Acta. 180 (2015) 268-279. doi:https://doi.org/10.1016/j.electacta.2015.08.119.

[180] G.A. El-Nagar, A.M. Mohammad, M.S. El-Deab, T. Ohsaka, B.E. El-Anadouli, Acrylonitrile-contamination induced enhancement of formic acid electro-oxidation at platinum nanoparticles modified glassy carbon electrodes, J. Power Sources. 265 (2014) 57-61. doi:https://doi.org/10.1016/j.jpowsour.2014.04.116.

[181] M. Choun, J. Lee, Electro-oxidation of mixed reactants of ethanol and formate on $\mathrm{Pd} / \mathrm{C}$ in alkaline fuel cells, J. Energy Chem. 25 (2016) 683-690. doi:https://doi.org/10.1016/j.jechem.2016.04.008.

[182] R. Reichert, J. Schnaidt, Z. Jusys, R.J. Behm, The Influence of Reactive Side Products in Electrocatalytic Reactions: Methanol Oxidation as Case Study, ChemPhysChem. 14 (2013) 3678-3681. doi:10.1002/cphc.201300726.

[183] R. Reichert, J. Schnaidt, Z. Jusys, R.J. Behm, The influence of reactive side products on the electrooxidation of methanol - a combined in situ infrared spectroscopy and online mass spectrometry study, Phys. Chem. Chem. Phys. 16 (2014) 13780-13799. doi:10.1039/C4CP01229A.

[184] Y.E. Seidel, Z. Jusys, R.W. Lindström, M. Stenfeldt, B. Kasemo, K. Krischer, Oscillatory behaviour in Galvanostatic Formaldehyde Oxidation on Nanostructured Pt/Glassy Carbon Model Electrodes, ChemPhysChem. 11 (2010) 1405-1415. doi:10.1002/cphc.200901029.

[185] H.F. Hunger, The Mechanism of Oscillatory Behavior During the Anodic Oxidation of Formaldehyde, J. Electrochem. Soc. . 115 (1968) 492-497. doi:10.1149/1.2411288.

[186] Samjeské Gabor, A. Miki, M. Osawa, Electrocatalytic Oxidation of Formaldehyde on Platinum under Galvanostatic and Potential Sweep Conditions Studied by TimeResolved Surface-Enhanced Infrared Spectroscopy, J. Phys. Chem. C. 111 (2007) 15074-15083. doi:10.1021/jp0743020.

[187] H. Okamoto, N. Tanaka, M. Naito, Potential Oscillations Related to Proton Concentration in Formaldehyde Oxidation, J. Electrochem. Soc. . 147 (2000) 26292635. doi:10.1149/1.1393581. 
[188] E. Mishina, A. Karantonis, Q.-K. Yu, S. Nakabayashi, Optical Second Harmonic Generation during the Electrocatalytic Oxidation of Formaldehyde on $\operatorname{Pt}(111)$ : Potentiostatic Regime versus Galvanostatic Potential Oscillations, J. Phys. Chem. B. 106 (2002) 10199-10204. doi:10.1021/jp026146x.

[189] H. Okamoto, N. Tanaka, Potential oscillation mechanism for formaldehyde oxidation on platinum, Electrochim. Acta. 38 (1993) 503-509. doi:https://doi.org/10.1016/00134686(93)85005-J.

[190] M.T.M. Koper, M. Hachkar, B. Beden, Investigation of the oscillatory electrooxidation of formaldehyde on Pt and Rh electrodes by cyclic voltammetry $\{$, impedance spectroscopy and the electrochemical quartz crystal microbalance, J. Chem. Soc. $\{$, \} Faraday Trans. 92 (1996) 3975-3982. doi:10.1039/FT9969203975.

[191] S. Chen, M. Schell, Effects of anion adsorption different from blocking surface sites deduced from instabilities in the oxidation of formic acid, J. Electroanal. Chem. 504 (2001) 78-88. doi:https://doi.org/10.1016/S0022-0728(01)00415-6.

[192] A. Mota-Lima, E.R. Gonzalez, M. Eiswirth, Complex electrooxidation of formic acid on palladium , J. Brazilian Chem. Soc. . 25 (2014) 1208-1217.

[193] X. Yu, P.G. Pickup, Recent advances in direct formic acid fuel cells (DFAFC), J. Power Sources. 182 (2008) 124-132. doi:https://doi.org/10.1016/j.jpowsour.2008.03.075. 